$$
\begin{aligned}
& \text { Universidade de São Paulo } \\
& \text { Instituto de Física e Química de S. Carlos }
\end{aligned}
$$

\title{
Projeto de uma Arqúitetura de \\ Hardware para \\ Visualização de Imagens Digitais
}

Maria Stela Veludo de Paiva

Tese apresentada ao Instituto de Física e Química de São Carlos, para a obtenção do título de

Doutora em Ciências (Física Aplicada).

Orientador : Prof. Dr. Jan Frans Willem Slaets

Departamento de Física e Ciência dos Materiais

São Carlos - 1990

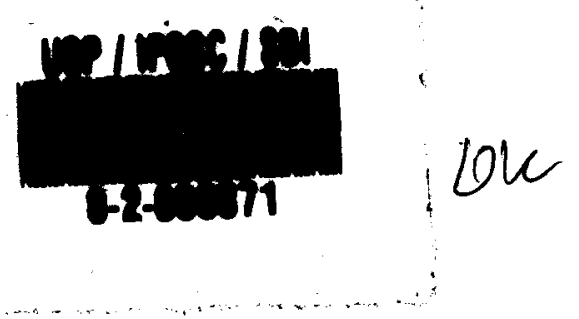

SERVIÇO DE 8IBLIOTECA E ITFORAACAO - IFQSC 


\section{UNIVERSIDADE DE SÃo PAULO}

INSTITUTO DE FISICA E OUIMICA DE SAO CARLOS

AEMBROS DA COMISSAO JULGADORA DA TESE DE DOUTORADO DE MARIA STELA YELUDO DE PAIUA APRESENTADA AO INSTITUTO DE FISICA E OUIMICA DE SAO CARLOS, DA UNIUERSIDADE DE SAO PAULO, EH 20/11/90

COHISSAO JULGADORA:

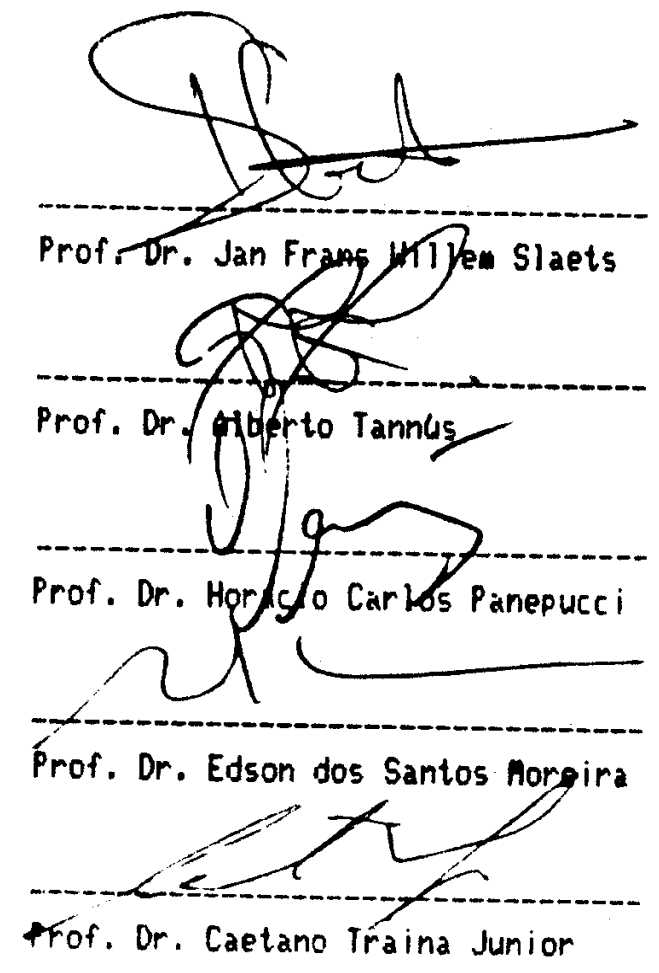

Cx. Postal, 369 - FONE (0162) 71.1016 - CEP 13.560 - São Carlos - SP : Telex 162374 - FOSC - BA - BRASIL 
Projeto financiado pela

Fundação Banco do Brasil 

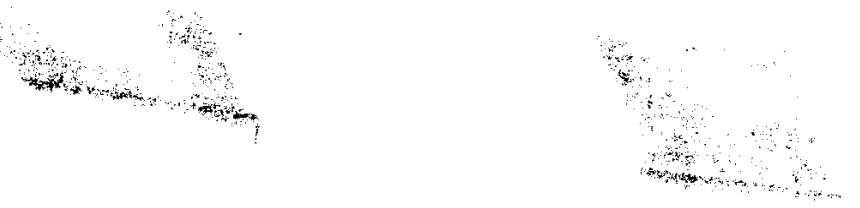

A todo pessoal do Grupo de Instrumentação Eletrônica, e aos colegas do Departamento de Eletricidade. 


\section{AGRADECIMENTOS}

Este trabalho é resultado do esforço conjunto de muitas pessoas, que colaboraram não só tecnicamente, mas também dando incentivo, coragem e principalmente amizade à autora durante sua realização. Fica então nesta página registrada a eterna gratidão para com todos. Em especial :

.ao Prof. Dr. Jan F. W. Slaets, não só pela colaboração na realização deste trabalho, mas também pela grande influência na formação profissional da autora.

.à Ivanilda H. Zucolotto, Ailton B. Alves e Marcos R. Gonçalves, pelo auxílio na parte técnica.

.ao Lírio O. B. de Almeida, pelo auxílio na depuração do sistema, pelas sugestōes e discussões técnicas.

.à Maria Benedita de Souza, pelo excelente trabalho realizado na confeç̧ão das figuras.

.à Lia Mara C. Chinaglia, pelo trabalho de secretaria, pelas horas extras dispendidas na digitação da tese.

.à Maria Helena, pelo trabalho de secretaria.

.à Mônica e Gonzalo por todo auxílio prestado durante o desenvolvimento da tese.

.à companheira Agma e ao Caetano, pela colaboração na parte de software, pelas ricas discussões técnicas, e pelo imenso auxilio prestado na elaboração deste trabalho.

.aos companheiros do Departamento de Eletricidade, Prof. Adilson, Profa. Annie e Prof Evandro, pela inestimável colaboração nas atividades didáticas.

.ao companheiro João Batista de Paiva, pelo incentivo constante e pela paciência.

.aos colegas Mateus, Prof. Ruggiero, Prof. Valentin e Paulo Ruffino, pelas consultas técnicas. 


\section{ÍNDICE}

Lista de Figuras

Lista de Tabelas $\quad$ v

Resumo vi

Abstract vii

Introdução viii

Símbolos e Convenções xi

Capítulo I - Princípios para Visualização de Imagem em Tubos de Raios Catódicos

1.1 Introdução 1

1.2 Monitores Vetoriais 3

$\begin{array}{ll}1.3 \text { Monitores por Varredura } & 4\end{array}$

Capítulo II - "Hardware" para Visualização de Imagens

2.1 Introdução $\quad 8$

$\begin{array}{ll}2.2 \text { Terminologia para Monitores por Varredura } & 10\end{array}$

2.3 Memórias para Sistemas Gráficos $\quad 13$

$\begin{array}{ll}\text { 2.3.1 Gravação Durante o Retraço } & 17\end{array}$

$\begin{array}{ll}\text { 2.3.2 Sistemas com "Double-Buffer" } & 17\end{array}$

$\begin{array}{ll}\text { 2.3.3 Memórias de Resolução Variável } & 19\end{array}$

$\begin{array}{ll}\text { 2.3.4 Memórias Gráficas } & 19\end{array}$

2.4 Processadores em Sistemas Gráficos $\quad 22$

2.5 Controlador de Refrescamento de Vídeo e Circuito de Saída para Vídeo 


\section{Capítulo III - O Processador Gráfico TMS34010}

3.1 Arquitetura do GSP $\quad 30$

3.2 Endereçamento da Memória $\quad 34$

3.3 Paralelismo Interno $\quad 35$

3.4 Estruturas de Dados Suportadas pelo "Hardware" 36

\begin{tabular}{ll}
3.4 .1 & "Fields" \\
\hline
\end{tabular}

$\begin{array}{ll}3.4 .2 \text { "Bytes" } & 37\end{array}$

3.4.3 "Pixels" $\quad 37$

3.4.4 Matriz Bidimensional de "Pixels" 42

3.5 Registradores do GSP $\quad 43$

3.5.1 Registradores para Propósito Geral 43

3.5.2 Registradores de E/S $\quad 45$

3.6 Instruções e Operações Gráficas $\quad 49$

3.6.1 Instruções Gráficas $\quad 50$

3.6.2 Operações Gráficas $\quad 52$

3.6.3 Instruçoes para o Modo de Endereçamento XY

3.7 Interrupções, "Traps" e "Reset"

3.7.1 Registradores Dedicados à Interrupção 57

$\begin{array}{ll}\text { 3.7.2 "Traps" } & 57\end{array}$

3.7.3 "Reset" $\quad 57$

3.8 Temporização do Vídeo e Refrescamento da Tela 59

$\begin{array}{ll}\text { 3.8.1 Memória de Vídeo } & 60\end{array}$

3.8.2 Geração do Endereço de Refrescamento de Tela 61

3.9 Duto Dedicado ao Hospedeiro $\quad 61$

3.9.1 Convenções de Endereçamento por "Byte" 62

3.9.2 Acesso Indireto à Memória Local $\quad 63$

$\begin{array}{ll}\text { 3.9.3 Largura de Banda } & 63\end{array}$

3.10 Barramento da Memória Local $\quad 64$

3.10.1 Ciclos da Memória Local do GSP $\quad 66$

3.10.2 Prioridade na Solicitação do Barramento da

Memória 
3.10.3 Mecanismos de Endereçamento

3.10.4 Operação de Refrescamento .

3.11 Temporização das Instruções $\quad 76$

3.12 Ferramentas para Desenvolvimento do "Software"

3.12.1 Introdução 77

3.12.2 Assembler 78

3.12.3 Archiver $\quad 79$

3.12.4 Linker $\quad 79$

3.12.5 Utilitário para Conversão de Código 79

$\begin{array}{ll}3.12 .6 \text { Simulador } & 79\end{array}$

3.12.7 Programa de Depuração - $\quad 80$

3.12.8 Loader SDBL $\quad 82$

Capítulo IV - Sistemas Desenvolvidos

4.1 Sistema Gráfico com 16 Cores $\quad 83$

4.1.1 Descrição das Interfaces $\quad 85$

4.1.2 Exemplos de Programação dos Registradores de E/S do GSP 108

4.2 Sistema Gráfico com 256 Níveis de Cinza 121

4.2.1 Descrição das Interfaces

4.2.2 Registradores de E/S do GSP 138

Capítulo V - "Software"

5.1 Programa Principal 141

5.2 Subrotinas e Programas $\quad 141$

5.2.1 Subrotinas para Inicialização dos Registradores 142

5.2.2 Subrotina para Inicializar a "Color Palette"

5.2.3 Subrotina para Apagar a Tela 144

5.2.4 Subrotina para Desenhar o Padrão de Cores da

"Color Palette" 145

5.2.5 Subrotina para Trocar o Banco de Memória de 
5.2.6 Programa para Desenhar Caracteres ASCII $\quad 146$

5.2.7 Programa para Controle do "Mouse"

5.2.8 Programa para Configurar o Vídeo para o Modo

Entrelaçado

5.2.9 Programa para Trocar Alternadamente os Bancos

de Memória

5.2.10 Programa para Dividir a Tela em Duas Partes

5.2.11 Programa para Realizar "Pan" na Horizontal

5.2.12 Programa para Realizar "Pan" na Vertical

5.2.13 Formato de Arquivos de Imagem

Capítulo VII - Conclusōes

\section{Anexo I}

Anexo 1.1 - Programa Principal

Anexo 1.2 - Subrotinas para Inicialização dos Registradores

Anexo 1.3 - Subrotina para Inicializar a "Color Palette"

Anexo 1.4 - Subrotina para Apagar a Tela

Anexo 1.5 - Subrotina para Desenhar o Padrão de Cores da "Color Palette" 188

Anexo 1.6 - Subrotina para Trocar o Banco da Memória de Imagem 189

Anexo 1.7 - Subrotina para Desenhar Caracteres ASCII $\quad 190$

Anexo 1.8 - Programa para Controle do "Mouse" 191

Anexo 1.9 - Programa para Configurar o Vídeo para o Modo Entrelaçado $\quad 202$

Anexo 1.10 - Programa para Trocar Alternadamente os Bancos de Memória 206

Anexo 1.11 - Programa para Dividir a Tela em Duas Partes 211

Anexo 1.12 - Programa para Realizar "Pan" na Horizontal 217

Anexo 1.13 - Programa para Realizar "Pan" na Vertical 227 


\section{LISTA DE FIGURAS}

1 - Modelo de um Sistema Gráfico 2

2 - Exemplo de uma Figura Mostrada num Monitor Vetorial 4

3 - Exemplo de um Sistema Gráfico para Monitor Vetorial 4

4 - Padrão de Varredura 5

5 - Exemplo de um Sistema Gráfico por Varredura 6

6 - Exemplo de uma Figura Mostrada num Monitor por

$\begin{array}{ll}\text { Varredura } & 7\end{array}$

7 - Diagrama em Blocos de um Sistema Gráfico por Varredura 8

8 - Memória de Porta Dupla 10

9 - Varredura para Vídeo Entrelaçado 12

10 - Elementos de Temporização de um "Frame" do Vídeo 13

11 - Alocação de Ciclos de Memória no Tempo de Linha

Ativa, para o Controlador de Refrescamento de

Vídeo (VRC) e Processador Gráfico (DP); 16 DRAMS

de 116Kx1; Resolução do Sistema de 512 × 512,30 Hz 16

12 - DRAM com Palavras Longas $\quad 17$

13 - Técnicas de "Double Buffering" 18

14 - Diagrama em Blocos da Memória VRAM 20

15 - Oito Planos de Memória e um Conversor D/A de 8 Bits $\begin{array}{ll}\text { para Gerar } 256 \text { Níveis de Cinza } & 28\end{array}$

16 - Dois Planos de Memória para Cada Cor Primária,

Possibilitando a Programação de 64 Cores Diferentes 29

17 - Diagrama de Blocos do TMS34010 31

18 - Arquitetura Interna do TMS34010 32

19 - Registrador de "Status" 33

20 - Conjunto de Sinais do TMS34010 33

21 - Mapa de Memória do GSP $\quad 34$ 
22 - Fluxo de Dados Interno do GSP

23 - Mapeamento de "Pixels" na Tela do Monitor de Vídeo 39

24 - Endereçamento do "Pixel" em Termos das Coordenadas XY 40

25 - Origem Configurável da Tela 41

26 - Registradores dos Arquivos A e B 44

27 - Registradores de E/S $\quad 46$

28 - Mapa dos Vetores de Interrup̧ão 56

29 - Multiplexação de Enderę̧o e Dado no Duto LAD0-LAD15 65

30 - Endereço da Linha e Coluna de um Ciclo de Memória 65

31 - Ciclo de Gravação em Memória 67

32 - Ciclo de Leitura em Memória $\quad 68$

33 - Ciclo de Memória para Registrador de Deslocamento 69

34 - Ciclo de Leitura com um Estado de Espera $\quad 71$

35 - Bits de Endereço Lógico Durante as Transições de /RAS e /CAS 73

36 - Ciclo de Refrescamento "/RAS-only"

37 - Estado da Máquina Mostrado pelo Simulador 81

38 - Diagrama em Blocos do Sistema Gráfico com 16 Cores 84

39 - Interface com o Hospedeiro 86

40 - Mapeamento dos Registradores Dedicados ao Hospedeiro 86

41 - Equações da PAL 20L10 para a Interface do Hospedeiro 88

42 - Interface para a Memória Local $\quad 89$

43 - Bits de Endereço no Duto Multiplexado LAD0-LAD15 91

44 - Mapeamento das Memórias e da Interface Serial 91

45 - Equaçōes da PAL 16L8 para Seleção das Memórias -

Sistema com 16 Cores $\quad 92$

46 - Diagrama de Tempo Mustrando os Sinais de Seleção das Memórias, para o Sistema de 16 Cores 94

47 - Diagrama em Blocos da "Color Palette" 95

48 - Registrador da Tabela de Cores 96

49 - Diagrama de Tempo para a "Color Palette" 97

50 - Diagrama de Tempo para o Carregamento da Tabela de 
51 - Diagrama de Tempo para o Início da Linha Ativa

60 - Geração dos Bits do campo SRFADR no Duto Multiplexado LAD

61 - Exemplo para Determinação do Valor do Campo SRSTRT

62 - Diagrama em Blocos do Sistema Gráfico com 256 níveis de cinza

63 - Mapeamento das Memórias para o Sistema com 256 Níveis de Cinza

64 - Equações da PAL para a Seleção das Memórias - Sistema com 256 Níveis de Cinza

65 - Diagrama de Tempo Ilustrando os Sinais de Seleção das Memórias

66 - Diagrama de Tempo Ilustrando a Seleção das Saídas Seriais das VRAMs

67 - Circuito de Saída para Vídeo

68 - Diagrama em Blocos Interno do Conversor D/A BT106

72 - Circuito da Interface Serial para "Mouse"

73 - Equações da PAL para a Interface Serial, parte A -

Sistema com 256 Níveis de Cinza

74 - Equações da PAL para a Interface Serial, parte B - 
Sistema com 256 Niveis de Cinza

75 - Diagrama em Blocos para o Programa "Mouse" - Parte 1

76 - Diagrama em Blocos para o Programa "Mouse" - Parte 2

77 - "Frame Buffer" com "Pitch" Maior que o da Tela

78 - Tela do Monitor de Vídeo Contendo Duas Vistas

Diferentes da Memória de Imagem

79 - Memória de Imagem para "Pan" na Horizontal

80 - "Pan Horizontal - Deslocamento da Tela sobre a

Imagem Original

81 - Memória de Imagem para "Pan" na Vertical

82 - "Pan" Vertical - Deslocamento da Tela Sobre a Imagem

83 - Estrutura Global para o Arquivo Objeto do TMS34010

84 - Mapeamento da EPROM no Sistema com 256 Níveis de

Cinza

85 - Projeto para Inclusão de uma EPROM - Sistema com

256 Níveis de Cinza

86 - Equações para a Seleção das Memórias - Sistema

com EPROM

87 - Equações para a Seleção da Interface Serial -

Sistema com EPROM 


\section{Lista de Tabelas}

Tabela I - Ciclos de Memória Usados pelo Controlador de

Refrescamento de Vídeo

Tabela II - Prioridade das Interrupções

Tabela III - Estado dos Pinos do GSP durante "Reset"

Tabela IV - Largura de Banda Estimada para a Interface do Hospedeiro

Tabela V - Prioridade para Acessar a Memória Local

Tabela VI - Exemplo de Taxas de Refrescamento para DRAMs

Tabela VII - Mapa de Endereços para a Interface Serial -

Sistema com 16 Cores

Tabela VIII - Valores dos Registradores de E/S para o Sistema com 16 Cores

Tabela IX - Mapa de Endereços para a Interface Serial -

Sistema com 256 Níveis de Cinza

Tabela X - Registradores de E/S para o Sistema com 256 Níveis de Cinza

Tabela XI - Configuração do Sistema para o Exemplo 4, Anexo 1.2

Tabela XII - Conteúdo do Arquivo "Header"

Tabela XIII - Conteúdo do Arquivo "Header" Opcional

Tabela XIV - Conteúdo da Seção de Dados

Tabela XV - Início do Arquivo Objeto de uma Imagem

Tabela XVI - Fim do Arquivo Objeto de uma Imagem 


\section{RESUMO}

Neste trabalho são apresentadas a implementação e avaliação da aplicação do processador gráfico TMS34010. O objetivo foi o desenvolvimento de um sistema para visualização de imagens com este processador, a ser integrado ao Tomógrafo por Ressonância Magnética, do Departamento de Física e Ciência dos Materiais.

A fim de avaliar tanto os aspectos do "hardware" quanto as capacidades do processador, foram desenvolvidos dois sistemas: um com 16 cores, e outro com 256 níveis de cinza, ambos contendo uma interface serial para interligação de um "mouse" convencional para microcomputadores do tipo PC-AT.

Através destes sistemas foram avaliados recursos tais como "pan" horizontal e vertical, divisão da tela ao meio, vídeo no modo entrelaçado, transparência, operações lógicas, e instruções de transferência de blocos de "pixels". 


\begin{abstract}
This work describes the implementation and evaluation of a TMS34010 graphics processor based system.

The system was developed to be used for the visualization of Magnetic Ressonance Images in the MR tomography system under development in our Department .

To evaluate the design and the performance of the processor, two systems were developed: one capable to show pictures with 16 simultaneous colors, and a second one able to display pictures with a gray scale of 256 levels.

Both systems are equipped with a serial interface supporting a conventional mouse as used for PC compatibles.

The hardware developed was used to evaluate implementations of resources such as horizontal and vertical PAN, screen division, interlaced video, transparency, logic operations and pixels block transfer routines.
\end{abstract}




\section{Introdução}

As aplicações de sistemas gráficos têm crescido significativamente nos últimos anos, principalmente devido aos avanços feitos na área de circuitos integrados, resultando no aumento da densidade e complexidade dos circuitos, e na diminuição do custo.

Assim, além das aplicações de visualizações tais como as utilizadas tanto em computação gráfica quanto em processamento digital de imagens, a existência desta nova tecnologia está sendo empregada amplamente para a implementação de uma interface gráfica interativa Homem-Máquina .

Desta forma, os sistemas gráficos são utilizados não somente para a visualização, mas inclusive para a determinação e escolha de comandos através de menus e ponteiros ativados por caneta ótica ou "mouse".

Atualmente estes recursos estão se tornando muito populares, inclusive em sistemas de baixo custo (PC, Macintosh), facilitando a utilização de sistemas de computação, por leigos .

A maior parte das aplicações de sistemas gráficos podem ser englobadas em duas áreas principais: a computação gráfica e o processamento digital de imagens. A principal diferença entre ambas está na origem da imagem. No processamento digital, o dado da imagem é obtido de uma fonte externa, e é então processado com - objetivo de melhorar sua qualidade e possibilitar a extração de suas características. Em computação gráfica, a imagem é gerada pelo computador.

É interessante ressaltar que na área de processamento de imagens, operações como filtragem espacial, deteç̧ão de borda, e aplicação de algorítmos complexos para a modificação da imagem, são realizados por um sistema de processamento dedicado, e não pelo sistema gráfico. Cabe a este último, além de possibilitar a visualização da imagem, a realização de operaçōes gráficas como: operações lógicas e aritmética entre imagens, zoom, operações com janelas, alteração da cor da imagem, animação, etc. 
Como exemplo de aplicação de sistemas gráficos na área de processamento de imagens, podem-se citar na biomedicina as imagens obtidas por radiografia digital, por tomografia, por radiação nuclear, e por ultrassom. $\mathrm{Na}$ telecomunicação a análise de recursos naturais em sensoriamento remoto e metereologia, por meio de imagens por satélites.

Na computação gráfica podem-se citar como aplicações: a criação de animação para simuladores de vôo, ou vinhetas em programas de televisão; visualização de simulação e controle de processo na área industrial e na área de produção de energia e de transporte; elaboração de projetos de novos produtos na área industrial (CAD/CAM); realização de mapas em cartografia; visualização do comportamento de funções matemáticas em educação.

No meio científico, o uso de sistemas gráficos torna-se cada vez mais importante para a visualizacão de dados e imagens. Já desde 1981 o Departamento de Física mostrou-se interessado no desenvolvimente de um terminal gráfico. Em 1983, foi concluído no Laboratório de Instrumentação Eletrônica (LIE), o primeiro projeto de um terminal gráfico de baixo custo ${ }^{1}$. Este terminal podia operar também como um terminal alfanumérico comum, mas não possuía capacidade de processamento local. Este projeto viabilizou a visualização das primeiras imagens tomográficas por RM, obtidas no DFCM/IFQSC.

Em 1986, o aparecimento de "chips" VLSI com processador e controlador integrados possibilitou o projeto de um sistema gráfico interativo. $O$ objetivo principal deste projeto, assunto desta tese, foi desenvolver um sistema capaz de ser empregado como console de visualização de imagens de ToRM .

As metas deste sistema gráfico foram, além de permitir a visualizacão das próprias imagens, criar um ambiente interativo capaz de determinar regiōes de interesse para viabilizar a medição de distâncias, o cálculo de dados estátisticos, e a determinação de cortes ou planos oblíquos.

O trabalho dividiu-se assim no desenvolvimento de "hardware" - assunto desta tese - e o desenvolvimento do "software", trabalho que está sendo elaborado por Agma J. M. Traina

\footnotetext{
${ }^{1}$ Prof. Dr. Carlos A. Ruggiero
} 
A presente tese é dividida em sete capítulos.

No primeiro são apresentadas as noçōes fundamentais dos sistemas gráficos, introduzindo o leitor aos termos próprios da área.

No segundo capítulo são descritos os elementos que fazem parte de um sistema gráfico do ponto de vista do "hardware".

No terceiro capítulo é apresentada uma descrição geral do processador gráfico utilizado no projeto, o TMS34010.

No quarto capítulo é descrito o "hardware" do sistema gráfico.

No quinto capítulo é apresenta a descrição do "software" desenvolvido para teste do sistema gráfico.

No sexto capítulo é apresentada uma proposta para interligação de uma memória do tipo EPROM. 


\section{Símbolos e Convenções}

a) Palavras entre aspas que aparecem no texto, indicam termos em inglês, comumente utilizados em Eletrônica e Computação.

b) Números seguidos por "H" ou iniciados com ">" são hexadecimais.

c) No decorrer do texto é utilizada a convenção de lógica positiva, com o nível lógico baixo representado por "0", e o nível lógico alto por " 1 ".

d) No texto, todo sinal ativo baixo (ativo em "0"), é antecedido pelo símbolo "r".

e) Nas figuras, todo sinal ativo baixo é representado por uma barra sobre o nome do sinal.

f) No texto e nas figuras, as siglas MSB e LSB representam respectivamente, o bit mais significativo e o bit menos significativo da palavra.

g) Os demais símbolos utilizados podem ser encontrados nas referências [1], [2], [3] e [4]. 


\section{Capítulo I}

\section{Princípios Básicos para Visualização de Imagem em Tubos de Raios Catódicos}

\subsection{Introdução}

Como já mencionado anteriormente, um sistema gráfico é um sistema que possibilita a visualização de uma imagem, e que, além disso, contém recursos para a realização de uma série de operações gráficas tais como: operações lógicas e aritmética entre imagens, "zoom", operações com janelas, alteração da cor da imagem, animação, etc.

Até recentemente o custo do "hardware" de sistemas gráficos era bastante elevado, e somente nos últimos anos, com a evolução da tecnologia dos monitores de vídeo, dos circuitos integrados, e com o aparecimento dos circuitos VLSI, houve uma redução na relação custo-desempenho dos sistemas gráficos, além da compactação física dos mesmos.

Na figura 1 é mostrada a representação em blocos de um sistema gráfico [5]. Nesta figura, o dispositivo gráfico representa o meio de comunicação entre o usuário do sistema gráfico e este sistema. $O$ tipo de dispositivo gráfico define o "hardware" do sistema gráfico, e o que tem sido predominantemente utilizado é o dispositivo gráfico de vídeo. Diferentes tecnologias têm sido empregadas na implementação destes dispositivos, algumas das quais já consolidadas, como os monitores CRT ("Cathode Ray Tube"), enquanto outras encontram-se no início da fase comercial, como a tecnologia de plasma e a de laser. A descrição dos diversos tipos de dispositivos gráficos pode ser encontrada nas referências [5], [6],[7] e [8]. 
Atualmente, os monitores CRT ainda continuam sendo os mais utilizados para a visualização de imagens.

$\mathrm{Na}$ década de 50, $\mathrm{C}$ CRT era o único dispositivo capaz de converter os sinais elétricos do computador em imagens visíveis, em alta velocidade. Mas eram caros e de pequenas dimensões [?].

Com o avanço da tecnologia dos CRTs, foram sendo produzidos terminais cada vez mais eficientes para a visualização de imagens.

Entre os diversos tipos de monitores CRT que foram desenvolvidos, serão descritos dois em particular: os monitores vetoriais e os monitores por varredura. Estes últimos têm sido amplamente utilizados, devido à sua grande versatilidade e ao baixo custo em relação aos demais tipos.

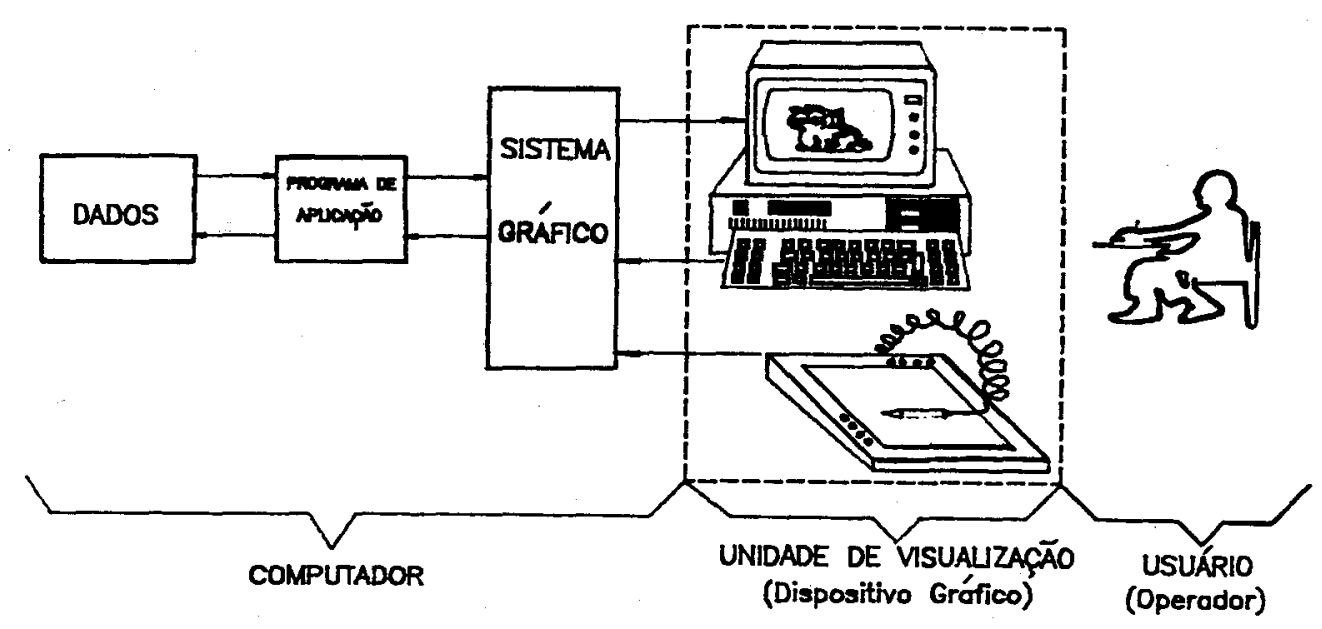

Figura 1 - Modelo de um Sistema Gráfico 


\subsection{Monitores Vetoriais}

Os monitores vetoriais ("vector display") foram desenvolvidos na década de 60. Estes monitores têm entradas X e Y, como no oscilóscópio. Os sinais enviados para estas entradas movem o feixe de elétrons para um ponto proporcional à amplitude dos mesmos.

0 nome atribuído aos mesmos, monitores vetoriais, é decorrente do fato de os sinais enviados a eles serem pares de pontos de tensão, e de o feixe desenhar um segmento de reta entre este ponto e o ponto desenhado anteriormente. A figura 2 ilustra a operação deste monitor. A figura é desenhada, movendo o feixe para 0 ponto inicial, ligando-o e defletindo-o continuamente entre os pontos finais das linhas para traçar o contorno da figura.

Um sistema gráfico típico para este tipo de monitor é mostrado na figura 3, e consiste de um processador, um controlador de vídeo, a memória de imagem e o monitor CRT.

O processador gera os pontos para o desenho de linhas ou caracteres, e armazena esta informação na memória de imagem, também denominada de "buffer" de refrescamento ou restauração.

O controlador de vídeo converte os valores digitais da memória, em valores analógicos, adequados para o deslocamento do feixe de elétrons no monitor CRT, e realiza esta operação de uma maneira cíclica. Isto é necessário porque a luz gerada no fósforo que recobre a tela do monitor CRT, decai. Para evitar cintilamento ("flicking"), o controlador deve repetir a varredura na memória pelo menos 30 vezes por segundo.

Este tipo de dispositivo pode representar imagens dinamicamente, estando, porém, sujeito ao problema de cintilamento, em decorrência do aumento de elementos a serem processados. São adequados para a visualização de retas e desenhos geométricos, mas têm capacidade limitada para preencher áreas, e não são adequados para a obtenção de muitas cores. 


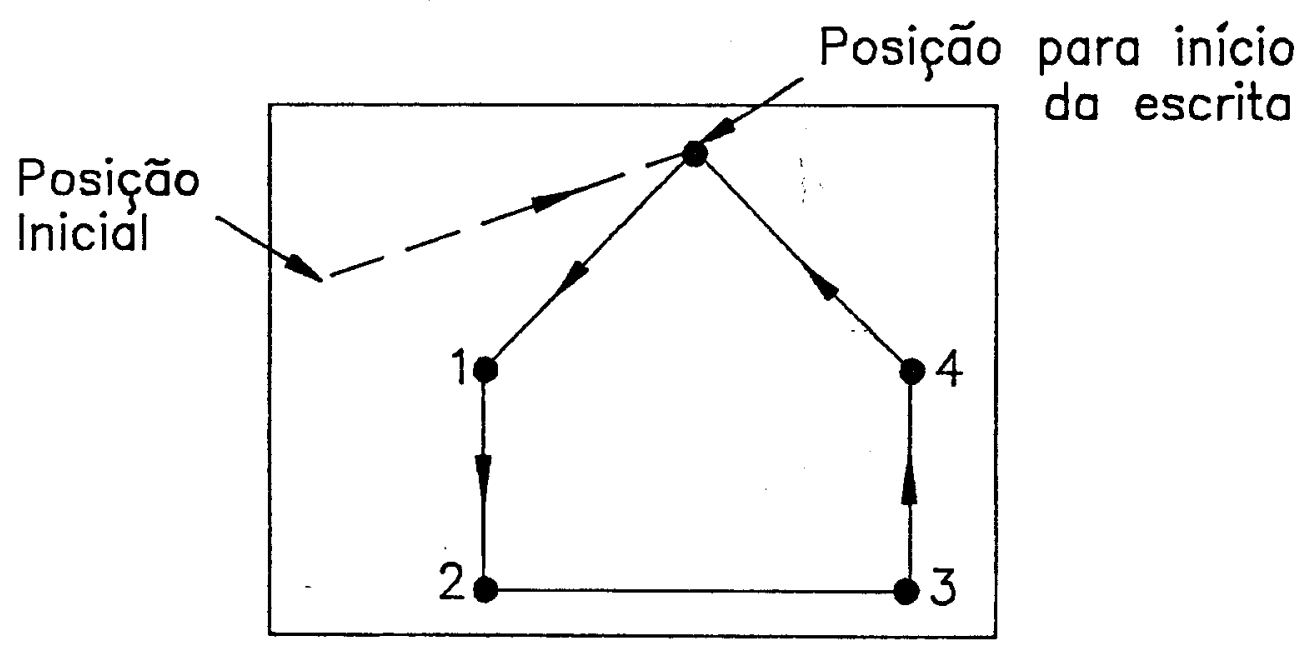

Figura 2 - Exemplo de uma figura mostrada num monitor vetorial.

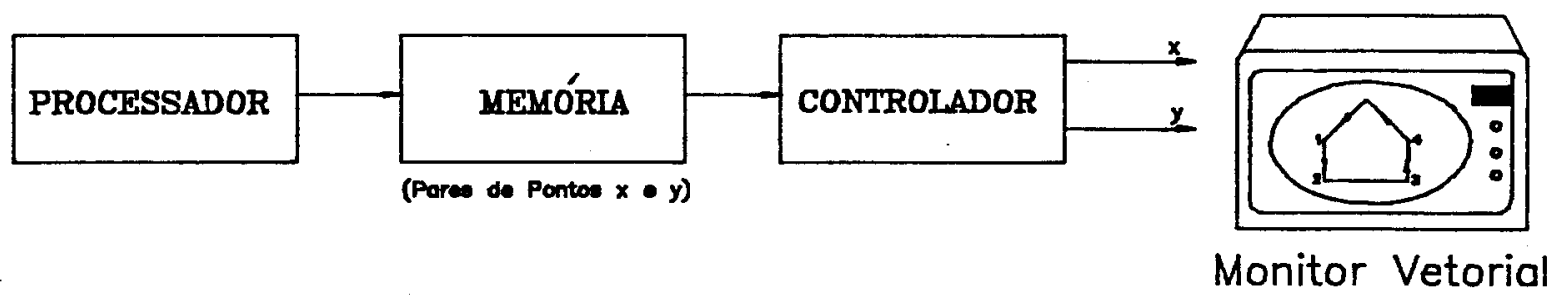

Figura 3 - Exemplo de um sistema gráfico para monitor vetorial

\subsection{Monitores por Varredura}

$\mathrm{Na}$ década de 70 surgiram os monitores por varredura, que se baseiam na tecnologia da televisão. Nestes tipos de monitores, os sinais de deflexão horizontal e vertical são gerados de forma a mover o feixe no padrão de varredura ilustrado na figura 4. 
A varredura ("raster") inicia-se no canto superior esquerdo da tela, e cada linha horizontal é varrida da esquerda para a direita. Após o fim de cada linha, o feixe de elétrons deve retornar à esquerda, a fim de iniciar a próxima linha, e isso decorre num intervalo de tempo denominado tempo de retraço horizontal. Situação semelhante ocorre quando o feixe desenha a última linha na tela e retorna para o seu início. Este tempo de retorno é denominado retraço vertical. Durante o tempo de retraço, horizontal ou vertical, o feixe de elétrons é desligado e o sinal de vídeo é dito apagado ("blanked"). Na figura 4, o tempo de retraço é representado por linhas pontilhadas.

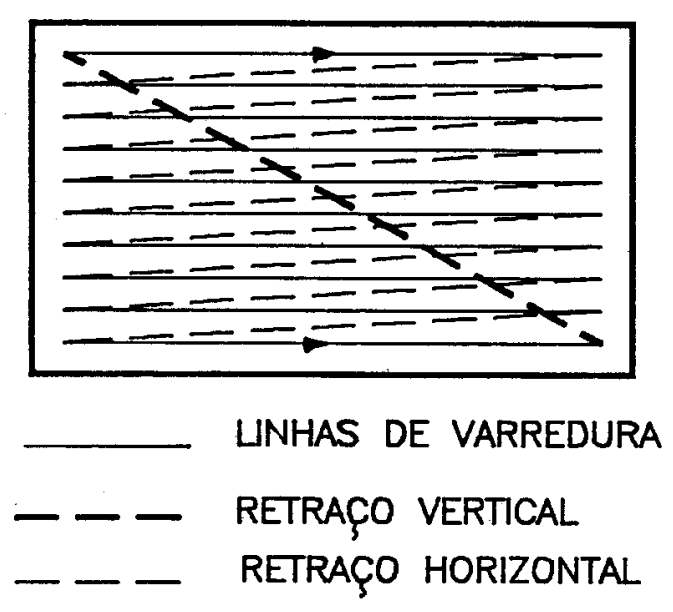

Figura 4 - Padrão de Varredura.

Cada linha horizontal é constituída por pontos individuais denominados "pixels" ("picture element"). A varredura é então uma matriz bidimensional de "pixels" cobrindo toda a tela.

Cada "pixel" pode ser constituído por um ou mais bits, sendo que o número de bits do "pixel" define o número de tons de cinza, ou o número de cores. Assim para "pixels" de 4 bits, pode-se ter até 16 intensidades de cinza, ou 16 cores diferentes. 
A resolução da tela do monitor é definida pelo número de linhas horizontais, o número de "pixels" por linha, e o número de bits por "pixels". Por exemplo, um monitor com resolução de $256 \times 512 \times 4$, contem 256 linhas horizontais, 512 "pixels" por linha e 4 bits por "pixel".

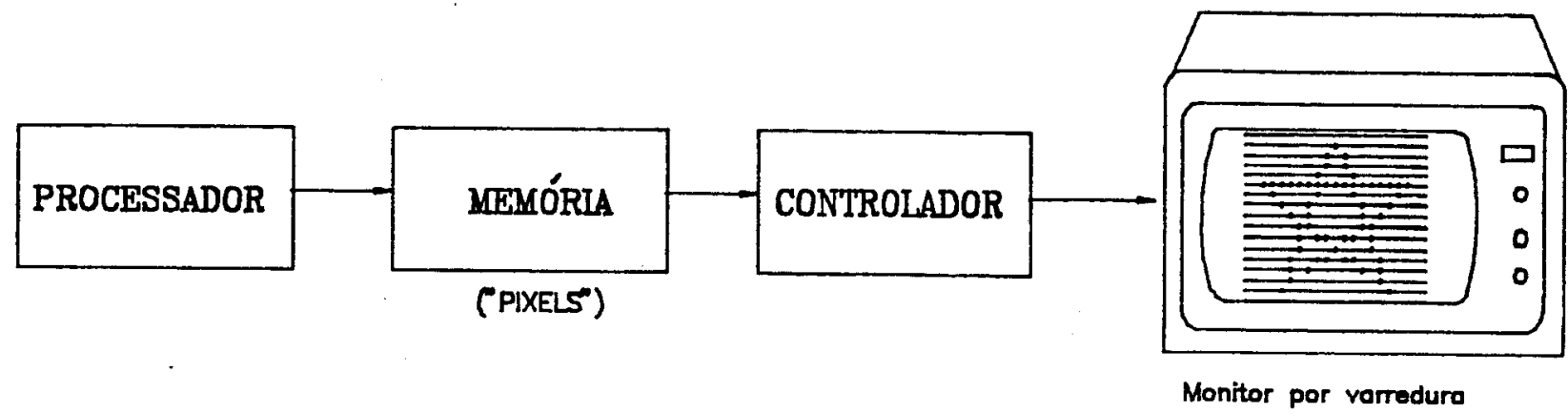

Figura 5 - Exemplo de um sistema gráfico por varredura.

O diagrama em blocos simplificado de um sistema gráfico por varredura é mostrado na figura 5. Na memória é armazenado o mapa de bits, contendo pontos que mapeiam um a um os pontos da tela. O controlador lê estes dados e os converte no sinal de vídeo que alimentará o monitor. $O$ controlador deve repetir esta operação pelo menos 30 vezes por segundo, para manter a figura estável na tela. O valor do "pixel" armazenado na memória pode representar diretamente a cor, ou pode representar o endereço de uma tabela de cores ("look-up table").

Estes monitores são adequados para mostrar sólidos e áreas que variam continuamente em intensidade na escala de cinza ou dentro de uma faixa de cores. A tabela de cores permite a fácil implementação das modificações de contraste.

A figura 6 mostra como uma imagem é desenhada a cada varredura horizontal. Nesta figura fica evidente a dificuldade deste tipo de sistema em representar retas contínuas, com inclinação diferente de 0, 45 graus, 90 graus, etc., em relação à horizontal. Este efeito é denominado de "aliasing". 


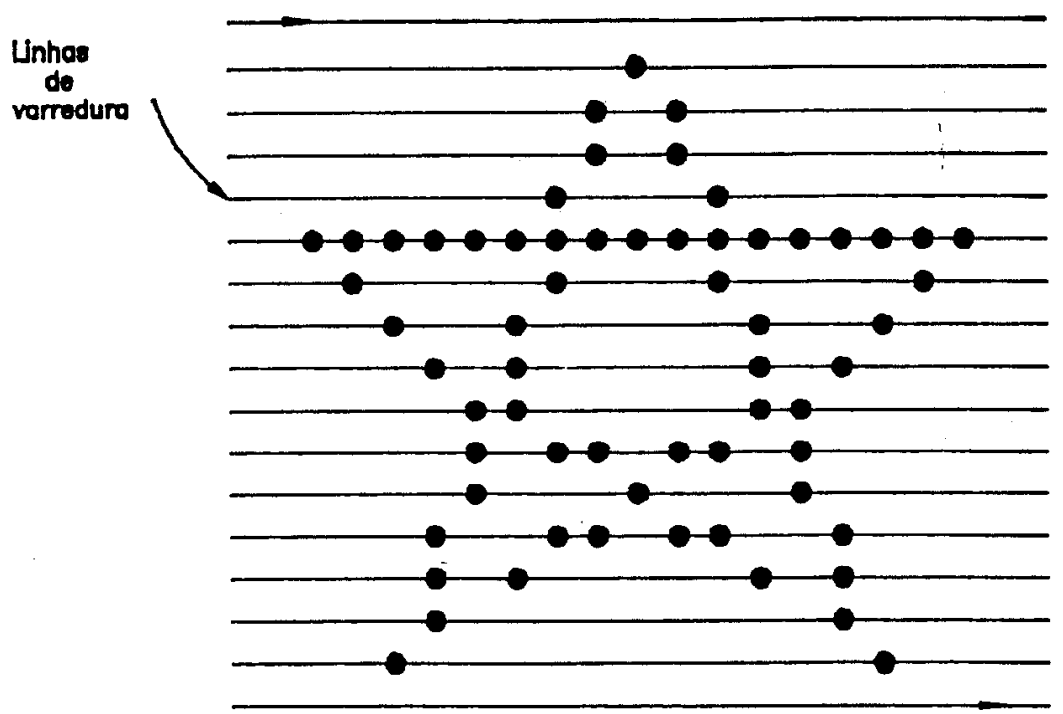

Figura 6 - Exemplo de uma figura mostrada num monitor por varredura.

Outra desvantagem destes sistemas é que requerem memórias de grande capacidade, já que todos os pontos da tela devem estar armazenados. Na época de seu desenvolvimento, esta característica tornou-o um dispositivo caro. Mas, atualmente, com o progresso tecnológico na fabricação de memórias, o tamanho da imagem deixou de ser problema, em virtude da existência de memórias de maior capacidade e a um custo menor.

Em relação aos monitores vetoriais, a desvantagem destes sistemas, além da grande capacidade de memória requerida, é o tempo computacional necessário wara realizar a atualização dinâmica de uma tela inteira. Por outro lado, o processo de refrescamento é independente da complexidade (número de linhas, etc) da imagem, e desta forma não há cintilação. Isto já não é verdade para os monitores vetoriais, nos quais ocorre cintilação, quando o número de primitivas (linhas, retângulos, etc) cresce muito.

No capítulo seguinte serão vistos com mais detalhes, os elementos que compõem um sistema gráfico por varredura. 


\section{Capítulo II}

\section{Hardware para Visualizaçāo de Imagens}

\subsection{Introdução}

Como já mencionado no capítulo 1, o sistema gráfico por varredura usualmente contém um processador gráfico, memórias de imagem, um controlador para o refrescamento do monitor de vídeo, um circuito de saída para vídeo, que pode incluir "look-up tables", e um monitor de vídeo [9]. Este sistema pode comunicar-se com outros dispositivos através de um barramento. A figura 7 mostra uma configuração possível para um sistema gráfico que contém estes elementos. Nesta figura, a memória de imagem tem uma porta dedicada ao processador gráfico. Neste caso, a

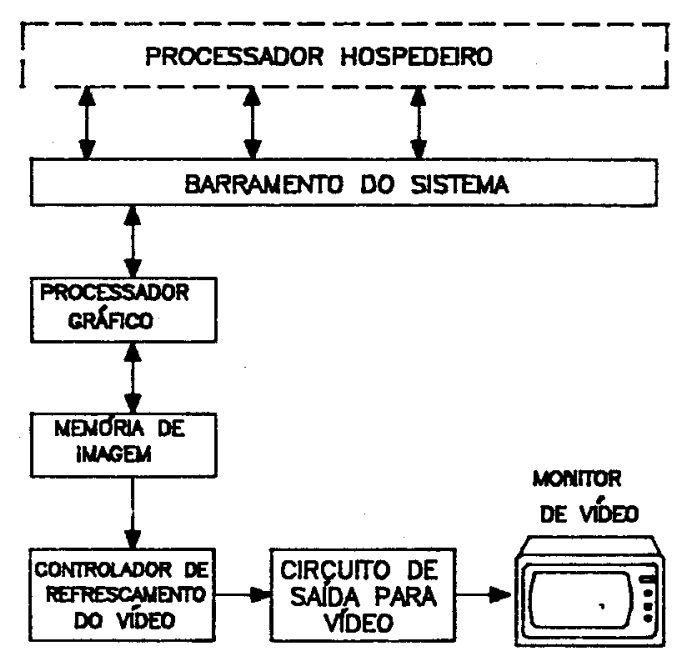

Figura 7 - Diagrama em blocos de um sistema gráfico por varredura. 
transferência de dados entre processador hospedeiro e memória de imagem é feita através do processador gráfico.

0 processador gráfico deve ser capaz de calcular, de forma eficiente, diversos tipos de figuras como linhas retas e curvas, polígonos, caracteres; preencher áreas, e copiar ou combinar logicamente áreas de memória (função "raster op").

0 controlador para o refrescamento do vídeo tem como principal função, gerar o endereço para a memória, ler os dados da mesma e convertê-los da forma paralela para a forma serial. Além disso, pode controlar funções como "pan" e janelas.

O circuito de saída para vídeo converte os dados provenientes do seu controlador em níveis de intensidade ou cores, e os passa para o monitor.

Como já visto no capítulo 1 , a memória de imagem, também denominada de "frame buffer", memória de vídeo ou "bit map", contém uma matriz de valores que representam uma imagem. O tamanho da matriz (por exemplo 512X512) é denominado resoluçào da memória. Cada elemento da matriz ("pixel"), pode ser constituído por vários bits. A memória de vídeo pode então ser pensada como constituída por planos de bits, de forma que o número de planos seja igual ao número de bits do "pixel". Assim, uma matriz da memória cujos "pixels" sejam de 1 bit contém um plano de 1 bit. Uma memória cujos "pixels" sejam constituídos por 8 bits, contém 8 planos. O número de bits por "pixel", é denominado profundidade de "pixel" ou resolução da cor.

A memória de imagem é frequentemente de porta dupla ("dual ported"), ou de múltiplas portas ("multiported"), significando que a mesma tem dois ou mais caminhos de dados em sua entrada/saída, e que pode ser compartilhada pelos dois dispositivos. Assim, por exemplo, enquanto uma porta é acessada pelo processador gráfico, a outra é acessada pelo controlador de vídeo (figura 8).

Alguns sistemas "frame buffer" contêm memória suficiente para armazenar duas imagens completas, com a desejada profundidade de "pixel" e resolução. Para tal sistema é possível, para o controlador de vídeo, acessar e mostrar a memória 0 , enquanto o processador grava uma nova imagem na memória 1. Quando a gravação da nova imagem é completada, o controlador de vídeo passa a acessar a memória 1 , 
enquanto o processador gráfico acessa a memória 0. Esta técnica é denominada "double buffering" ou ping-pong.

Nos próximos itens serão vistas as características principais dos elementos do sistema gráfico por varredura.

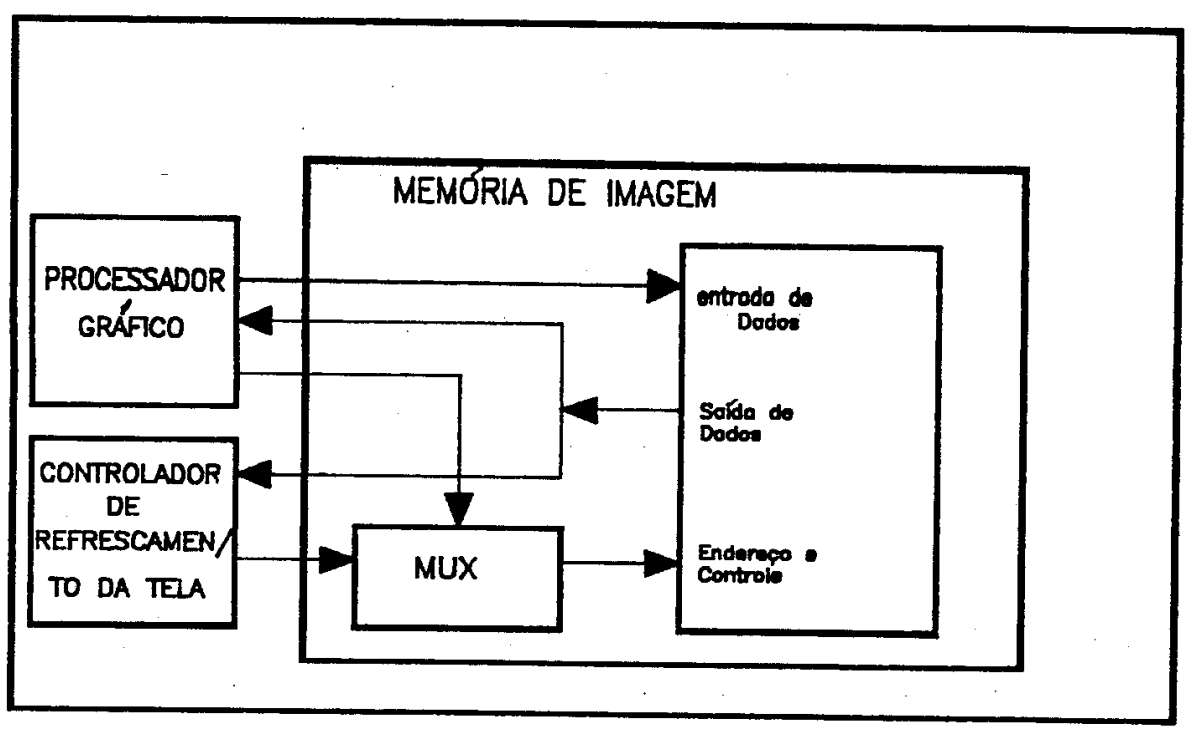

Figura 8 - Memória de Porta Dupla.

\subsection{Terminologia para Monitores por Varredura}

Nos sistemas gráficos por varredura, o controlador de vídeo deve acessar a memória de imagem dentro de um intervalo de tempo, definido pelas características do monitor de vídeo. É necessário, então, definir a terminologia e a temporização de vídeo.

Um monitor de vídeo convencional necessita de três sinais externos que serão aplicados ao controlador do CRT e à eletrônica associada a ele. Estes três sinais são: Sincronismo Horizontal (HSYNC), Vertical (VSYNC), e VÍDEO.

O propósito dos sinais de sincronismo não é iniciar ou parar o movimento da varredura, mas sim aumentar ou diminuir a duração desta, de forma a sincronizar a 
informação a ser apresentada com o deslocamento do feixe de elétrons. 0 sinal víDEO modula a intensidade do feixe de elétrons.

Em alguns monitores CRT, existe uma única entrada denominada vídeo composto. 0 sinal de vídeo composto que deve ser aplicado a esta entrada é constituído por sinais HSYNC, VSYNC e VÍDEO. Estes monitores contêm internamente o circuito para a separação destes três sinais. A vantagem do sinal de vídeo composto é poder ser enviado através de um único cabo coaxial.

Nos monitores a cores há três entradas separadas para controle das cores primárias: vermelha (R), verde (G), e azul (B). Cada uma destas entradas é na verdade um sinal monocromático separado. A combinação destas três cores em diferentes intensidades gera as demais.

Há dois métodos utilizados para mostrar uma imagem nos monitores por varredura. No primeiro, denominado de vídeo não entrelaçado, todas as linhas da imagem são desenhadas na tela em sequência. Considerando a frequência de $60 \mathrm{~Hz}$ como especificação usual para este modo, uma imagem completa é desenhada na tela 60 vezes por segundo.

No segundo modo, denominado vídeo entrelaçado, são desenhadas linhas pares alternadamente com linhas ímpares. Desta forma um "frame" completo será constituído pelo campo par e pelo campo ímpar, e a imagem completa será desenhada na taxa de $30 \mathrm{~Hz}$, como ilustrado na figura 9. A desvantagem de se usar vídeo entrelaçado é a ocorrência de cintilação ("flicking"), particularmente para linhas horizontais que são desenhadas na tela somente 30 vezes por segundo. Este efeito é minimizado com o uso de fósforo de maior persistência na tela, mas por outro lado isto impede a manipulação dinâmica de imagens na tela. A vantagem deste método é a obtenção do dobro de linhas em relação ao outro método, sem ser necessário alterar as frequências da varredura horizontal ou vertical.

Outro recurso utilizado para aumentar o número de linhas horizontais, é a redução da frequência vertical, normalmente de $60 \mathrm{~Hz}$ para $45 \mathrm{~Hz}$. O principal problema deste método consiste na inexistência de sincronismo entre a frequência vertical e a da rede além de o feixe de elétrons do CRT poder ser modulado ou 
defletido por campos eletromagnéticos existentes no ambiente externo, tais como aqueles produzidos por transformadores de potência que estejam próximos. Escolhendo-se a frequência vertical idêntica à da rede, estas perturbações na imagem serão estáveis.

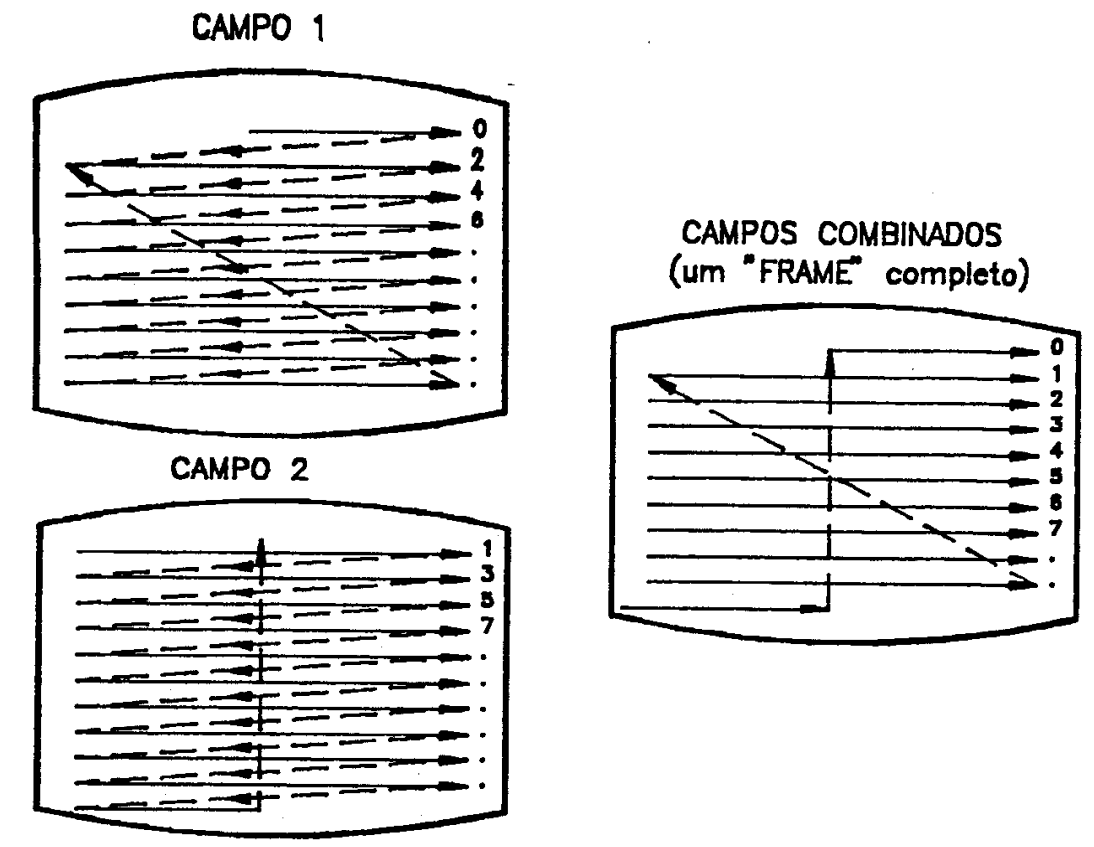

Figura 9 - Varredura para vídeo entrelaçado.

A taxa de refrescamento do monitor é o número de imagens completas ou "frames" desenhadas na tela, no tempo de um segundo, e é medida em frames por segundo. $O$ tempo de um "frame" é o recíproco da taxa de refrescamento (figura 10).

Para se saber com que frequência a memória deve ser acessada, é essencial saber a frequência necessária ao envio do "pixel" ao vídeo. A figura 10 mostra a representação de todos os tempos de vídeo quando uma imagem está sendo mostrada na tela. Desta figura pode-se obter o tempo de um "pixel" como sendo:

tempo do "pixel " = [((1/TR) - RV)/NL - RH $] / N P$ 
onde:

TR: Taxa de Refrescamento

RV: Retraço Vertical

NL: Número de Linhas visíveis por "frame"

RH: Retraço Horizontal

NP: Número de "Pixels" por linha

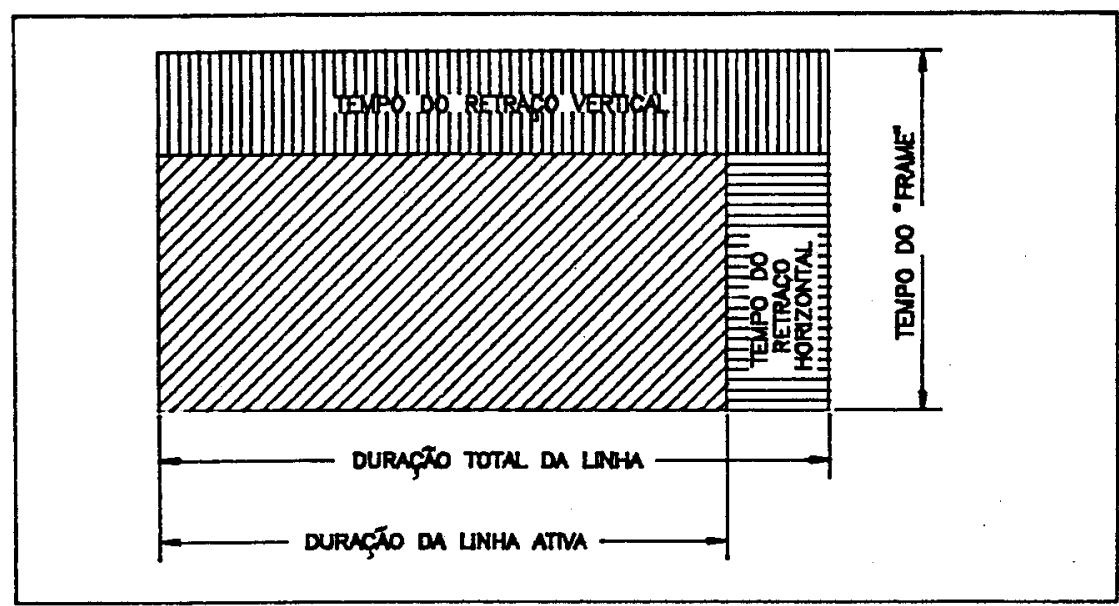

Figura 10 - Elementos da Temporização de um "Frame" do vídeo.

\subsection{Memórias para Sistemas Gráficos}

Dois parâmetros básicos caracterizam a performance de uma memória: o tempo de acesso e o de ciclo. $O$ tempo de acesso é o tempo mínimo para os dados tornarem-se válidos nas saídas de dados da memória, após a mesma ter sido endereçada e selecionada. O tempo de ciclo é o tempo mínimo entre acessos sucessivos à mesma memória.

Atualmente, por considerações de custo, as memórias utilizadas em sistemas gráficos são as dinâmicas (DRAMs), já que as estáticas, além de serem mais caras, 
têm capacidade menor quando comparadas às dinâmicas. Exceção ocorre em sistemas que requeiram memórias mais rápidas, e neste caso são usadas as RAMs estáticas (SRAM).

Dois problemas ocorrem com as memórias de imagem e estão relacionados entre si. 0 primeiro deve-se ao fato do processador não poder ter acesso irrestrito à memória de imagem, já que o controlador de vídeo também necessita buscar dados nesta memória para atualização da tela.

O segundo ocorre quando o tempo de ciclo da memória é maior que o de "pixel".

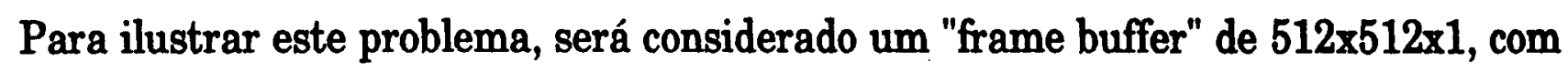
taxa de refrescamento de $30 \mathrm{~Hz}$, implementado com memórias DRAMs de $16 \mathrm{Kx} 1$, com tempo de ciclo de 400 ns. Para esse "frame buffer" são necessários 16 "chips" para armazenar toda a imagem. Como o tempo de ciclo da memória (400 ns) apresenta-se maior que o de "pixel" (100 ns), é incluído no controlador de refrescamento do vídeo um registrador de deslocamento paralelo/série, de 16 bits, que permite o carregamento simultâneo de um "pixel" de cada memória. Desta forma, os 16 "pixels" carregados em paralelo são transferidos serialmente para o circuito de saída de vídeo, no intervalo de tempo de 1600 ns. Este circuito permite que a memória possa ser acessada pelo processador por um tempo de $1200 \mathrm{~ns}$, a cada $1600 \mathrm{~ns}$, como é ilustrado na figura 11. Além disso o processador pode acessá-la durante o retraço horizontal e vertical.

A tabela I mostra que a porcentagem de ciclos de memória usada pelo controlador de refrescamento aumenta, quando são usadas memórias de capacidade maior, com ciclo de tempo de $\mathbf{4 0 0} \mathrm{ns}$ e dados de 1 bit, sendo maior para a frequência de $60 \mathrm{~Hz}$. Para memórias de $16 \mathrm{Kx} 1$, são necessários 16 "chips" para uma tela de $512 \times 512$, sendo $25 \%$ dos ciclos de memória usados para o refrescamento desta tela. Para memórias de 64Kx1, são necesários 4 "chips", e 100\% dos ciclos de memória são usados para o refrescamento de uma tela de 512×512. Uma única memória de $256 \mathrm{Kx} 1$ poderia conter toda a imagem para essa resolução de tela; no entanto, torna-se inviável, em virtude de não poder ser acessada na taxa de vídeo requerida. 
Assim, a memória de $64 \mathrm{~K} \times 1$ passou a ser usada com frequência nos sistemas gráficos por varredura, na implementação do "frame buffer",devido ao fato de possuir maior capacidade de refrescamento da tela. Devido a isso é que diversas soluções foram propostas para memórias com esta organização (64kx1), a fim de melhorar o acesso do processador a estas memórias de imagem.

Tabela I - Ciclos de Memória Usados pelo Controlador de Refrescamento de Vídeo.

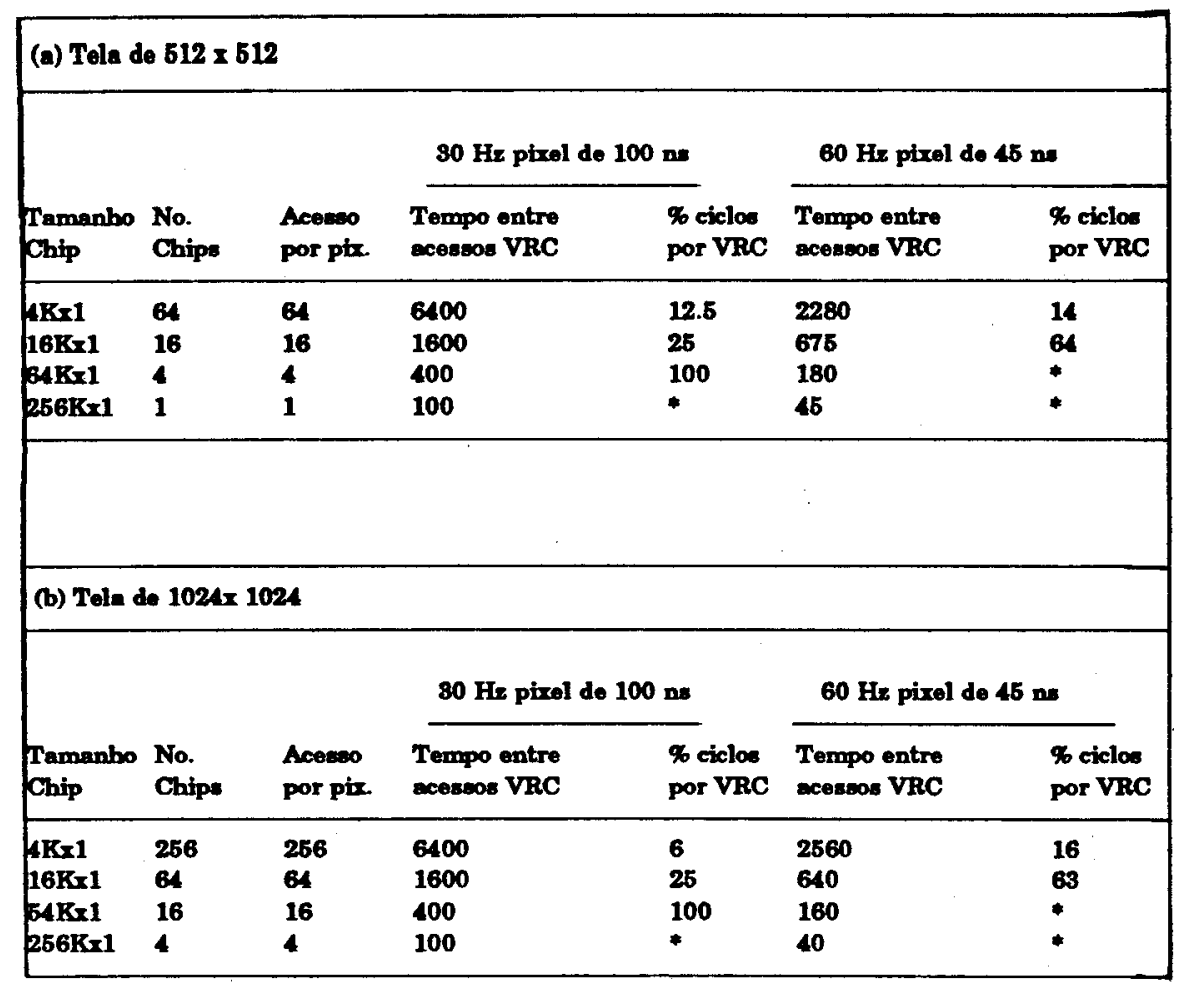

Posteriormente surgiram memórias com tamanho de palavra maior. Estas memórias podem ser organizadas como múltiplos "pixels" por "chip", ou como múltiplos bits por "pixel", por "chip" (figura 12).

No caso de serem organizadas como "pixels" por chip, considerando que todas as memórias são acessadas simultâneamente, mais "pixels" serão lidos em cada ciclo 
de memória. Desta forma a frequência de ciclos do controlador de vídeo à memória diminui, enquanto o acesso do processador às memórias aumenta. Isto é válido para memórias que tenham capacidade total de 64k bits. Projetos que utilizem chips organizados como $64 \mathrm{Kx} 4$, usam todos os ciclos para o controlador de refrescamento de vídeo. Por exemplo, para uma tela de 512×512, são necessários 4 "chips" de 16K×4, e a cada ciclo de leitura são lidos 16 "pixels".

A desvantagem de se utilizar memórias com múltiplos "pixels" numa palavra, provém da impossibilidade de se endereçar "pixels" individuais na mesma.

No caso de sistemas com múltiplos bits por "pixel", ocorre situação semelhante. Um sistema com "chips" de 16×4 aumenta o acesso do processador às memórias.

Serão analisados a seguir, alguns métodos de acesso do controlador às memórias.

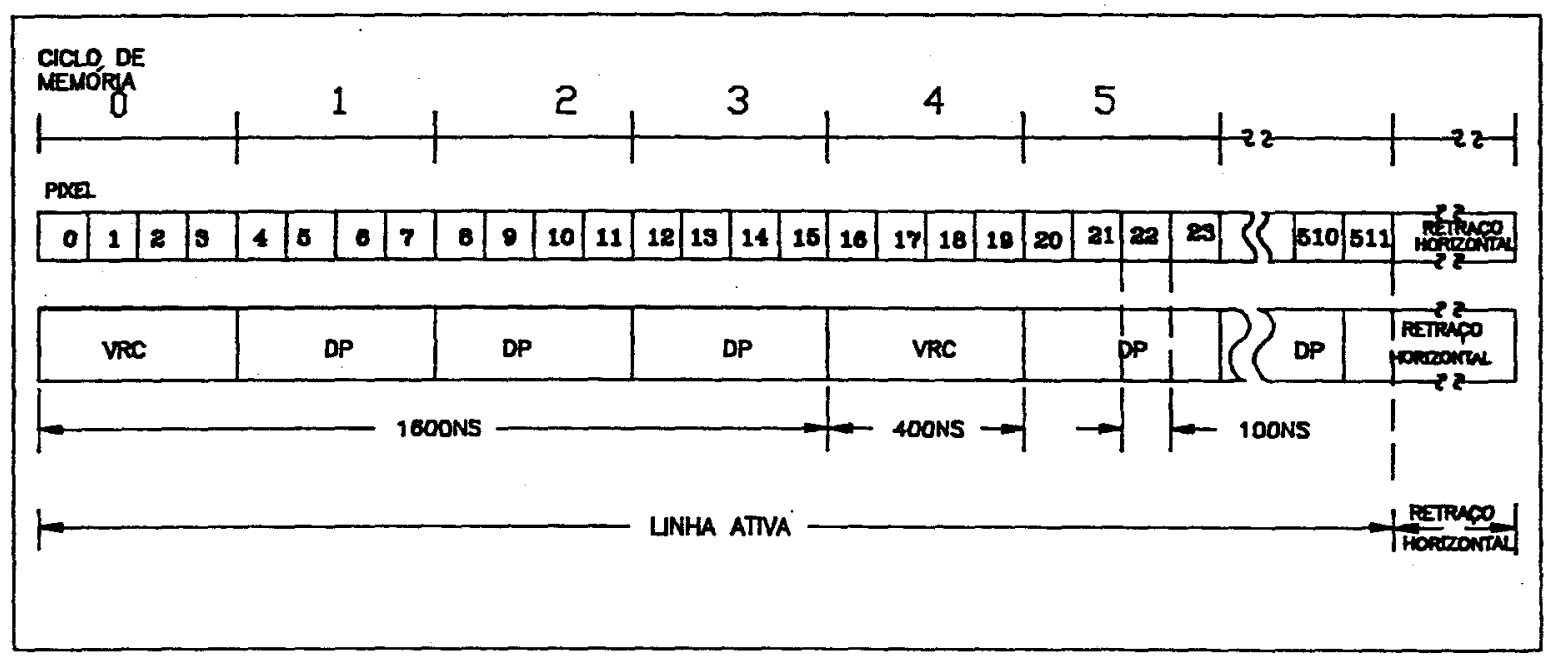

Figura 11 - Alocação de ciclos de memória no tempo de linha ativa, para controlador de refrescamento de vídeo (VRC) e o processador gráfico (DP); 16 DRAMS de 16Kx1; a resolução do sistema é 512 x 512, $30 \mathrm{~Hz}$. 


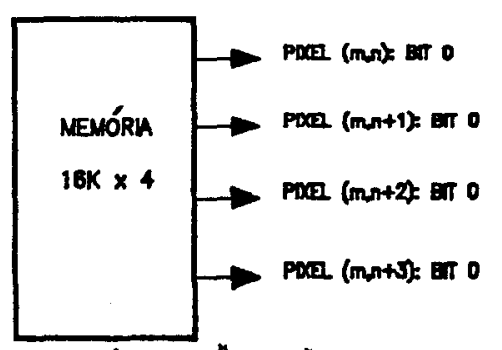

(a) Múltiplos "Pixels" por polovro

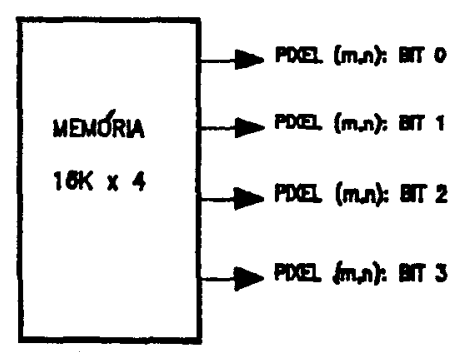

(b) Multiplos bits por "Pixe"

Figura 12 - DRAM com palavras longas.

\subsubsection{Gravação Durante o Retraço}

A maneira mais simples e econômica de implementar memória de imagem com DRAMs de 64Kx1 consiste em permitir o acesso do processador às memórias somente durante a ocorrência do retraço horizontal e vertical. Neste caso, o número de acessos executados pelo processador à memória dependerá da duração do ciclo de instrução do processador e da necessidade de ciclos de espera para a memória.

Para um sistema com resolução de tela de 512x512, e frequência vertical de $60 \mathrm{~Hz}$, a duração total dos retraços é de $4.83 \mathrm{~ms}$ em cada frame de $16.67 \mathrm{~ms}$, permitindo a ocorrência de até 12000 ciclos de "clock" de 400 ns durante o tempo de retraço.

\subsubsection{Sistemas com "Double-Buffer"}

Outra maneira de resolver o problema de contenção nas memórias, embora mais dispendiosa, caracteriza-se pelo uso do esquema com "double-buffer", onde uma área de memória é acessada pelo processador, para modificação da imagem, enquanto a 
outra área é acessada pelo controlador de vídeo, o qual envia os dados para o monitor. Esse sistema possui custos mais elevados por necessitar duas vezes da quantidade de memória necessária para conter a imagem de uma tela, mas, por outro lado, permite uma transição suave entre imagens sucessivas, em aplicações onde se torna impossível a realização de modificações na imagem ou a gravação de uma nova imagem durante o retraço vertical.

"Double buffering" pode ser implementado de duas maneiras: separando o tamanho do "pixel" da memória disponível, de forma a reduzir a resolução da cor; ou mantendo o tamanho do "pixel" e reduzindo a resolução XY da memória.

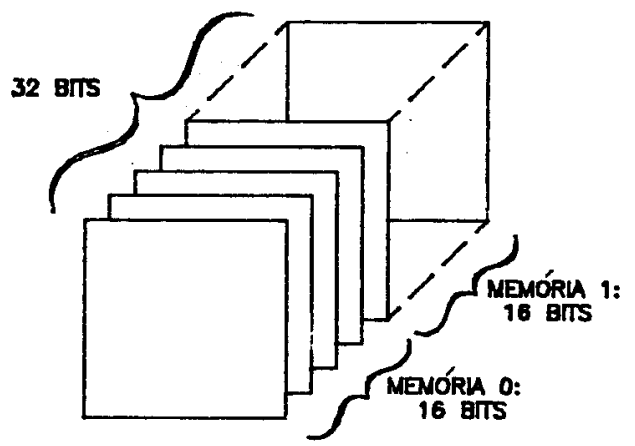

(o) Reduçäo do tamanho do

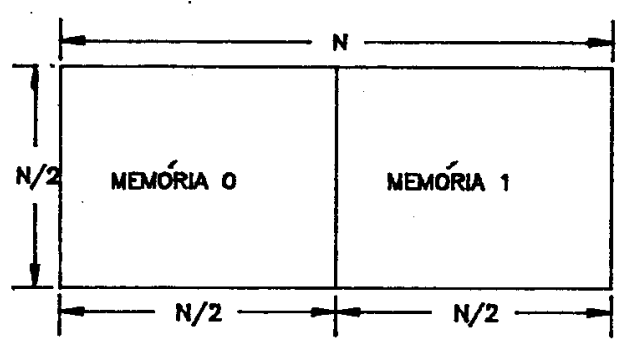

(c) Reduçōo de resoluçăo xy

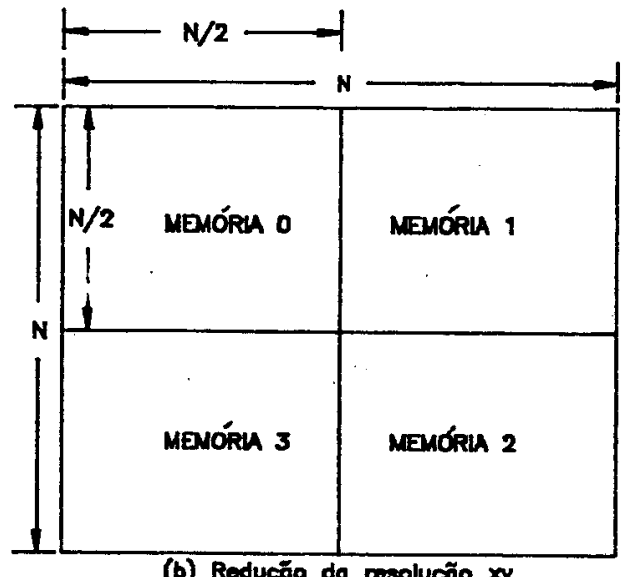

(b) Redufäo da resoluçäo $x y$

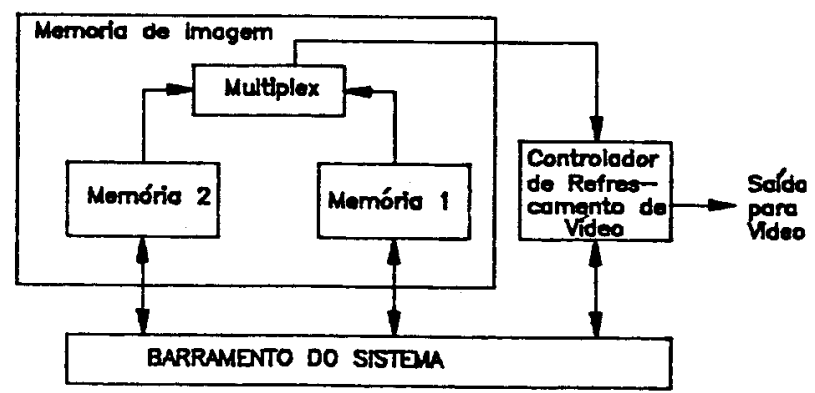

(d) roduçōo da rosolupăo $x y$

Figura 13 - Técnicas de "Double Buffering". 
Para exemplificar, um "frame buffer" com $512 \times 512 \times 16$ pode ser tratado como

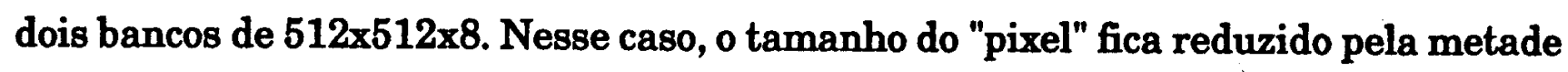
em cada banco, e o endereçamento de cada banco pode ser independente, ou deve haver uma habilitação de gravação para cada plano de bit. Este mesmo "frame buffer" pode ser tratado como quatro bancos de $256 \times 256 \times 8$, onde cada quadrante pode ser mostrado separadamente, podendo-se usar para isso a função janela, ou pode deslocarse de um quadrante a outro através da função "pan", como será explicado no item 2.3.4. A figura 13 ilustra as duas técnicas.

Se os dois "buffers" usam "chips" de memória separados, o controlador e o processador tem acesso completo às suas respectivas memórias. No entanto, se eles têm de compartilhar o mesmo "buffer", nenhuma melhora resulta no sistema.

\subsubsection{Memórias de Resolução Variável}

Nesses sistemas é possível selecionar o tipo de "double buffer": com redução da resolução da cor, ou da resolução XY. Como exemplo, uma memória pode ser alternadamente endereçada como $512 \times 512 \times 32$ ou $1024 \times 1024 \times 8$.

A resolução variável é obtida pela manipulação do "buffer" de vídeo. Um "buffer" que suporta um bit/"pixel" em 10ns /'pixel", pode também suportar quatro bits em 40ns/"pixel", e oito bits em $80 \mathrm{ns/"pixel".} 0$ controlador de refrescamento de vídeo formata os bits do "buffer" de vídeo em "pixels" de determinado número de bits, e os passa ao circuito de saída para vídeo, na taxa requerida pelo monitor de vídeo.

\subsubsection{Memórias Gráficas}

As memórias gráficas, também denominadas de RAMs para vídeo (VRAM), surgiram por volta de 1983, e foram projetadas para minimizar o conflito existente entre processador e controlador. A idéia foi de implementar uma memória de porta 
dupla ("dual ported"), com um registrador interno suficientemente grande, de forma a conter os dados de pelo menos uma linha da tela, e que pudesse ser carregado num ciclo de memória. Com a memória de porta dupla, o problema do conflito entre processador e controlador ficaria reduzido.

Nas memórias VRAMs comerciais, o número de bits do registrador de deslocamento interno é igual ao de uma linha da matriz de memória. 0 registrador de deslocamento interno é carregado com uma linha da matriz de memória, endereçada externamente através de um ciclo de memória para registrador de deslocamento. Esta operação pode ocorrer durante o retraço horizontal.

A figura 14 ilustra o diagrama em blocos deste tipo de memória. Como se pode observar na figura, esta memória contém duas portas, onde uma opera como entrada/saída convencional de dados, enquanto a outra, como entrada/saída serial de dados para o registrador de deslocamento, podendo ambas ser acessadas simultaneamente, exceto durante o ciclo de memória para registrador de deslocamento. Após este ciclo, o "chip" comporta-se como dois dispositivos independentes; uma memória dinâmica na qual se pode realizar as operą̧ões convencionais de leitura e gravação, e um registrador de deslocamento que opera na

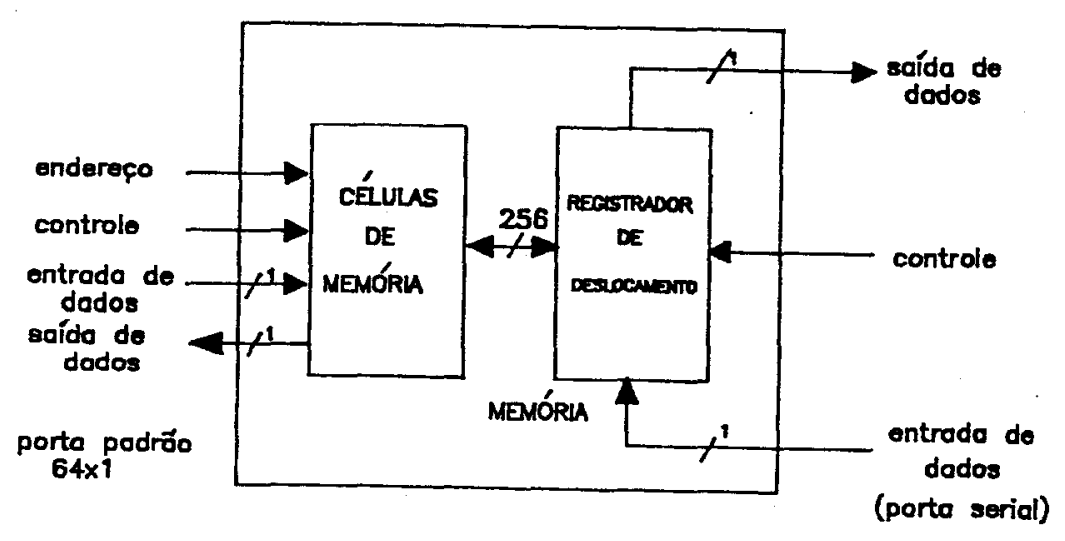

Figura 14 - Diagrama em blocos da memória VRAM. 
frequência necessária para o refrescamento do monitor de vídeo.

Esse tipo de memória, além de minimizar o problema de contenção, dando ao processador um acesso quase que ilimitado às memórias, permitiu uma redução no circuito dos sistemas gráficos.

Uma das primeiras memórias deste tipo a ser desenvolvida foi a TMS4161, com ciclo de tempo de $260 \mathrm{~ns}$, organizada como $64 \mathrm{Kx} 1$, e com registrador de deslocamento interno de 256x1. A frequência máxima do registrador de deslocamento é de $25 \mathrm{MHz}$, ou 40 ns. Para uma taxa de "pixel" mais elevada do que esta, torna-se necessário o uso de registradores de deslocamento externo. Com essas memórias, dependendo da resolução da tela, mais de uma linha de varredura pode ser desenhada entre ciclos de memória para registrador de deslocamento. Isso permite que o acesso do processador às memórias aumente significativamente, visto que, durante todo $o$ tempo de desenho dos "pixels" na tela, o processador pode ter acesso às memórias.

Um problema a que estão sujeitas estas memórias refere-se ao recurso de "pan". O "pan" consiste no deslocamento da tela sobre uma memória de imagem que tenha dimensões maiores do que as da tela. $O$ "pan" somente poderá ser realizado, se o conteúdo dos registradores de deslocamento for suficiente para desenhar mais de uma linha na tela. Isso ocorre devido ao fato de a lógica interna destas memórias, não permitir que seja carregado nos registradores de deslocamento parte de uma linha da matriz de memória e parte da linha seguinte.

Uma característica importante destas memórias é o recurso que as mesmas apresentam de transferir dados do registrador interno para qualquer linha da memória, em apenas um ciclo de memória. Este recurso torna possível estabelecer o conteúdo da memória para um valor único, ou uma cor de fundo, em apenas 256 ciclos de memória (aproximadamente 70 us), o que representa um tempo 256 vezes mais rápido que as memórias DRAMs padrões de 64K. Este recurso pode também ter outras aplicações, como por exemplo, a reordenaçăo das linhas para facilitar o "display scrolling".

Com este tipo de memória foi reduzido o problema do conflito entre processador e controlador, mas não foi melhorado o tempo para se gravar dados. 
Outras organizações de memória são então sugeridas na referência [5], para acelerar o processo de gravação de dados nas memórias. Numa das organizações sugeridas é usada uma palavra contendo uma máscara, onde cada bit da máscara está associado a um "chip" da memória, e tem a função de habilitar ou não a gravação de dados. A gravação é realizada em paralelo, de acordo com a máscara.

Outra organização sugerida refere-se a um sistema constituído por um processador que gere dados na forma matricial, e a memórias que aceitem dados na forma matricial em um único ciclo de gravação.

\subsection{Processadores em Sistemas Gráficos}

Os sistemas iniciais não continham processador dedicado, mas apenas o controle necessário para gerar os sinais de sincronismo para vídeo, e mostrar os dados que haviam sido armazenados nas memórias gráficas pelo processador mestre. As memórias existentes na época eram de $4 \mathrm{~K} \times 1$ [9].

As primeiras funções gráficas a serem realizadas foram a geração de caracteres e a de vetores. Estas funções eram implementadas em hardware, com o processador mestre enviando os dados necessários e os sinais de controle para o "hardware" dedicado.

À medida em que as funções gráficas foram aumentando em número e complexidade, o "hardware" também foi tornando-se cada vez mais complexo.

Com o advento dos controladores gráficos, foi incluído num único "chip" o "hardware" para gerar os sinais de sincronismo para vídeo, e o hardware para implementar funções gráficas como retas, círculos e retângulos. Nos mais avançados, foram incluídos também os recursos para gerenciar a memória de imagem, e funções como "pan" e "zoom".

A partir de 1980 vários controladores tornaram-se disponíveis, mas nem todos podendo ser interligados diretamente com memórias como as DRAMs, necessitando para isto de lógica adicional. A vantagem destes controladores é a de poderem 
executar as operaçōes gráficas mais rapidamente do que o processador mestre. Porém, a desvantagem destes controladores reside no fato de além de necessitarem da intervenção frequente do processador mestre, para enviar os comandos e parâmetros, eles estão limitados apenas à execução das funções para as quais foram projetados. Assim, novos comandos não podem ser adicionados ao controlador, a não ser que seja construída uma nova versão do "chip". Outra limitação possível consiste em poderem operar com um ou poucos tamanhos de "pixels". Um exemplo de controlador gráfico pode ser encontrado na referência [ig].

0 passo seguinte foi utilizar um microprocessador de propósitos gerais para a realização das funções gráficas, de forma a gerar um novo "pixel" sem a intervenção do processador mestre, cabendo a este a função única de transferir dados $e$ instruções para o microprocessador.

Conforme é explicado na referência [ụ], a vantagem encontrada no uso destes microprocessadores foi a de possibilitar a programação de tarefas de processamento gráfico, o que não era possível com os controladores gráficos. Mas por outro lado, a ausência de funçōes gráficas especializadas nestes processadores mostrou que não eram totalmente eficientes para aplicações gráficas. Embora alguns dos microprocessadores de 32 bits apresentassem o recurso de inserçao e extração de campos na memória, parecendo úteis à manipulação de "pixels", verificou-se serem desapontadoramente lentos com relação ao tempo de execução. Mesmo os microprocessadores mais rápidos mostraram-se incapazes de suportar toda a gama de características de um sistema gráfico, incluindo o alinhamento de um "pixel" na memória, operações aritméticas sobre grupos de "pixels", translação de coordenadas $\mathrm{X}-\mathrm{Y}$, gerenciamento de janelas, mascaramento do plano de cores e controle de transparência; considerando-se que todas estas operações tinham de ser realizadas por "software". Outro problema fundamental encontrado foi o número relativamente pequeno de registradores existentes nestes microprocessadores. $O$ "loop" interno dos algorítmos gráficos normalmente contém mais de 16 variáveis, e se o número de variáveis exceder o número de registradores, um tempo consideravelmente grande será gasto na transferência de dados entre registradores e memória. Para algumas 
operações gráficas, a limitação de velocidade foi contornada utilizando-se a linguagem de máquina.

Com a introdução de processadores "bit-sliced", conseguiu-se taxas de $400 \mathrm{~ns}$ a $500 \mathrm{~ns}$ por "pixel", para o desenho de vetores. Melhor desempenho foi obtido com o uso de processadores "bit-sliced" e "hardware" de propósito especial, como nos sistemas utilizados para CAD/CAM, onde o processador "bit-sliced" foi utilizado para gerar dados ao hardware dedicado ao desenho de vetores". Obteve-se para estes sistemas taxas de 40 a 50 ns por "pixel".

Somente em 1986 é que surgiram os processadores gráficos.

O termo processador gráfico descreve um processador que tenha as seguintes características:

. um conjunto de instruções que permitam a manipulação eficiente de "pixels", além de um conjunto de instruções para propósitos gerais;

- ao invés de implementar o conjunto de funções gráficas de alto nível em "hardware", o conjunto de instruçōes deve incluir um conjunto de primitivas gráficas, que facilitem ao programador a construção eficiente de funções de alto nível, como por exemplo círculos, elipses e outras curvas;

. deve possuir um grande número de registradores, que, juntamente com as primitivas gráficas, possibilitem a rápida execução de funções gráficas;

- o conjunto de instruções deve incluir operaçōes com matrizes de "pixels", tipicamente usadas para desenhar textos mapeados em bit no "frame buffer", operações lógicas e aritméticas, e suporte em "hardware" para o gerenciamento de janelas;

- para propósito de portabilidade do "software", o conjunto de instruções deve permitir que as rotinas sejam escritas de forma independente da configuração da tela;

- a arquitetura deve suportar diferentes tamanhos de "pixels", de "frame buffer" e de tela.

. deve possibilitar a execução de linguagens de alto nível, como por exemplo a linguagem C; 
. deve operar de maneira autônoma, isto é, sem necessidade de um processador mestre ou hospedeiro, e, consequentemente, liberando o mesmo para outras tarefas; - deve ter facilidades para comunicąãa com diferentes processadores hospedeiros.

Os primeiros processadores gráficos a serem lançados no mercado em 1986 foram o TMS34010 (Texas Instruments) e 082786 (Intel).

As referências [12], [13] e [14] mostram que, com relação aos recursos em "hardware", estes "chips" apresentam em comum, a inclusão de outros circuitos no mesmo, além do processador gráfico, com o objetivo de compactação do sistema gráfico. Estes outros circuitos incluem o controle para vídeo (no 82786 é um processador de vídeo), o controle para o refrescamento de memórias RAM dinâmicas, e um circuito para permitir o fácil interfaceamento com um processador hospedeiro. Em ambos os "chips", a arquitetura interna é de 32 bits; e apresentam facilidades para interligação com memórias VRAMs.

As diferenças entre ambos são muitas podendo-se destacar as seguintes:

a.) No 82786, o processador gráfico e o processador de vídeo podem endereçar somente 4 Mbytes de memória, enquanto no TMS34010, o processador gráfico pode endereçar até 128 Mbytes de memória.

b.) No 82786, o processador de vídeo, além de gerar os sinais de sincronismo para vídeo, pode organizar a tela em diferentes janelas, com cada janela contendo uma vista diferente da memória de imagem ou vistas de diferentes memórias de imagem. Desta forma, não é necessário copiar trechos de imagem das várias memórias de imagem, considerando-se a memória que seria a memória de vídeo, normalmente denominada como "frame buffer".

O TMS34010 não apresenta todas as facilidades do 82786 para organizar a tela em janelas, mas contem recursos para dividir a tela ao meio, mostrando partes de duas imagens diferentes, e para realizar o "pan" horizontal e vertical.

c.) Ambos processadores apresentam facilidades para manipulação de caracteres, mas os recursos utilizados por cada um são diferentes. No TMS34010, 
além da instruçào PixBlt, o endereçamento é a nível de bit, o que facilita 0 posicionamento dos caracteres em qualquer lugar na memória gráfica. 082786 contém a instrução BitBlt e recursos adicionais para realizar a rotação de caracteres em 4 direções diferentes, desenhar caracteres subscritos e superescritos, e programar um cursor.

d.) 0 recurso de zoom, em ambos processadores, consiste em uma função de replicação. No 82786, o "zoom" pode ser feito tanto horizontalmente como verticalmente. Mas caso as memórias gráficas sejam constituídas por VRAMs, torna-se necessário um circuito externo, para realizar o "zoom" horizontalmente. No TMS34010, o "zoom" também pode ser feito horizontalmente e verticalmente, através da alteração dos parâmetros gráficos.

Em 1989, foi lançado um outro processador gráfico, o 8514 da IBM. A vantagem deste processador, em relação ao TMS34010 [11], está na existência de um grande número de aplicações disponíveis, com o sistema gráfico desenvolvido com o mesmo, o que não ocorre com o TMS34010. Para este último, as aplicações não estão bem definidas.

A crítica feita ao 8514/A refere-se ao fato de a IBM estar ocultando os seus dados técnicos chave, e ter comunicado que o "hardware" futuro pode sofrer modificaçōes. Além disso, o projeto e desenvolvimento dos circuitos associados ao sistema com o 8514/A tem sido lento, por problemas de compatibilidade.

O TMS34010, nesse aspecto, encontra-se em vantagem, considerando-se sua disponibilidade no mercado há 3 anos, com boa aceitação, além de ter preço mais acessível.

\subsection{Controlador de Refrescamento de Vídeo e Circuito de Saída para Vídeo}

Fisicamente, todas as funções do circuito de saída para vídeo podem ser incorporadas ao projeto do controlador de vídeo. Assim considerando, as funções destes dois circuitos serão descritas conjuntamente, dentro do projeto do controlador.

As principais funções do controlador podem ser resumidas da seguinte maneira: 
a.) gerar os sinais de sincronismo para vídeo.

b.) converter os dados provenientes da memória, em sinal de vídeo.

Normalmente, na conversão dos dados, utilizam-se conversores D/A, com o número de bits idêntico ao número de bits do "pixel", como mostram as figuras 15 e 16. Os "pixels" devem ser gerados pelo controlador, numa taxa determinada pela resolução e frequência de refrescamento do sistema.

Como mencionado no capítulo 1 , a intensidade de cada "pixel" pode ser representada por $1,2,4,8$, ou mais bits. Um bit é suficiente para a representação de textos e figuras simples; pixels de 2 e 4 bits são úteis em aplicações que requeiram a visualização de áreas sólidas coloridas ou na escala de cinza, "pixels" com 8 bits ou mais são necessários para figuras de alta qualidade.

A escala de cinza consiste na representação de tons de cinza, iniciando pela cor preta e finalizando pela cor branca. $O$ número de níveis de cinza normalmente é definido pelo tamanho do "pixel". Assim, um "pixel" com tamanho de 8 bits possibilita a obtenção de até 256 níveis de cinza.

Diferentes métodos podem ser utilizados para a atribuição de cores (ou representação na escala de cinza) a uma imagem ou figura. $O$ método mais simples caracteriza-se por ser aquele onde o valor de cada "pixel" armazenado na memória representa a intensidade de cor, ou de cinza. A desvantagem deste método reside no fato de que qualquer modificação na intensidade de cor implica alteração do "frame buffer", e como, normalmente, em sistemas por varredura grandes "frame buffers" são necessários para conter toda a imagem, estas modificações necessitarão de um tempo de processamento razoável.

Outro método frequentemente utilizado, é a atribuíção a cada "pixel" de um valor que representa um endereço de uma tabela de cores ("look-up table"). A vantagem desta técnica, em relação à anterior, é que a modificação das cores implica alteração somente da tabela de cores, mantendo o "frame buffer" inalterado.

A atribuição de múltiplos bits por "pixel" não se apresenta util somente para representação de cores ou intensidade, mas também permite que o "frame buffer" seja 
tratado como vários planos, cada um contendo uma imagem separada. Desta forma há possibilidade de se fazer diversas composições com os planos. Um plano pode ser usado para mostrar uma imagem estática, enquanto outro, exibe outra imagem ou símbolo que se deseja movimentar na tela. Em sistemas com animação, os vários objetos a serem movimentados podem ser colocados em planos separados. Um plano de um bit pode ser usado como máscara para selecionar certas regiōes de outro plano que será mostrada na tela.

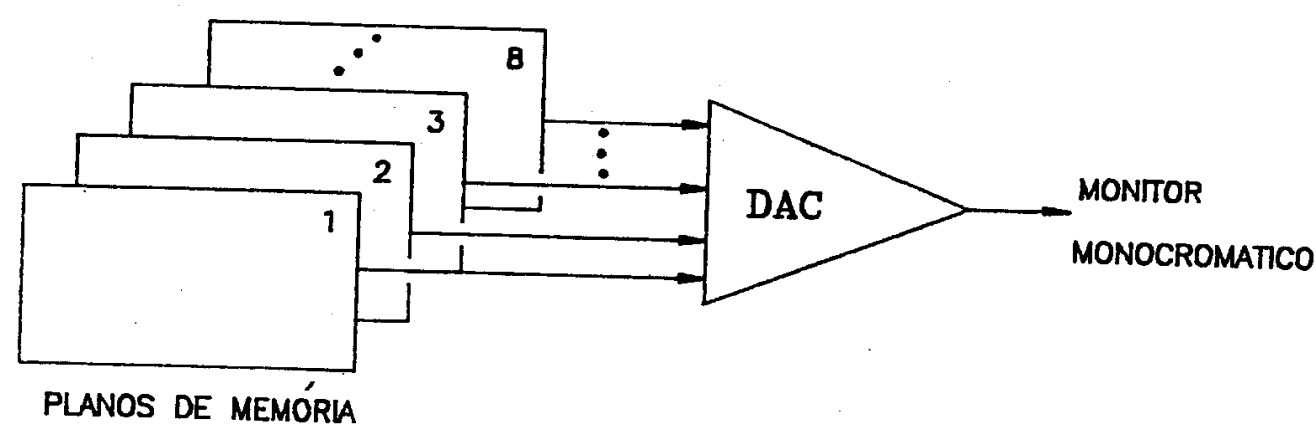

Figura 15 - Oito planos de memória e um conversor D/A de 8 bits para gerar 256 níveis de cinza. 


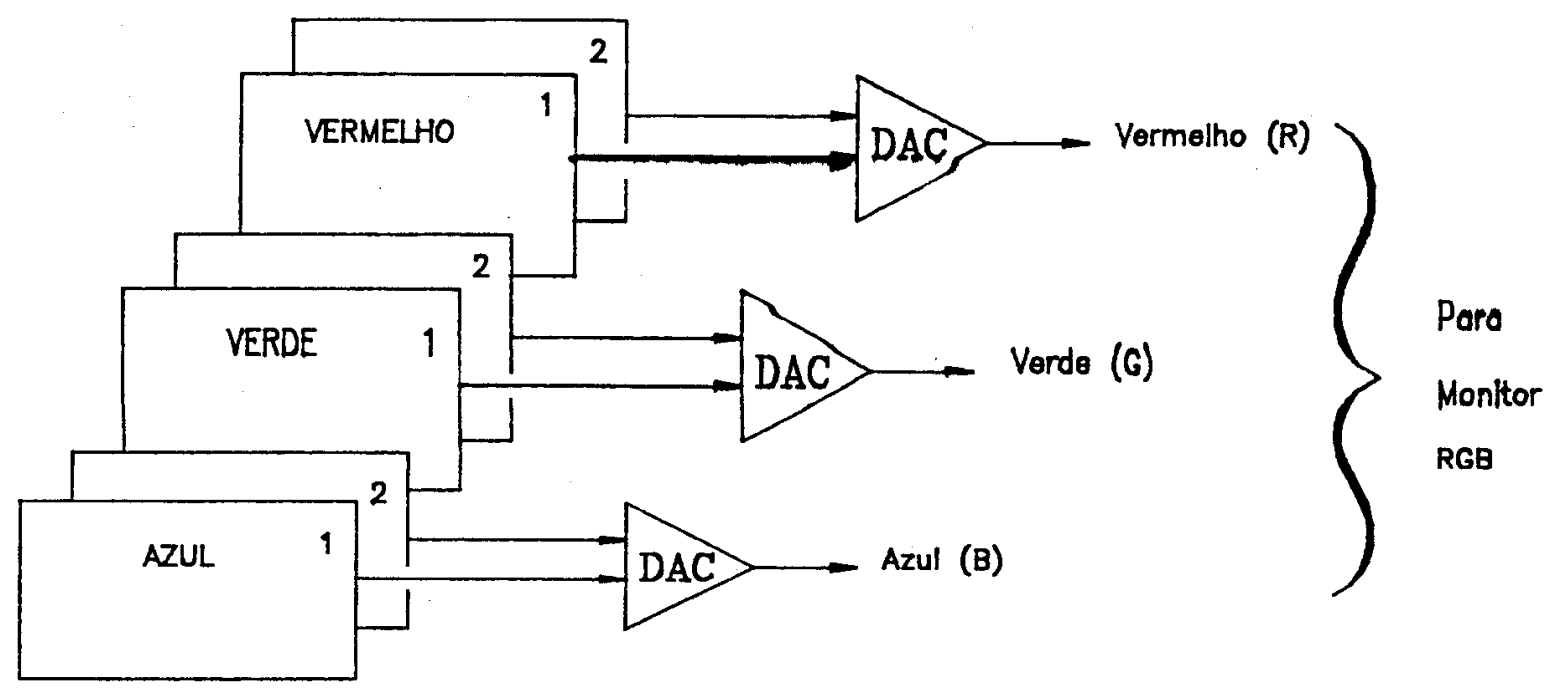

Figura 16 - Dois planos de memória para cada cor primária, possibilitando a programação de 64 cores diferentes. 


\section{Capítulo III}

\section{O Processador Gráfico TMS34010}

O Processador para Sistemas Gráficos (GSP) TMS34010 caracteriza-se por ser um processador de 32 bits, tecnologia CMOS, otimizado para sistemas gráficos, combinando as vantagens do processador para propósito geral com as do controlador gráfico.

As principais características deste processador serão apresentadas a seguir.

\subsection{Arquitetura do GSP}

A fig. 17 mostra o diagrama em blocos do TMS34010. Além do processador gráfico, foram incluídos neste "chip" os seguintes circuitos:

. circuito para o refrescamento de memórias do tipo "RAM" dinâmica;

. circuito para gerar os sinais de sincronismo para vídeo;

- circuito para controle da atualização da tela;

. circuito para facilitar a comunicação com um processador hospedeiro.

Além disso, o barramento para comunicação com o processador hospedeiro, o barramento para conexão de memórias "DRAMs" e "VRAMs", e o barramento para os sinais de vídeo são fisicamente separados. $O$ processador opera independentemente do controlador de memória, a não ser que ocorra a solicitação de estados de espera 
("wait states") por algum dispositivo externo.

A inclusão destes circuitos no "chip" do GSP possibilitou uma redução considerável do número de componentes necessários para o projeto de um sistema gráfico.

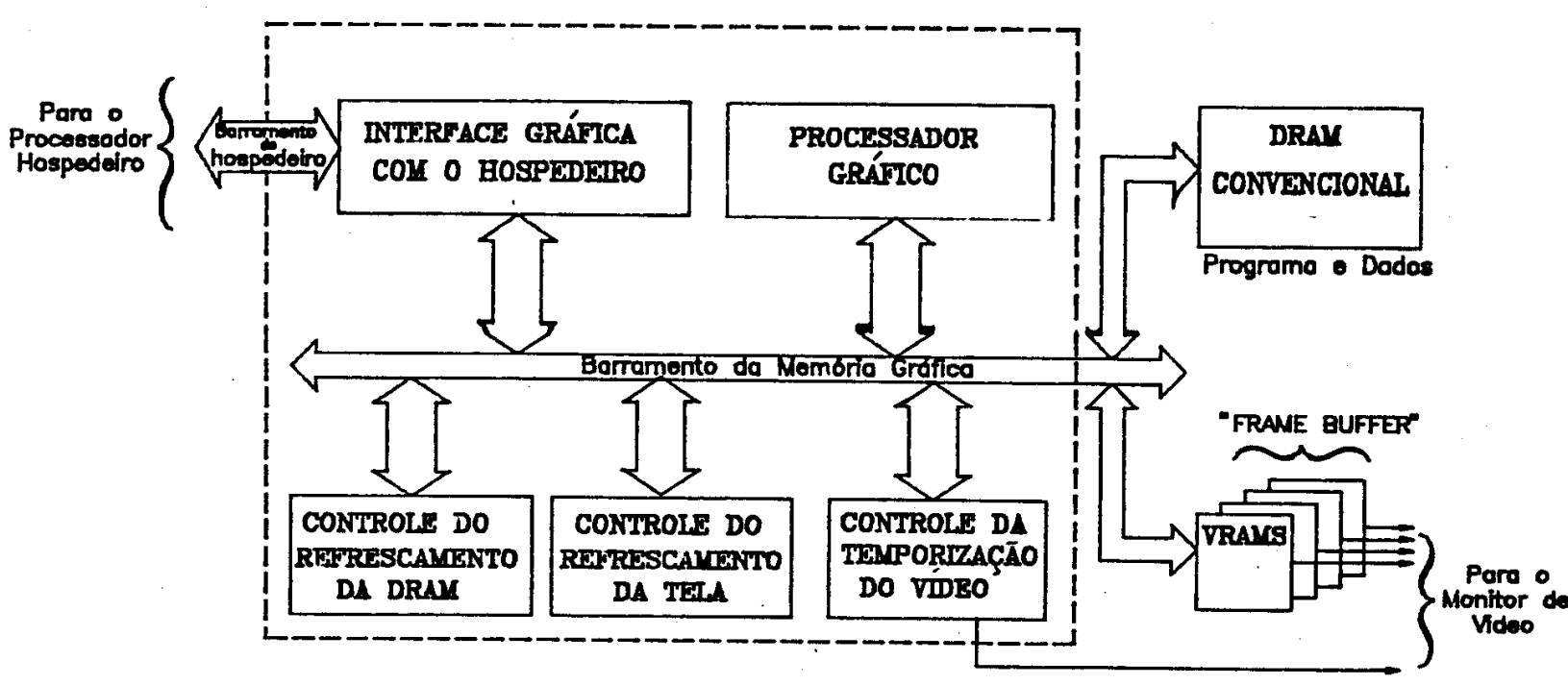

Figura 17 - Diagrama em Blocos do TMS34010.

A figura 18 ilustra o diagrama em blocos da arquitetura interna do GSP. Todos os registradores relacionados à unidade de execução, assim como o "barrel shifter" e a unidade lógica e aritmética, são de 32 bits.

O "barrel shifter" possibilita que operações de deslocamento ou rotação sejam realizadas em um único ciclo de máquina.

0 registrador de "status" contém os bits de "status" de sinal, "carry", zero, "overflow", habilitação de interrupção, "status " da execução da instrução PLXBLT, e também especifica o comprimento e modos de extensão dos "fields" 0 e 1 (figura 19).

$O$ arquivo de registradores $A$ e $B$ contém, cada um, 15 registradores de 32 bits para propósito geral, A0 - A14 e B0 - B14, respectivamente. Os registradores do arquivo $B$ são também usados como operandos para as instruções gráficas.

O GSP contém 28 registradores de E/S, de 16 bits cada um. Estes registradores são divididos em 4 categorias, como ilustrado na figura 18 : 
1. registradores dedicados ao controle dos sinais do barramento da memória local, em número de 7;

2. registradores para o controle do temporização de vídeo e da atualização da tela, em número de 14;

3. registradores para controle dos sinais do duto do processador hospedeiro, em número de 5;

4. registradores para controle das interrupções, em número de dois.

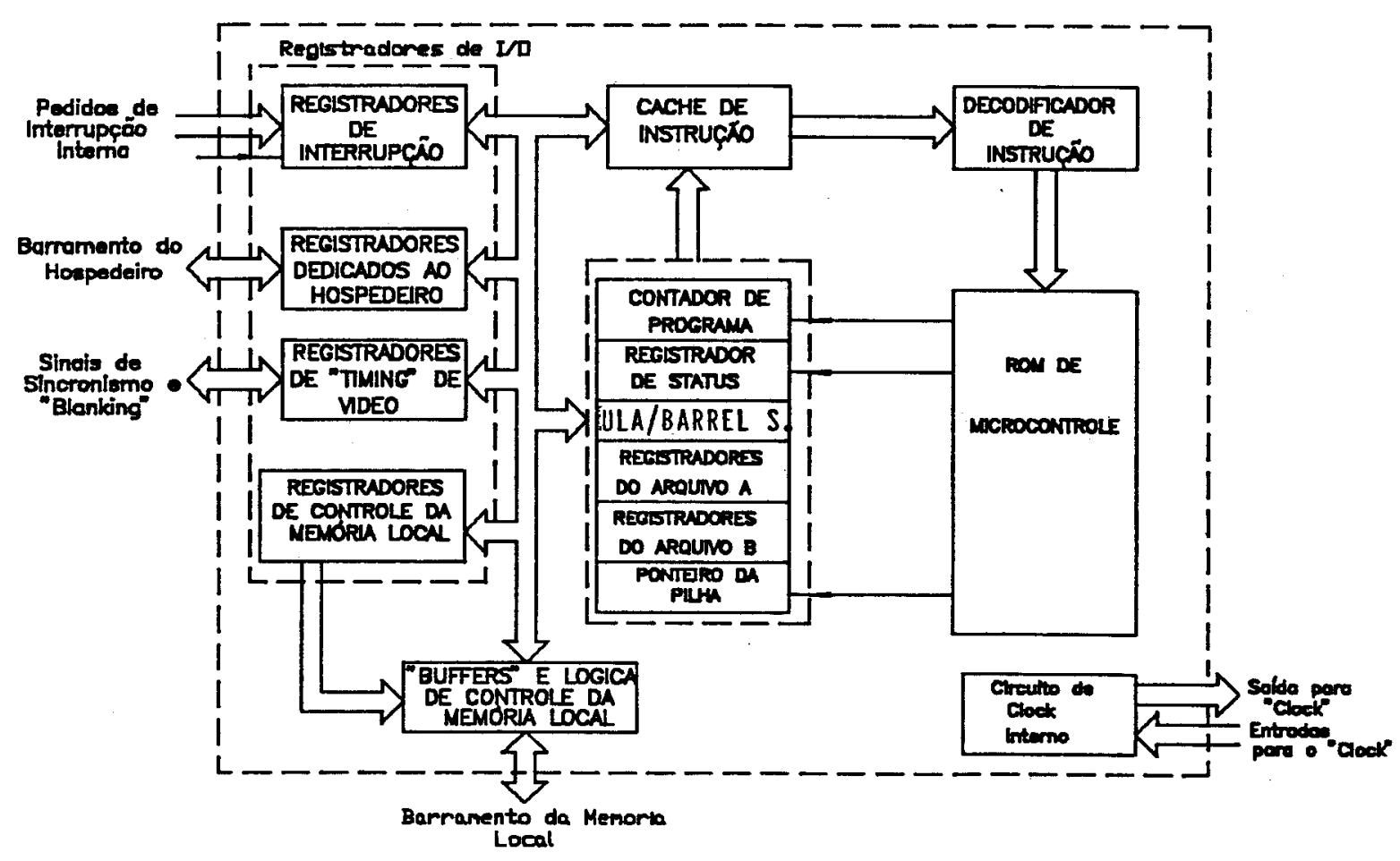

Figura 18 - Arquitetura Interna do TMS34010. 

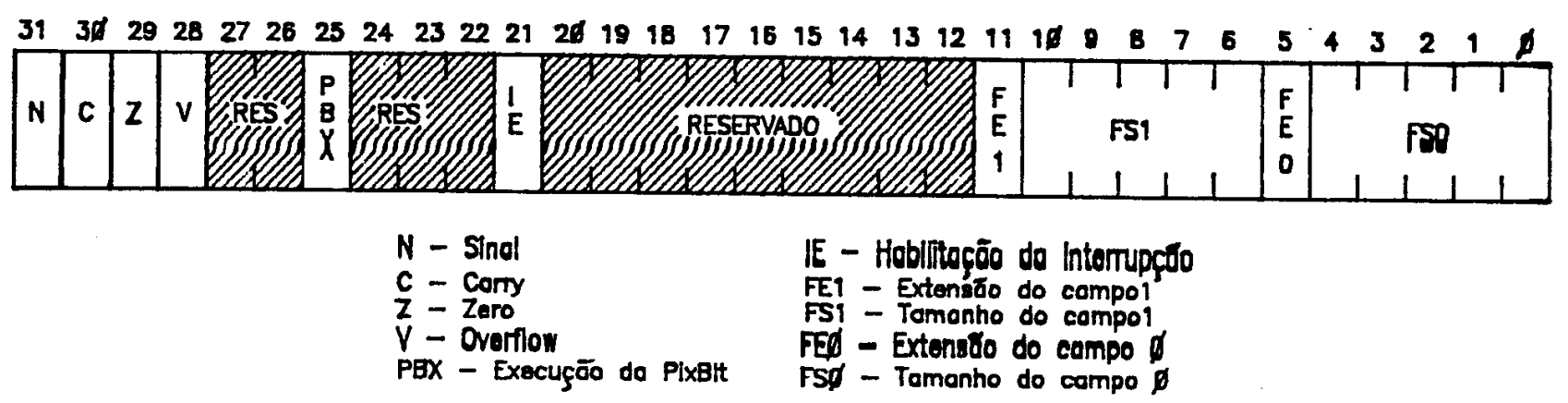

Figura 19 - Registrador de "Status".

O circuito interno de "clock" gera a temporização interna e os sinais externos LCLK1 e LCLK2, defasados de 90 graus.

A figura 20 mostra o conjunto de sinais de entrada e saída do GSP, relacionados a cada interface.

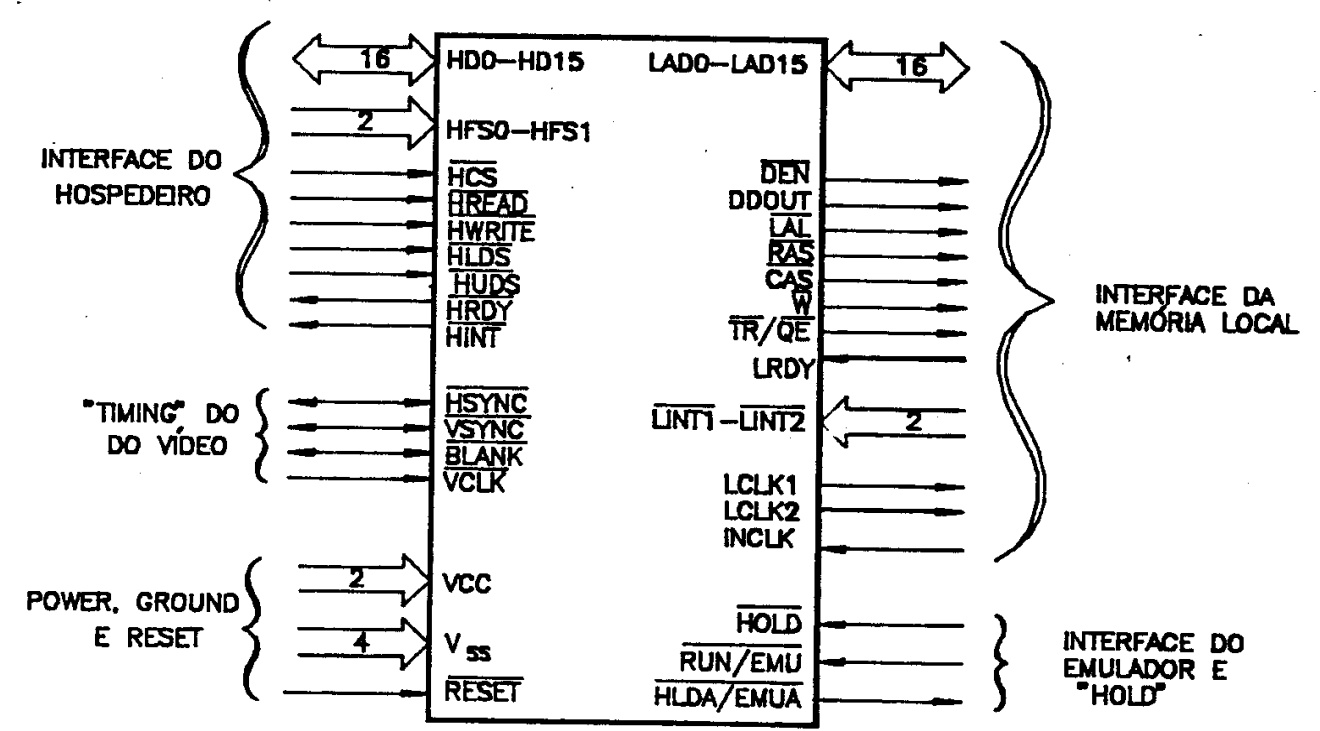

Figura 20 - Conjunto de Sinais do TMS34010. 


\subsection{Endereçamento de Memória}

Embora a capacidade total de endereçamento do TMS34010 seja de 512 Mbytes, é possível o endereçamento de somente 128 Mbytes de memória.

A figura 21 mostra o mapa de memória do GSP, que se encontra dividido em 3 regiões:

a. vetores TRAP

b. registradores de $\mathrm{E} / \mathrm{S}$

c. uso geral

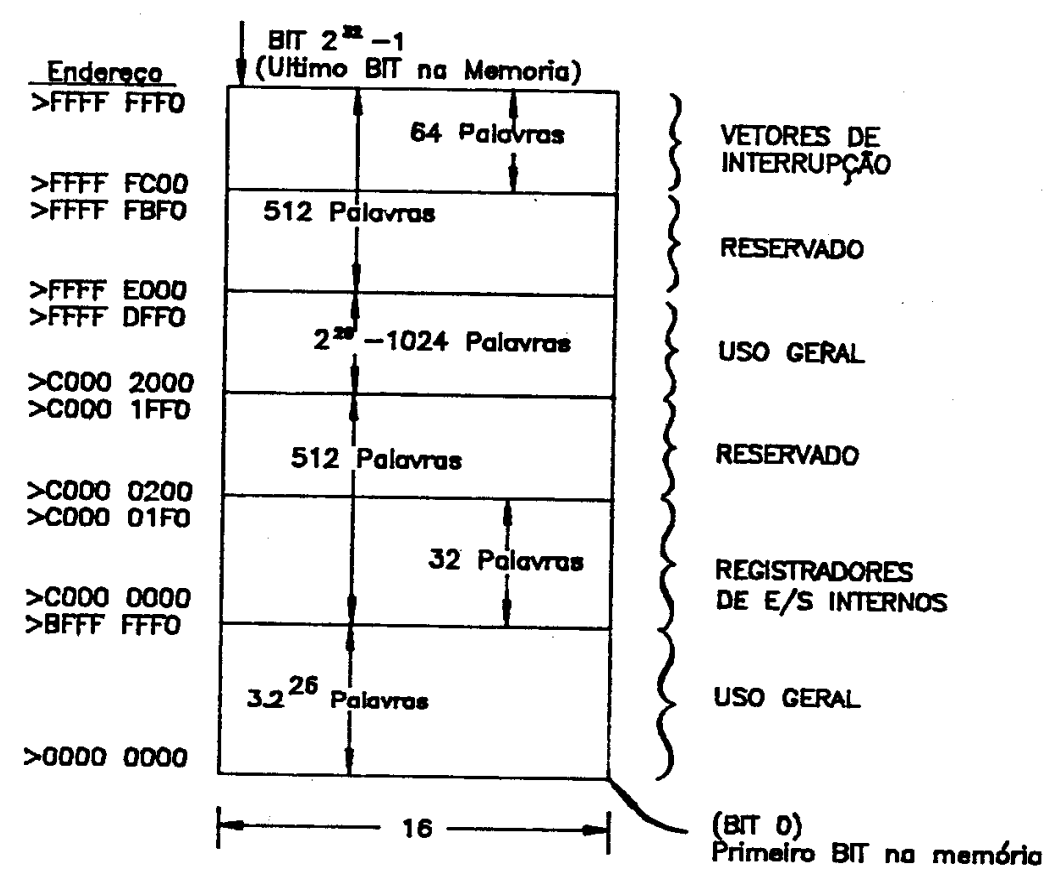

Figura 21 - Mapa de Memória do GSP.

No GSP, o endereçamento é feito a nível de bit, isto é, cada endereço de 32 bits aponta para um bit individual na memória.

A comunicação com a memória é feita através de um duto de dados de 16 bits, e a cada acesso à memória, o GSP lê ou grava uma palavra (16 bits). 0 endereço de 
cada palavra tem os 4 LSBs idênticos a zero. Estes 4 LSBs são usados para o endereçamento dos bits da palavra.

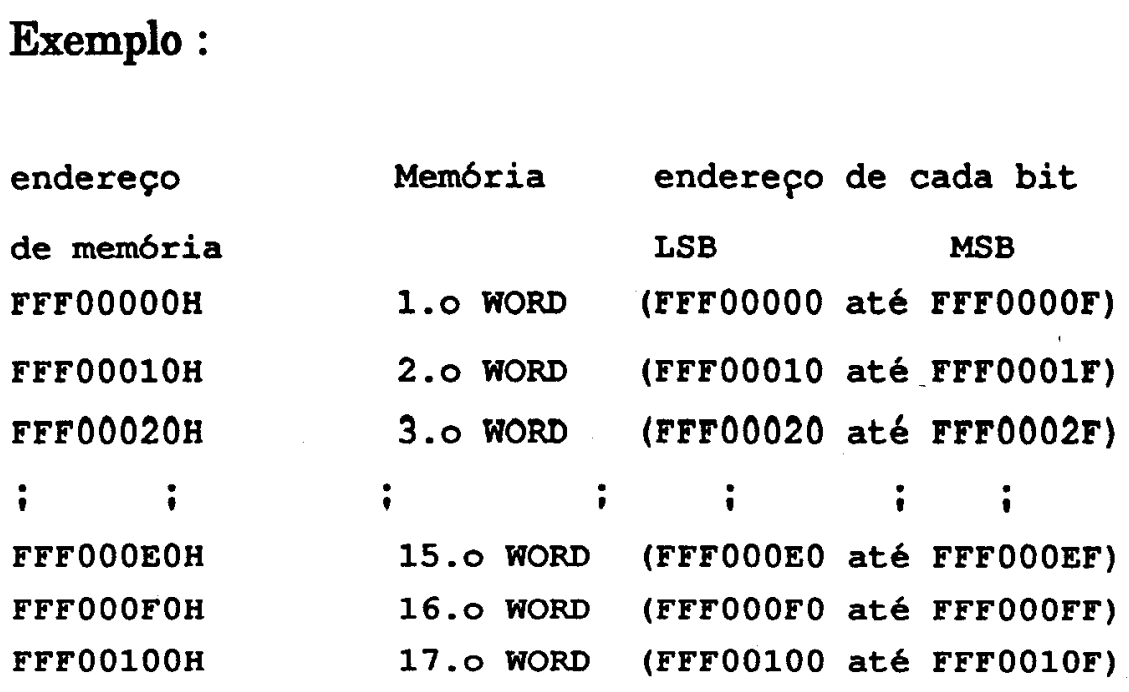

\subsection{Paralelismo Interno}

A figura 22 ilustra o fluxo interno de dados, associado à função do processador. A possibilidade de buscar instruções da "cache" em paralelo com o acesso de dados na memória melhora consideravelmente a velocidade de execução. Cada área de armazenamento de dados pode ser acessada independentemente uma da outra. Isto permite que o GSP execute as seguintes ações em paralelo:

. um ciclo de memória externa.

. duas buscas de instruções da cache

- quatro leituras e duas gravaçōes em registradores para propósito geral. 


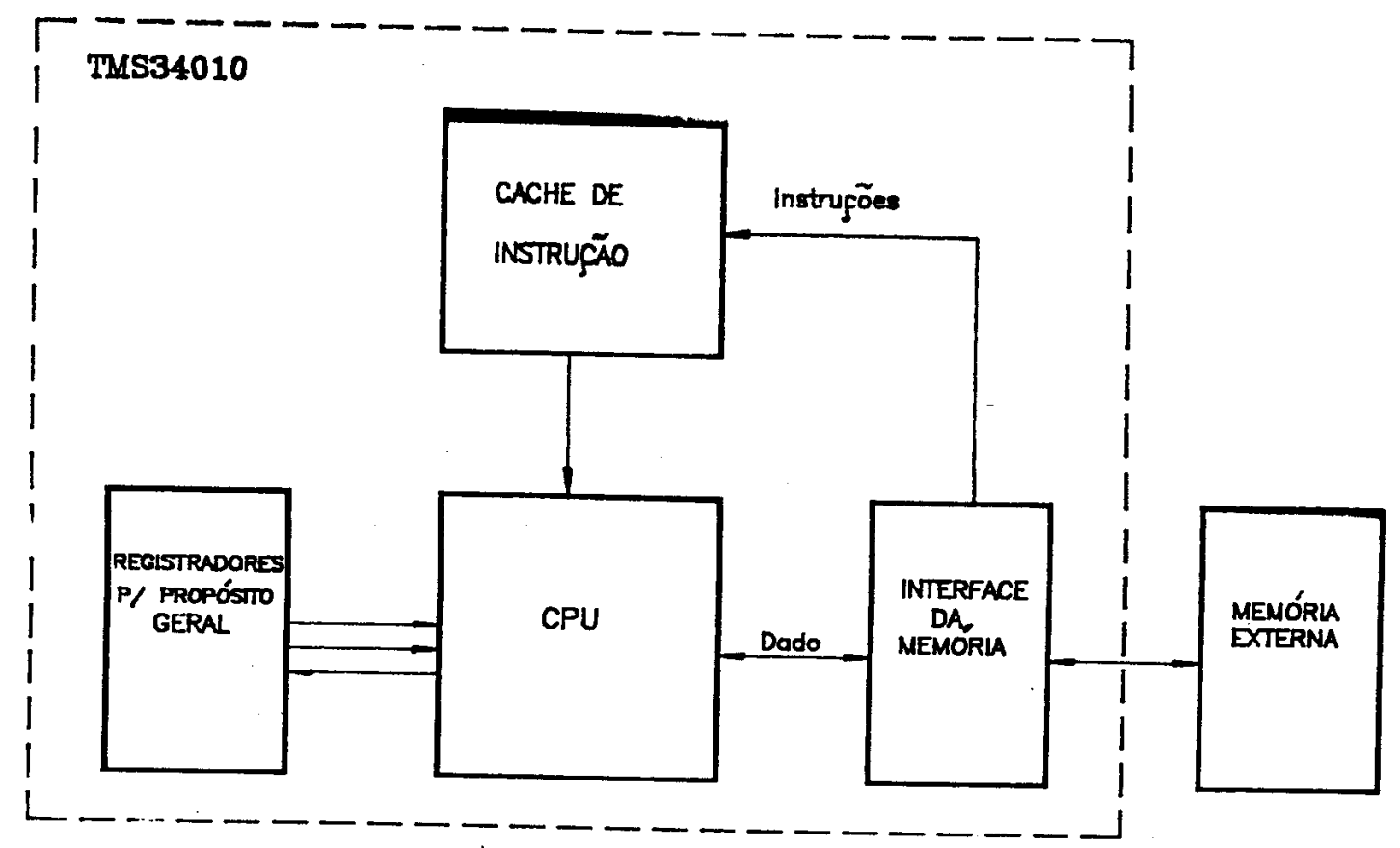

Figura 22 - Fluxo de Dados Interno do GSP.

\subsection{Estruturas de Dados Suportadas Pelo "Hardware"}

O GSP suporta as seguintes estruturas a nível de máquina:

"fields", "bytes", "pixels" e matriz de "pixels". Estas estruturas serão definidas a seguir.

\subsection{1."Fields"}

"Fields" são estruturas de dados configuráveis, cujo comprimento pode ser definido entre 1 e 32 bits.

No GSP dois "fields" podem ser definidos através da instrução SETF: "field 0" e "field 1". Um "field" pode iniciar e terminar em qualquer endereço de bit. Como 
exemplo, será utilizado o seguinte trecho de programa:

$\begin{array}{ll}\text { SETF } & 6,0,1 ; \text { configura o "field" } 1 \text { para } 6 \text { bits } \\ \text { MOVE } & >0 F F A 85, A 0,1 \text {; transfere para A0 os } 6 \text { bits ;que se }\end{array}$
encontram armazenados a partir do endereço $0 \mathrm{FFA85H}$.

Considerando que, antes da execução da instrução MOVE, o conteúdo do endereço OFFA80H seja o seguinte :

$\begin{array}{ll}\text { endereço } & \text { dado } \\ \text { OFFA80H } & \text { 57D9H }\end{array}$

então, o endereço 0FFA85H aponta para o 6.0 bit do dado 57D9H, e após a execução da instrução MOVE, o registrador A0 conterá o seguinte valor :

A0: 0000003EH

\subsection{2 "Bytes"}

"Byte" consiste num caso particular do "field", cujo comprimento é definido como sendo de 8 bits, com sinal extendido. Podem ser endereçados a partir de qualquer bit dentro da palavra.

\subsection{3 "Pixels"}

"Pixels" são estruturas de dados configuráveis, cujo comprimento pode ser programado para ser 1, 2, 4, 8 ou 16 bits. No caso do "pixel" ser menor do que 16 bits, a palavra contém dois ou mais "pixels". 
No GSP, os "pixels" devem estar alinhados com a palavra, isto é, não podem ter parte de seu valor armazenado em uma palavra, e outra parte em palavra diferente. Para exemplificar, considerando o enderę̧o FFF0A090H de um palavra que contém 4 "pixels" de 4 bits, o endereço de cada "pixel" na palavra será:

1.0 "pixel": FFF0A090H

2.0 "pixel": FFF0A094H

3.0 "pixel"; FFFOA098H

4.o "pixel": FFF0A09CH

O tamanho do "pixel" deve ser definido através do registrador de E/S, denominado PSIZE, e cujo endereço é C0000150H. Exemplificando-se, pode-se usar o seguinte conjunto de instruções para estabelecer o tamanho do "pixel" para 4 bits:

$\begin{array}{ll}\text { SETF } & 16,0,0 ; \text { "field" } 0 \text { é de } 16 \text { bits } \\ \text { MOVK } & 4, \mathrm{~A} 0 ; \text { o tamanho do "pixel" é armazenado em A0 } \\ \text { MOVE } & \text { A0,0C0000150H,0 ; armazena o tamanho do "pixel" } \\ & ; \text { no registrador de E/S PSIZE. }\end{array}$

3.4.3.1 Mapeamento de "Pixels" na Tela do Monitor de Vídeo

A informação de uma linha horizontal de "pixels" na tela, normalmente é armazenada em palavras consecutivas na memória. Os "pixels" de uma palavra são desenhados, iniciando por aquele que ocupa a posição menos significativa na palavra. O referido "pixel" aparece, então, na posição mais à esquerda na tela, enquanto o "pixel" que ocupa a posição mais significativa da palavra aparece na posição mais à direita (fig. 23). Desta forma, para se desenhar um caracter na tela, este deve ser desenhado de forma invertida na memória, como ilustrado a seguir para o caracter L: 


letra: $\begin{aligned} & \text {.byte } 00000011 B \\ & \text {.byte } 00000011 B \\ & \text {.byte } 00000011 B \\ & \text {.byte } 00000011 B \\ & \text {.byte } 00111111 B\end{aligned}$

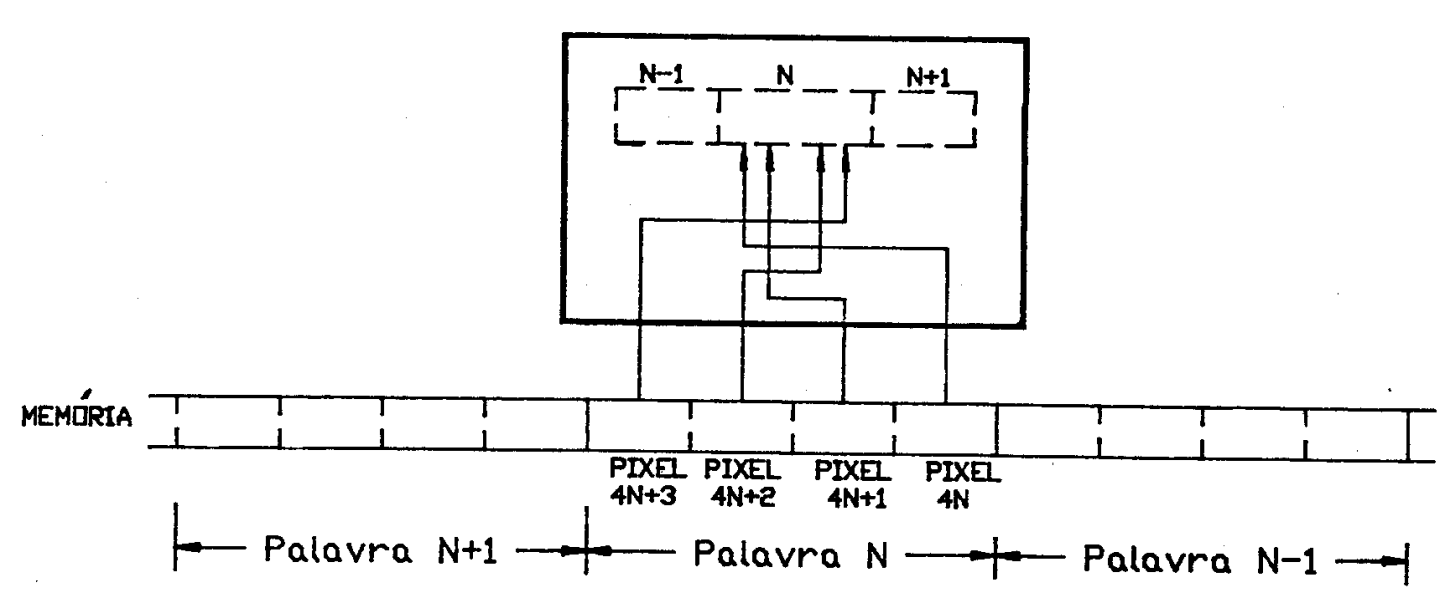

Figura 23 - Mapeamento de "Pixels" na Tela do Monitor de Vídeo.

\subsubsection{Métodos de Endereçamento de "Pixels"}

O GSP permite que um "pixel" seja identificado pelo seu endereço de memória, ou em termos de suas coordenadas XY na tela. Estes dois métodos denominam-se respectivamente endereçamento linear e endereçamento $X Y$.

No endereçamento $X Y$, o endereço é armazenado em um registrador de 32 bits para propósito geral, e as componentes $\mathrm{X}$ e $\mathrm{Y}$ são tratadas como inteiro de 16 bits com sinal. A componente $X$ ocupa os 16 LSB's do registrador, como pode ser observado na figura 24. 


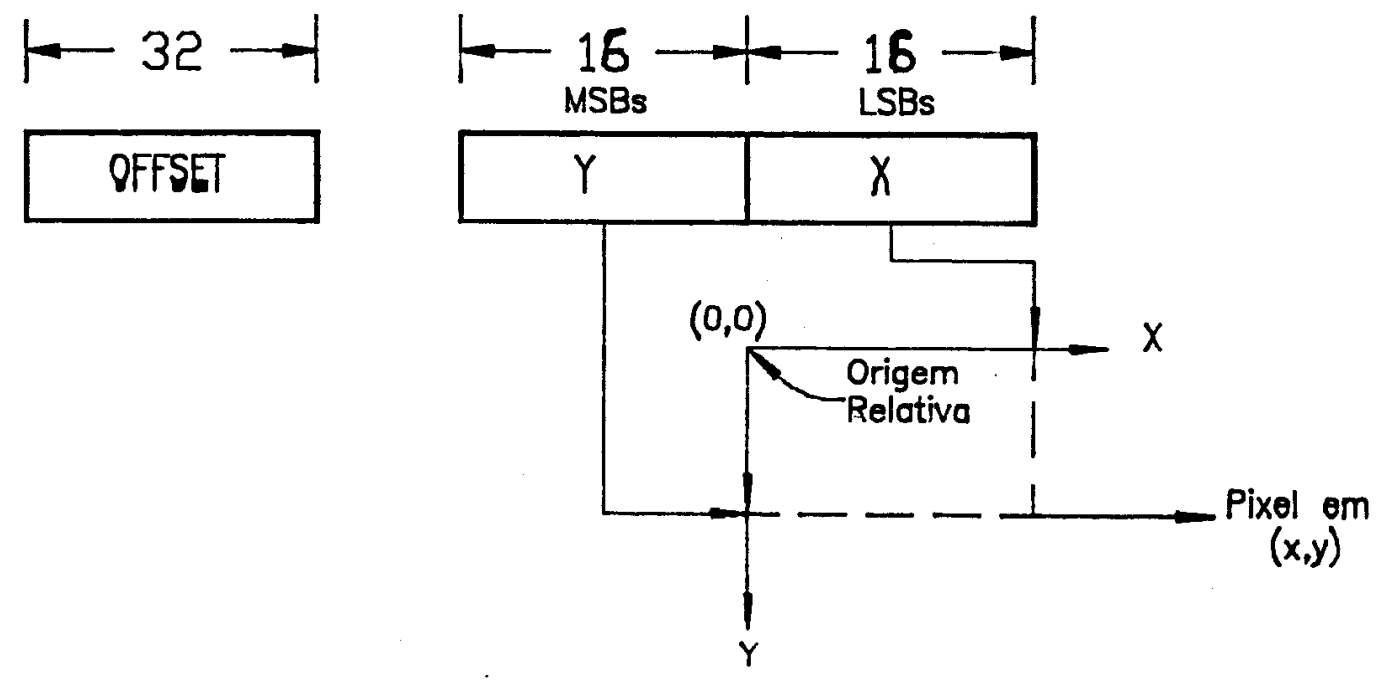

Figura 24 - Endereçamento do "Pixel" em Termos das Coordenadas XY.

O GSP contém um conjunto de instruções gráficas dedicadas ao modo de endereçamento XY. Essas instruções encontram-se descritas no item 3.6.

A vantagem deste modo de endereçamento refere-se à indepêndencia do software em relação à configuração da tela. No entanto, faz-se interessante ressaltar que a transferência de uma imagem, de uma configuração de tela a outra, pode implicar alteração de seu tamanho. Para exemplificar, transferindo-se uma imagem de uma configuração de tela menor (por ex. 512 "pixels", 256 linhas, 4 bits/"pixel") para outra maior (por ex. 1024 "pixels", 256 linhas, 4 bits/"pixel"), ter-se-á uma redução no tamanho da imagem, na direção $\mathrm{X}$, e, além disso, o "offset" terá de ser ajustado.

\subsubsection{Origem da Tela}

Ao se usar o modo de endereçamento XY, a origem pode ser selecionada no canto superior esquerdo da tela, ou no canto inferior esquerdo da tela. A posição da 
origem é controlada pelo bit ORG do registrador de E/S, DPYCTL. A figura 25 ilustra os dois modos em que pode ser configurada a origem.

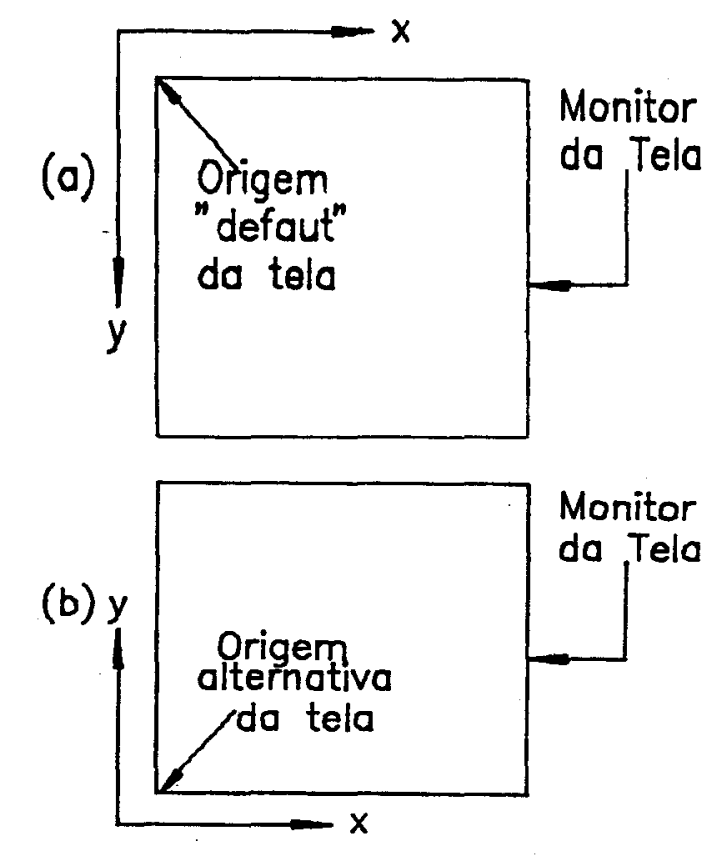

Figura 25 - Origem Configurável da Tela.

\subsubsection{4 "Display pitch"}

O termo "diplay pitch" refere-se à diferença entre os endereços de memória de dois "pixels" situados em posições adjacentes verticalmente. Pode-se também pensar no "diplay pitch" como o número de palavras da memória de vídeo que contém os "pixels" de uma linha do monitor de vídeo. Observe que, quanto maior o tamanho do "pixel", maior número de palavras será necessário para armazenar os "pixels" de uma linha, e consequentemente, maior será o "display pitch".

Para o caso de endereçamento XY de "pixels" na tela, o "display pitch" deve ser uma potência de dois. $O$ endereçamento linear impõe poucas restrições, e em particular, o "display pitch" pode ser qualquer valor múltiplo de 16, isto é, com os 4 
LSB's iguais a zero.

Para uma matriz de "pixels", o "pitch" é definido como a diferença entre os endereços de memória de dois "pixels" adjacentes verticalmente.

O cálculo do "pitch" pode ser feito pela expressão:

$$
\text { "pitch" = (n.o de "pixels" na linha) * (n.o de bits/"pixel") }
$$

Exemplo:

$$
\begin{aligned}
& \text { n.o de "pixels"/linha = } 512 \\
& \text { n.o de bits/"pixels" = } 8 \\
& \text { "pitch" }=512 * 8=4096=1000 \mathrm{H}
\end{aligned}
$$

\subsubsection{Conversão Linear para XY}

O GSP converte automaticamente um endereço XY para um endereço linear, para todas as instruçoes que usam endereçamento XY. Para isso, três parâmetros são utilizados:

a. tamanho do "pixel", armazenado no registrador de E/S, PSIZE;

b. fator de conversão do "pitch", armazenado nos registradores de E/S, CONVDP e CONVSP;

c. $\mathrm{o}$ "offset", que define a origem XY, armazenado no registador OFFSET.

\subsubsection{Matriz Bidimensional de "pixels"}

Matriz bidimensional de "pixels" são grupos retangulares de "pixels", que são manipulados usando-se instruções gráficas como a PIXBLT (transfere um bloco de 
"pixels"), ou a FILL (preenche um bloco de "pixels" com uma cor). Utilizando-se uma única instrução PIXBLT, pode-se mover a matriz de uma área de memória para outra, podendo-se ainda combiná-la com outra, através de operaçōes Booleanas ou aritméticas. Uma matriz de "pixels" é especificada em termos de sua altura, largura, "pitch", e endereço inicial. Se o endereço inicial for especificado como um endereço XY, a matriz será referida como uma matriz XY. Caso o endereço inicial seja especificado como um endereço linear, a matriz será referida como uma matriz linear.

0 uso de uma matriz XY tem a vantagem de ser independente do endereço de memória, e de se poder usar os modos de verificação de janela do GSP, que só são permitidos com o modo de endereçamento XY. Porém, a desvantagem do formato XY reside na necessidade de o "pitch" ser uma potência de dois.

O formato linear tem a vantagem de o "pitch" não precisar ser uma potência de dois, permitindo, assim, uma grande variedade de organizações de memória.

\subsection{Registradores do GSP}

\subsubsection{Registradores para Propósito Geral}

Os 15 registradores do arquivo $A$ e os 15 registradores do arquivo $B$ podem ser usados para armazenamento e manipulação de dados. A figura 26 mostra esses dois conjuntos de registradores.

Os registradores do arquivo B podem assumir funções dedicadas de "hardware", no caso do uso de instruções gráficas. Essas funções serão descritas a seguir, usandose como exemplo uma matriz bidimensional de "pixels", definida na memória de sistema a partir do "label" letra, com as seguintes características: 16 "pixels" por linha, 1 bit por "pixel" e 5 linhas. Considere que esta matriz será transferida para a memória de vídeo, durante a execução do programa, e que a configuracão para o vídeo é a seguinte: 256 linhas, 512 "pixels" e 8 bits por "pixel". 
letra:

.word 0000000000000011B

.word $0000000000000011 B$

.word 0000000000000011B

.word $0000000000000011 B$

.word 0000000000111111B

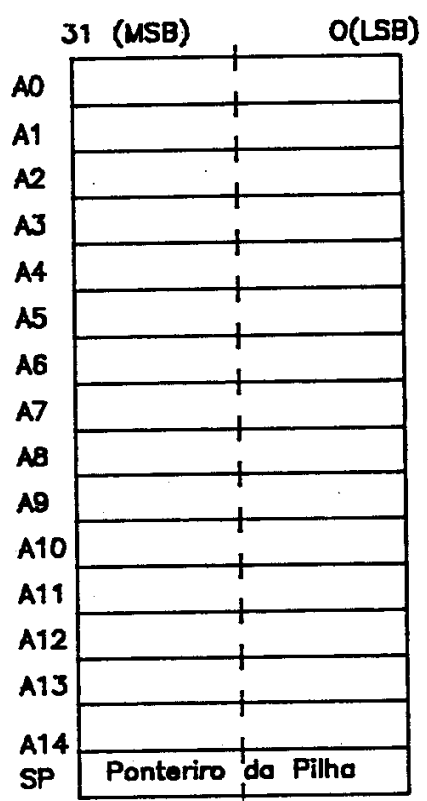

\begin{tabular}{|c|c|c|c|}
\hline \multicolumn{2}{|c|}{31 (MSB) } & $O($ LSB $)$ & \multirow{4}{*}{ 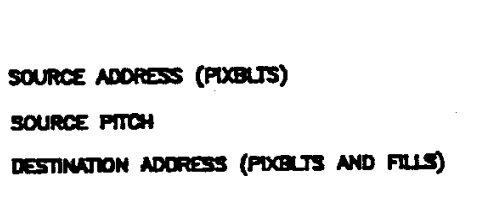 } \\
\hline BO & SADDF & & \\
\hline B1 & SPTC & & \\
\hline $\mathbf{B 2}$ & DADD: & & \\
\hline 83 & DPTC! & & DESTIUTON PITCH \\
\hline B4 & OFFSt & & - Orfset \\
\hline 35 & WSTA & RT & WHNDOW START \\
\hline 86 & WENP & & Mandom ספ \\
\hline 87 & DYDX & & Dath $Y /$ Dezta $x$ \\
\hline $\mathbf{B 8}$ & colo & $R \varnothing$ & COLOF' (BNuFr PDERTS) \\
\hline B9 & COLQ & RI & COLOR1 (BINGFY PDELLTS,FULS AND DRA \\
\hline B10 & Rogistrador & Tomporário & \\
\hline B11 & Registrador & Tempordrio & Usados para amazenomento \\
\hline B12 & Registrador & Tempordrio & $>$ tempordíio para instruçóes \\
\hline B13 & Registrador & Temporório & PIXBLT e FIL \\
\hline B14 & Registrador & Tempordrio & \\
\hline & Ponteriro & da Pilho & \\
\hline
\end{tabular}

Figura 26 - Registradores dos Arquivos A e B.

B0(SADDR): contém o endereço linear ou XY da matriz fonte. Para o exemplo citado, este endereço é o "label" letra.

B1(SPTCH): contém o "pitch" da matriz fonte, que no caso vale 16 (16 "pixels", 1 bit por "pixel").

B2(DADDR): contém o endereço linear ou XY da memória de vídeo, a partir do qual a matriz será gravada.

B3(DPTCH): contém o "pitch" destino, que é o do vídeo, considerando-se o 
exemplo citado tem valor $1000 \mathrm{H}(512 * 8=1000 \mathrm{H})$.

B4(OFFSET): contém o endereço linear do "offset", para a memória de vídeo. B5(WSTART): contém o endereço inicial da janela ("pixel" menos significativo). B6(WEND): contém o endereço final da janela ("pixel" mais significativo). B7(DYDX): os 16 LSBs deste registrador especificam a largura (dimensão X) da matriz fonte, em termos de "pixels". Os $16 \mathrm{MSBs}$ especificam a altura (dimensão $\mathrm{Y}$ ) da matriz fonte. Se $\mathrm{DY}=0$ e $\mathrm{DX}=0$, nenhum "pixel" é movido.

Considerando-se o exemplo citado, B7 contém o valor $00050010 \mathrm{H}$.

B8(color 0): para o exemplo em questão, B8 contém uma cor especificada em 8 bits, que será atribuída aos bits " 0 " da matriz fonte, quando os mesmos forem transferidos para a memória de vídeo.

B9(color 1): para o exemplo, B9 contém uma cor especificada em 8 bits, que será atribuída aos bits "1" da matriz fonte.

B10 a B14 : são usados para armazenamento temporário de valores da instrução PIXBLT.

Todas as instruções de registrador para registrador (exceto MOVE RS,RD) requerem que ambos registradores sejam do mesmo arquivo.

\subsubsection{Registradores de E/S}

Estes registradores ocupam os endereços de $>\mathrm{C0000000}$ até $>\mathrm{C00001F0}$ (figura 27). Podem ser diretamente acessados pelo GSP, como também podem ser acessados pelo processador hospedeiro, através dos registradores dedicados à comunicação com o hospedeiro.

Quando um registrador de E/S é acessado, o ciclo de memória é alterado, de forma que, o endereço da linha é gerado, mas o endereço da coluna é inibido.

Será apresentada a seguir uma breve descrição dos registradores de E/S. 


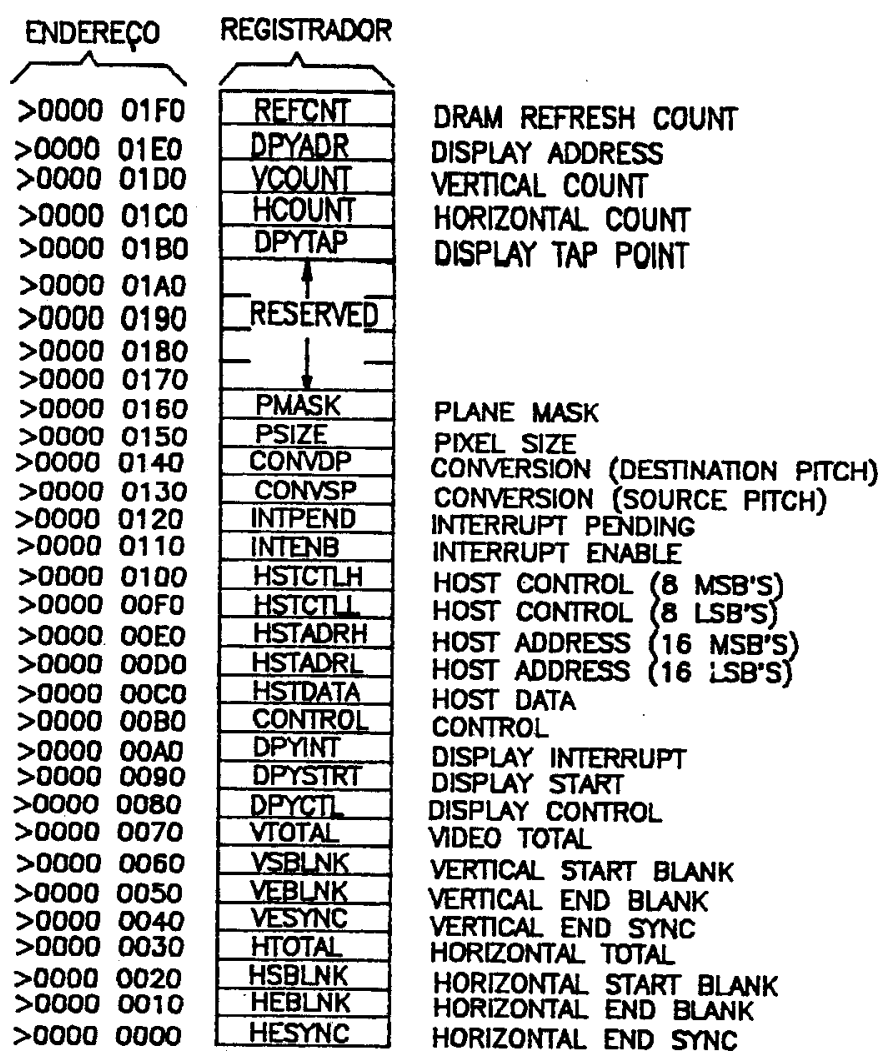

Figura 27 - Registradores de E/S.

3.5.2.1 Registradores Dedicados à Comunicação com o Processador Hospedeiro

Os cinco seguintes registradores de $\mathrm{E} / \mathrm{S}$ são dedicados à comunicação com o hospedeiro :

a. HSTADRH: contém os 16 MSBs de um ponteiro de endereço de 32 bits, usado pelo processador hospedeiro para acessar indiretamente a 
memória local do TMS34010.

b. HSTADRL: contém os 16 LSBs do ponteiro de endereço de 32 bits.

c. HSTCTLL : contém 7 bits programáveis, que controlam as funções de comunicação com o hospedeiro.

d. HSTCTLH: contém 8 bits programáveis, que controlam as funçōes de comunicação com o hospedeiro.

e. HSTDATA: contém o dado que será gravado na memória local, ou o dado lido da memória local.

Estes registradores são mapeados em 4 posições consecutivas de 16 bits, no espaço de endereço de memória ou de E/S do hospedeiro. Neste caso, os registradores HSTCTLL e HSTCTLH são acessados pelo hospedeiro, como os 8 LSBs e os 8 MSBs respectivamente, de uma única posição de memória.

As seguintes operações podem ser realizadas através destes registradores:

. transferência de grandes blocos de dados entre hospedeiro e memória

local do GSP;

. tranferencia de blocos de comandos do hospedeiro para o GSP;

. "halt" do GSP, através do hospedeiro, para o carregamento de um novo programa a ser executado;

- leitura de blocos de dados gráficos gerados pelo GSP;

. recebimento de pedidos de interrup̧ão solicitados pelo hospedeiro.

\subsubsection{Registradores Dedicados ao Controle da Memória Local}

Os seis registradores seguintes são dedicados ao controle da memória local do GSP:

a. CONTROL : contém vários parâmetros para controle da operação da memória local, tais como: operação de refrescamento, cache, janelas, operações lógicas e 
aritméticas, etc.

b. CONVDP : fator de conversão do "pitch" destino.

c. CONVSP : fator de conversão do "pitch" fonte.

d. PMASK : seletivamente, habilita ou não os vários planos da imagem, para "pixel" constituído por varios bits.

e. PSIZE : contém o tamanho do "pixel" .

f. REFCNT : contador para controle do refrescamento de memórias dinâmicas.

\subsubsection{Registradores Dedicados à Interrupção}

Dois registradores de E/S monitoram e mascaram pedidos de interrup̧ões internas e externas no TMS34010:

a. INTENB : contém as máscaras para habilitar ou desabilitar as interrupções.

b. INTPEND: indica quais pedidos de interrupções encontram-se pendentes.

\subsubsection{Registradores Dedicados ao Controle do Vídeo}

O GSP contém 15 registradores de $\mathrm{E} / \mathrm{S}$, dedicados à geração dos sinais de sincronismo para vídeo e refrescamento da tela. Através da programação dos registradores apropriados, torna-se possível selecionar diferentes resoluções de tela, além de vídeo entrelaçado ou não entrelaçado.

O GSP suporta diretamente memórias do tipo VRAM, e gera os ciclos de memória para registradores de deslocamento, necessários para o refrescamento da tela de um monitor CRT.

O GSP pode opcionalmente ser programado para sincronizar com sinais de vídeo gerados externamente. Isto permite imagens gráficas criadas pelo GSP serem superpostas a imagens criadas externamente. Este modo de sincronismo pode também 
ser usado para a temporização de vídeo de dois ou mais "chips " GSP, em um sistema com múltiplos GSP.

Será dada a seguir uma descrição resumida destes registradores:

a. DPYSTRT: possibilita o controle automático dos ciclos de memória para registrador de deslocamento, necessários para o refrescamento da tela. Contém o endereço inicial de memória, a partir do qual será mostrada a imagem, e o número de linhas horizontais mostradas entre ciclos de memória para registrador de deslocamento.

b. DPYADR: contador que gera o endereço das linhas e colunas da memória durante o ciclo de refrescamento da tela, e conta o número de linhas horizontais entre ciclos de memória para registrador de deslocamento.

c. DPYCTL: contém diversos parâmetros para controle dos sinais de temporização do vídeo.

d. DPYINT: especifica a próxima linha que causará uma solicitação de interrupção. Possibilita a divisão da tela ao meio, no sentido horizontal, para mostrar duas imagens diferentes.

e. DPYTAP: gera um endereço para a VRAM, de forma a possibilitar o deslocamento de uma imagem na tela, no sentido horizontal, quando a imagem a ser visualizada for maior que a tela ("panning" horizontal).

f. HCOUNT, HEBLNK, HESYNC, HSBLNK, HTOTAL : são registradores utilizados na geração do sinal de sincronismo horizontal para vídeo, /HSYNC. g. VCOUNT, VEBLNK, VESYNC, VSBLNK, VTOTAL : são registradores utilizados na geração do sinal de sincronismo vertical para vídeo, /VSYNC.

\subsection{Instruções e Operações Gráficas}

O conjunto de instruções do GSP é constituído por instruções para propósito geral e instruções gráficas. As instruções gráficas manipulam "pixels", acessados 
através de seu endereço linear ou XY. Serão apresentadas a seguir as instruçōes e operações gráficas do GSP.

\subsubsection{Instruções Gráficas}

\subsubsection{Instrução FILL}

Esta instrução preenche uma matriz de "pixels" com o valor do "pixel" especificado no registrador COLOR1. A matriz pode ser definida no formato linear ou $\mathrm{XY}$.

\subsubsection{Instruçāo PIXBLT ("pixel block transfer")}

O GSP contém um conjunto de instruções PIXBLT para manipulação de matrizes bidimensionais de bits ou "pixels".

Dois operandos devem ser especificados numa instrução PIXBLT, a matriz fonte e a matriz destino. Ambas devem ter a mesma largura e o mesmo comprimento, embora possam ter "pitches" diferentes.

Esta instrução combina cada "pixel" da matriz fonte com o "pixel" correspondente da matriz destino, utilizando as operações gráficas selecionadas previamente.

Algumas instruções PIXBLT permitem que qualquer canto da tela seja selecionado como localização inicial. Neste caso, a seleção do canto é feita pelos bits PBV e PBH do registrador CONTROL.

Com relação ao tempo de execução, tanto as instruçōes PIXBLT como as instruções FILL dependem do tamanho da matriz. Como isso poderia vir a causar atraso no atendimento de interrupções de alta prioridade, essas instruções verificam a ocorrência de interrupçoes a intervalos regulares durante sua execução. 


\subsubsection{Instruçāo PIXT}

Esta instrução transfere "pixels" individuais de um registrador para uma posição de memória, de uma posição de memória para um registrador, ou de uma posição de memória para outra.

\subsubsection{Instrução LINE}

Esta instrução implementa o "loop" interno do algorítimo de Bresenham, para desenhar linhas. Pode ser usada juntamente com as operações gráficas.

\subsubsection{Instrução DRAV}

Esta instrução desenha um "pixel", e incrementa o endereço do "pixel", através de uma quantidade específica. É usada principalmente em algorítmos incrementais, para desenhar círculos, elípses, arcos e outras curvas. Pode ser usada com quaisquer das operações gráficas.

\subsubsection{Instruçāo CPW}

Esta instrução compara um ponto com os limites de uma janela, utilizando apenas um estado de máquina para comparar as coordenadas XY do ponto com todos os quatro cantos da janela. Permite detectar rapidamente se um ponto está dentro ou fora de uma janela retangular, ou se uma linha está completamente dentro ou fora de uma janela. 


\subsubsection{Operaçōes Gráficas}

\subsubsection{Transparência}

Transparência consiste em um mecanismo que permite a especificação de "pixels" de uma matriz como invisíveis. Isso torna-se util quando se deseja mostrar na tela somente a figura definida numa matriz retangular de "pixels", e não todos os pontos da matriz. Para exemplificar, pode-se citar a matriz retangular de "pixels", utilizada anteriormente para definir a letra L. Para garantir que somente a letra $\mathrm{L}$ seja desenhada, usa-se o mecanismo da transparência, pois ele impede que os demais "pixels" da matriz retangular sejam desenhados.

A transparência torna-se ativa, fazendo-se o bit $\mathrm{T}$ do registrador CONTROL igual a um. Quando ativa, não altera o "pixel" destino, se o resultado das operacōes entre fonte e destino resultar num "pixel" de valor zero.

A operação de transparência não afeta a gravação de dados que não sejam "pixels".

\subsubsection{Máscara de Planos do "Pixel"}

O mascaramento de planos do "pixel" caracteriza-se por ser um mecanismo em "hardware", utilizado para proteger os bits que fazem parte do "pixel", permitindo a manipulação dos mesmos, como se a memória de vídeo fosse organizada em planos de bits (ou planos de cores). $O$ número de planos é igual ao número de bits por "pixel". Assim, um sistema com "pixel" de 8 bits conterá 8 planos.

A programação da máscara é feita através do registrador de E/S, PMASK. Os "1's" na máscara especificam os "pixels" que são protegidos, enquanto que os "0's" especificam os "pixels" que podem ser modificados. Os "pixels" protegidos serão sempre lidos como zero, e não serão alterados durante a gravação.

Se o tamanho do "pixel" for menor do que 16 bits, a máscara deverá ser 
replicada, de forma a preencher os 16 bits do registrador PMASK.

\subsubsection{Operações para Processamento de "pixel"}

As operações para processamento de "pixel" no TMS34010 incluem 16 operações Booleanas entre fonte e destino ( $E, \mathrm{OU}, \mathrm{XOU}$ e complemento), e 6 operações aritméticas envolvendo soma, subtração, valor máximo e mínimo. Uma determinada operação pode ser selecionada através do campo PPOP do registrador CONTROL.

As operações aritméticas consideram os "pixels" de 4, 8 ou 16 bits como inteiros em complemento de dois.

\subsubsection{Operação de Expansão de Cor}

O TMS34010 permite, através do uso das instruções PIXBLT B,XY e PIXBLT B,L , a realização da operação de expansão de cor. Nesta operação, a forma pode ser armazenada separadamente de atributos como cor e intensidade. A forma pode ser armazenada de maneira comprimida, como um mapa de bits (um bit por "pixel") contendo "1s" e "0s", numa memória que não seja a de vídeo.

A operação de expansão de cor adiciona cor à forma no momento em que a mesma for desenhada na memória de vídeo, usando-se a instrução PIXBLT B,XY ou a PIXBLT B,L. Neste caso, o registrador COLOR 0 contém a cor que será atribuida ao bit " 0 ", enquanto que o registrador COLOR 1 contém a cor que será atribuída ao bit "1".

Este recurso possui utilidade na definição dos caracteres para texto, e em aplicações que gerem, dinamicamente,formas ou padrões. $O$ benefício imediato deste recurso está na redução da área necessária para armazenar estes caracteres ou formas. 


\subsubsection{Operaçōes com Janelas}

Uma janela é uma região retangular da memória de vídeo, especificada em termos das coordenadas XY dos "pixels", em seus cantos extremos (mínimo X e Y, e máximo X e Y). Os "pixels" do canto são considerados como pertencentes à janela. As operações com janela apenas são possíveis com endereçamento XY; isto é, o endereço do "pixel" destino deve estar especificado no modo XY.

No TMS34010, o tamanho da janela é estabelecido pela programação dos registradores $\mathrm{B} 5$ e $\mathrm{B} 6$, e inclui-se suporte para verificação automática de janelas. Há 3 modos de verificação da janela. A seleção de um modo é feita através da programação de dois bits do campo $\mathrm{W}$, do registrador CONTROL, podendo assumir os seguintes valores:

a. $W=0$, a verificação de janela é desativada;

b. $W=1$, é feito um pedido de interrupção, na tentativa de se gravar dentro da janela;

c. $W=2$, é feito um pedido de interrupção, na tentativa de se gravar fora da janela;

d. $W=3$, grava somente os "pixels" que estejam dentro da janela.

A solicitação de interrupção por violação da janela apenas será atendida se o bit IE do registrador de "status" e o bit WVE do registrador INTENB estiverem em "1".

Os modos de verificação da janela afetam somente a gravação de "pixels", realizada com as instruções gráficas (PIXBLT, FILL, LINE, DRAV e PIXT).

O TMS34010 contém recursos que permitem rapidamente detectar se um ponto está dentro ou fora de uma janela, e se uma linha encontra-se inteiramente dentro ou inteiramente fora de uma janela retangular. Linhas completamente fora podem ser rejeitadas, significando que não mais consumirão tempo de processamento. Essas condições são detectadas através da instrução $\mathrm{CPW}$, que compara um ponto com os 
cantos de uma janela.

Outra operą̧ão que ocorre frequentemente em ambientes com janelas, consiste no cálculo da região onde dois retângulos se interceptam. Essa operação é possível com as instruções PIXBLT e FILL. Baseado nos modos de verificação de janelas, um dos dois métodos seguintes podem ser selecionados para calcular a região de in tersecção:

a. a matriz destino é recortada ("preclipped") numa janela retangular, antes que a instrução PIXBLT (ou FILL) inicie.

b. a intersecção da matriz destino com a janela retangular é calculada, mas os "pixels" não são transferidos.

\subsubsection{Instruções para o Modo de Endereçamento XY}

O TMS34010 possui um conjunto de instruções, que auxiliam as operações no modo XY. Estas instruções são as seguintes:
ADDXY RS,RD: adiciona registradores no modo XY
.CMPXY RS,RD: compara as metades $\mathrm{X}$ e $\mathrm{Y}$ dos registradores
.SUBXY RS,RD: subtrai registradores no modo $\mathrm{XY}$
.MOVX RS,RD: move somente a parte $\mathrm{X}$ do registrador
.MOVY RS,RD: move somente a parte $\mathrm{Y}$ do registrador
.CVXYL RS,RD: converte endereço XY para endereço linear

\subsection{Interrupçōes, Traps e Reset}

No TMS34010 há oito interrup̧̧ões, incluindo "reset". Os endereços de memória de $>$ FFFFFC00 até >FFFFFFFF contém os 32 vetores de endereço, usados durante interrupçōes, "traps" por software e "reset". Cada vetor é um endereço de 32 bits, que aponta para o início da rotina de interrupção. A tabela II e a figura 28 sumarizam as 
interrup̧̧ōes e suas prioridades.

A interrupção não mascarável e o "reset" não podem ser desativados.

Tabela II - Prioridade das Interrupções.

\begin{tabular}{|c|c|c|c|}
\hline Internup. & Prioridade & $\begin{array}{l}\text { Extomo/ } \\
\text { Intomo }\end{array}$ & DESCRIÇÃo \\
\hline Roout & 1 & I & $\begin{array}{l}\text { "roect do "chip": ocorre com a opliooeco de "o" } \\
\text { ne pino root }\end{array}$ \\
\hline NMI & 2 & I & $\begin{array}{l}\text { Interrupgōo noo mascaroveli gorade polo procesedor } \\
\text { hospedeliro. }\end{array}$ \\
\hline$H$ & 3 & I & $\begin{array}{l}\text { interrupepio do hospedeiro; gerado pelo processodior } \\
\text { hospodoifo }\end{array}$ \\
\hline DI & 4 & I & interruppōo do video; gercodo pelo TMS34010 \\
\hline w & 5 & 1 & $\begin{array}{l}\text { intermupeóo por violoceo de janela: geroda pelo } \\
\text { TMS340 to }\end{array}$ \\
\hline INT1 & $\frac{6}{7}$ & $\mathbf{B}$ & $\begin{array}{l}\text { intorrupeöos externos } 1 \text { - } 2 \text { gerodo por diaposittyos } \\
\text { externos }\end{array}$ \\
\hline INT2 & 7 & $\mathbf{E}$ & \\
\hline ILPP & 8 & I & $\begin{array}{l}\text { Intermpeáo cousoda por "opoode" llogat gerodo polo } \\
\text { TNS3 t010 }\end{array}$ \\
\hline
\end{tabular}

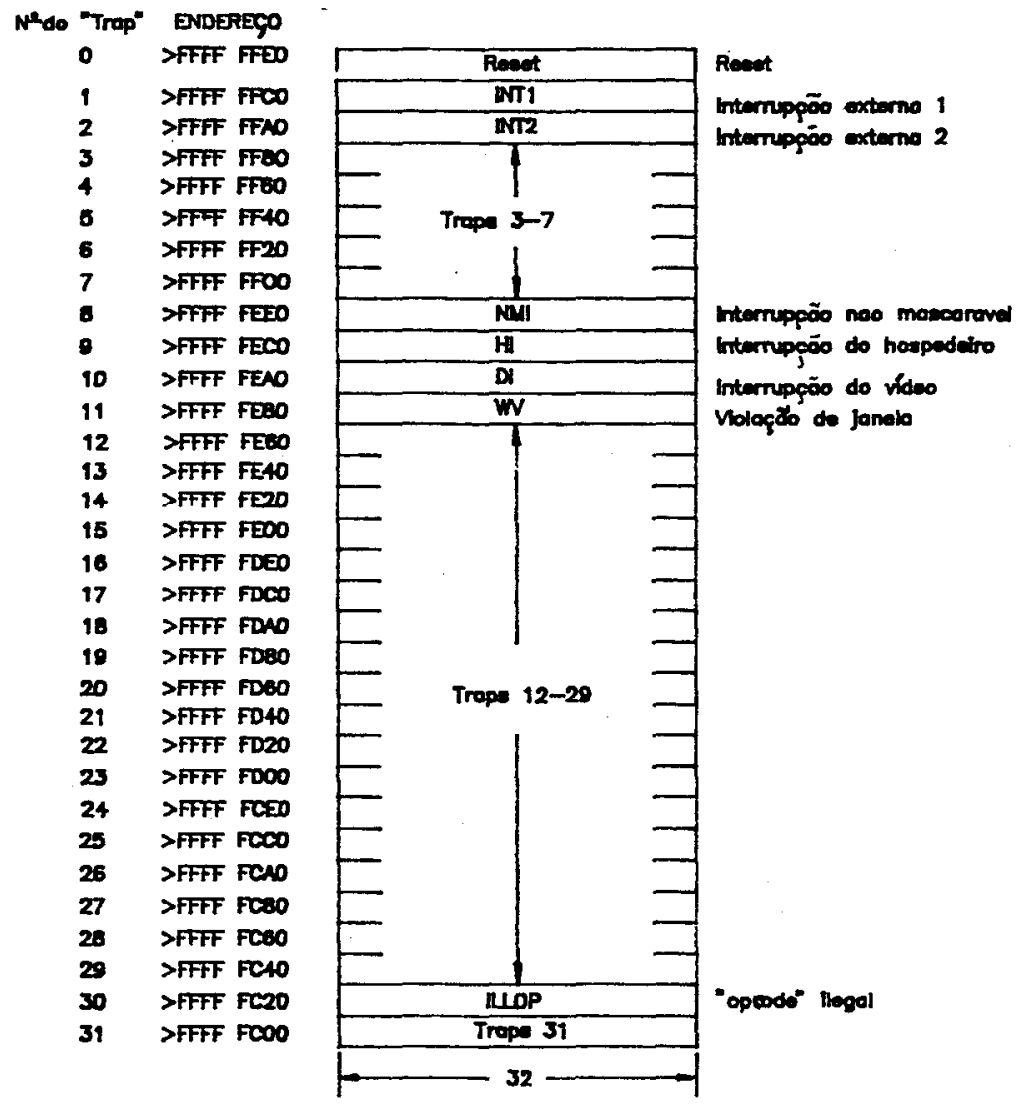

Figura 28 - Mapa dos Vetores de Interrupção. 


\subsubsection{Registradores Dedicados à Interrupcão}

Os dois registradores seguintes são dedicados à interrupção:

a. INTENB - contém as máscaras de habilitação para as interrupções INT1, INT2, HI, DI e WV.

b. INTPEND - indica as interrupções mascaráveis pendentes, isto é, que ainda não foram atendidas.

Além destes registradores, existe um bit de habilitação global de interrupção, o bit IE do registrador de "STATUS". Quando IE é idêntico a zero, todas as interrupções são desativadas, independente da máscara programada no registrador INTENB. Quando IE é programado com "1", a máscara determinará se uma interrupção estará ou não ativa.

\subsection{2 "Traps"}

O TMS34010 suporta 32 "traps" por "software", numerados de 0 a 31 . Estes "traps" comportam-se de maneira similar às interrupções, exceto que, um "trap" é iniciado quando a instrução TRAP for executada . O "trap" por "software" não pode ser desativado. As mesmas ações executadas para uma interrupção são executadas para o "trap". O "trap" 0, em particular, assemelha-se ao "reset" por "hardware", pelo fato de não salvar o PC e o ST na pilha, mas se diferencia do mesmo, por não colocar o GSP num estado inicial conhecido.

\subsection{3 "Reset"}

"Reset" coloca o TMS34010 num estado inicial conhecido. Ocorrerá quando um nível lógico " 0 " for aplicado no pino de entrada /RESET. Este nível deve ser mantido em "0" por um tempo mínimo de 40 períodos de clock local (LCLK1 e LCLK2), a fim 
de assegurar que o estado inicial interno do TMS34010 seja estabelecido.

Enquanto a entrada /RESET for mantida ativa, todas as saídas permanecerão num estado conhecido e nenhum ciclo de refrescamento da tela, ou de memória DRAM ocorrerá.

Tabela III - Estados dos Pinos do GSP durante "Reset".

\begin{tabular}{|c|c|c|}
\hline $\begin{array}{l}\text { SÁ́́A EM } \\
\text { NINELALTO }\end{array}$ & $\begin{array}{l}\text { SAÍDA EM } \\
\text { NÍEL BAIXO }\end{array}$ & $\begin{array}{l}\text { PINOS EM ALTA } \\
\text { IMPEDANCLA }\end{array}$ \\
\hline $\begin{array}{l}\text { DDOUT } \\
\frac{H R D Y}{D E N} \\
\frac{D E N}{L A L} \\
\frac{\overline{T R} / \overline{Q E E}}{\overline{R A S}} \\
\frac{R A S}{\overline{C A S}} \\
\frac{\bar{W}}{H I N T}\end{array}$ & $\overline{\text { BLANK }}$ & $\begin{array}{l}\overline{\text { HSYNC }} \\
\text { VSYNC } \\
\text { HDD-HD15 } \\
\text { LADO-LAD15 }\end{array}$ \\
\hline
\end{tabular}

A tabela III mostra o estado dos pinos do GSP durante "reset".

Imediatamente após "reset" e antes da execução da primeira instrução os registradores internos encontram-se no seguinte estado:

. Os registradores do arquivo A e B não são inicializados;

. O ST é inicializado para >00000010;

. O PC contém um vetor de 32 bits, obtido do endereço de memória $>$ FFFFFFE0;

. Os registradores de $\mathrm{E} / \mathrm{S}$ são zerados.

Imediatamente após a transição positiva de /RESET, o GSP executará 8 ciclos de memória /RAS - only, para levar as memórias VRAMs e DRAMs a seu estado inicial de operação. Estes ciclos são completados antes que qualquer acesso à memória do GSP seja permitido.

Na transição positiva do /RESET o GSP será configurado para um dos dois modos seguintes, dependendo do nível lógico do pino /HCS: 
a. modo "self-bootstrap" (/HCS=0): inicia a execução de instruções imediatamente após o reset ter sido completado.

b. modo "host - present" (/HCS=1): o GSP é colocado em "halt", mantendo-se neste estado até que o processador hospedeiro instrua-o para iniciar a execução de um programa.

0 modo "self -bootstrap" é usado em sistemas que contém uma memória não volátil, na qual se encontra armazenado o programa de inicialização do sistema. Assim, este tipo de sistema não necessariamente requer um processador hospedeiro.

0 modo "host-present" considera que um processador hospedeiro encontra-se conectado ao GSP, através do duto dedicado ao hospedeiro. Isto permite que a memória local possa ser constituída somente de RAMs. Para que o GSP seja configurado para este modo, o sinal do pino /HCS deve estar em "1", na transição positiva do /RESET. Se isto ocorrer, a lógica interna do GSP força o bit HLT(halt) do registrador HSTCTL para "1", colocando o GSP em "halt". Enquanto o GSP permanece neste estado, o processador hospedeiro carrega o programa objeto na memória local do GSP, e estabelece os vetores de interrupção; só então permite ao GSP iniciar a execução do programa.

\subsection{Temporização do Vídeo e Refrescamento da Tela}

O TMS34010 gera os sinais de sincronismo horizontal (/HSYNC), sincronismo vertical (/VSYNC) e "blanking" (/BLANK), a partir do "clock" de entrada para vídeo (VCLK), que por sua vez deve ser derivado do "clock" do "pixel"("dot clock").

O GSP pode ser programado para uma grande variedade de resoluções de tela, e para vídeo entrelaçado ou não entrelaçado.

O TMS34010 gera automaticamente os ciclos de memória para registrador de deslocamento, destinados a VRAM, necessários para o refrescamento da tela do monitor de vídeo. Estes ciclos são referidos como ciclos de refrescamento de tela, e 
ocorrem durante o retraço horizontal.

Cada ciclo de memória para registrador de deslocamento transfere dados de uma linha selecionada da memória VRAM para os registradores internos a VRAM. Estes dados são, então, deslocados serialmente para serem mostrados na tela.

Torna-se possível, também, configurar o GSP para executar os ciclos de memória para registrador de deslocamento e os ciclos de registrador de deslocamento para memória, sob controle do software. Este recurso facilita o apagamento quase instantâneo da tela.

\subsubsection{Memória de Vídeo}

A memória de vídeo, também denominada de memória de tela, caracteriza-se por ser a área de memória que mantém a imagem gráfica a ser mostrada na tela do monitor de vídeo. Esta memória é normalmente implementada com VRAMs. Durante um ciclo de refrescamento de tela, os registradores de deslocamento contêm a quantidade de "pixels" necessária para preencher pelo menos uma linha.

A largura da memória de tela é referida como "pitch" da tela, e tem a mesma definição de "pitch" vista anteriormente no item 3.4.3.4. 0 "pitch" da tela deve ser carregado no campo DUDATE do registrador DPYCTL, e representa a quantidade pela qual o endereço de refrescamento da tela deve ser incrementado após cada ciclo de refrescamento de tela.

O endereço do primeiro "pixel" a ser mostrado na tela é especificado no campo SRFADR do registrador DPYSTRT. Este enderę̧o é gerado no início de cada "frame", e é incrementado (ou decrementado) pelo valor do campo DUDATE, no fim do primeiro ciclo de refrescamento de tela, apontando para a área de memória que contém os "pixels" da próxima linha. Este processo é repetido para cada linha. 


\subsubsection{Geração do Endereço de Refrescamento de Tela}

Os seguintes registradores são utilizados na geração do endereço de refrescamento da tela:

a. DPYSTRT - o campo SRFADR deste registrador contém o endereço inicial da imagem a ser mostrada, ou o endereço inicial do "frame".

b. DPYADR - o campo SRSTRT deste registrador é carregado inicialmente com o valor do campo SRFADR do registrador DPYSTRT, e a cada ciclo de memória para registrador de deslocamento é incrementado pelo campo DUDATE do registrador DPYCTL.

c. DPYCTL - contém três campos que afetam o endereço de refrescamento da tela. $O$ campo DUDATE contém o "pitch" da tela. $O$ bit ORG determina a origem da tela, e se o endereço de refrescamento da tela for decrementado (ORG = 1), ou incrementado $(O R G=0)$. $O$ bit NIL determina se o GSP é configurado para vídeo entrelaçado, ou não entrelaçado.

d. DPYTAP - este registrador possibilita fazer "pan" em uma imagem com dimensões maiores do que as da tela. Durante o ciclo de refrescamento da tela, os bits menos significativos deste registrador geram os LSBs do endereço da coluna. Incrementando este valor resulta um "pan" à direita, e decrementando-o resulta um "pan" à esquerda. Os bits deste registrador que se superpõem aos do campo SRSTRT, são combinados logicamente.

\subsection{Duto Dedicado ao Hospedeiro}

O processador hospedeiro pode comunicar-se com o TMS34010, através de um barramento dedicado ao hospedeiro, que consiste de um duto de dados de 8/16 bits e 
vários sinais de controle. 0 processador hospedeiro tem acesso a quatro registradores do GSP, os quais são mapeados no espaço de endereço de memória ou E/S do hospedeiro.

O hospedeiro pode realizar operações de leitura ou gravação na memória do GSP, indiretamente, através do autoincremento do endereço contido em registradores do GSP, a ele dedicados. Esta característica de autoincremento, permite a transferência eficiente de blocos de dados.

É possível também ao GSP e ao hospedeiro, solicitarem interrupção um ao outro. Há um pino dedicado ao pedido de interrupção do GSP para o hospedeiro.

Para que a transferência de blocos de dados, iniciada pelo hospedeiro, seja feita de forma mais eficiente, ele pode suspender a execução do programa do GSP, eliminando a contenção, com a memória local do GSP. Os ciclos de refrescamento da DRAM e os ciclos de refrescamento da tela continuam a ocorrer, enquanto o GSP for mantido em "halt".

\subsubsection{Convenções de Endereçamento por "Byte"}

O GSP pode ser programado para acomodar as convenções particulares de endereçamento por "byte" usadas pelo hospedeiro. Esta característica é importante, pois assegura a compatibilidade em "software" entre as versões de 8 e 16 bits do mesmo processador, tais como as do 8088 e 8086 , ou as do 68008 e 68000 . Isto é possível com o bit LBL do registrador HSTCTL. Pela programação conveniente deste bit, um hospedeiro que tenha um duto de dados de 8 bits, pode especificar a ordem em que os "bytes" serão enviados para o GSP. 


\subsubsection{Acesso Indireto à Memória Local}

O hospedeiro acessa indiretamente a memória local do GSP pela leitura ou gravação de dados no registrador HSTDATA, onde o endereço de 32 bits é carregado pelo hospedeiro nos registradores HSTADRL e HSTADRH. Os 4 LSBs do HSTADRL são sempre forçados para " 0 " internamente, de forma que o endereço formado por HSTADRH e HSTADRL, sempre aponte para uma palavra. Desta forma o autoincremento é sempre de 16 bits.

Dois bits do registrador HSTCTL, controlam o autoincremento, o INCR, para leitura, e o INCW para gravação. Ambos ativam o autoincremento quando em "1".

$O$ hospedeiro pode acessar indiretamente os registradores de E/S do GSP através do mesmo processo de leitura/gravação na memória local do GSP.

Uma observação importante é que não existe qualquer proteção em "hardware" para evitar que o GSP e o hospedeiro acessem simultaneamente os registradores HSTDATA, HSTADRL e HSTADRH. Desta forma o "software" deve ser escrito de maneira a evitar que isto ocorra.

\subsubsection{Largura de Banda}

Define-se largura de banda como o número de bits por segundo que podem ser transferidos através do barramento dedicado ao hospedeiro, durante a transferência de um bloco de dados de ou para a memória do GSP. O que se espera é que a máxima taxa de dados através do barramento dedicado ao hospedeiro, seja próxima da largura de banda da memória local do GSP. Por exemplo, considerando que a frequência externa do GSP seja de $50 \mathrm{MHZ}$, e que a memória não necessite de estados de espera, se o "cycle time" desta memória for de 320 ns, então a largura de banda para esta memória será de $50 \mathrm{Mbits} /$ segundo. $O$ "access cycle time" para o hospedeiro será maior, devido a certos atrasos adicionais inerentes à operação da lógica interna do GSP dedicada ao hospedeiro, e consequentemente espera-se uma largura de banda menor. 
A tabela IV mostra uma estimativa da largura de banda do barramento dedicado ao hospedeiro, em duas situações distintas: com GSP em "halt", e com o GSP em operação.

Tabela IV - Largura de Banda Estimada para a Interface do Hospedeiro.

\begin{tabular}{|ll|}
\hline Consideração & "Throughput" aproximado \\
\hline $\begin{array}{l}\text { GSP em "Halt", } \\
50 \mathrm{MHz}, \\
\text { sem estado de } \\
\text { espera }\end{array}$ & $\frac{16 \mathrm{bits} / \text { transferência }}{400 \mathrm{~ns} / \text { transferência }}=40 \mathrm{mbits} / \mathrm{s}$ \\
\hline $\begin{array}{l}\text { GSP em operação, } \\
50 \text { MHz, } \\
\text { sem estado de } \\
\text { espera }\end{array}$ & $\frac{16 \mathrm{bits} / \mathrm{transferência}}{550 \mathrm{~ns} / \mathrm{transferência}}=29 \mathrm{mbits} / \mathrm{s}$ \\
\hline
\end{tabular}

\subsection{Barramento da Memória Local}

O barramento da memória local contém um duto tri-multiplexado em endereço/dados (figura 29). Os sinais de controle deste barramento permitem a conexão direta de VRAMs e DRAMs. No início de um ciclo de memória o endereço é gerado de forma multiplexada, com o endereço de linha seguido pelo endereço de coluna. O restante do ciclo é usado para a transferência de dados entre o TMS34010 e a memória.

A figura 30 ilustra o diagrama de tempo simplificado, onde $L A D$ representa o duto multiplexado. $O$ endereço da linha é válido antes e após a transição negativa de /RAS. O endereço da coluna não é válido na transição negativa de /CAS, mas é válido por um curto espaco de tempo que antecede e sucede a transição negativa do sinal /LAL. $O$ endereço da coluna deve então ser armazenado na transição negativa de /LAL, através de um "latch" externo, de forma a se manter estável pelo tempo necessário para as memórias.

Três bits de "status" são gerados juntamente com os bits de endereços: 
. /RF, indicando a ocorrência de ciclos de refrescamento de DRAMs;

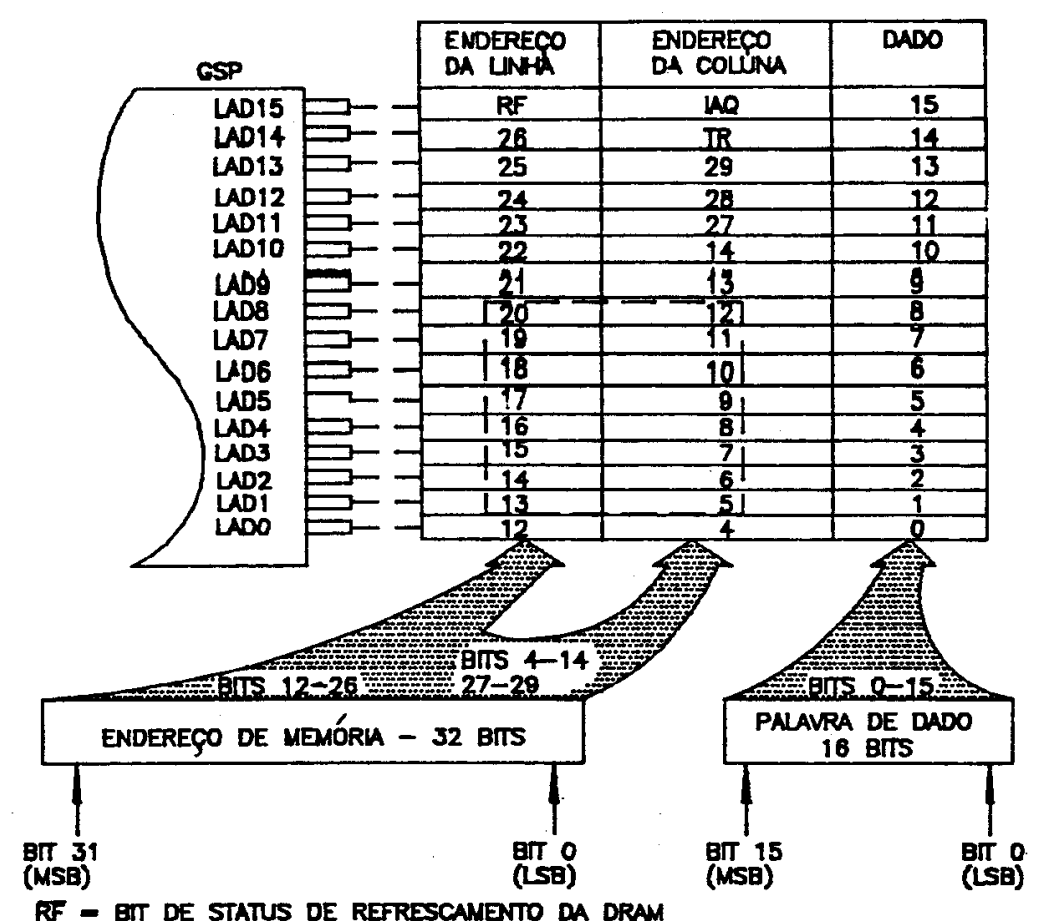

RF - BT DE STATUS DE RERRESCAMENTO DA DRAM

IAD = ATT DE STATUS DE AOUISICAO DE INSTRUYCAO

Figura 29 - Multiplexação de Endereço e Dado no Duto LAD0-LAD15.

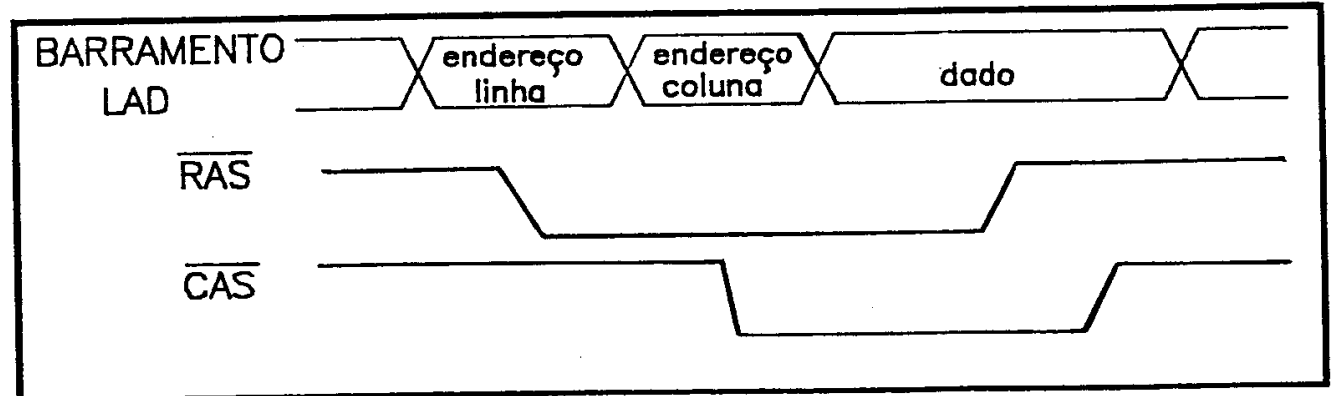

Figura 30 - Endereço da Linha e Coluna de um Ciclo de Memória. 
./TR, ciclo de refrescamento da tela (memória para registrador de deslocamento da VRAM);

. IAQ, indicando a ocorrência de ciclos de busca de instrução.

\subsubsection{Ciclos da Memória Local do GSP}

Os seguintes tipos de ciclos de memória são possíveis no TMS34010: leitura, gravação, registrador de deslocamento das VRAMs para memória, memória para registrador de deslocamento das VRAMs, ciclos de refrescamento da DRAM "CAS before /RAS" ou "/RAS only".

A título de exemplo serão vistos a seguir alguns ciclos de máquina da memória local do GSP. Os demais podem ser encontrados na referência [12].

Os ciclos de memória que serão apresentados, LCLK1 e LCLK2 são obtidos a partir de INCLK, e têm o período oito vezes maior que o do INCLK.

Dois ciclos do sinal LCLK1 são utilizados para o acesso à memória local. Considerando o INCLK de $40 \mathrm{MHZ}$, isto resulta num ciclo de memória de 400 ns. No primeiro ciclo de LCLK1, é gerado o endereço da linha e o da coluna. 0 segundo é usado para entrada ou saída de dados no barramento.

\subsubsection{Ciclo de Gravação da Memória Local}

A figura 31 ilustra um ciclo de gravação em memória.

O sinal /DEN é normalmente usado em sistemas com grandes configuraçōes de memórias, que necessitem de um "buffer" no duto de dados. Neste caso /DEN é usado para habilitar o "buffer" externo bidirecional, (por exemplo o 74AS245), enquanto DDOUT é usado como sinal de controle de direção do "buffer".

Os dados são válidos em ambas as bordas do sinal de $/ W$, e desta forma os dispositivos externos podem armazenar o dado tanto na transição positiva, como na 
transição negativa de $/ W$.

O sinal LRDY é uma entrada do TMS34010, utilizada por dispositivos lentos, para solicitação de estados de espera.

O sinal /TR/QE, quando em nível alto, impede a habilitação dos "drivers" de leitura, das DRAMs e VRAMs

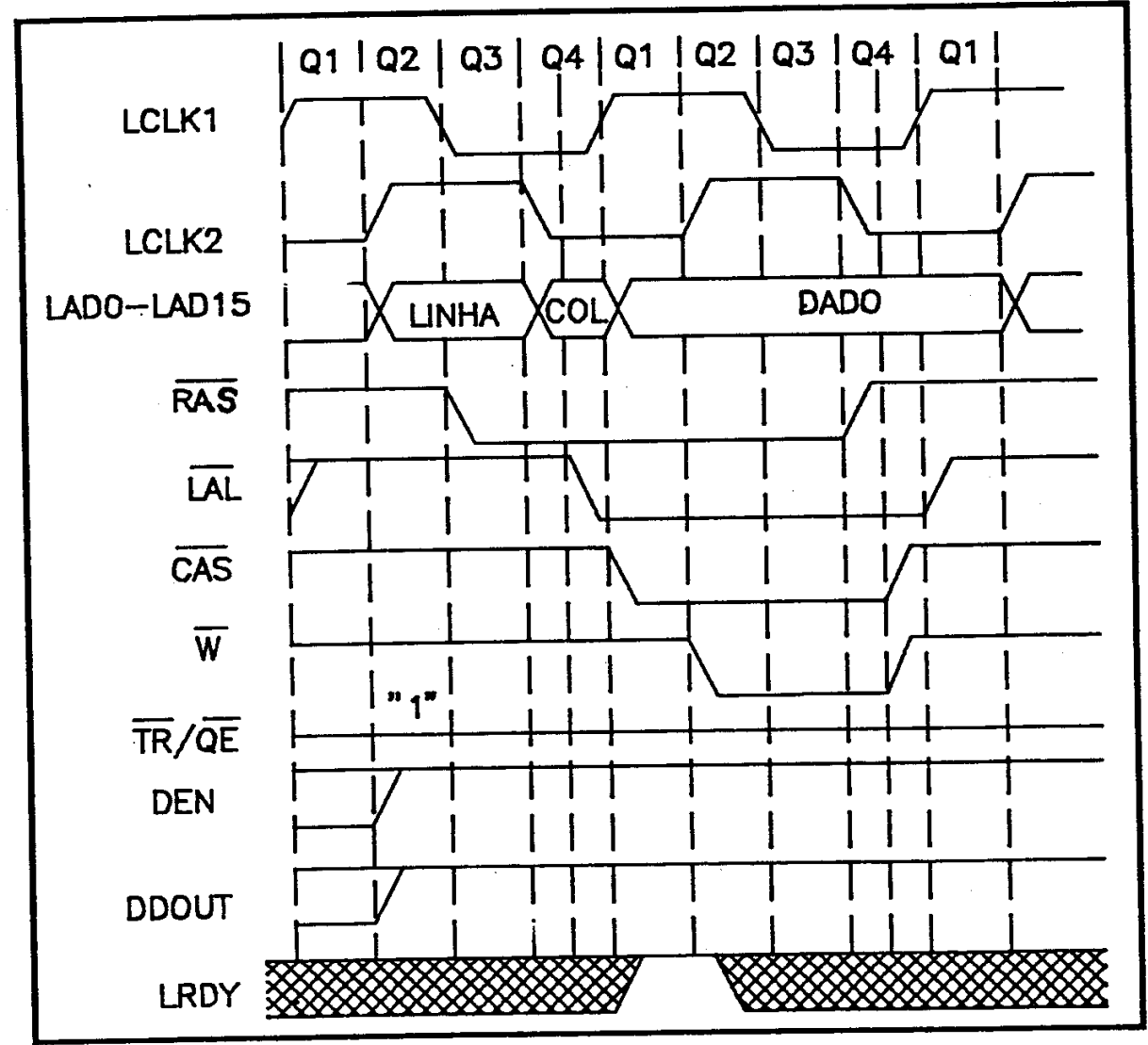

Figura 31 - Ciclo de Gravação em Memória. 


\subsubsection{Ciclo de Leitura da Memória Local}

\section{A figura 32 ilustra o ciclo de leitura da memória local.}

0 duto LAD0-LAD15 é forçado para o estado de alta impedância após o endereço das colunas. Os sinais /DEN e /TR/QE, tornam-se ambos ativos (em "0"), após /CAS tornar-se ativo, a fim de habilitar os "drivers" de saída das memórias DRAMs e VRAMs.

$\mathrm{O}$ dado da memória que é lido deve ser válido na metade de Q4, conforme é mostrado na figura 32.

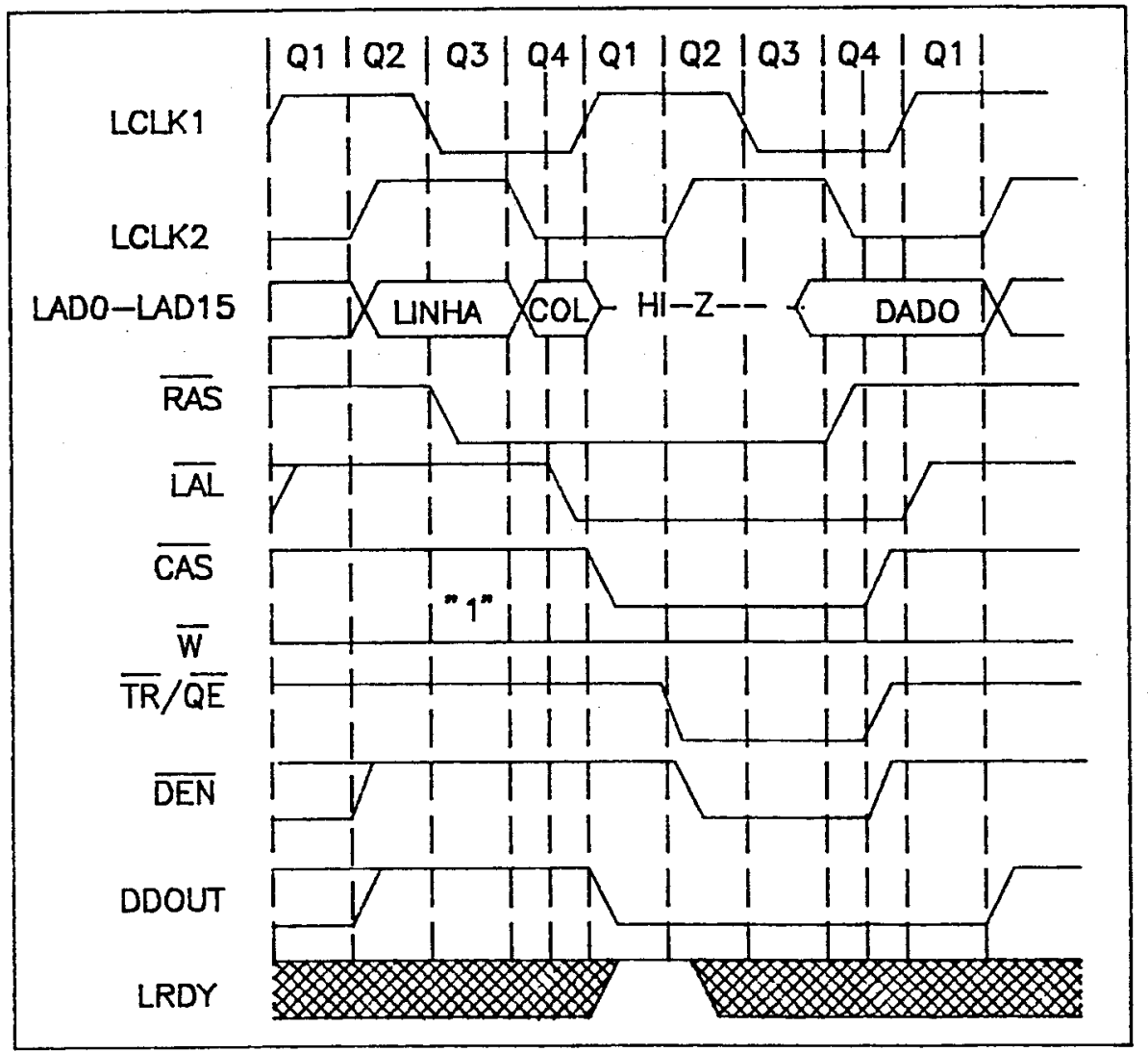

Figura 32 - Ciclo de Leitura em Memória. 
3.10.1.3 Ciclo de Memória para Registrador de Deslocamento

Este é um tipo de ciclo especial usado em sistemas com VRAMs. Neste ciclo, é transferido o conteúdo de uma linha selecionada da memória de vídeo para seus registradores de deslocamento internos. Este ciclo é referido como ciclo de refrescamento da tela.

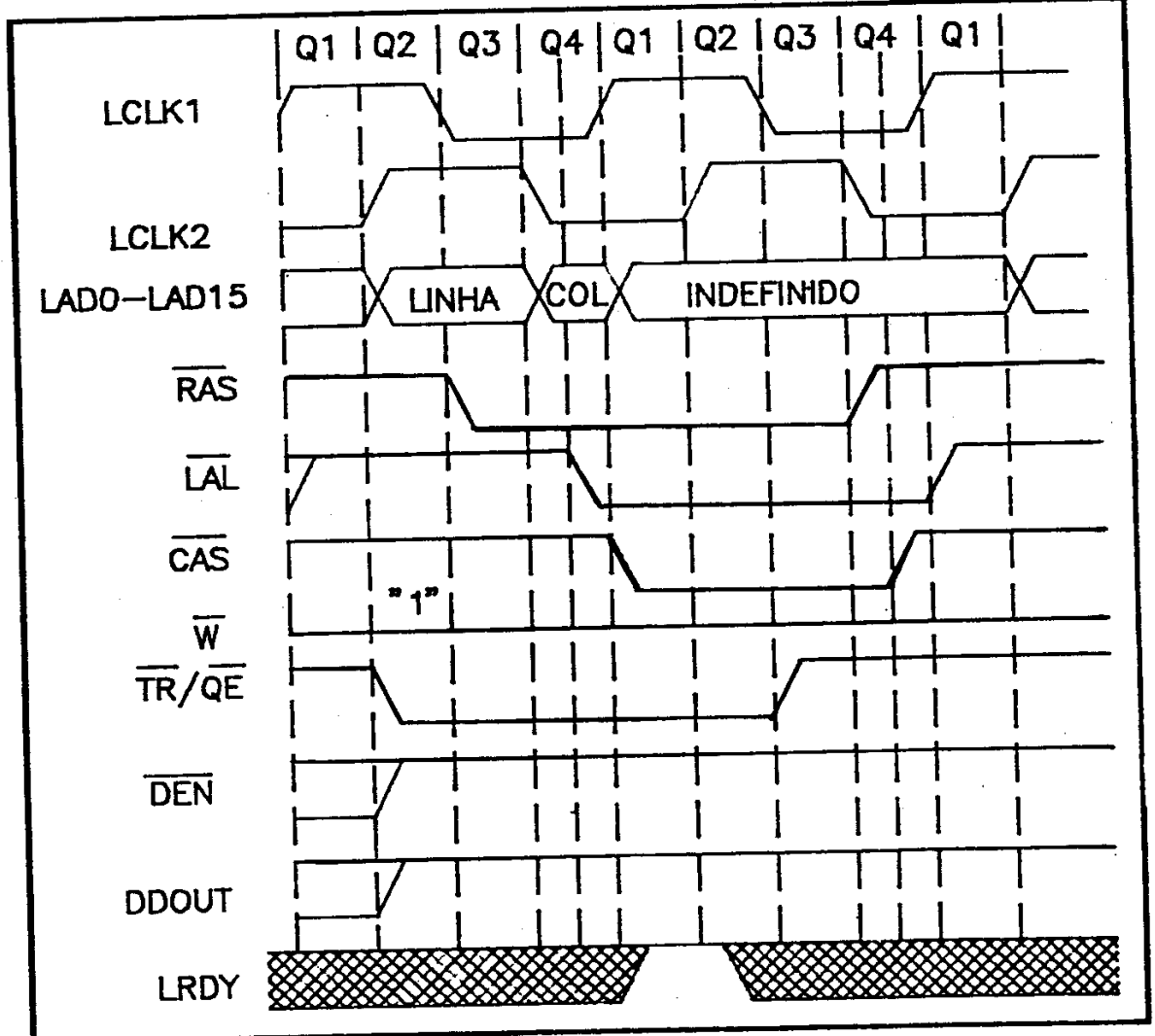

Figura 33 - Ciclo de Memória para Registrador de Deslocamento. 
Como se pode ver na figura 33, neste ciclo o sinal /TR/QE é mantido em nível lógico baixo, durante a transição negativa de /RAS, enquanto /W permanece em nível lógico alto. Durante este ciclo as saídas das VRAMs permanecem em alta impedância. A transição positiva de /TR/QE ocorre após a transição negativa de /CAS, mas antes da transição positiva de /RAS. Este ciclo possibilita a compatibilidade com uma grande variedade de VRAMs.

\subsubsection{Ciclo de Leitura com Estados de Espera}

Uma solicitação de estado de espera ocorre quando é aplicado um nível lógico baixo no pino LRDY do GSP, por memórias que necessitem de um ciclo com duração mais longa.

O GSP verifica a entrada LRDY no fim de Q1, conforme pode ser visto na figura 34. Se LRDY estiver em nível "0", o GSP irá inserir um estado adicional no ciclo de memória, denominado de estado de espera. Estes estados continuarão a ser inseridos até que a entrada LRDY, quando for verificada pelo GSP, esteja em nível "1". 


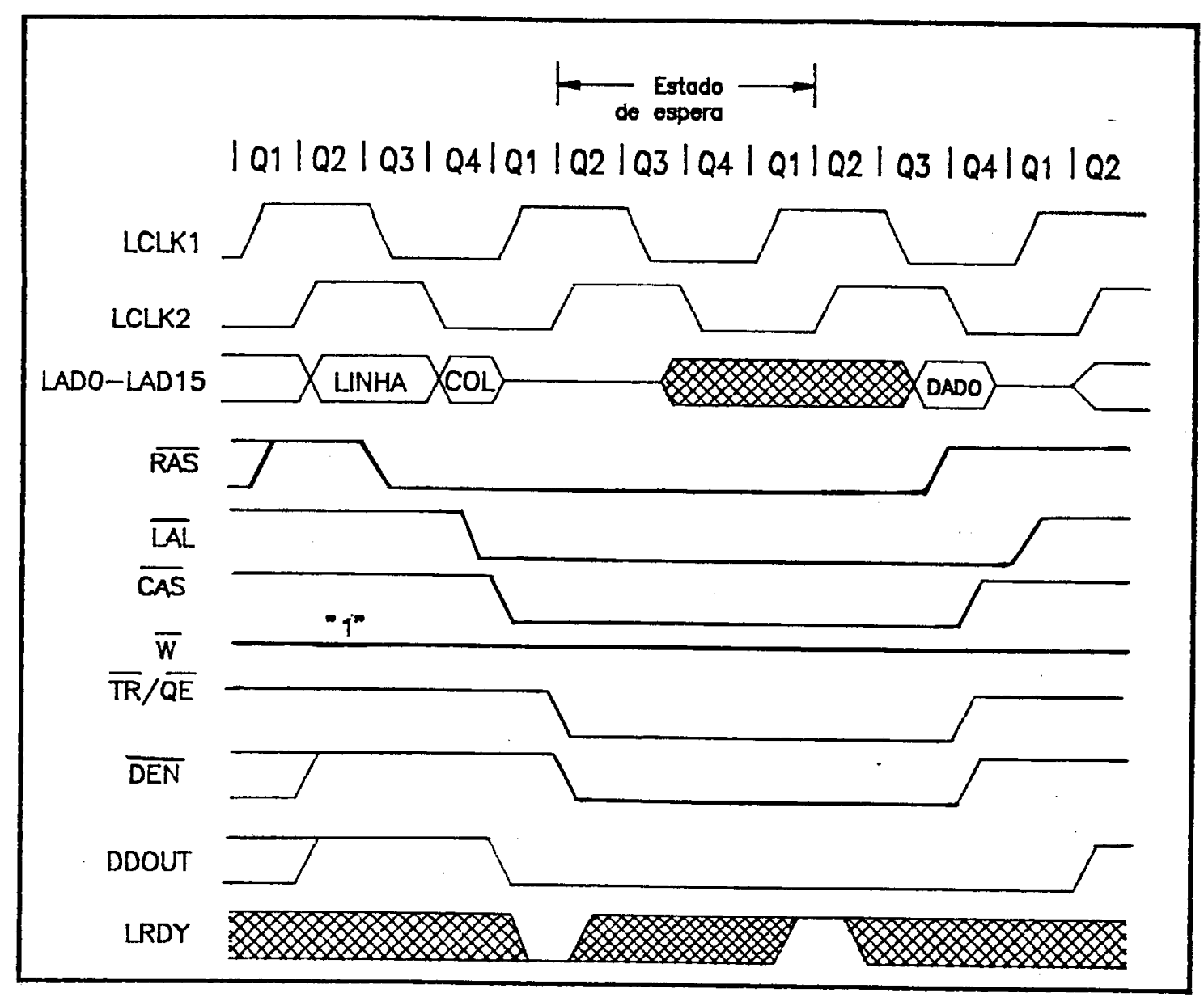

Figura 34 - Ciclo de Leitura com um Estado de Espera. 


\subsubsection{Prioridade na Solicitação do Barramento da Memória}

O controlador do circuito da memória local estabelece a prioridade mostrada na tabela V, para acesso à memória local.

Tabela V - Prioridade para Acessar a Memória.

\begin{tabular}{|ll|}
\hline Prioridade & \multicolumn{1}{c|}{ ciclo de memoria solicitado } \\
\hline 1 & solicitação do barramento por um dispositivo externo \\
2 & ciclo de refrescamento da tela \\
3 & ciclo de refrescamento da DRAM \\
4 & ciclo de memória da CPU do GSP
\end{tabular}

A solicitação do barramento da memória local por outro dispositivo tem a prioridade mais alta (prioridade 1), e esta requisição é feita através do pino de entrada "hold". Após reconhecer este pedido, o GSP coloca o duto de endereço/dados e as saídas de controle em alta impedância. $O$ dispositivo que solicitou o barramento não deve controlá-lo por um tempo muito longo, de forma a impedir que o GSP execute os ciclos de refrescamento da tela e das memória dinâmicas.

No caso do hospedeiro tentar um acesso indireto à memória do GSP, ele será bloqueado enquanto o disposivo externo mantiver o controle do barramento. Se ocorrer nova tentativa de acesso pelo hospedeiro, o GSP enviará um sinal de "not ready" até que o dispositivo externo libere o barramento.

3.10.3 Mecanismos de Endereçamento

O GSP endereça memória através de um endereço lógico de 32 bits, onde cada endereço aponta para um bit na memória. A figura 35 ilustra a maneira como os bits são gerados para a memória física. Cada coluna, nesta figura, indica um pino do duto 
de endereço/dado, LAD0 - LAD15, e o bit de endereço lógico correspondente a cada pino, durante as transiçōes de /RAS e de /CAS.

\begin{tabular}{|c|c|c|c|c|c|c|c|c|c|c|c|c|c|c|c|c|c|}
\hline & & \multicolumn{16}{|c|}{ NÚNEROS DOS PINOS LN } \\
\hline & & 15 & 14 & 13 & 12 & 11 & 10 & 8 & 8 & 7 & 6 & 5 & 4 & 3 & 2 & 1 & 0 \\
\hline \multirow{2}{*}{ 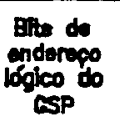 } & $\begin{array}{l}\text { No tranolicio } \\
\text { nogotivo of } \overline{\mathrm{RS}}\end{array}$ & $\overline{\mathrm{RF}}$ & 26 & 25 & 24 & 23 & 22 & 21 & 20 & 19 & 18 & 17 & 16 & 15 & 14 & 13 & 12 \\
\hline & 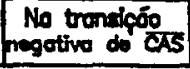 & $\overline{\mathrm{IAQ}}$ & $\mathbf{T R}$ & 20 & 28 & 27 & 14 & 13 & 12 & 11 & 10 & $\boldsymbol{\theta}$ & 8 & 7 & 6 & 5 & 4 \\
\hline
\end{tabular}

Sinols de stotus do borromento

FF- Ciclo do refrecomento de DRAM

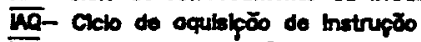

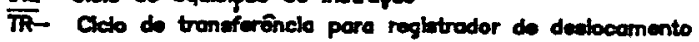

Figura 35 - Bits de Endereço Lógico Durante as Transições de /RAS e /CAS.

O modo de gerar os bits para o endereçamento de memória apresenta algumas características:

a. Os dois bits MSBs de endereço lógico, bits 30 e 31, nunca são gerados.

b. Os quatro LSBs do endereço lógico de 32 bits não são gerados externamente, mas são usados internamente na designação do "field" da palavra.

c. Os bits de endereço dos pinos LAD0-LAD10, são gerados de uma maneira tal que, selecionando-se 8 entre estes pinos, para serem usados no endereçamento das memórias, o endereço lógico será sequencial. Isto elimina a necessidade de "multiplexers" externos. 


\subsubsection{Operação de Refrescamento}

O GSP gera automaticamente ciclos de refrescamento para memórias dinâmicas, a intervalos regulares . 0 intervalo entre ciclos de refrescamento é programável, e o refrescamento pode ser desativado em sistemas que não o requeiram.

Há dois tipos de ciclos de refrescamento que podem ser escolhidos: "RAS - only" ou "CAS before RAS". Durante o ciclo "RAS-only" o GSP gera os 8 bits de endereço de linha, necessários para o refrescamento desta linha em particular.

Memórias dinâmicas que suportem o ciclo "CAS before RAS", contêm internamente um contador que gera o endereço da linha, necessário para o refrescamento.

Mas independentemente do tipo de ciclo selecionado, o GSP gera um endereço válido de linha, permitindo desta forma a implementação de um sistema híbrido, onde parte das memórias usem o ciclo "RAS-only" e outra parte use o ciclo "CAS before RAS".

O modo e a taxa de refrescamento podem ser selecionados pela programação dos bits RM e RR do registrador CONTROL. Para valores de RR de 00 e 01, os ciclos de refrescamento da memória dinâmica podem ocorrer a cada 32 e 64 períodos de clock, respectivamente. Para memórias dinâmicas com 256 linhas, e que requeiram o refrescamento de cada linha a cada $4 \mathrm{~ms}$, o máximo período de refrescamento é de 15,625 microsegundos (4 ms/256). A tabela VI mostra a taxa de refrescamento para alguns valores da frequência INCLK, e a figura 36 mostra o ciclo de refrescamento "RAS-only". 


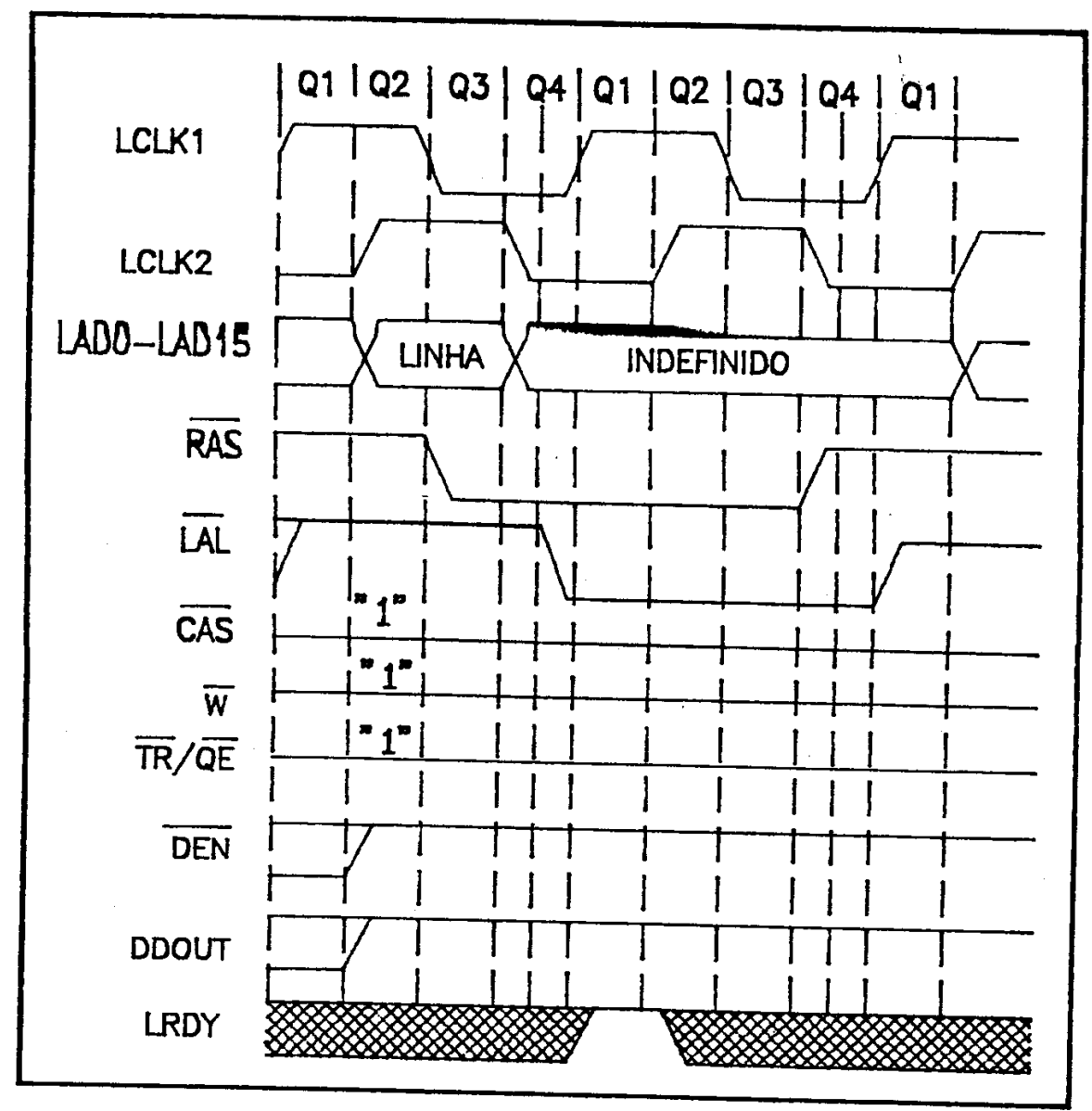

Figura 36 - Ciclo de Refrescamento "RAS-only".

Tabela VI - Exemplo de Taxas de Refrescamento para DRAMs

\begin{tabular}{|lcc|}
\hline $\begin{array}{c}\text { INCLK } \\
(\mathrm{MHz})\end{array}$ & $\begin{array}{c}\text { Periodo de } \\
\mathrm{RR}=0\end{array}$ & $\begin{array}{c}\text { Refrescamento (us) } \\
\text { RR=01 }\end{array}$ \\
\hline 50 & 5.12 & 10.24 \\
40 & 6.40 & 12.80 \\
33 & 7.75 & $15.51 \star$ \\
16.5 & $15.51 \star$ & -- \\
\hline
\end{tabular}

* Atinge o limite de 15.625, requerido pelas DRAMs. 


\subsection{Temporização das Instruçōes}

O formato geral de todas as instruções segue a convenção de que a primeira palavra de instrução contém o código de operação, e as palavras subsequentes contêm o dado, ou o endereço imediato.

Na descrição de cada instrução do TMS34010 há um campo designado como "machine states", que especifica o número de estados da CPU necessários para a execução da instrução. Este campo pode conter até três valores, que aparecem como segue:

Machine State: <cache hit> + (<hidden states>),<cache disable>

O primeiro valor (cache hit) representa o número de estados necessários para a execução da instrução com a "cache" ativa, considerando que o código de operação da instrução assim como os operandos encontram-se totalmente contidos na "cache".

$O$ terceiro valor representa a situação onde a "cache" não se encontra ativa.

$O$ segundo valor refere-se a ciclos de gravação que ocorrem em paralelo com o final de uma instrução que está sendo executada.

Para algumas instruções como a PIXBLT, MOVE, MOVEB, LINE e FILL, o número de estados não é especificado, pois depende dos valores dos operandos implicados na instrução e do alinhamento e tamanho do "field" especificado para a instrução. $O$ tempo de execução destas instruções deve então ser calculado para cada caso em particular.

Além da "cache", o tempo de execução das instruções depende dos seguintes fatores:

a. o número de estados de espera, se utilizados

b. acesso à memoria local pelo hospedeiro

c. operações de refrescamento da tela

d. operações de refrescamento da DRAM 
e. solicitação do barramento por um dispositivo externo.

Para instruções gráficas como a FILL e PIXBLT, o tempo de execução é obtido pela adição do tempo de inicialização ( tempo para realizar conversões $X Y$, opções de janela e ajuste do canto), e o tempo para executar a transferência de dados para a memória.

Exemplos de cá́culo são encontrados na referência [1].

\subsection{Ferramentas para Desenvolvimento de Software}

\subsubsection{Introdução}

O TMS34010 dispõe do seguinte conjunto de ferramentas para desenvolvimento de "software", e para auxiliar a depuração do "hardware" [3]:

. Assembler

. Archiver

. Linker

. Utilitário para conversão de código

. Simulador

. Compilador $\mathbf{C}$

. Loader SDBL

Além destes, há um programa de depuração disponível para $\mathrm{PC}$, que pode ser utilizado para corrigir e refinar o "software" residente num sistema desenvolvido com o TMS34010, e interfaceado com um PC. 
Essas ferramentas podem ser instaladas nos seguintes sistemas:

a) $\mathrm{PCs}$

.TI-PC com MS-DOS

IBM-PC com PC-DOS

b) VAX

.VMS (a partir da revisão 3.7)

.DEC Ultrix

.Sistema Unix V

As ferramentas da linguagem Montadora para o TMS34010, criam e usam arquivos-objeto que estejam em "Common Object File Format", ou COFF. O formato objeto COFF facilita a programação modular. Neste formato, os arquivos-objeto contêm blocos separados (denominados seções) de código e dado, que podem ser carregados em diferentes espaços de memória.

\subsubsection{Assembler}

O Assembler converte os arquivos-fonte em linguagem Montadora, para arquivos-objeto em linguagem de máquina. Os arquivos fonte podem conter instruçōes, diretivos do Assembler, e diretivos macro. Os diretivos do Assembler podem ser usados para controlar o formato da listagem fonte, o alinhamento dos dados, e para se definir as seções do código fonte. 


\subsubsection{Archiver}

O Archiver permite a criação de bibliotecas. Pode-se por exemplo, criar uma biblioteca de macros, e neste caso, o Assembler pesquisa a biblioteca para buscar os macros que foram referenciados no arquivo fonte. Pode-se também criar uma biblioteca de arquivos objeto, e neste caso as referências externas serão buscadas na biblioteca durante a execução do Linker.

\subsubsection{Linker}

O Linker combina arquivos objeto num único módulo objeto executável. Quando cria o módulo executável, executa relocação e determina as referências externas. Os diretivos do Linker permitem que se combinem seçōes do arquivo objeto, símbolos para um endereço específico ou dentro de porções específicas da memória do TMS34010, e permitem definir ou redefinir símbolos globais.

\subsubsection{Utilitário para Conversão de Código}

A função deste utilitário é converter um arquivo objeto COFF, para o formato objeto hexadecimal da INTEL ou TEKTRONIX, pois a maioria dos programadores de EPROM não aceitam arquivos objeto COFF como entrada. $O$ arquivo convertido pode então ser utilizado pelo programador de EPROM.

\subsubsection{Simulador}

O simulador é uma ferramenta de depuração que possibilita a simulação em "software" das funções em "hardware" do TMS34010, e com a resolução de tela 
definida pelo usuário.

Seu principal objetivo é permitir uma simulação precisa do conjunto de instruções do TMS34010. É possível a simulação da cache, das interrupções, da interface do hospedeiro, e a simulação gráfica. Mas não é possível a simulação da temporização do vídeo, o refrescamento das memórias dinâmicas, e operações de registradores de deslocamento definidas pelos registradores de E/S.

O simulador mostra dois conjuntos separados de informação:

a. o estado da máquina, contendo os valores dos registradores dos arquivos A e B (ou os de VO), o valor do PC, SP, flags, do "status", o estado da cache, o tamanho do "pixel", etc, como é ilustrado na figura 37.

b. o ambiente gráfico, que permite a visualização de figuras ou imagens.

O simulador contém um conjunto de comandos que possibilitam:

. a alteração dos registradores e "flags", individualmente ou por bloco;

- a alteração ou visualização do conteúdo de uma posição ou um bloco de memória;

. estabelecer "breakpoints";

. executar o programa passo a passo, ou por grupo de instruções, ou o programa completo;

- modificar parâmetros como o tamanho do "pixel", o estado da cache, o tamanho do "field", etc, de forma a alterar o estado da máquina.

\subsubsection{Programa de Depuração}

Esta é uma outra ferramenta para se depurar o "software" em desenvolvimento, e deve ser utilizada com uma placa gráfica que contenha o TMS34010. É semelhante 
ao Simulador, dotado de um conjunto de comandos semelhantes, diferenciando do mesmo por acessar realmente o GSP, permitindo então a programação da temporização do vídeo, o refrescamento das memórias dinâmicas e as operações de registrador de deslocamento.

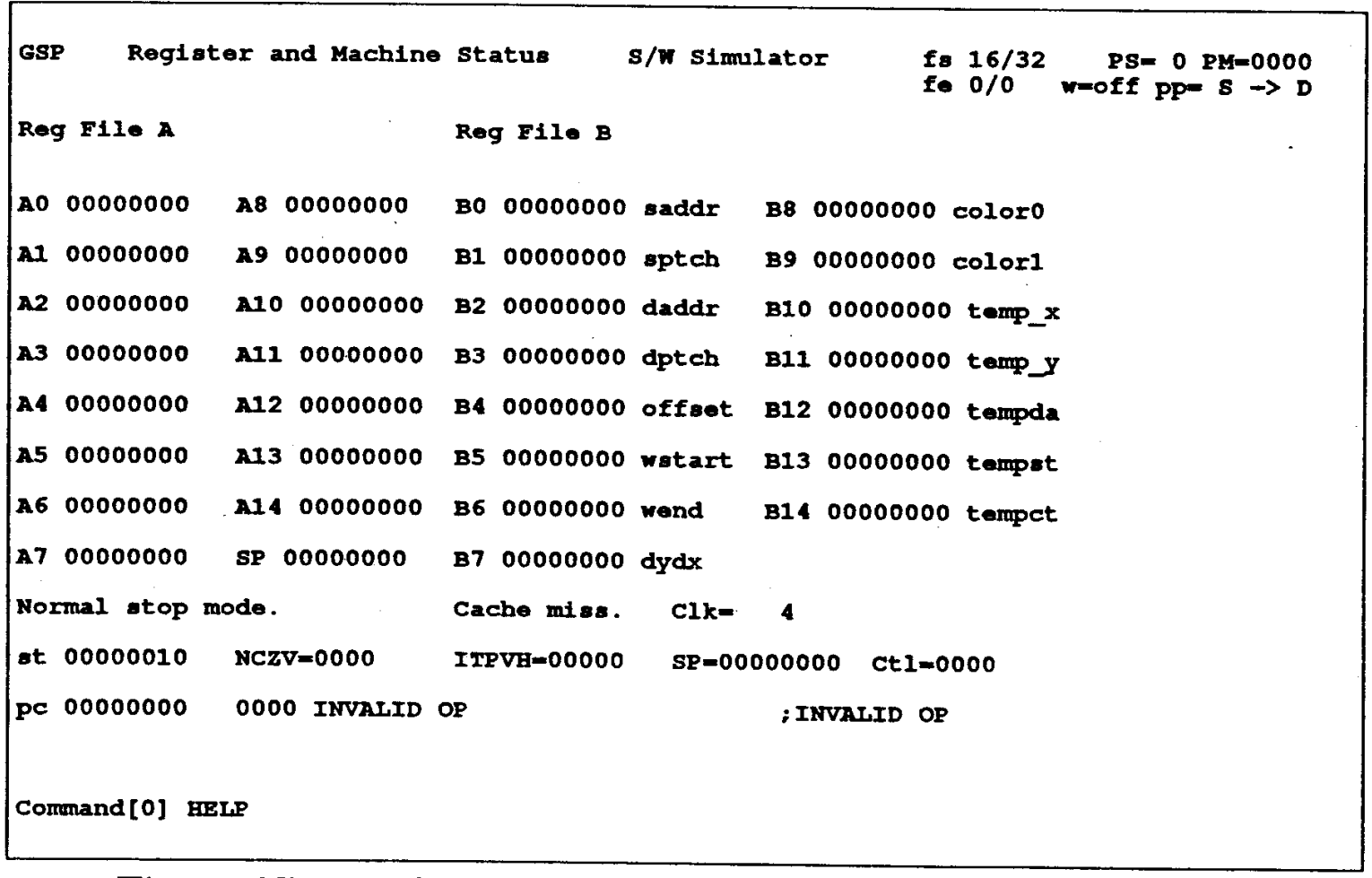

Figura 37: Estado da Máquina Mostrado pelo simulador 


\subsubsection{Loader SDBL}

Este programa permite que um programa objeto seja carregado na memória local do GSP, através dos registradores da interface do hospedeiro. 


\section{Capítulo IV}

\section{Sistemas Desenvolvidos}

Dois sistemas foram desenvolvidos baseados no processador gráfico TMS34010: um com 16 cores, e outro com 256 níveis de cinza, ambos contendo um "mouse".

O sistema com 16 cores foi inspirado nas notas de aplicações do fabricante [2], e foi implementado por não haver na época um sistema de desenvolvimento.

O objetivo do seu desenvolvimento foi a avaliação e teste não só da parte de "hardware", como também da parte de programação, utilizando como hospedeiro um microcomputador tipo PC/XT. Problemas relativos às equações das PALs foram detetados na documentação deste sistema.

Com base na experiência adquirida a partir do sistema com 16 cores, foi implementado o sistema com 256 níveis de cinza, contendo expansão da memória de sistema e de vídeo, e com a lógica de seleção realizada por PALs.

Estes dois sistemas serão descritos a seguir.

\subsection{Sistema Gráfico com 16 Cores}

O sistema com 16 cores é constituído pelos seguintes blocos, conforme ilustrado na figura 38:

a) o processador gráfico TMS34010, que possui barramentos independentes para comunicação com um processador hospedeiro e com a memória local, além de gerar os sinais de sincronismo para vídeo; 
b) a memória de sistema, implementada com memórias RAM dinâmicas convencionais (DRAMs), para armazenamento do programa a ser executado; c) a memória de vídeo, constituída por memórias DRAMs específicas para aplicaçōes de vídeo (VRAMs), para armazenamento das imagens que se deseja visualizar na tela do monitor de vídeo;

d) uma interface serial para conecção de um "mouse";

e) um circuito para controle da temporização de vídeo, que inclui os sinais de controle para as saídas seriais das VRAMs;

f) uma interface para vídeo, que utiliza uma "Color Palette", um circuito integrado que contem uma tabela de cores endereçável pelos dados de entrada, e gera os 3 sinais de saída analógica para vídeo, para monitores CRT do tipo RGB.

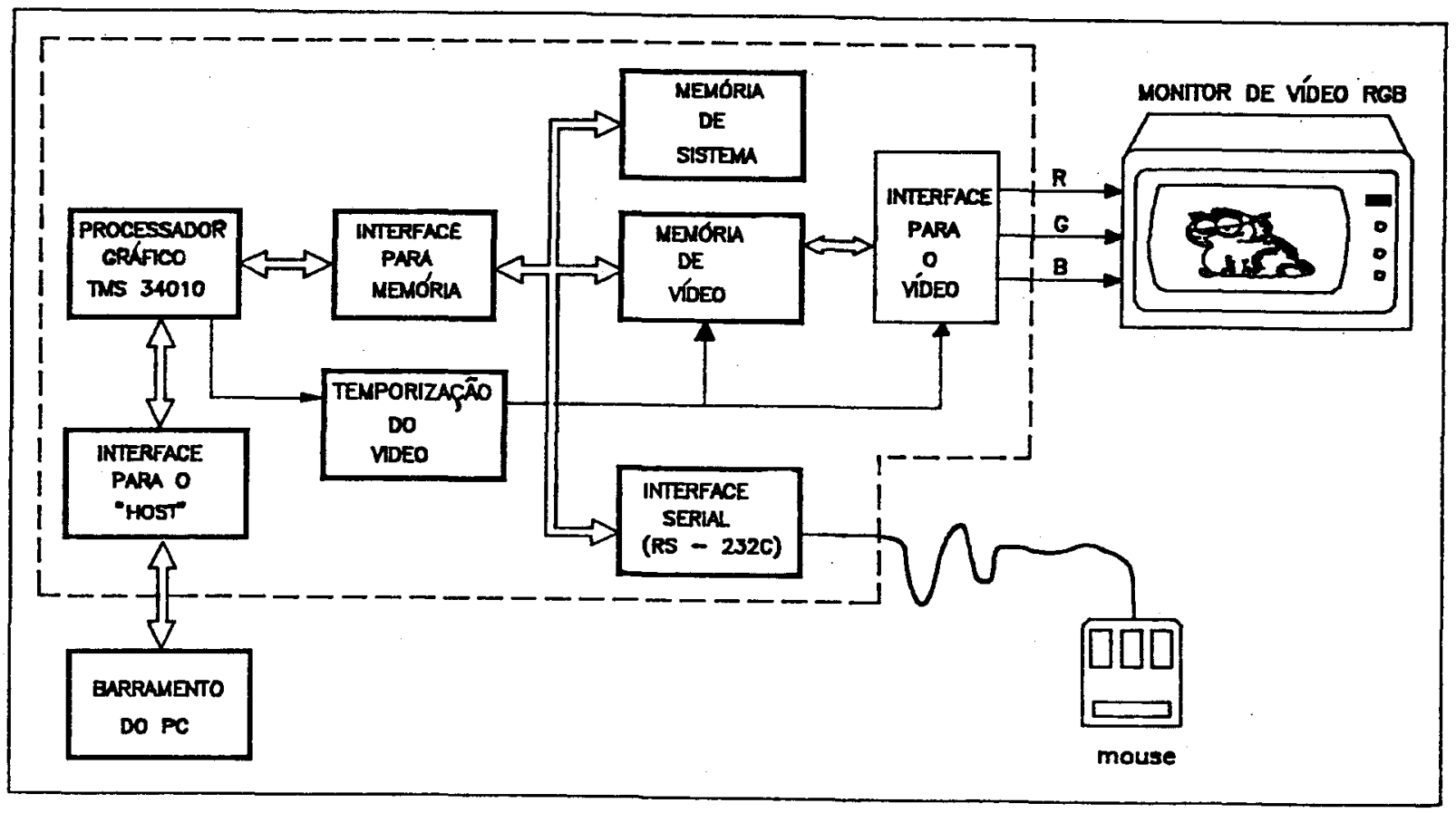

Figura 38 - Diagrama em Blocos do Sistema Gráfico com 16 Cores 
Este sistema apresenta as seguintes características:
a) frequência externa do TMS34010: 20MHz;
b) frequência do pixel: $10 \mathrm{MHz}$;
c) resolução da tela: 512 "pixels", 256 linhas, com "pixels" de 4 bits;
d) interface serial RS232-C: para coneç̧ão de um "mouse", com taxa de transmissão de 1200 Bauds, 1 bit "stop", sem paridade;
e) memória de sistema (DRAM): 128 Kbytes;
f) memória de vídeo (VRAM): 128 Kbytes.

Cada um dos blocos do diagrama da figura 38, será explicado nos itens seguintes.

\subsubsection{Descrição das Interfaces}

\subsubsection{Interface com o Processador Hospedeiro}

Como processador hospedeiro foi utilizado um microcomputador tipo PC/XT. Neste microcomputador são gerados e armazenados os programas-fonte, bem como é feita sua compilação e depuração, e são armazenados os programas-objeto, dados e as imagens que se pretende visualizar.

A função do processador hospedeiro em relação ao "hardware" do sistema gráfico, é somente a transferência do programa objeto ou imagem, para a memória do sistema gráfico, já que este não contém memórias do tipo EPROM.

Como já visto anteriormente, o GSP contém um conjunto independente de sinais para interligação com um hospedeiro. A figura 39 mostra que o duto de dados dedicado ao hospedeiro, é conectado ao duto de dados do PC através de um "buffer" bidirecional (74ALS245), habilitado pelo sinal /HCS, e com a direção determinada pelo 


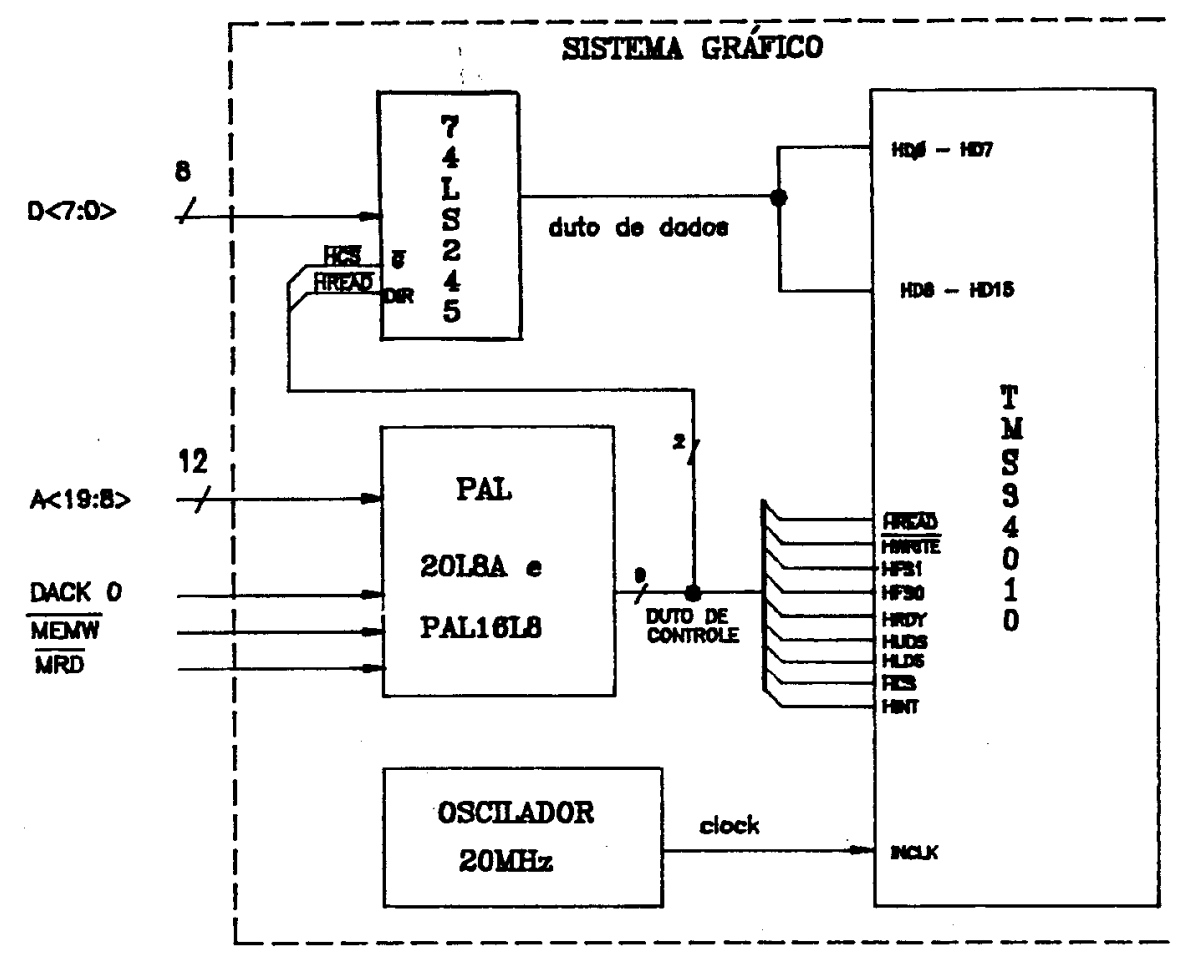

Figura 39 - Interface com o Hospedeiro.

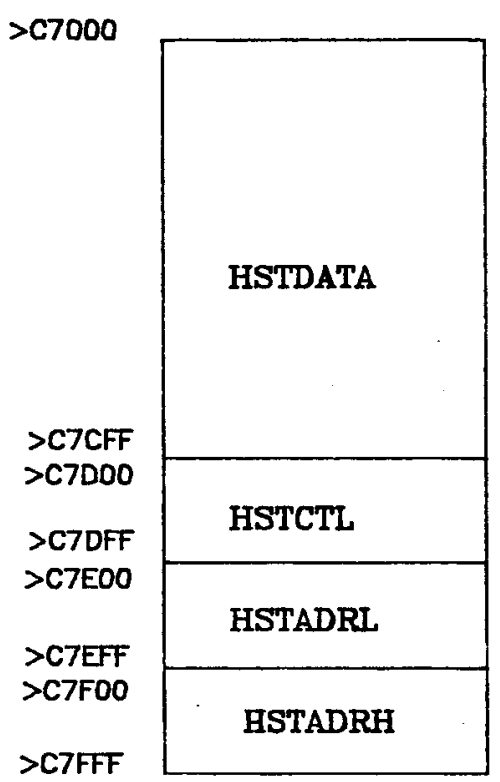

Figura 40 - Mapeamento dos Registradores Dedicados ao Hospedeiro 
sinal /HREAD.

Como o duto de dados do PC é de 8 bits e o do GSP é de 16 bits, dois sinais do GSP, HUDS E HLDS, controlados pela linha de endereço A0 do PC, designam o "byte" mais e menos significativo acessado.

Os registradores do GSP para comunicação com o processador hospedeiro sao mapeados no espaço de endereço do $\mathrm{PC}$, como mostrado na figura 40 . 0 registrador HSTCTL é acessado pelo processador hospedeiro como um único registrador de 16 bits, mas é acessado pelo GSP como dois registradores de E/S separados, HSTCTLL e HSTCTLH. As duas entradas HFSO e HFS1, selecionam um entre estes quatro registradores. Na lógica de endereçamento destes registradores é utilizada uma PAL20L8, que também gera a maior parte dos sinais de controle para o GSP.

As equações programadas na PAL 20L10A foram obtidas do fabricante [2], e são apresentadas na figura 41. Essas equações definem o mapeamento dos registradores do GSP, no espaço de memória do PC, conforme figura 40. Assim, sempre que o processador do $\mathrm{PC}$ tiver acesso à memória, dentro da faixa de endereço que inicia em C7000H e termina em C7FFFH, um sinal de seleção do PC será gerado (/HCS), se DACK0 estiver em nível lógico alto, e se simultaneamente ocorrer uma das seguintes condições:

. o sinal de leitura em memória, /MRD, estiver ativo em "0";

. o sinal de gravação em memória, /MWR, estiver ativo em "0".

Nessas equações o sinal DACK0 indica uma operação em memória, ou uma operação DMA, e seu uso evita que os ciclos de refrescamento do PC afetem o sistema gráfico.

Como o sistema gráfico implementado não contém memórias do tipo EPROM, após a transição positiva do sinal RESET, o sinal /HCS é mantido em nível lógico alto, para que o GSP entre no modo "hospedeiro presente". Neste modo, como já visto anteriormente no capítulo 3, o GSP é levado automaticamente ao estado "halt", e se mantém neste estado até que o "hospedeiro", no caso o PC, desative o "halt", programando " 0 " no bit HLT do registrador de controle HSTCTL. 


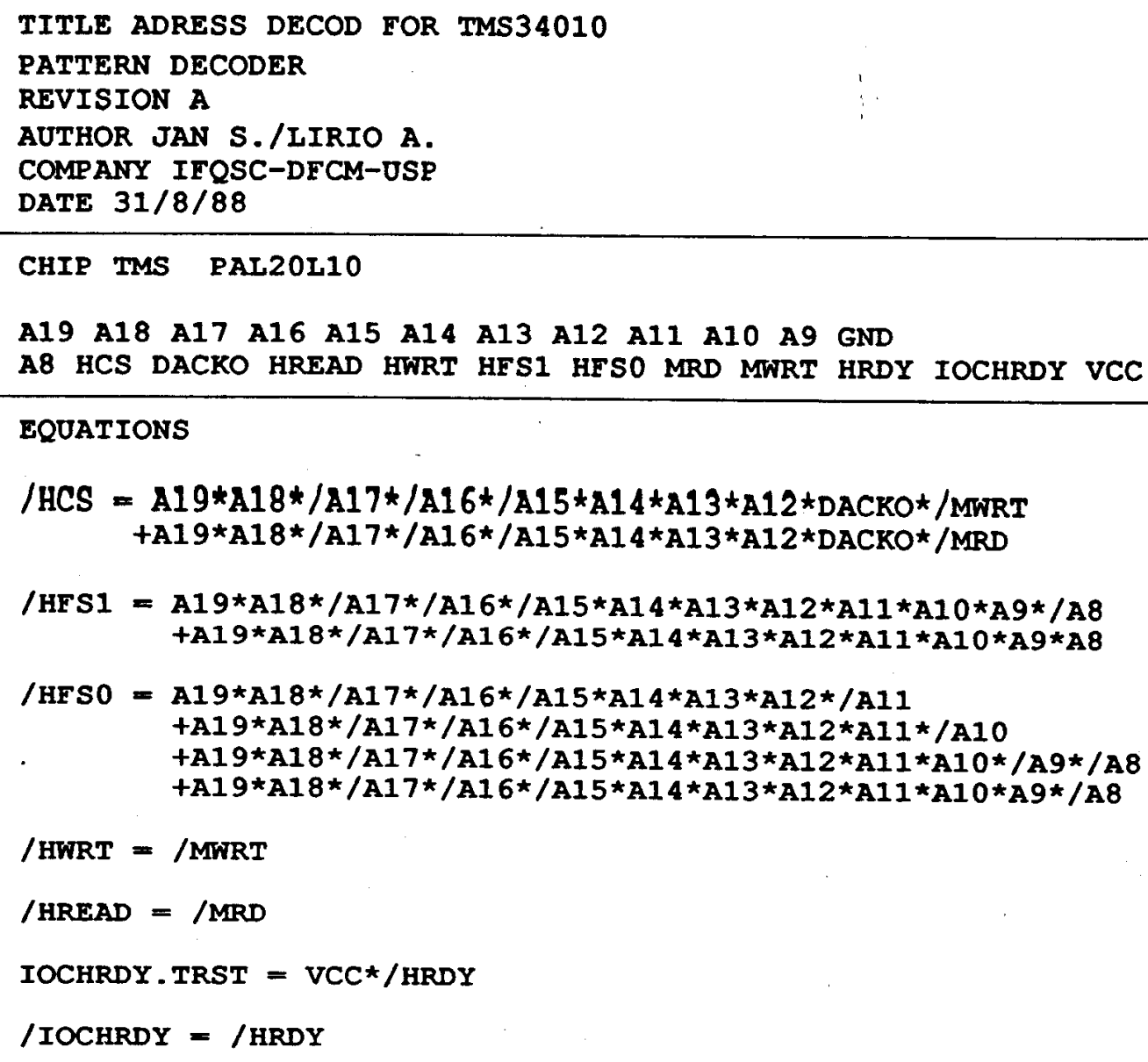

Figura 41: Equações da PAL 20L10 para a Interface do Hospedeiro

Enquanto o GSP permanece em "halt", o PC transfere o programa objeto para a memória de sistema do GSP, através de um "software" que usa o seguinte procedimento:

1.) programa o registrador de controle HSTCTL para leitura e/ou gravacao;

2.) transfere o programa objeto para a memória de sistema do GSP, utilizando os registradores dedicados ao hospedeiro;

3.) grava o endereço inicial do programa no endereço de desvio da interrupção NMI;

4.) ativa a interrupção NMI e o modo de interrupção; 
5.) desabilita o estado "halt".

A intermupção NMI tem a prioridade mais alta, não podendo ser desativada. Após a execução do procedimento 5, o GSP busca o endereço inicial do programa a ser executado, no endereço de desvio da interrupção NMI, armazena-o no contador de programa (PC), e inicia a execução do programa.

\subsubsection{Interface para a Memória Local}

Este sistema foi implementado com dois tipos de memória diferentes: memórias dinâmicas convencionais (DRAM) e memórias específicas para aplicações de vídeo (VRAM), como ilustrado na figura 42.

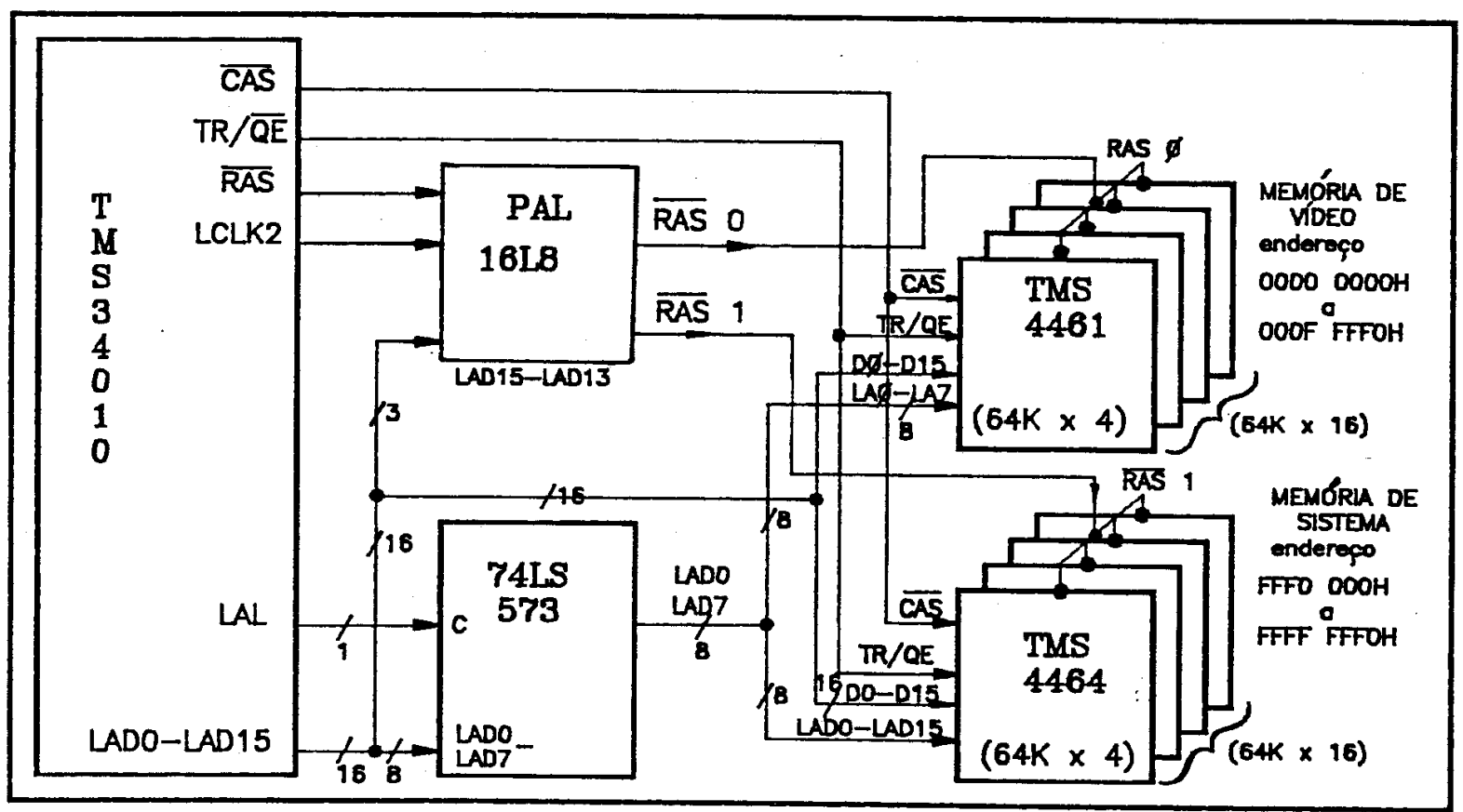

Figura 42 - Interface para a Memória Local 
Os 128 Kbytes de DRAMs constituem a memória de sistema, sendo organizada como um banco de quatro DRAMs de 64Kx4. Os 128 Kbytes de VRAMs constituem a memória de vídeo ou "frame buffer", sendo também organizada como um banco de quatro VRAMs de $64 \mathrm{Kx} 4$.

A VRAM utilizada, TMS4461, contem internamente 4 registradores de deslocamento de 256 bits cada um, que podem operar numa frequência máxima de 25 MHz. Assim, os registradores de deslocamento do sistema de memória de vídeo implementado, permitem um valor máximo de 4096 bits por linha de varredura, sem a adição de registradores externos, e com a frequência de "pixel" limitada a $25 \mathrm{MHz}$. Desta forma, a resolução de tela em relação ao número de "pixels" por linha, pode ser organizada da maneira desejada, como por exemplo 1024 "pixels" de 4 "bits", ou 512 "pixels" de 8 bits, desde que não seja ultrapassado o limite em frequência, e o número máximo de bits dos registradores de deslocamento, estabelecidos pelo sistema de memória de vídeo.

O refrescamento destas memórias é realizado automaticamente pelo GSP. Após "reset", são executados oito ciclos de memória "RAS-ONLY", para leva-las aos seus estados iniciais, e em seguida os ciclos de refrescamento são executados automaticamente a cada 32 ciclos de "clock".

É importante salientar que, quando a entrada /RESET do GSP torna-se ativa, o refrescamento não é executado, e o conteúdo das memórias pode não ser válido após "reset".

Como já visto no item 3.10, no barramento tri-multiplexado LAD0-LAD15 é gerado o endereço da linha, seguido do endereço da coluna e finalmente os 16 bits de dados. A multiplexação é feita de forma tal que, sendo selecionado um grupo de 8 pinos LAD entre os pinos LADO - LAD10 (figura 43) para o endereçamento de memórias de 64K, sempre é gerado o endereço correto da linha e da coluna. Para DRAMs maiores que 64K, é necessário uma lógica adicional para multiplexar os bits de endereço restantes [2]. 


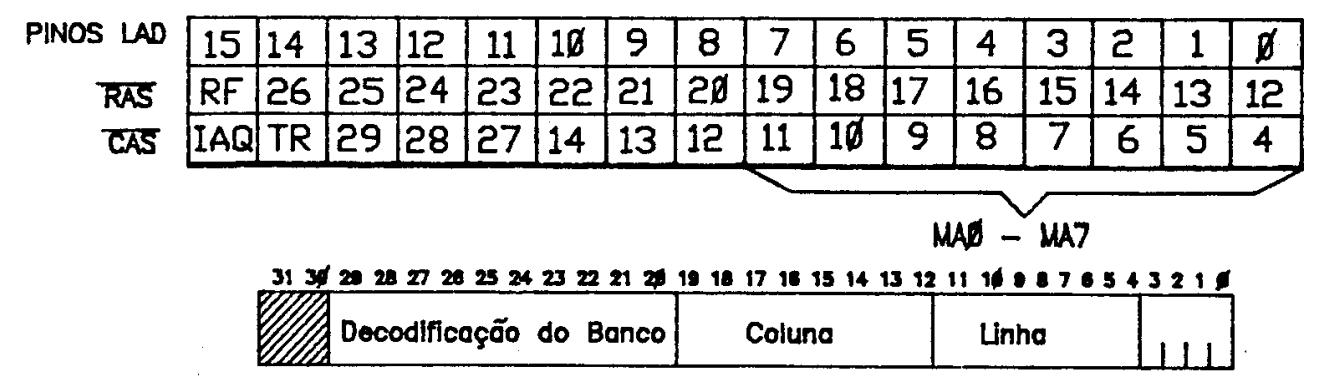

Figura 43 - Bits de Endereço no Duto Multiplexado LAD0 - LAD15.

No projeto em questão, foram utilizados os primeiros oito pinos, LAD0 - LAD7, para o endereçamento das memórias DRAMs e VRAMs. O "latch" (74ALS573) mostrado na figura 42, tem a função de armazenar o endereço da coluna durante a transição negativa do sinal LAL, já que este não é válido durante a transição negativa de /CAS.

O mapeamento das memórias e da interface serial é mostrado na figura 44.

\begin{tabular}{|c|c|c|c|c|c|}
\hline \multirow{3}{*}{$\begin{array}{l}>00000000 \\
>000 \mathrm{~F} \text { FFO }\end{array}$} & \multirow{3}{*}{$\begin{array}{c}\begin{array}{c}\text { Memoria de Vídeo } \\
\text { (128 kbytes) }\end{array} \\
\text { Area não mapeada }\end{array}$} & \multirow{2}{*}{\multicolumn{2}{|c|}{$\begin{array}{c}\text { Bits } \mathrm{p} / \mathrm{a} \\
\text { seleção }\end{array}$}} & \multirow{3}{*}{$\begin{array}{r}\text { dispositivo } \\
\text { selecionado }\end{array}$} & \multirow{3}{*}{$\begin{array}{l}\text { Sinal de } \\
\text { Seleçäo }\end{array}$} \\
\hline & & & & & \\
\hline & & A26 & 125 & & \\
\hline \multirow[t]{2}{*}{$>0200 \quad 0000$} & & 1 & 1 & Memórla de & $\overline{\overline{R A S}} 1$ \\
\hline & Interface Serial & 0 & 0 & $\begin{array}{l}\text { Memonio de } \\
\text { Vídeo (NRAM) }\end{array}$ & $\overline{R A S}$ \\
\hline$>020 F$ FFFO & Area não mapeada & 0 & 1 & $\begin{array}{c}\text { Interfoce } \\
\text { Serial } \\
\end{array}$ & \\
\hline >FFFO 0000 & $\begin{array}{c}\text { Memória de sistema } \\
\text { (128 kbytes) }\end{array}$ & & & & \\
\hline
\end{tabular}

Figura 44 - Mapeamento das Memórias e da Interface Serial. 
É interessante lembrar aqui, que somente a quarta parte do espaço de endereço disponível do GSP é implementada externamente, pois os bits de enderę̧o 30 e 31 não são gerados no duto multiplexado. Assim, externamente, a referência à posição FFFFFFF0H será a mesma que a 3FFFFFFOH, ou a 7FFFFFFOH, ou a BFFFFFFOH. Os bits 30 e 31 são irrelevantes externamente, mas internamente os registradores de E/S são mapeados em memória, e os 32 bits de endereço são usados.

A lógica de seleção das memórias é feita pela PAL 16L8, programada de acordo com as equações mostradas na figura 45 .

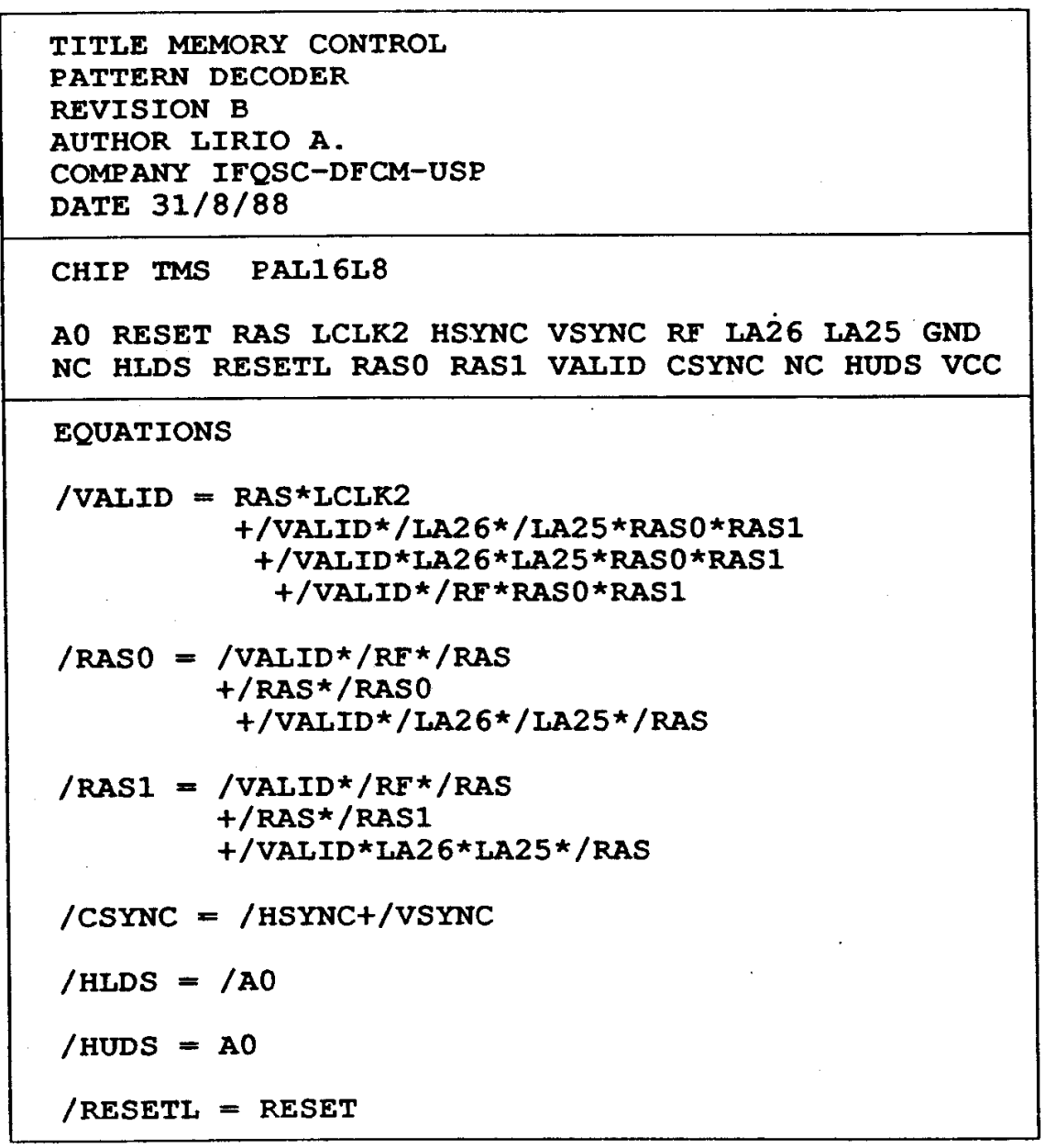

Figura 45 - Equações da PAL 16L8 para Seleção das Memórias Sistema com 16 Cores. 
A seleção da interface serial 8251A é feita por um circuito lógico, à parte.

Nas equações da figura 45, o sinal NALID sempre é gerado no início de um ciclo de memória. Torna-se ativo, se o sinal /RAS do GSP não estiver ativo (em "1"), e com LCLK2 também em "1". Mantém-se ativo se durante a geração do endereço da linha, o bit /RF também o for, indicando que este será um ciclo de refrescamento de memória, ou se um dos bancos de memória for selecionado através dos bits de endereço da linha. $\mathbf{E}$ desabilitado assim que um dos sinais de seleção das memórias, /RAS0 ou /RAS1, tornar-se ativo.

O sinal /RAS0 seleciona a memória de vídeo. Torna-se ativo se /VALID e se /RF também estiverem, indicando um ciclo de refrescamento de memória, ou se /VALID estiver ativo e se a memória for selecionada através dos bits de endereço da linha especificados na equação. Mantém-se ativo enquanto o sinal /RAS, gerado pelo GSP se mantiver ativo.

O sinal /RAS1 seleciona a memória de sistema e é gerado de forma semelhante ao sinal /RASO.

A figura 46, ilustra a geração destes sinais para os diversos tipos de ciclos de memória que podem ocorrer.

Com relação aos ciclos de refrescamento da tela, as saídas seriais das VRAMs são mantidas permanentemente habilitadas, já que existe um único banco de memória de vídeo. 


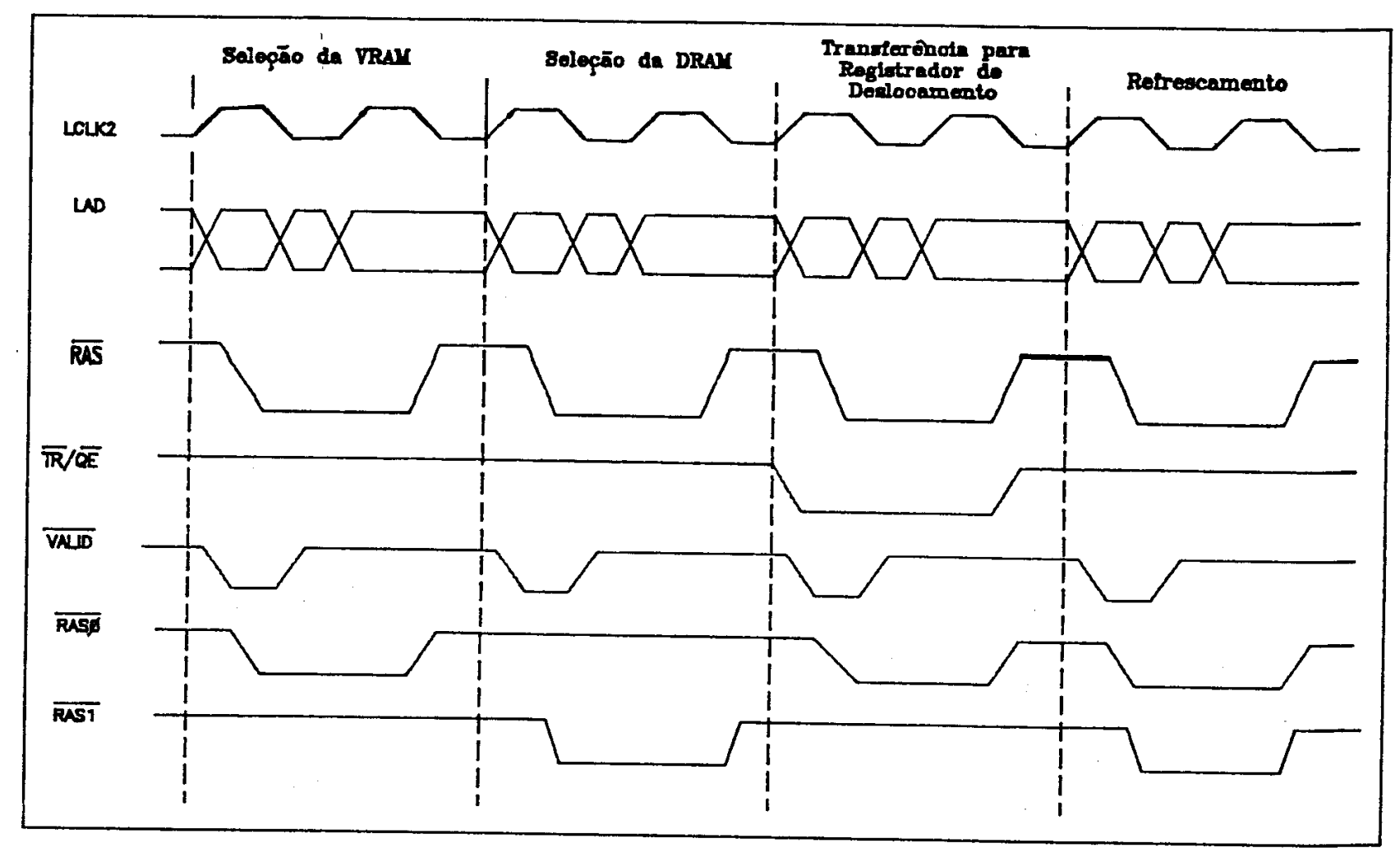

Figura 46 - Diagrama de Tempo Ilustrando os Sinais de Seleção das Memórias, para o Sistema com 16 Cores

\subsubsection{Circuito de Saída para Vídeo}

Neste circuito foi usado uma "Color Pallete" (TMS34070), circuito integrado que contém uma tabela de cores endereçável pelos dados de entrada DA3-DA0 e DB3-DB0.

Este "chip" contém 3 canais de saída analógica para vídeo, para monitores CRT do tipo RGB, e opera numa frequência de até $36 \mathrm{MHz}$. Isto corresponde a uma resolução de tela de até 800 × 600 "pixels", com o monitor de vídeo no modo não entrelaçado, e frequência vertical de $60 \mathrm{~Hz}$ [15].

O TMS34070 suporta "frame buffers" com até 4 bits/"pixels", e permite a obtenção simultânea de até 16 cores diferentes, selecionadas entre 4096 possíveis. 
0 diagrama em blocos simplificado da "Color Pallete" é mostrado na figura 47. Internamente a tabela de cores deste "chip" contem 16 registradores de 14 bits, sendo 2 bits para atributo ("overlaying" e repetição de cor), e os demais para cores.

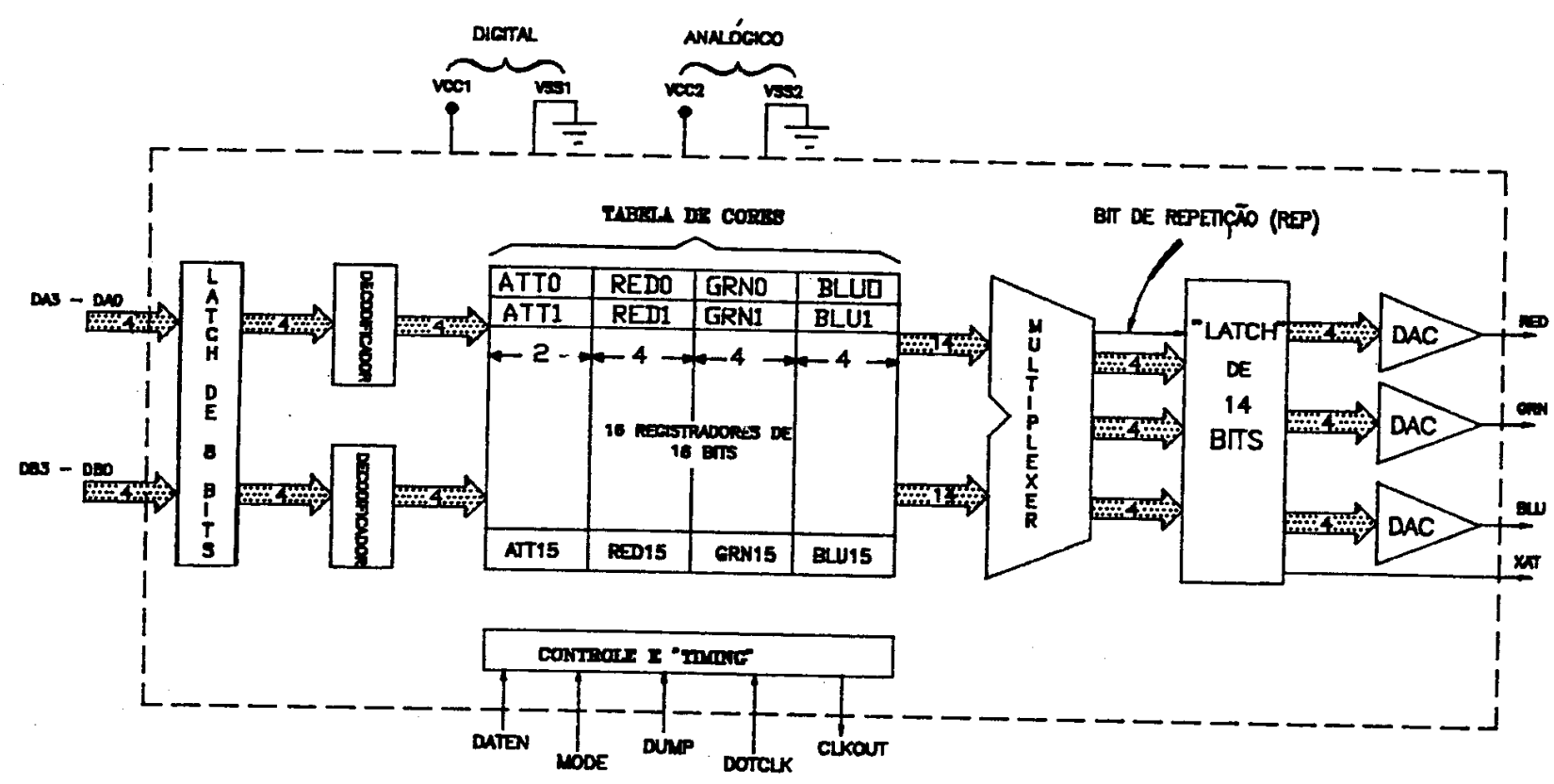

Figura 47 - Diagrama em Blocos da "Color Palette".

Os bits de cores são divididos em 3 grupos de 4 bits, sendo um grupo designado para a cor vermelha(R), outro para verde(G), e o último para azul(B). Os 12 bits para cor permitem que se tenha até 4096 cores diferentes. Cada "pixel" de 4 bits representa um ponteiro para um dos 16 registradores da tabela de cores. O conteúdo do registrador selecionado é utilizado para alimentar os conversores D/A internos ao TMS34070. Sendo cada conversor D/A de 4 bits, isto possibilita até 16 níveis de intensidade para cada cor, a vermelha (R), a verde (G) e a azul (B). A figura 48 mostra a correspondência de cada bit destes registradores com as entradas DA3-DA0 e DB3-DB0.

Toda a temporização interna da "Color Palette" é gerada pela entrada 
DOTCLK. 0 período do sinal aplicado a essa entrada representa o tempo durante o qual um "pixel" é gerado para o monitor de vídeo. Este sinal é ainda dividido por 2 e aplicado à saída CLKOUT.

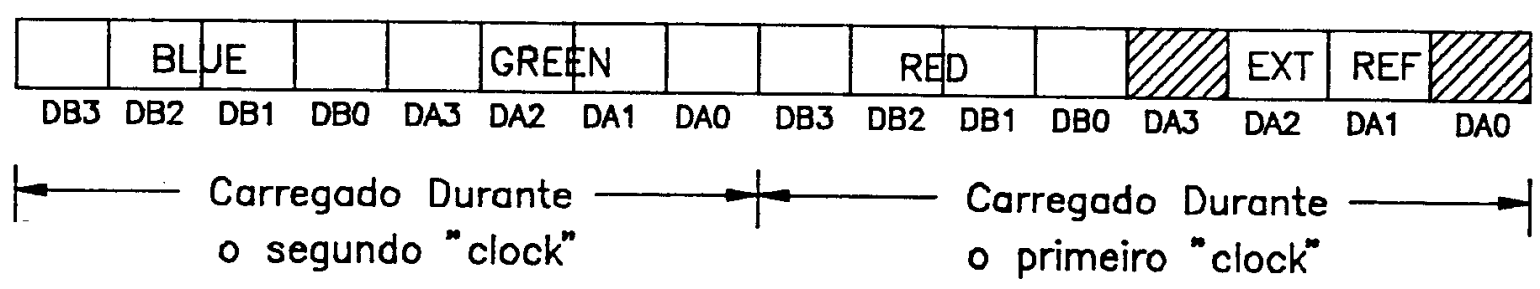

Figura 48 - Registrador da Tabela de Cores

O TMS34070 permite 4 modos diferentes de carregar a tabela de cores:

a. Frame-Load: carrega a tabela armazenada na memória de vídeo, no início de cada "frame".

b. Command-Load: carrega a tabela somente quando ocorrer um comando para carregar.

c. Line-Load: carrega a tabela no início de cada linha de varredura.

d. Dump: coloca o conteúdo da tabela na memória, durante a linha de varredura selecionada.

No sistema implementado, a "Color Palette" é conectada para operar no modo "frame load", com o sinal NSYNC aplicado ao pino MODE, e com o pino DUMP em zero lógico. Desta forma, a tabela de cores é carregada a cada retraço vertical, com os dados armazenados na primeira linha horizontal da memória de vídeo.

O pino DATEN é conectado a um sinal derivado do /BLANK, que indica a ocorrência de retraço horizontal ou vertical, intervalo de tempo em que a entrada de dados na "Color Palette" é bloqueada.

O diagrama de tempo da figura 49 mostra o conjunto de sinais para a "Color Palette". Cada transição negativa na entrada MODE indica ao TMS34070 que 
ocorrerá o carregamento da tabela de cores durante a próxima linha (linha 0). Esta transição negativa ocorre sempre no início do "frame buffer", e a linha que contém a tabela de cores é a primeira do "frame buffer". Esta linha não é exibida, é apagada.

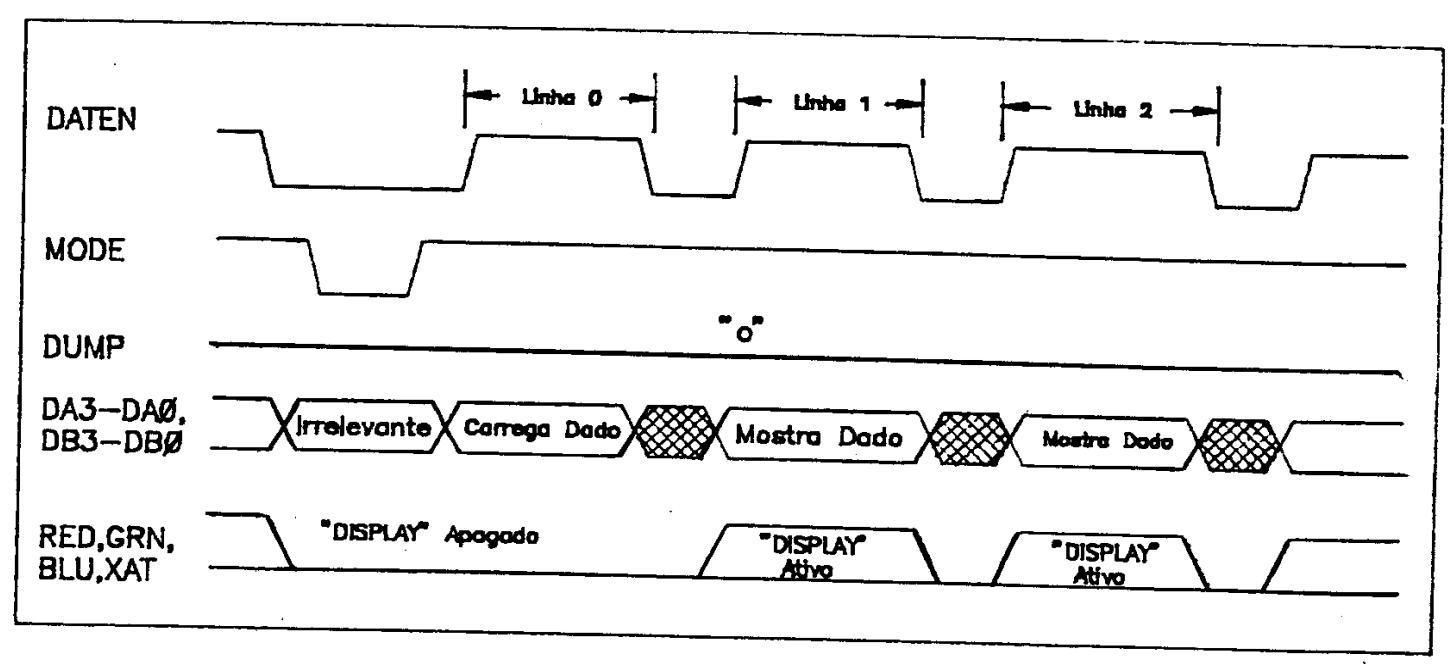

Figura 49 - Diagrama de Tempo para a "Color Palette"

A figura 50 mostra o diagrama de tempo para a operação de carregamento da tabela de cores, com mais detalhes. A primeira transição positiva no pino DATEN, após a transição negativa no pino MODE, é interpretada como um sinal para o TMS34070 iniciar o carregamento da tabela de cores, a partir dos dados das entradas DA3-DA0 e DB3-DB0. O carregamento é completado após um total de 32 períodos de "clock", e os dados subsequentes, pertencentes à linha 0, são ignorados. O TMS34070 apaga o feixe do monitor durante toda a linha 0 .

A próxima transição negativa de DATEN marca o fim da linha 0. O TMS34070 começa então a enviar os dados para o vídeo na próxima transição positiva de DATEN, o que marca o início da linha 1. Os dados das entradas DA3-DA0 e DB3-DB0 são armazenados a cada transição positiva de CLKOUT.

A figura 51 ilustra o diagrama de tempo para o início de cada linha ativa. Nesta figura pode-se observar que o primeiro "pixel" a ser mostrado na tela é aquele das entradas DA3-DA0, e que existe um atraso de 6 períodos de "clock" destas entradas 
para as correspondentes transições nas saídas R, G e B. Para as entradas DB3-DB0, há um atraso adicional de meio período de "clock".

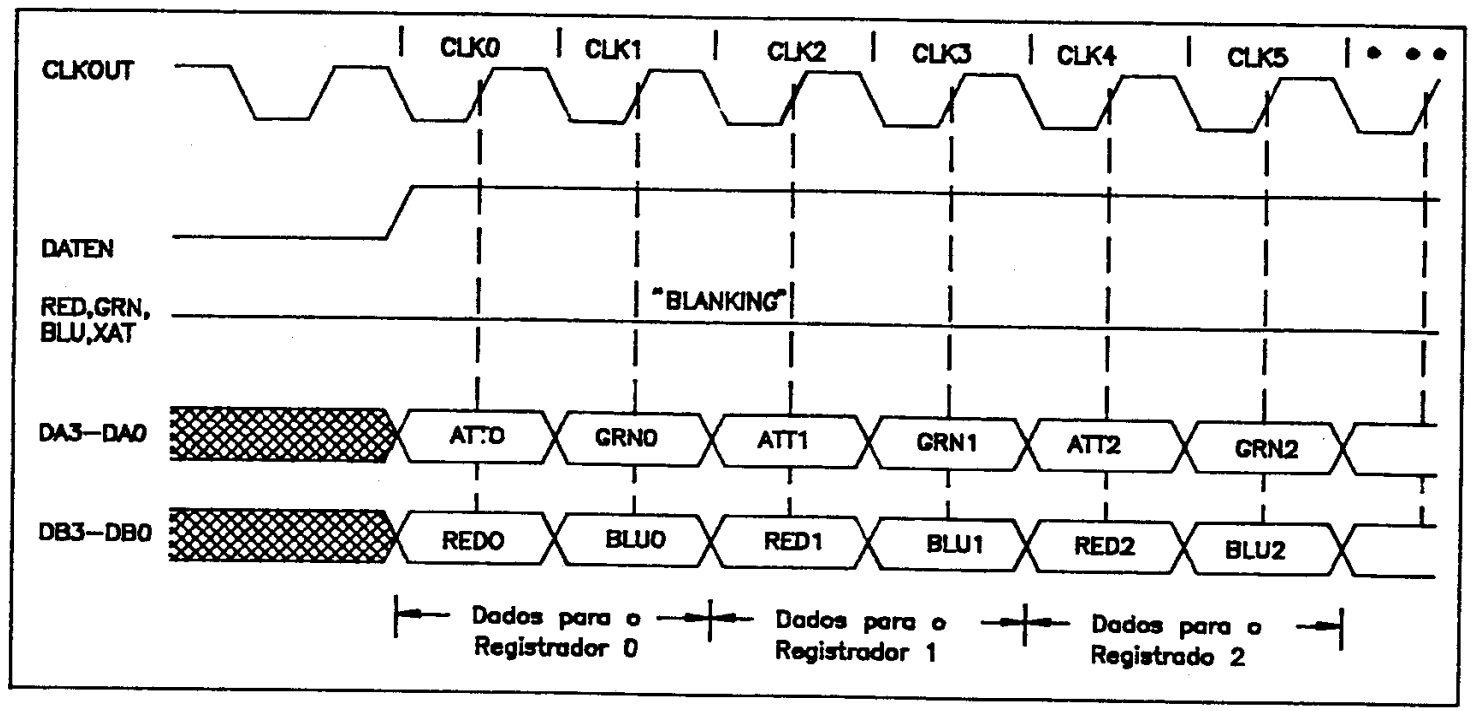

Figura 50 - Diagrama de Tempo para o Carregamento da Tabela de Cores

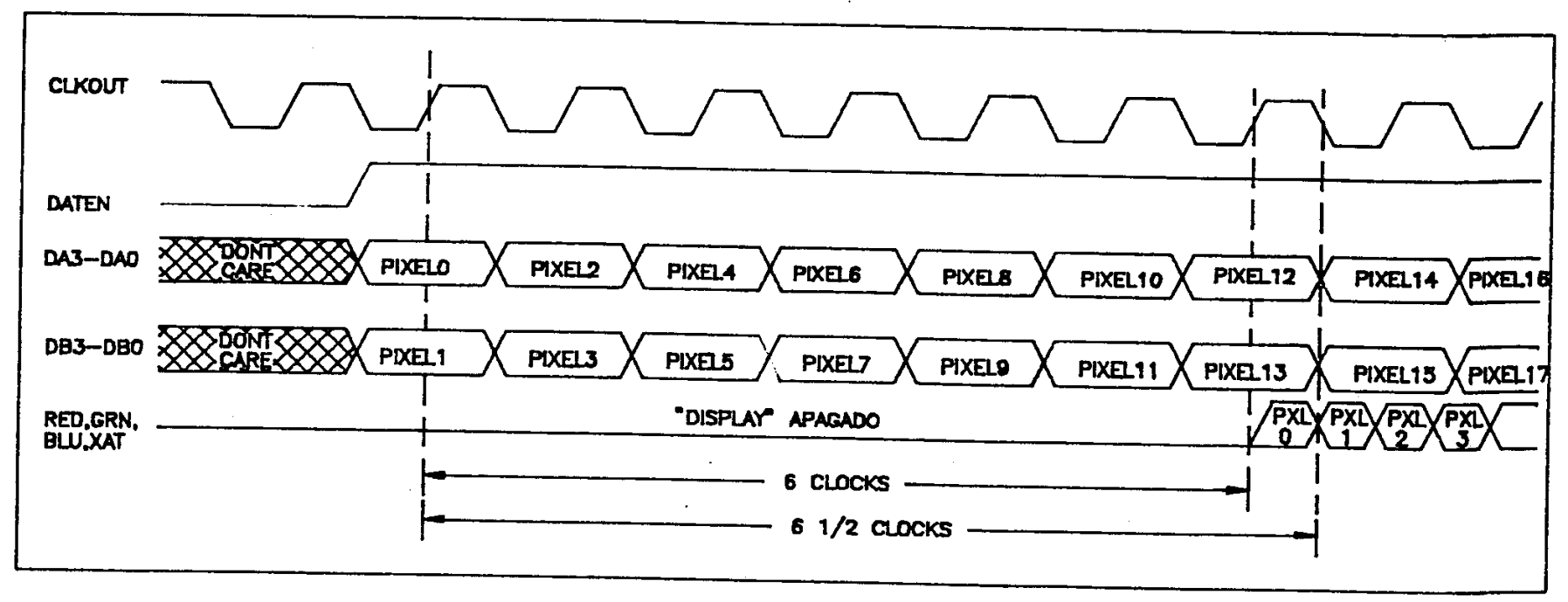

Figura 51 - Diagrama de Tempo para o Início da Linha Ativa 
Os "pixels" são transferidos da VRAM para a "Color Palette" através de dois multiplexers (74ALS157), com os "pixels" pares aplicados a um dos multiplexers, e os ímpares a outro, como é ilustrado na figura 52. Os multiplexers são usados porque o duto de dados serial do "frame buffer " é organizado em 16 bits, e a "Color Palette" consegue armazenar somente 8 bits (dois "pixels" de 4 bits) de cada vez.

\subsubsection{Circuito de Temporização de Vídeo}

A função do circuito de temporização de vídeo é gerar os sinais de sincronismo para a "Color Palette", para os multiplexers e para as saídas seriais das memórias VRAMs. Estes sinais são gerados a partir do sinal INCLK de $20 \mathrm{MHz}$, do TMS34010, e a frequência dos mesmos é determinada pela resolução da tela escolhida.

A figura 52 mostra o diagrama lógico deste circuito, e a figura 53 mostra o diagrama de tempo.

Na figura 52 os flip-flops tipo D contidos no 74ALS74, são utilizados como divisores por 2.

A resolução de tela escolhida para este sistema foi de 256 linhas/512 "pixels", com 4 bits por "pixel", e com o monitor CRT no modo CGA. Na verdade somente 255 linhas são mostradas, já que a primeira linha da memória de vídeo é utilizada para armazenar os dados da "Color Palette". Com esta resolução de tela somente metade do "frame buffer" é ocupado, e desta forma a memória de vídeo pode conter até duas imagens.

Para se ter os 512 "pixels" por linha de varredura, a frequência de "pixel" deve ser de $10 \mathrm{MHz}$. Como a "Color Palette" consegue armazenar dois "pixels" a cada meio período do sinal aplicado à entrada /A/B dos multiplexers, o sinal destas entradas deve ser quatro vezes mais lento do que a frequência de "pixel", ou seja 2,5 MHz. As saídas seriais das memórias de vídeo por sua vez, liberam 4 "pixels" a cada período de "clock" serial. Assim a frequência do "clock" serial das memórias VRAMs deve ter o mesmo valor da frequência dos multiplexers, isto é, 2,5 MHz.

$\mathrm{Na}$ figura 52 a frequência de "pixel", $10 \mathrm{MHz}$, é obtida dividindo-se INCLK por 


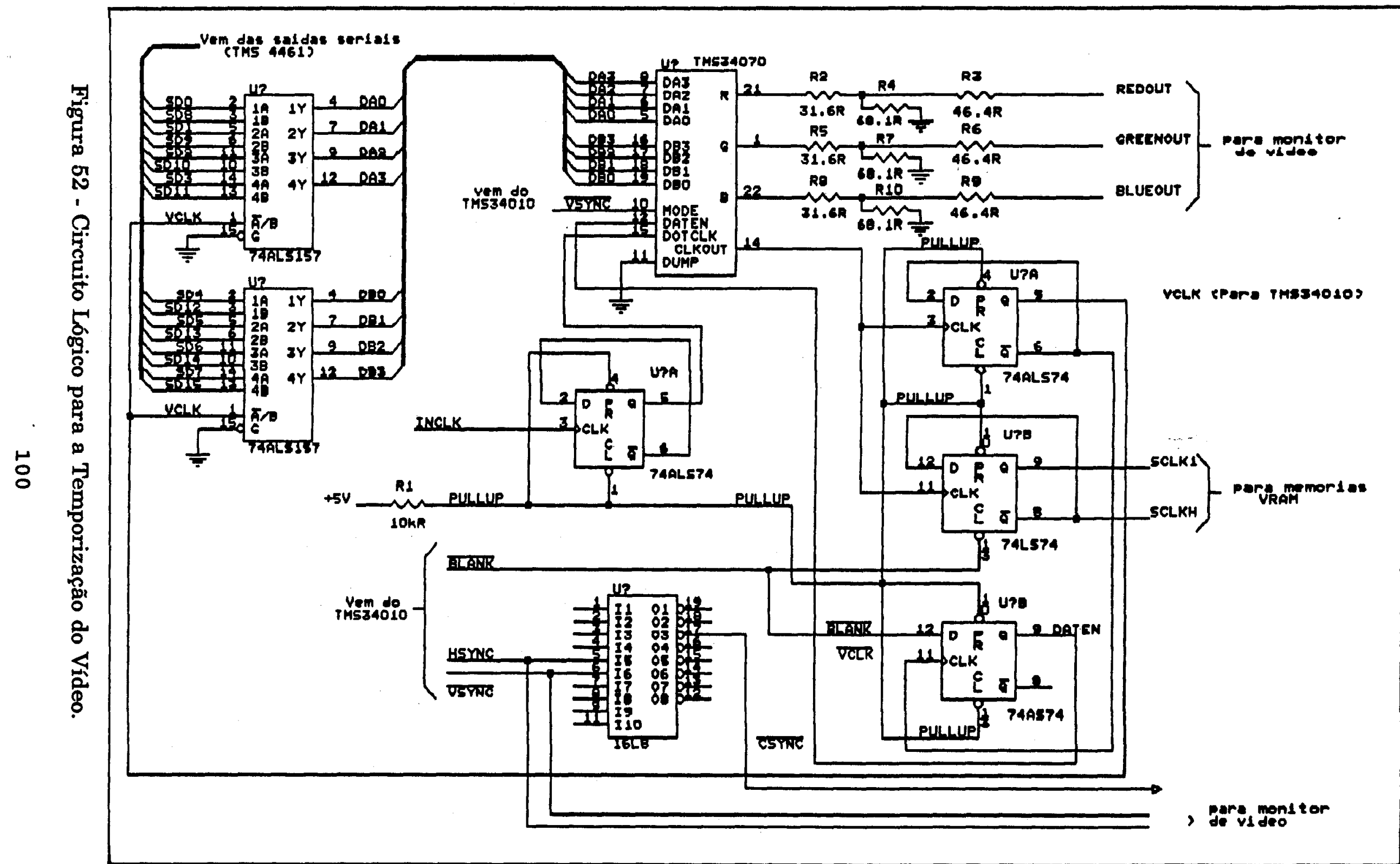


2, e aplicando-se este sinal à entrada DOTCLK do TMS34070. A saída CLKOUT do TMS34070 tem a metade da frequência da entrada DOTCLK do TMS34070, isto é, 5 MHz e alimenta dois flip-flops tipo $\mathrm{D}$, usados como divisores por 2 . Um deles gera o sinal de 2,5 MHz para a entrada VCLK do TMS34010, e para os multiplexers. $O$ outro flip-flop gera os sinais SCLKL e SCLKH para a entrada "clock" serial (SC) das memórias de vídeo. Estes sinais, SCLKL e SCLKH, embora com frequência idêntica (2,5 MHz), são complementares (figura 52).

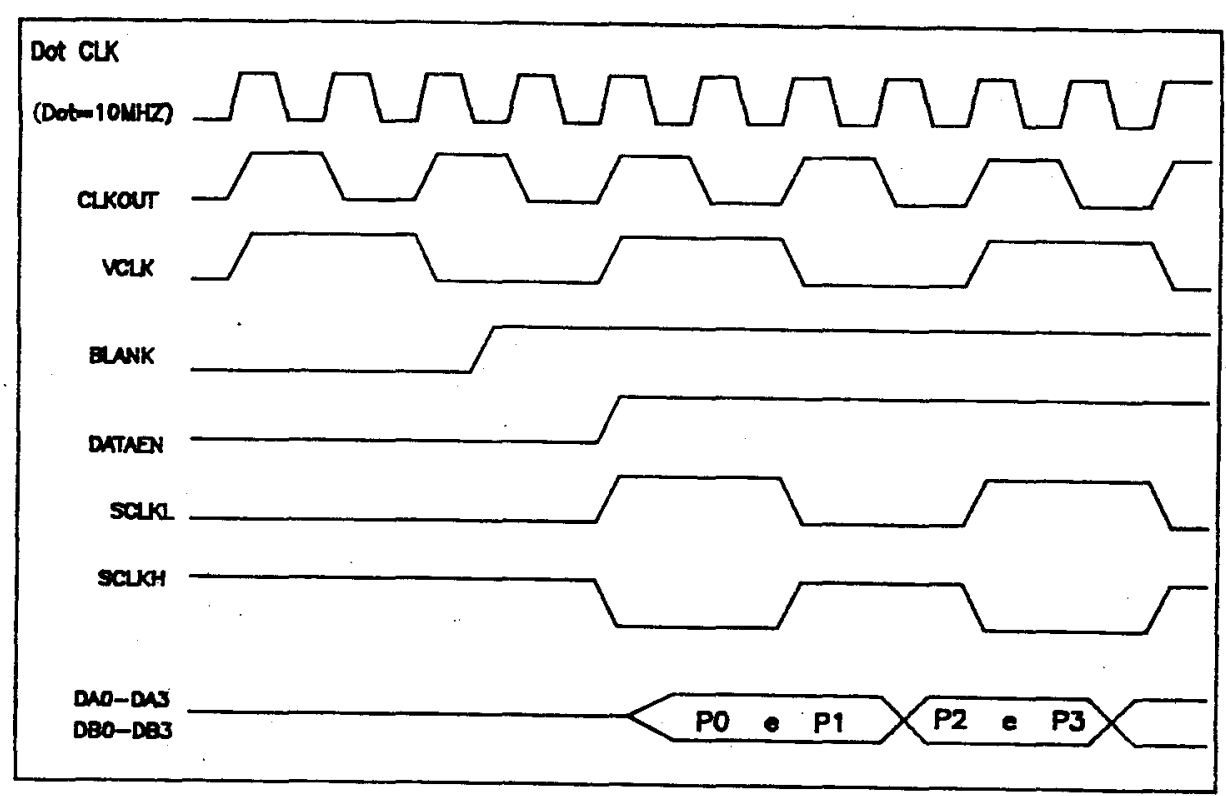

Figura 53 - Diagrama de Tempo para o Circuito da Figura 52.

O uso de "clocks" complementares permite estabelecer a ordem em que os "pixels" serão tranferidos para a "Color Palette ", o que é extremamente importante pois, caso contrário a imagem poderá ser desenhada de uma forma completamente errada.

O sinal SCLKL é aplicado na entrada "clock" serial das memórias que contém os dois "pixels" menos significativos, enquanto que SCLKH é aplicado às memórias que contém os "pixels" mais significativos.

Outra alternativa ao uso de "clocks" complementares seria a utilização de um 
único "clock", como por exemplo VCLK, mas tomando-se o cuidado de conectar os bits menos significativos às entradas DB0-DB3 dos multiplexers. Este é o modo usado no sistema gráfico SDB340 da TEXAS INSTRUMENTS.

Os sinais SCLKL e SCLKH devem ser inibidos durante o retraço horizontal e vertical, intervalo de tempo em que ocorrerá um ciclo de transferência de memória para registrador de deslocamento das VRAMs.

\subsubsection{Interface Serial Para "Mouse"}

Neste sistema foi implementada uma interface serial, para permitir a ligação de um "mouse" comercial para porta serial, tais como aqueles utilizados em microcomputadores do tipo PC.

O objetivo da instalação deste "mouse" foi o de permitir a interação do usuário com o sistema, quando da implantação do "software" definitivo" , já que este "software" permitirá a seleção de operações através de menus.

O "mouse" comercial utilizado é eletromecânico, com 3 teclas de controle na parte superior, e com 2 sensores de movimento na parte inferior, como é mostrado na figura 54. Este "mouse" foi conectado a uma interface serial, usando-se o padrão de comunicação RS-232C, sem sinais de sincronismo, com o sinal CTS da interface serial ligado ao RTS.

As características de comunicação do "mouse" são as seguintes:

.taxa de transmissão de dados: 1200 bauds

.número de bits/caracter: 8 bits

.sem paridade

.número de bits stop: 1

1 Em desenvolvimento por Agma J. M. Traina 
Quando uma tecla de controle do "mouse" é acionada, um conjunto de 5 "bytes" é enviado à interface serial, sendo o primeiro um "byte" de controle, que indica qual tecla foi acionada, o segundo e o quarto "byte" indicam movimento na direção X, e o terceiro e o quinto "byte" indicam movimento na direção $\mathrm{Y}$.

Quando os sensores de movimento são acionados, vários conjuntos de 5 "bytes" idênticos aos das teclas de controle são enviados. $O$ código do primeiro "byte" será $87 \mathrm{H}$, caso nenhuma tecla de controle tenha sido acionada simultaneamente.

A figura 54 mostra o conjunto de 5 "bytes" que o "mouse" transmite. 0 movimento para a direita na direção $X$, e para cima na direção $Y$ é considerado positivo, e nas direções opostas a estas, negativo. Os valôres negativos são enviados em complemento de 2 . Os três bits menos significativos do "byte" de controle indicam qual tecla foi acionada.

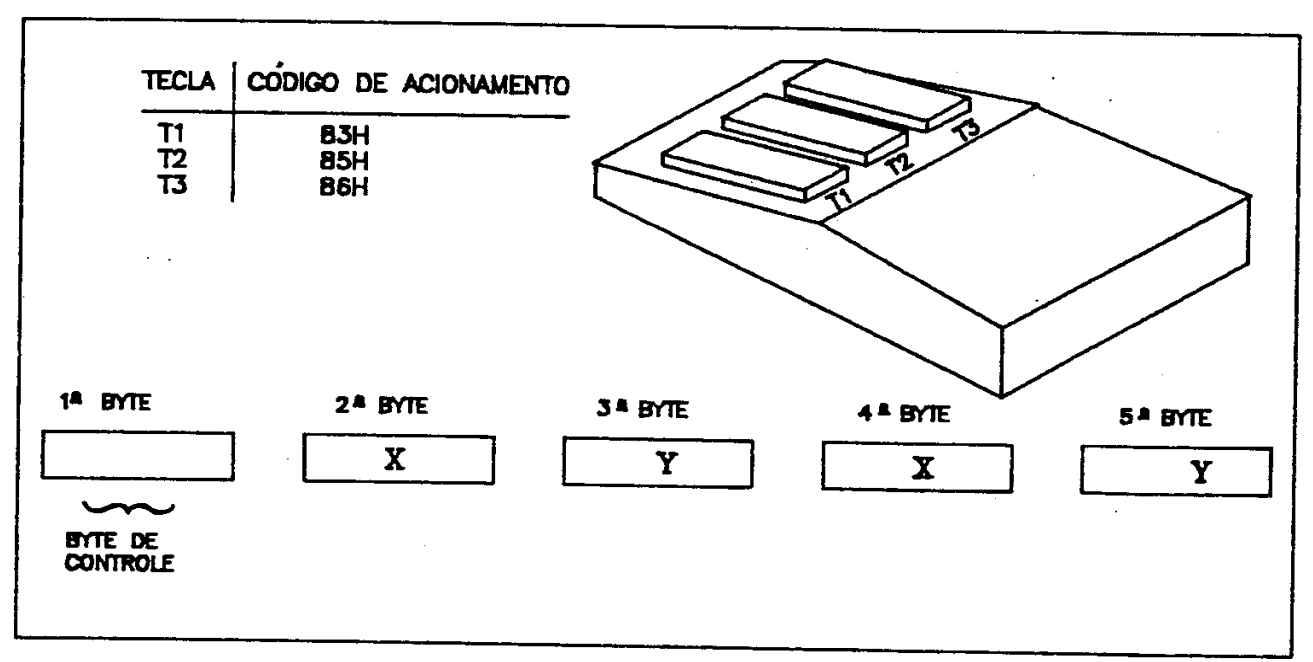

Figura 54 - Informação Transmitida pelo "Mouse".

A figura 54 mostra também as seguintes especificações dos códigos de controle para cada tecla do "mouse": 
$.87 \mathrm{H}$ : nenhuma tecla foi acionada

$.86 \mathrm{H}$ : tecla da esquerda

$.85 \mathrm{H}$ : tecla do meio

$.83 \mathrm{H}$ : tecla da direita

O circuito da interface serial desenvolvido para a coneç̧ão do "mouse", é mostrado na figura 55. Este circuito é constituído pela USART 8251A, pelos "line drivers" e "line receivers" e pela lógica para seleção do 8251A, geração de estados de espera e pedido de interrupção.

Na lógica de seleção do 8251A foram utilizados endereços diferentes para a leitura e gravação de dados e comandos, pois este "chip" tem sinais independentes para leitura e gravação, enquanto que o GSP gera um sinal único para leitura/gravação.

A tabela VII mostra os endereços correspondentes a cada tipo de operação no 8251A.

Tabela VII: Mapa de Endereços para a Interface

Serial - Sistema com 16 Cores.

\begin{tabular}{|ll|}
\hline endereço & \multicolumn{1}{c|}{ operação } \\
\hline $02000000 \mathrm{H}$ & lê dado da 8251A \\
$02001000 \mathrm{H}$ & lê status da 8251A \\
$02200000 \mathrm{H}$ & grava dado na 8251A \\
$02201000 \mathrm{H}$ & grava controle na 8251A \\
$04000000 \mathrm{H}$ & ativa "reset" \\
$04001000 \mathrm{H}$ & desabilita "reset" \\
\hline
\end{tabular}

Como o duto LAD0-LAD15 do GSP é tri-multiplexado, o "latch" 74LS373 é necessário para armazenar os sinais das linhas LAD utilizadas na lógica de seleção do 8251, durante a ocorrência do endereço da linha, quando ocorrer uma transição negativa do sinal /RAS.

O sinal LAL do GSP é utilizado juntamente com o /RAS na habilitação do 


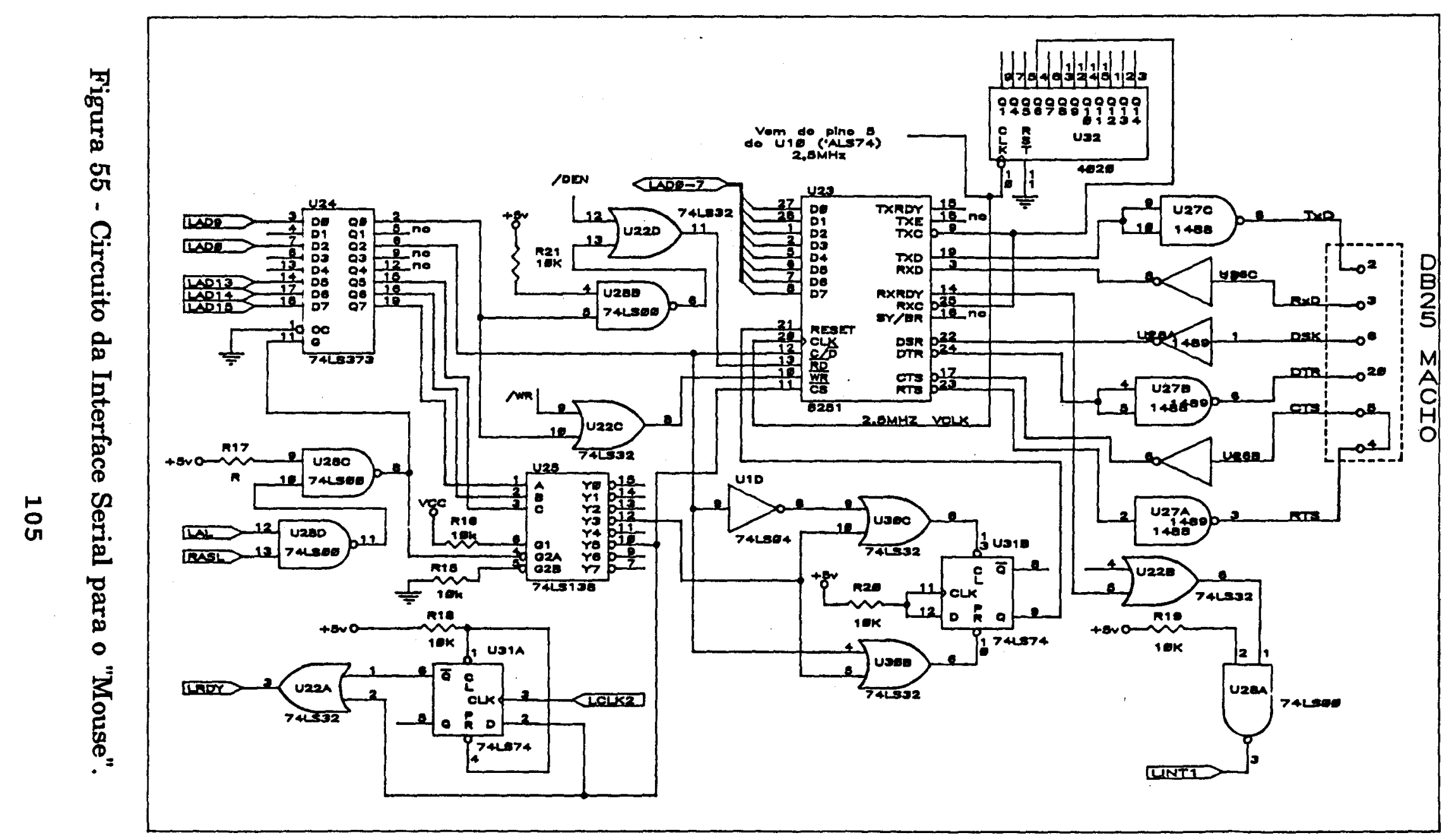


"latch", para estender a duração do sinal de seleção do 8251, tornando-o compatível com a temporização deste circuito.

O diagrama de tempo da figura 56 ilustra a geração do sinal de seleção e do estado de espera do 8251A. O sinal de seleção do 8251A torna-se ativo com a aplicação dos níveis lógicos 0 e 1 às linhas LA26 e LA25 do GSP, e quando não estiver ocorrendo o refrescamento das memórias dinâmicas.

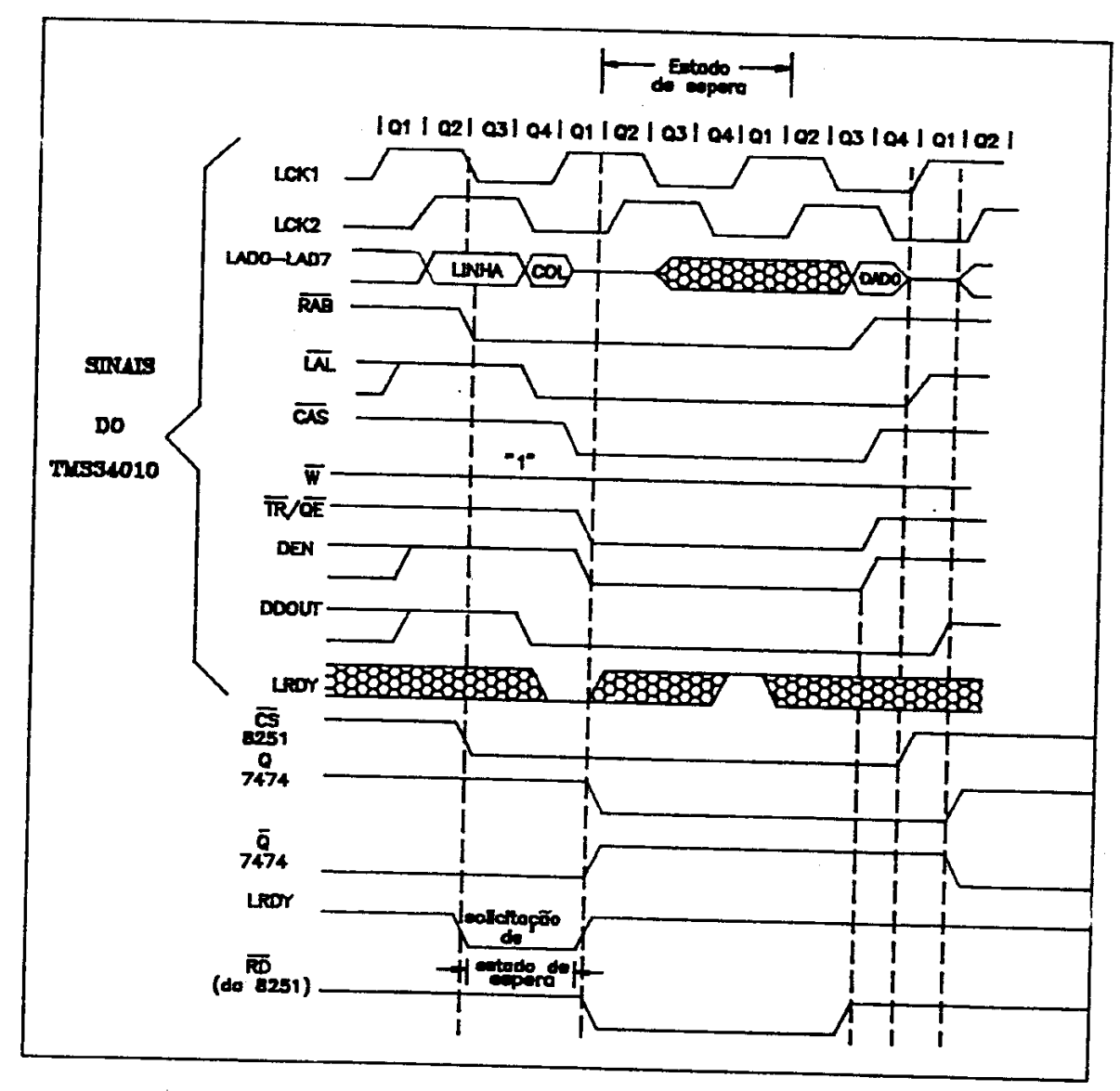

Figura 56 - Ciclo de Leitura no 8251

Lembrando novamente que como o duto LAD0-LAD15 do GSP é trimultiplexado, os sinais /RD e /WR do $8251 \mathrm{~A}$, que indicam respectivamente as operações de leitura e gravação no $8251 \mathrm{~A}$, só podem tornar-se ativos durante a ocorrência de dados neste duto, para evitar conflito com os sinais de endereço. 
Por este motivo, para ativar /WR é utilizada a linha de endereço LA21 e o sinal /WR do GSP, e para ativar /RD é utilizado /LA21 e o sinal /DEN do GSP.

0 "reset" do 8251A foi implementado em "hardware", com um flip-flop tipo D, e com a duração programável por "software". Os endereços para habilitar e desabilitar o "reset" são mostrados na tabela VII.

0 "reset" quando habilitado, deve permanecer ativo por pelo menos seis períodos de "clock" do 8251A, cuja frequência para o sistema implementado é de 2,5 MHz. No programa de inicialização da interface serial, este tempo é obtido através de um "loop" de atraso, após o qual o sinal de "reset" é desabilitado. A alteração da frequência de trabalho do TMS34010 implicará na modificação do "loop", de maneira tal que possa ser mantida sempre a mesma duração do tempo de "reset".

0 "reset" foi assim implementado porque, estando a placa gráfica alimentada, e sendo necessário inicializar a interface novamente, a programação do modo de operação do 8251, será interpretado como programação de comando, e a 8251A irá funcionar de uma maneira completamente errônea. Isto acontece pelo fato do $8251 \mathrm{~A}$ utilizar o mesmo endereço para a programação do modo e do comando.

O 8251A solicita uma interrupção ao GSP sempre que estiver pronto para receber do GSP o próximo dado a ser transmitido, ou quando receber um dado de um dispositivo externo. Para isso gera dois sinais, o TxRDY e o RxRDY.

$O$ sinal TxRDY indica ao GSP que o 8251A está pronto para receber o próximo dado a ser transmitido, e vai para nível lógico zero quando o dado é gravado pelo GSP, na transição negativa do sinal de gravação, /WR.

$O$ sinal RxRDY indica ao GSP que o 8251A contem um caracter que pode ser lido, e vai para nível lógico zero quando o caracter é lido pelo GSP.

A interrupção do GSP utilizada é a interrupção mascarável /LINT1.

A geração de um estado de espera para o 8251A foi necessária pelo fato da duração mínima do sinal de leitura ou gravação ser de 250 ns, e no GSP para a frequência externa de $20 \mathrm{MHz}$, a duração do sinal de gravaçào é menor do que $250 \mathrm{~ns}$. A geração do estado de espera foi implementada com um flip-flop tipo $D$, utilizando-se o sinal de seleção do 8251A e o sinal LCLK2 do GSP, como é mostrado na figura 55. 


\subsubsection{Exemplos de Programação dos Registradores de E/S do GSP}

\subsubsection{Descrição dos Registradores de E/S}

Como já visto anteriormente no capítulo 4, o TMS34010 tem 28 registradores de E/S que controlam e monitoram a memória local, a interrupção, a temporização de vídeo, o refrescamento da tela e as comunicações com o hospedeiro. Estes registradores devem então ser programados com valôres adequados para a execução dessas funções.

Um exemplo de programação destes registradores será mostrado a seguir.

\subsection{Registradores Dedicados ao Vídeo}

Estes registradores destinam-se à geração dos sinais de sincronismo para um monitor de vídeo CRT: sincronismo horizontal (/HSYNC), sincronismo vertical (/VSYNC), e o sinal usado para desligar o feixe do CRT, durante o intervalo de retraço horizontal e vertical (BLANK). O sinal /BLANK é uma composição dos sinais de "blanking" horizontal e vertical gerados internamente.

Este conjunto de três sinais são gerados a partir dos valôres programados pelo usuário no conjunto de registradores de $\mathrm{E} / \mathrm{S}$, dedicados a estas funções.

A lógica interna para a geração destes sinais é alimentada pelo sinal de entrada do TMS34010, VCLK, cuja frequência, para o sistema implementado é de 2,5 MHZ.

Estes registradores são divididos em dois grupos:

1.o) Registradores para a geração da temporização horizontal, os quais controlam a temporização do sinal/HSYNC, e o sinal de "blanking" horizontal interno:

HCOUNT - conta o número de períodos VCLK por linha de varredura horizontal. 
HESYNC - especifica o ponto na linha horizontal no qual o sinal /HSYNC termina.

HEBLNK - especifica o ponto final do intervalo de "blanking" horizontal.

HSBLNK - especifica o ponto inicial do intervalo de "blanking" vertical.

HTOTAL - define o número de períodos VCLK permitidos por linha de varredura horizontal.

2.o) Registradores para a geração do temporização vertical, os quais controlam a temporização do sinal /VSYNC, e o sinal de "blanking" vertical interno:

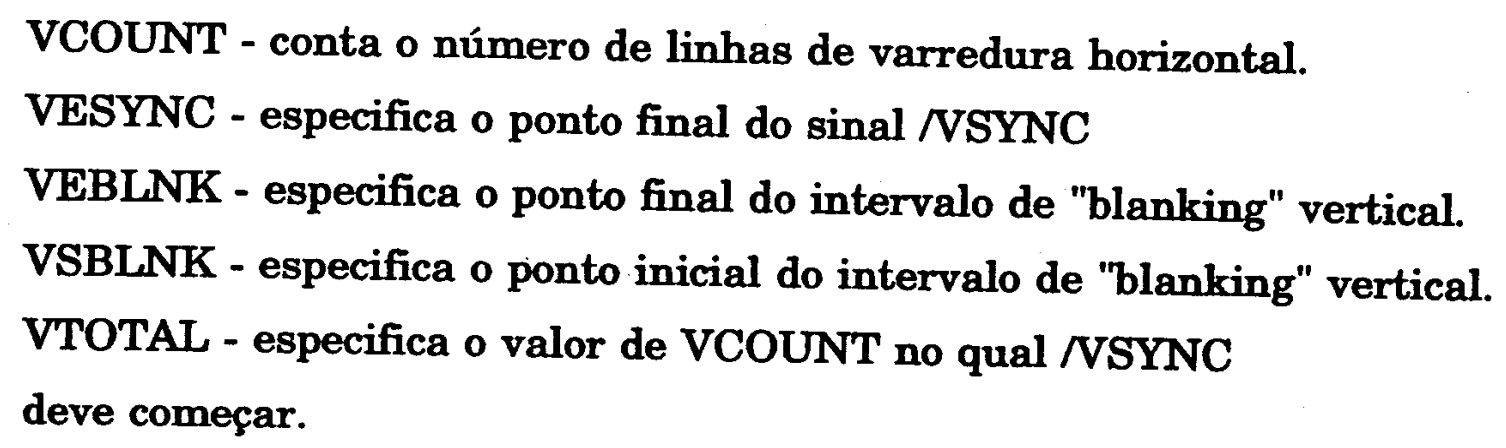

A figura 57 illustra as relações entre os sinais de temporização horizontal e vertical, na construção do padrão de varredura bidimensional.

A fim de viabilizar a utilização de monitores CGA e EGA, disponíveis no Laboratório de Instrumentação, foram determinados os valores dos registradores para cada um destes modos, o CGA e o EGA, e estes exemplos de cálculo são apresentados a seguir. Em ambas situações foram mantidos os 512 "pixels" por linha, com 4 bits por "pixel", frequência vertical de $60 \mathrm{~Hz}$ e modo não entrelaçado.

Para o modo EGA, a frequência de "pixel" deve ter um valor maior, a fim de ser mantido o número de "pixels" por linha.

As figuras 58 e 59, ilustram a ligação dos sinais de sincronismo do GSP ao monitor de vídeo. Nestas figuras Fh e Fv representam respectivamente a frequência do sincronismo horizontal e vertical, e HTOTAL e VTOTAL são os registradores de E/S para vídeo. 


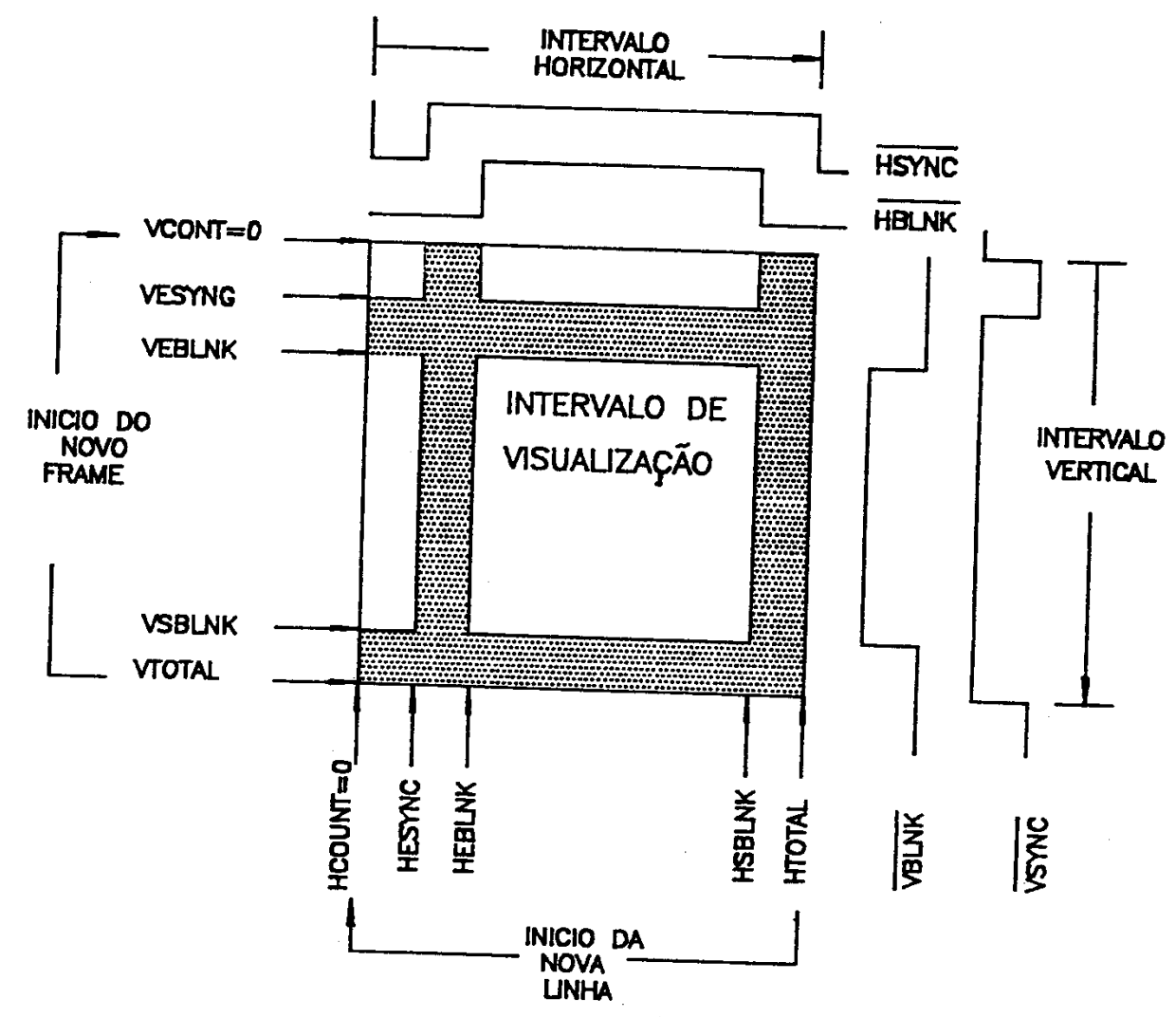

Figura 57 - Relação entre a Temporização Horizontal e Vertical.
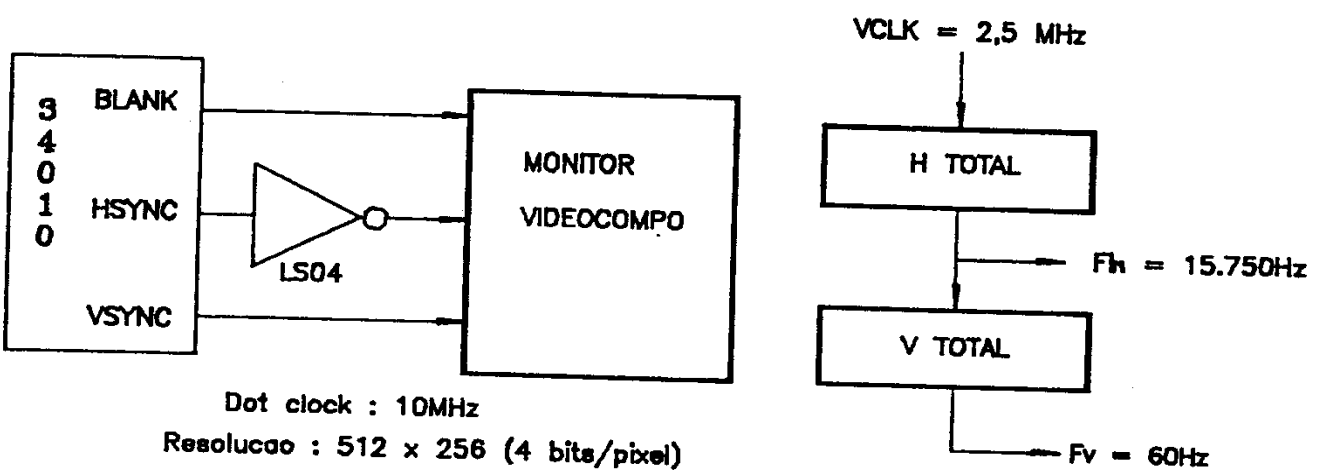

Figura 58 - Monitor no Modo CGA 

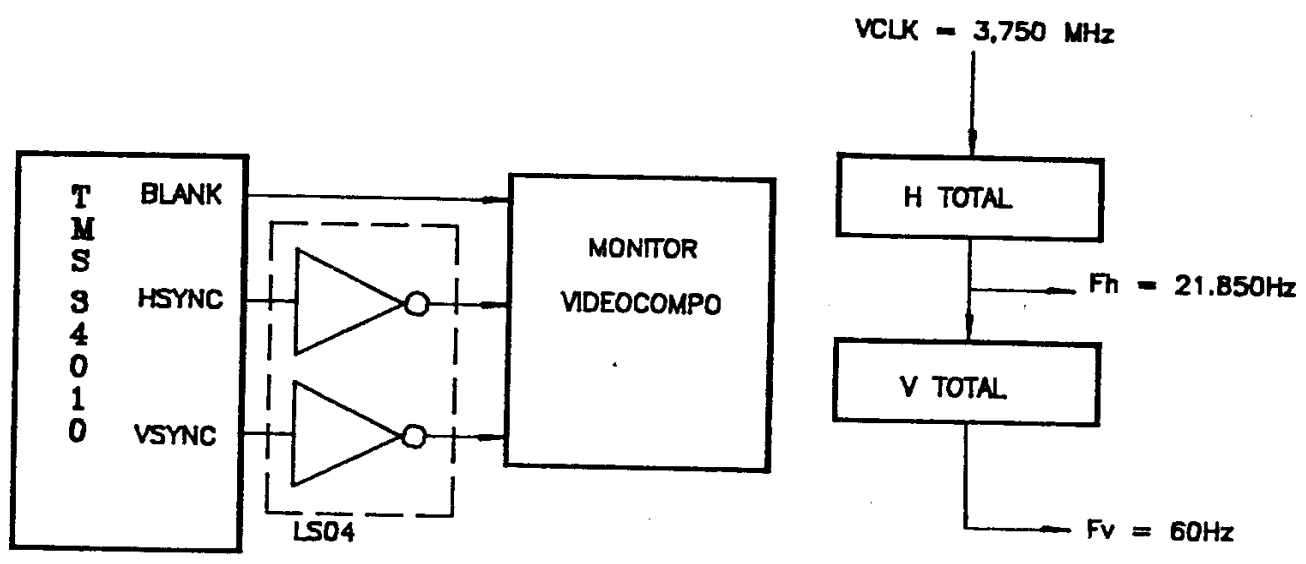

Figura 59 - Monitor no Modo EGA.

Para o modo CGA, o sinal HSYNC do GSP deve ser invertido para se tornar compatível com o monitor de vídeo utilizado, enquanto que para o modo EGA, tanto o sinal HSYNC como o VSYNC devem ser invertidos.

\section{a.) Exemplo de cálculo para o modo CGA}

Para este modo os seguintes valores foram considerados para VCLK, Fh, Fv, e fdot(frequência de "pixel"):

$$
\begin{aligned}
& \text { VCLK }=2,5 \mathrm{MHz} \\
& \text { Fh }=15750 \mathrm{~Hz} \\
& \text { Fv }=60 \mathrm{~Hz} \\
& \text { fdot }=10 \mathrm{MHz}
\end{aligned}
$$

a.1) HTOTAL : este registrador determina o período do sincronismo horizontal. 


$$
\text { HTOTAL }=\frac{\text { VCLK }}{\text { Fh }}=\frac{2,5 \mathrm{MHz}}{15750 \mathrm{~Hz}}=158,73=9 \mathrm{EH}
$$

a.2) HEBLNK e HSBLNK : estes registradores determinam a duração do retraço horizontal ([1] e [16]).

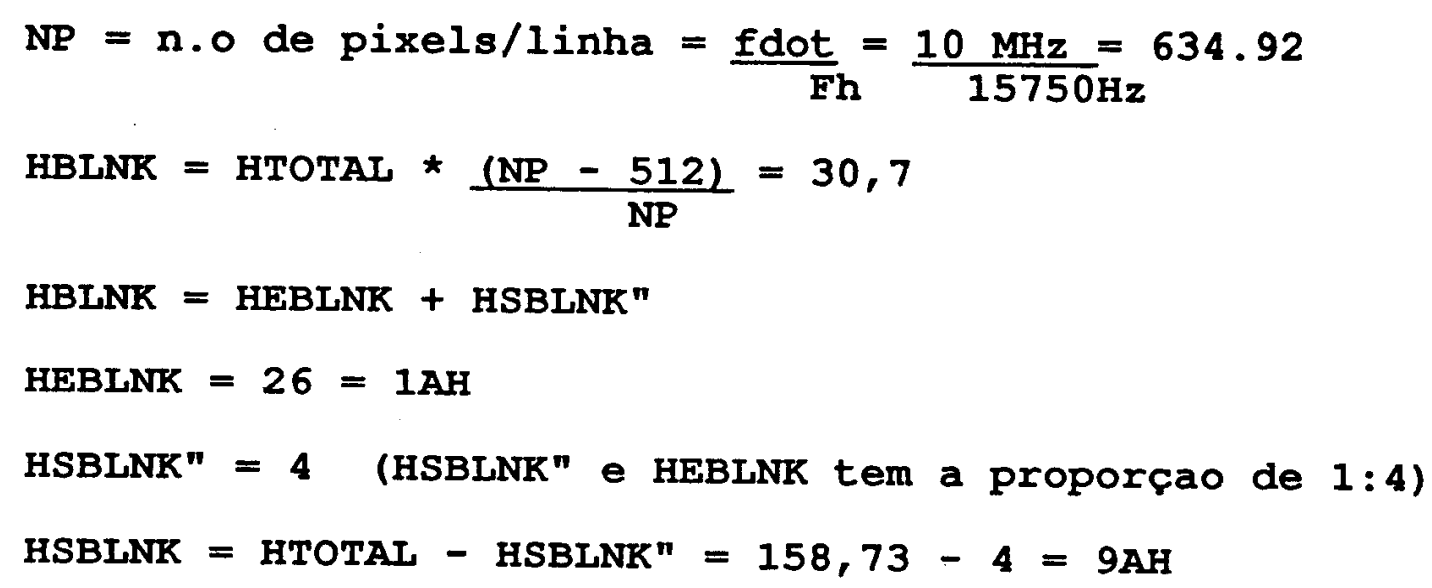

a.3) VTOTAL : este registrador determina o período do sincronismo vertical.

VTOTAL $=\frac{F h}{F v}=\frac{15750 \mathrm{~Hz}}{60 \mathrm{~Hz}}=262,5=105 \mathrm{H}$

a.4) VSBLNK e VEBLNK : estes registradores determinam a duração do retraço vertical.

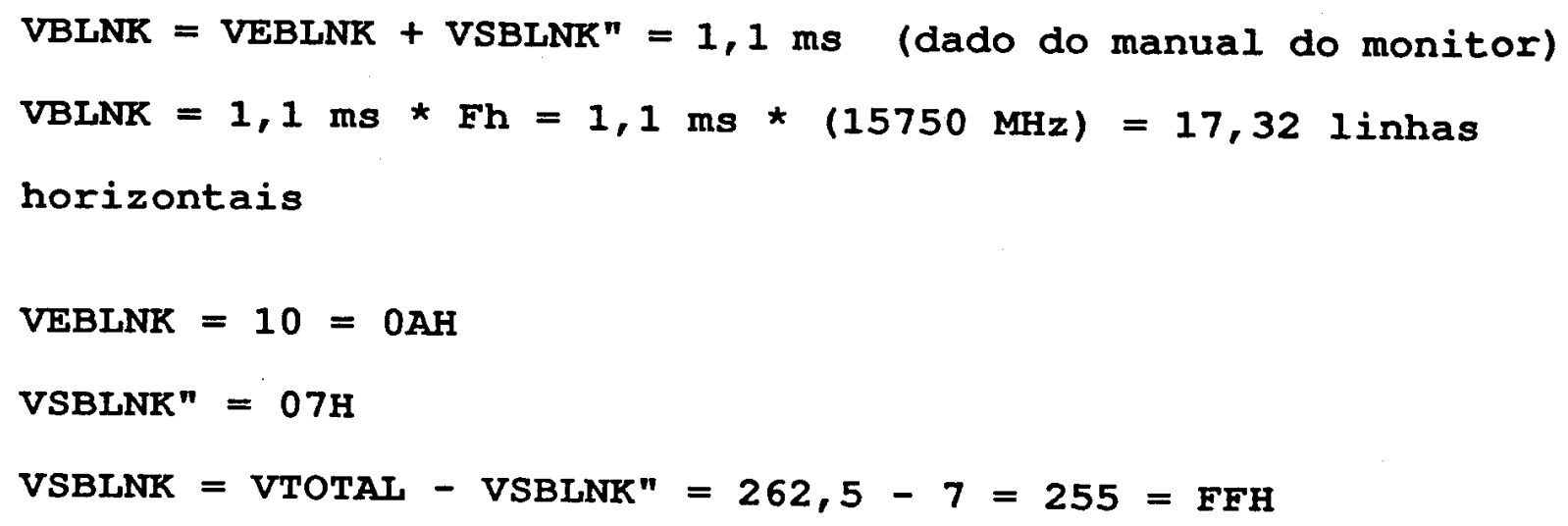


a.5) Número de linhas horizontais

N.O de linhas horiz. = VTOTAI - VBLNK $=262-17=245$

Do cálculo do número de linhas horizontais observa-se que não se consegue as 256 linhas horizontais desejadas, devido à duração do retraço vertical.

b.) Exemplo de cálculo para o modo EGA

Para este modo os seguintes valores foram considerados para VCLK, Fh, Fv, e fdot (frequência de "pixel"):

$$
\begin{aligned}
& \text { VCLK }=3,75 \mathrm{MHz} \\
& \text { Fh }=21850 \mathrm{~Hz} \\
& \text { Fv }=60 \mathrm{~Hz} \\
& \text { Fdot }=15 \mathrm{MHz}
\end{aligned}
$$

b.1) HTOTAL : este registrador determina o período do sincronismo horizontal.

$$
\text { HTOTAL }=\frac{\text { VCLK }}{\mathrm{Fh}}=\frac{3,75 \mathrm{MHz}}{21850 \mathrm{~Hz}}=171,6=\mathrm{ABH}
$$

b.2) HEBLNK e HSBLNK : estes registradores determinam a duração do retraço horizontal.

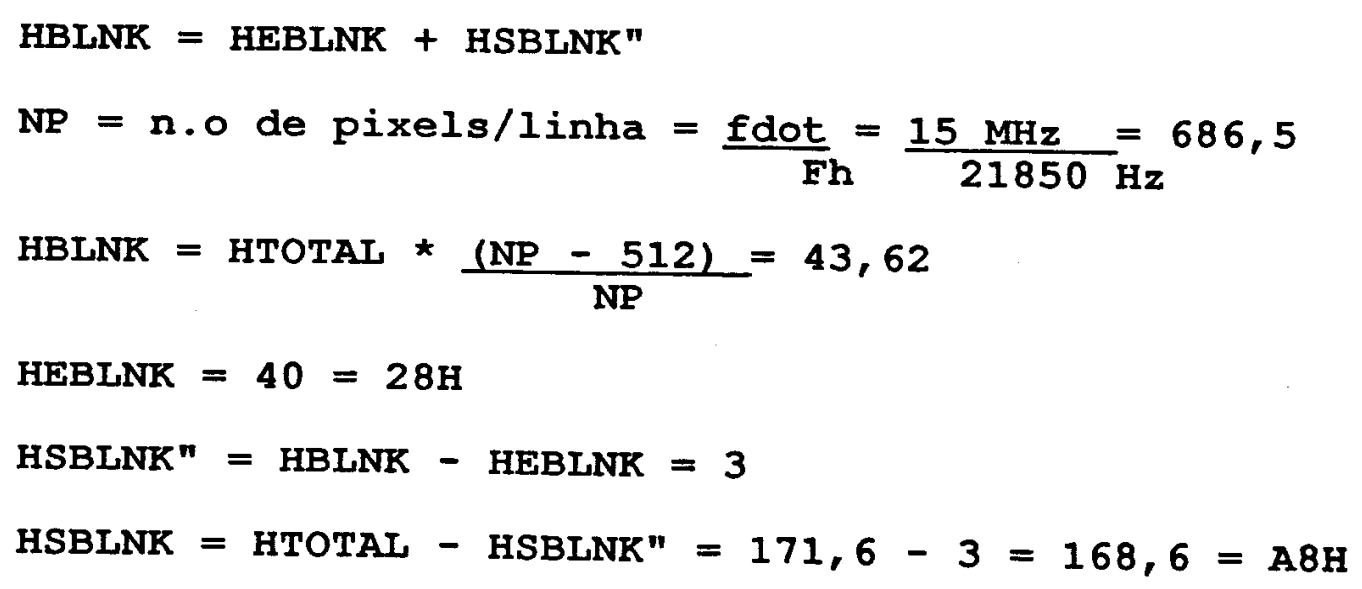


b.3) VTOTAL : este registrador determina o período do sincronismo vertical.

$$
\text { VTOTAL }=\underset{\mathrm{FV}}{=}=\frac{21850 \mathrm{~Hz}}{60 \mathrm{~Hz}}=364,16=16 \mathrm{CH}
$$

b.4) VSBLNK e VEBLNK : estes registradores determinam a duração do retraço vertical.

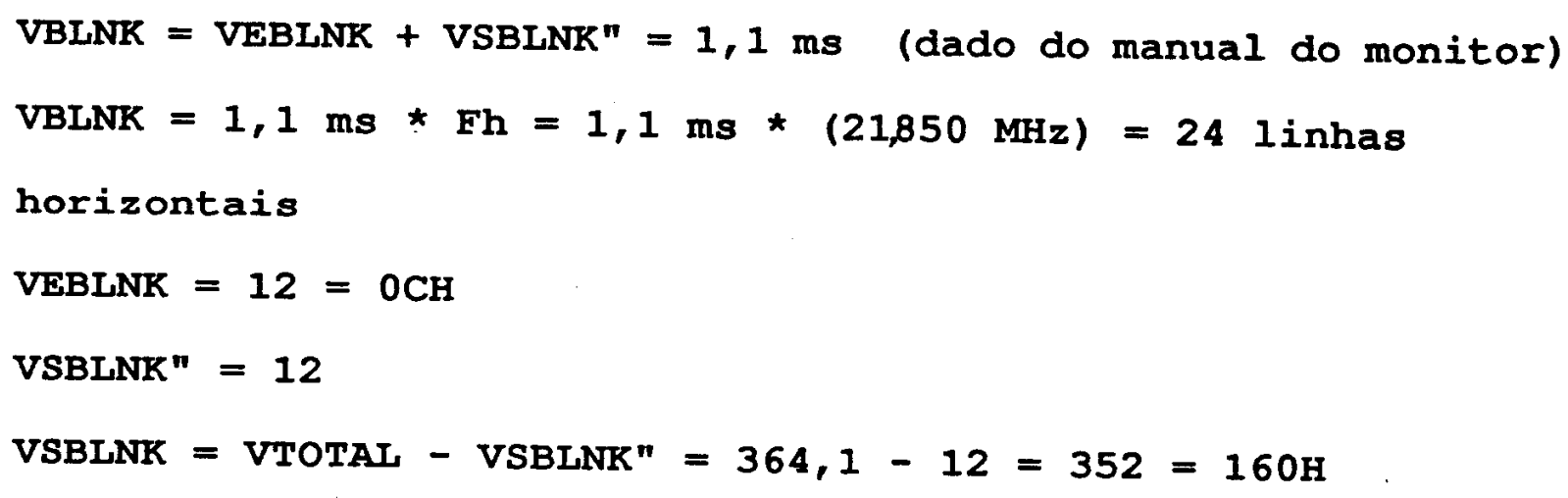

b.5) Número de linhas horizontais

N.o de linhas horiz. = VTOTAL - VBLNR $=364,1-24=340$

Para que os sinais de sincronismo comecem a ser gerados é necessário ainda a programação de alguns parâmetros do vídeo no registrador DPYCTL, o que será visto no próximo item.

\subsection{Registradores para o Controle do Vídeo e Refrescamento da Tela}

a.) DPYCTL : este registrador contem vários parâmetos que controlam os sinais de temporização do vídeo, e os ciclos de transferência para os registradores de deslocamento das VRAMs. O valor $\mathrm{F} 010 \mathrm{H}$, utilizado, estabelece estes parâmetros como segue:

. bits 0 e 13, HSD e DXV, são programados com 00, configurando os pinos 
/VSYNC e /HSYNC do GSP como entradas.

- bits 2 a 9, campo DUDATE, especifica o número de palavras que são carregadas nos registradores de deslocamento a cada ciclo de transferência de memória para registrador de deslocamento.

Este campo é carregado com sete "0" e um único "1" . 0 "1" indica a posição do bit onde o campo SRFADR do registrador DPYADR deve ser incrementado (ou decrementado se ORG $=1$ ).

Nos registradores de deslocamento das VRAMs há um total de 4096 bits, o que corresponde a 256 palavras. Para se determinar qual bit do campo DUDATE deve ser programado com "1", de forma a somar 256 ao campo SRFADR do registrador DPYADR, deve-se conhecer como os bits deste campo (SRFADR), são colocados no duto LAD0 - LAD15, e quais linhas de endereço são utilizadas nas memórias. A figura 60 mostra a posição dos bits do campo SRFADR, durante o tempo das linhas e das colunas.

\section{Exemplo:}

Na figura 60, considerando que são usadas as linhas de endereço LAD0 -LAD7 para o endereçamento das memórias, conclui-se que 256 palavras correspondem a fazer o bit 4 do campo DUDATE igual a "1".

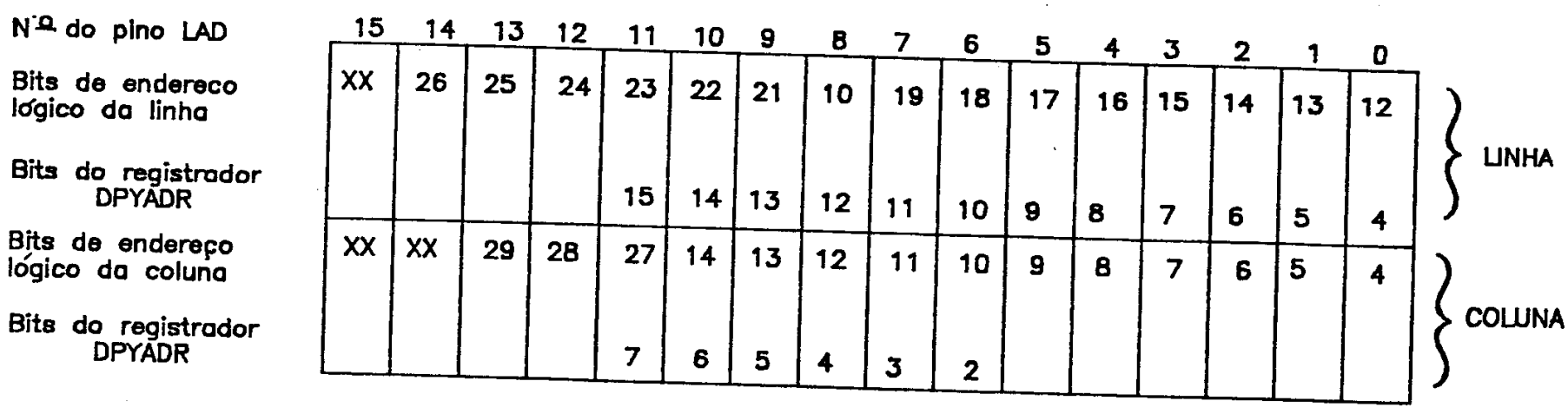

Figura 60 - Geração dos Bits do Campo SRFADR no Duto Multiplexado LAD 
.bit 10, ORG, é programado com 0 , estabelecendo a origem do sistema de coordenadas da tela no canto esquerdo superior.

.bit 11, SRT, é programado com 0, indicando que os ciclos de acesso ao "pixel" ocorrem normalmente.

.bit 12, SRE, é programado com "1", habilitando o refrescamento da tela.

.bit 13, DXV, é programado com 1, selecionando a temporização de vídeo gerado internamente.

.bit 14, NIL, é programado selecionando o temporização para vídeo não entrelaçado.

bit 15, ENV, é programado com 1, habilitando o sinal de vídeo. Se ENV é programado com 0 , a saída /BLANK é forçada para 0 .

b.) DPYSTRT : este registrador contem dois parâmetros que controlam automaticamente os ciclos de memória para registrador de deslocamento, necessários para o refrescamento da tela.

b.1) LCSTRT : este campo de dois bits é programado com 01, indicando que 2 linhas de varredura são mostradas entre ciclos de refrescamento da tela. Este valor é determinado considerando que uma linha com 512 "pixels" de 4 bits, possui um total de 2048 bits. Como os registradores de deslocamento conseguem armazenar até 4096 bits, conclui-se que em cada ciclo de refrescamento duas linhas podem ser desenhadas.

b.2) SRSTRT : este campo de 14 bits é programado com o valor que especifica o endereço inicial de cada "frame". Este valor é carregado no campo SRFADR 
do registrador DPYADR no início de cada retraço vertical. Este campo por sua vez (SRFADR) é um contador que gera o endereço das linhas e das colunas durante o refrescamento da tela, sendo decrementado a cada ciclo de refrescamento pelo campo DUDATE do registrador DPYCTL.

O valor do campo SRSTRT dependerá do bit ORG do registrador DPYCTL. Com ORG $=0$ a origem está localizada no canto superior esquerdo da tela e este campo deve ser carregado com o complemento 1 de determinados bits do endereço inicial da imagem.

Para se determinar quais são os bits deve-se separar o endereço inicial da memória de vídeo em endereço de linha e coluna, como é mostrado na figura 60.

Em seguida, e de acordo com as linhas LAD utilizadas no endereçamento das memórias, atribui-se o valor dos bits LAD aos correspondentes do campo SRSTRT, complementando ou não estes bits dependendo do bit ORG.

No sistema implementado a memória de vídeo pode conter duas imagens e o bit ORG foi estabelecido para 0. Portanto os bits do campo SRSTRT serão o complemento 1 dos bits de endereço correspondentes. $O$ endereço inicial de cada imagem é o seguinte:

1.a imagem: $00000000 \mathrm{H}$

2.a imagem: $00080000 \mathrm{H}$

Separando-se estes endereços como endereços de linha e coluna como é mostrado na figura 61, determina-se o valor do registrador DPYADR para cada imagem como sendo:

1.a imagem : FFFDH

2.a imagem : F7FDH

c.) DPYINT : este registrador foi programado com FFFFH, não sendo usado 
inicialmente no sistema. Especifica a próxima linha que causará a interrupção do vídeo.

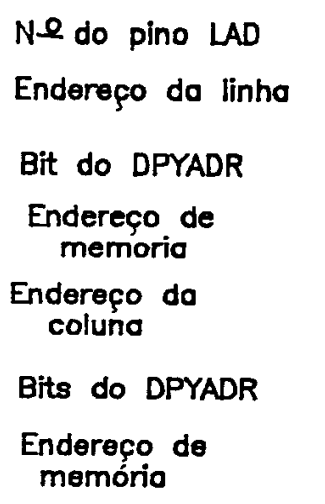

\begin{tabular}{|c|c|c|c|c|c|c|c|c|c|c|c|c|c|c|c|}
\hline 15 & 14 & 13 & 12 & 11 & 10 & 9 & 8 & 7 & 6 & 5 & 4 & 3 & 2 & 1 & 0 \\
\hline$x$ & 28 & 25 & 24 & 23 & 22 & 21 & 10 & 19 & 18 & 17 & 16 & 15 & 14 & 13 & 12 \\
\hline & & & & 15 & 14 & 13 & 12 & 11 & 10 & 9 & 8 & 7 & 6 & 5 & 4 \\
\hline & 0 & 0 & 0 & 0 & 0 & 0 & 0 & 1 & 0 & 0 & 0 & 0 & 0 & 0 & 0 \\
\hline$x$ & $\times$ & 29 & 28 & 27 & 14 & 13 & 12 & 11 & 10 & 9 & 8 & 7 & 6 & 5 & 4 \\
\hline & & & & 7 & 6 & 5 & 4 & 3 & 2 & & & & & & \\
\hline & & 0 & 0 & 0 & 0 & 0 & 0 & 0 & 0 & 0 & 0 & 0 & 0 & 0 & 0 \\
\hline
\end{tabular}

Figura 61 - Exemplo para Determinação do Valor do Campo SRSTRT

\subsection{Registradores Dedicados à Memória Local}

\section{a.) CONTROL}

a.1) bit 2, RM, foi programado com 0 , especificando o ciclo de refrescamento /RAS- only para as memórias dinâmicas.

a.2) bits 3 e 4, campo RR, foi programado com 00 especificando o refrescamento das memórias dinâmicas a cada 32 períodos de "clock".

a.3) bit 15, CD, foi programado com 0 habilitando a "cache". 
Os demais campos deste registrador são utilizados para o controle de transparência, modo de deteção de violação de janela, controle da direção da instrução PIXBLT, e seleção da operação de processamento de "pixel". Estes campos podem ser alterados pelos programas em execução.

\section{b. CONVDP}

Este registrador contem o fator de conversão do "pitch" destino. É usado durante a conversão XY para linear de um endereço de memória destino. Na maior parte das vezes o "pitch" destino é o da tela.

Para o sistema implementado o "pitch" da tela é calculado como o número de "pixels" de uma linha, pelo número de bits por "pixel":

$$
\text { "pitch" da tela }=512 * 4=2048=0800 \mathrm{H}
$$

Este valor é armazenado no registrador B3 (DPTCH), em caso de uso de instruções gráficas.

O valor de CONVDP pode ser determinado de duas maneiras:

b.1) usando a instrução LMO, cujo operando de entrada é o "pitch" destino $(0800 \mathrm{H})$, contido no registrador $\mathrm{B} 3(\mathrm{DPTCH})$ :

LMO B3,B0 ; converte o valor DPTCH

MOVE B0,@CONVDP,0 ; armazena o resultado em ; CONVDP

b.2) calculando o complemento 1 de $\log _{2}(\mathrm{DPTCH})$,para os 5 primeiros bits do registrador CONVDP e mantendo os demais bits em 0 . Para endereçamento XY, DPTCH deve ser uma potência de 2 , e portanto $\log _{2}(\mathrm{DPTCH})$ é um inteiro. 
$\log _{2}(2048)=11=01011 \mathrm{~B}$

complemento $1(01011 \mathrm{~B})=10100=14 \mathrm{H}$

\section{c. CONVSP}

Este registrador contem o fator de conversão para o "pitch" fonte. Tem aplicação semelhante ao do CONVDP, e é calculado da mesma forma. $O$ valor deste registrador para o sistema implementado, depende do programa sendoexecutado.

\section{d. PMASK}

Este registrador foi programado com 0000, habilitando a gravação em todos os planos do sistema gráfico.

e. PSIZE

Este registrador especifica o tamanho do "pixel", e foi programado com o valor 4.

\subsection{Registradores de Controle de Interrupção}

Os dois registradores usados na habilitação das interrupções, são programados com 0000, desabilitando inicialmente todas as interrupções.

\subsubsection{Resumo dos Valores Utilizados}

A tabela VIII resume o conjunto de valores dos registradores de $\mathrm{E} / \mathrm{S}$, que devem ser programados para o sistema gráfico em questão. 
Tabela VIII: Valores dos registradores de E/S para o Sistema com 16 Cores

\begin{tabular}{|c|c|c|}
\hline registradores & modo CGA & modo EGA \\
\hline \multicolumn{3}{|c|}{ 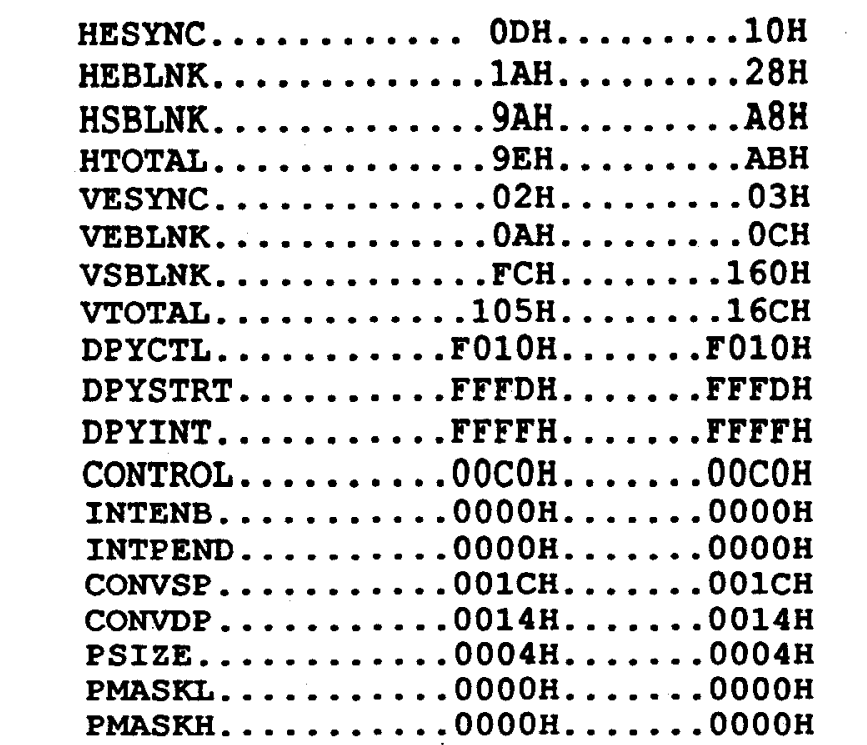 } \\
\hline
\end{tabular}

\subsection{Sistema Gráfico com 256 níveis de Cinza}

A implementação do sistema com 256 níveis de cinza teve dois objetivos. 0 primeiro foi o de desenvolver um sistema gráfico para visualização de imagens em níveis de cinza, já que este sistema deverá fazer parte do equipamento de Ressonância Magnética para obtenção de imagens médicas, em desenvolvimento no Departamento de Física.

O segundo objetivo foi o de expandir a memória de sistema e de vídeo, realizando toda a lógica de seleção de memórias e da interface serial com PALs, para compactar o sistema.

As diferenças deste sistema em relação ao primeiro, apresentado no item 4.1, consistem na expansão de memória, na troca da "Color Palette" por um conversor A/D de 8 bits, no aumento do número de bits por "pixel" de 4 para 8 bits e na 
implementação da lógica de decodificação somente com PALs.

A interface com o sistema hospedeiro permaneceu inalterada, e assim a descrição da mesma pode ser encontrada no item 5.1.1. As demais serão descritas nos próximos itens.

0 diagrama em blocos deste sistema é mostrado na figura 62 , sendo constituído pelos seguintes elementos:

. o processador gráfico TMS34010;

. memória de sistema, implementada com memórias RAM dinâmicas;

. memória de vídeo, implementada com VRAMs;

. circuito para controle da temporização do vídeo;

. conversor D/A de 8 bits, utilizado na geração do sinal de vídeo, com os 256 níveis de cinza;

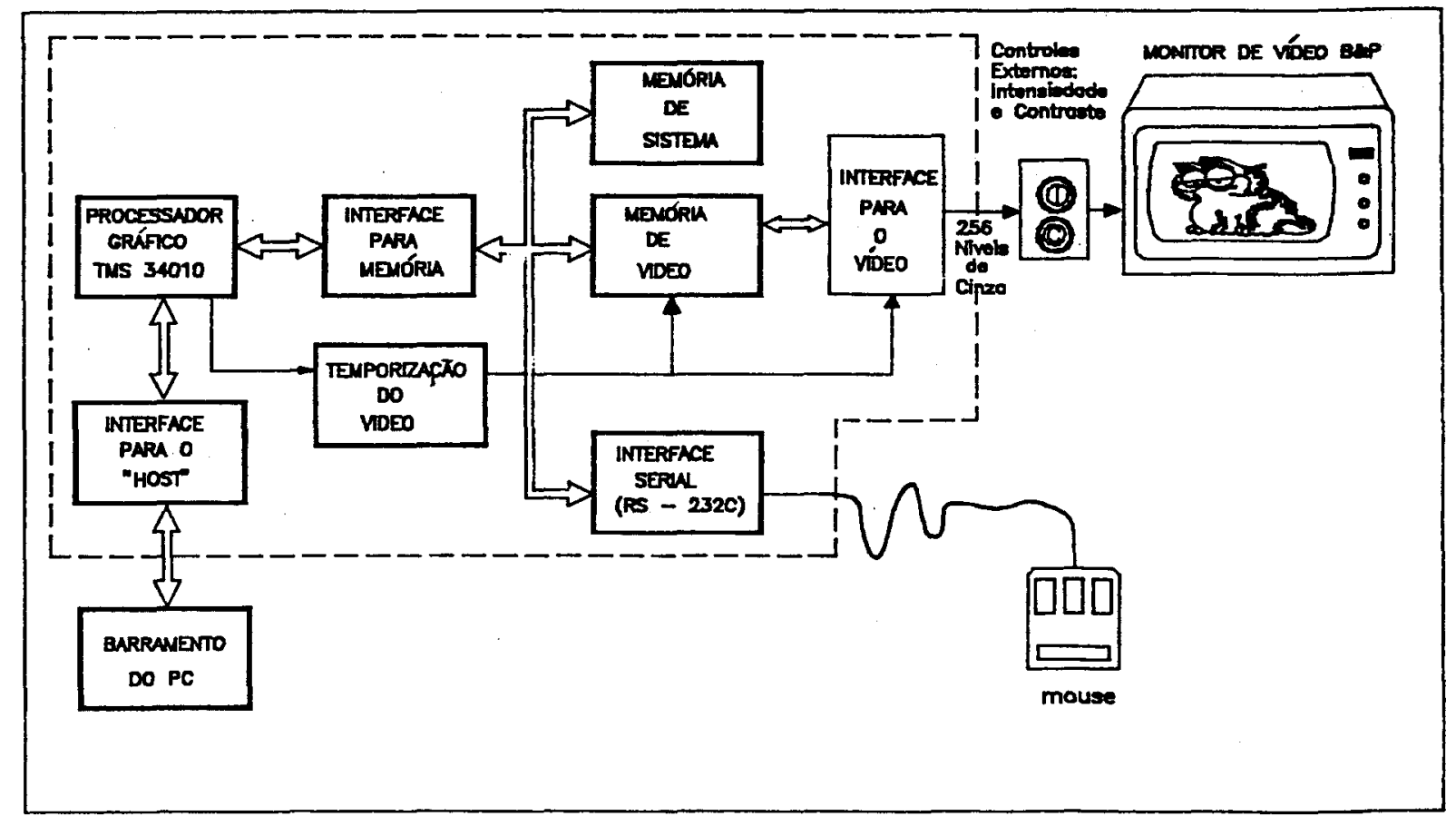

Figura 62 - Diagrama em Blocos do Sistema Gráfico com 256 Níveis de Cinza 
. interface para a comunicação do TMS34010 com o PC.

. interface serial para a coneç̧ão de um "mouse".

As características deste sistema são as seguintes:

a.) frequência externa do TMS34010 : $20 \mathrm{MHz}$;

b.) frequência do "pixel" : $10 \mathrm{MHz}$;

c.) resolução da tela : 512 "pixels", 256 linhas e 8 bits por "pixel";

d.) interface serial RS232-C : para conecção de um "mouse", com taxa de transmissão de 1200 Bauds, 1 bit "stop", sem paridade;

e.) memória de sistema (DRAM) : 2 × 128 Kbytes;

f.) memória de vídeo (VRAM) : 3 × 128 Kbytes.

\subsubsection{Descrição das Interfaces}

\subsubsection{Interface com a Memória Local}

Para a implementação do sistema de memórias, foram utilizadas DRAMs como memória de sistema, e VRAMs como memórias de vídeo.

A memória de sistema foi organizada como três bancos de DRAMs (TMS4464), de $64 \mathrm{~K} \times 16$. A memória de vídeo foi organizada como dois bancos de VRAMs (TMS4164), de 64K $\times 16$.

Para a resolução de tela escolhida, a imagem de uma tela ocupa exatamente um banco de VRAM. Assim até duas imagens podem ser armazenadas nos dois bancos de VRAMs.

O mapeamento destas memórias e da interface serial é mostrado nas figuras 63a e 63b. As linhas de enderę̧o LA26 e LA25 selecionam a memória de sistema, a memória de vídeo ou a interface serial. As demais linhas de endereço usadas na lógica 


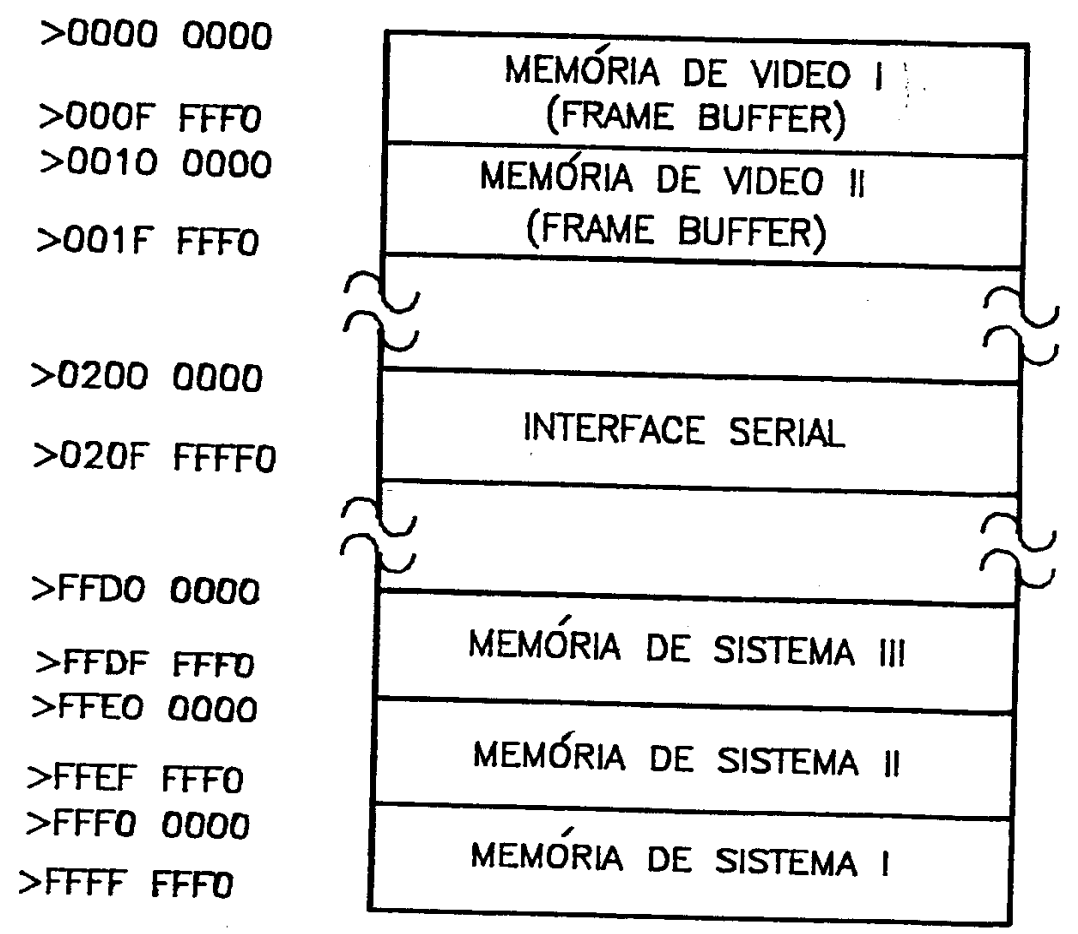

a. Mapa de Memória

\begin{tabular}{|c|c|c|c|c|c|}
\hline \multicolumn{4}{|c|}{ BITS DE SELEÇAXO } & \multirow{2}{*}{$\begin{array}{l}\text { DISPOSITIVO } \\
\text { SELECIONADO }\end{array}$} & \multirow{2}{*}{$\begin{array}{l}\text { SINAL DE } \\
\text { HABILTAÇÃOO }\end{array}$} \\
\hline A26 & A25 & $A 21$ & A2O & & \\
\hline 0 & 0 & 0 & 0 & Memória de video 1 & RASVø \\
\hline 0 & 0 & 0 & 1 & Memória de video II & RASV1 \\
\hline 0 & 1 & $x$ & $x$ & Interface serial & CSER \\
\hline 1 & 1 & 0 & 1 & Memória de sistema III & RASS2 \\
\hline 1 & 1 & 1 & 0 & Memória de sistema \| & RASS1 \\
\hline 1 & 1 & 1 & 1 & Memório de sistema 1 & RASSø \\
\hline
\end{tabular}

b. Bits de Seleção

Figura 63 - Mapeamento das Memórias para o Sistema com 256 Níveis de Cinza 
de seleção, selecionam os bancos de memória, e geram os sinais de controle para a interface serial.

A lógica de seleção das memórias foi implementada com uma PAL 16L8, programada com as equações mostradas na figura 64. Nessas equações o sinal /VALID ocorre no início de um ciclo de memória. Torna-se ativo quando /RAS e LCLK2 estiverem em nível lógico alto, e permanece ativo quando ocorrer uma das situações seguintes: se for selecionado um dos bancos de memória de sistema ou de vídeo, ou se for selecionada a interface serial, ou se ocorrer o refrescamento das memórias (/RF). É desabilitado assim que um destes sinais de seleção de memória ou da interface serial tornar-se ativo.

Um dos sinais de seleção das memórias, /RASS ou /RASV, tornar-se-á ativo se, quando /VALID e /RAS estiverem ativos, ocorrer o refrescamento das memórias, ou o banco de memória for selecionado pela combinação das linhas de endereço, de acordo com o mapeamento mostrado na figura 63. Este sinal é então mantido ativo durante o intervalo de tempo em que /RAS se mantiver ativo. A figura 65 ilustra a geração de alguns destes sinais.

A saída serial dos dois bancos de memórias de vídeo é selecionada pelos sinais /SOE0 (banco 0) e /SOE1 (banco 1). Um destes sinais torna-se ativo sempre que estando NALID ativo, for iniciado um ciclo de transferência de memória para registrador de deslocamento, o que é definido pelo primeiro termo da equação. Este ciclo ocorre quando o sinal TR/QE tornar-se ativo no início de um ciclo de memória. Os demais termos da equação mostram que este sinal se mantem ativo até que outro ciclo de transferência de memória para registrador de deslocamento seja iniciado.

$O$ segundo termo da equação mantém este sinal ativo durante o tempo do endereço da linha, enquanto o terceiro termo o mantém ativo enquanto /VALID não estiver ativo:

O quarto termo faz com que o sinal /SOE permaneça ativo na ocorrência de outros ciclos de memória, que não sejam o de transferência para registrador de deslocamento.

O sinal /SOE é desabilitado assim que o sinal de seleção serial do outro banco 
tornar-se ativo, o que está expresso no primeiro termo da equação.

0 diagrama de tempo da figura 66 , ilustra a geração destes sinais.

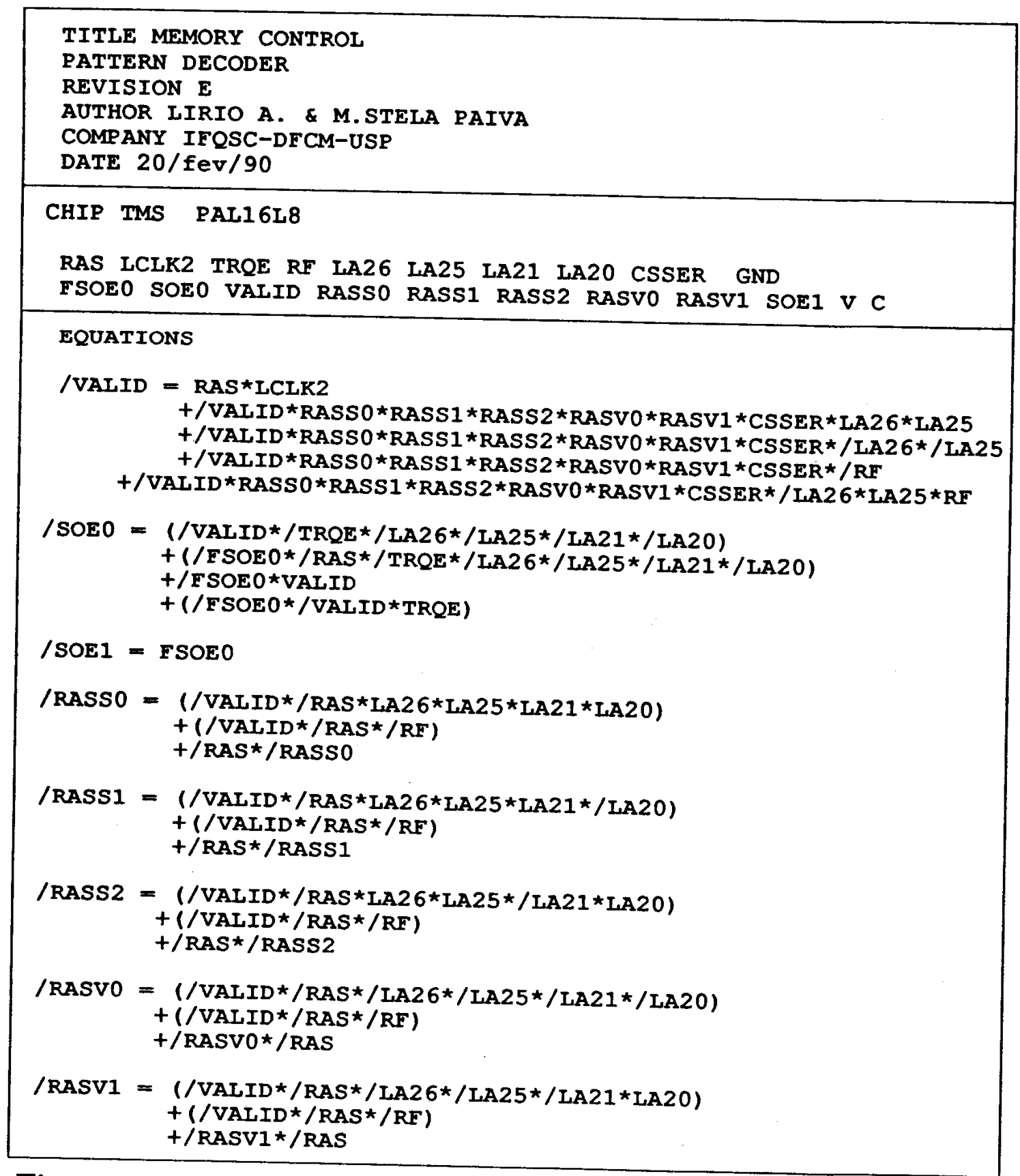

Figura 64: Equações da PAL para a Seleção das Memórias -

Sistema com 256 Níveis de Cinza 


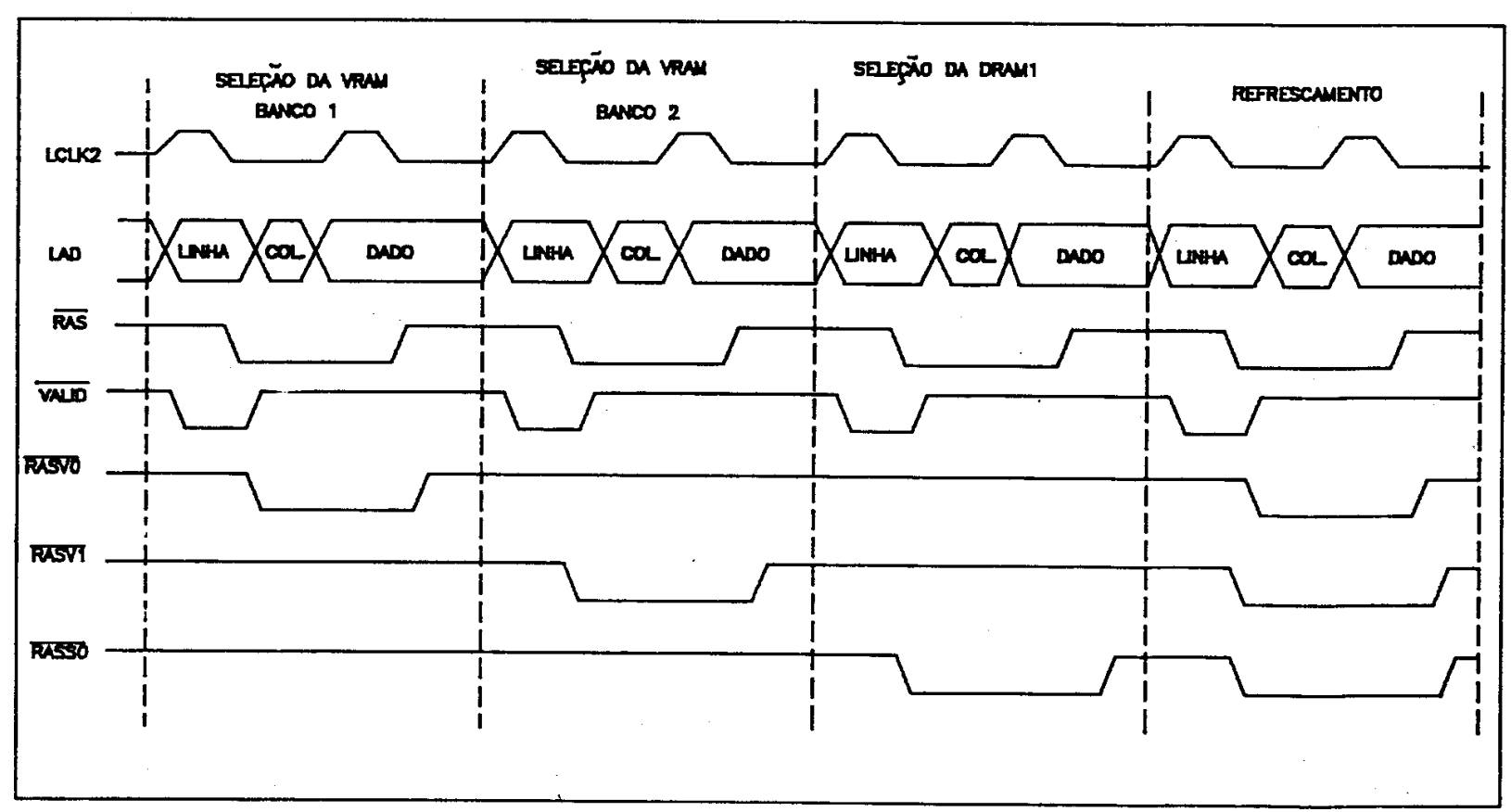

Figura 65 - Diagrama de Tempo Ilustrando os Sinais de Seleção das Memórias. 


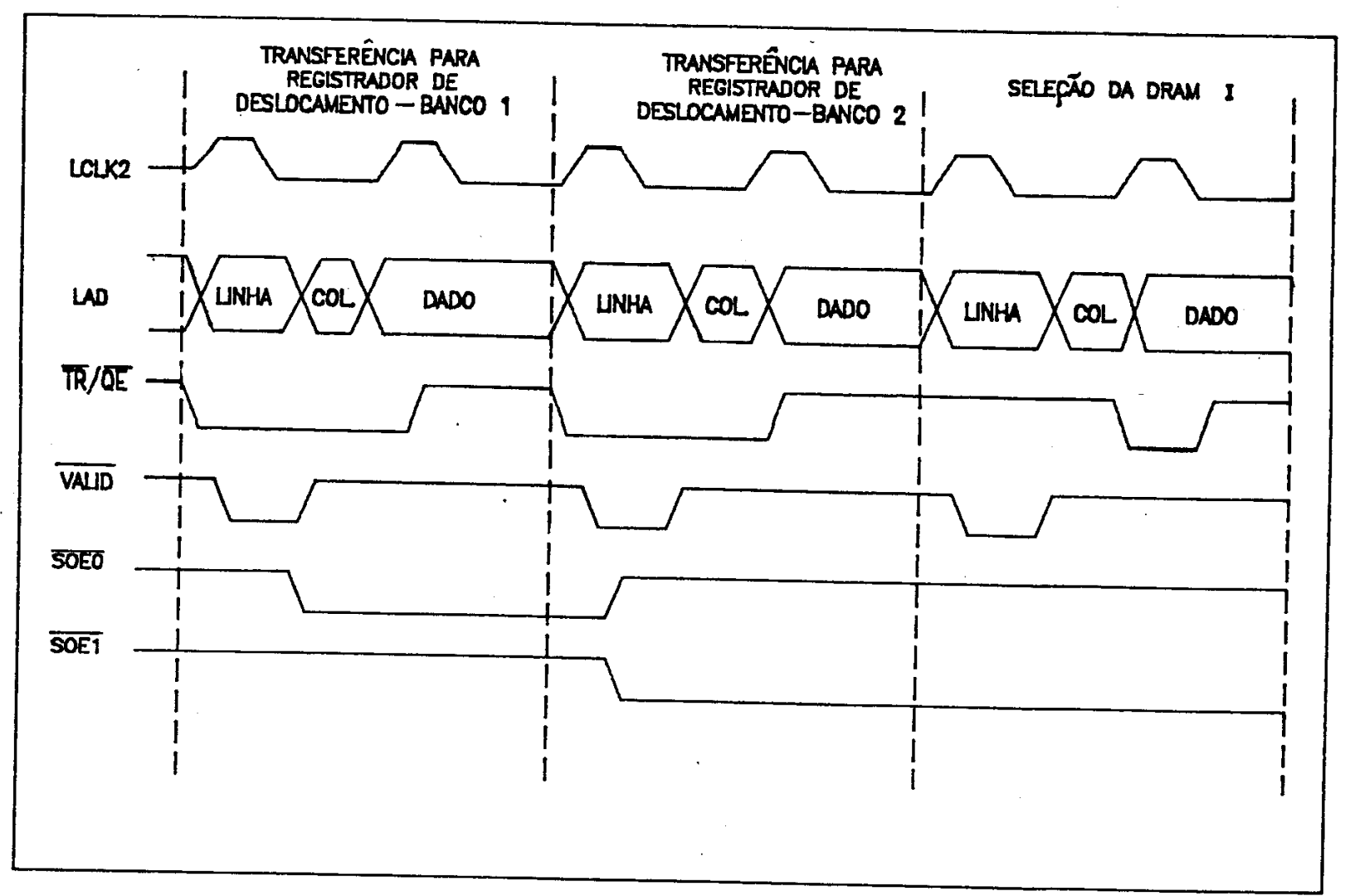

Figura 66 - Diagrama de Tempo Ilustrando a Seleção das Saídas Seriais das VRAMs.

\subsubsection{Circuito de Saída para Vídeo}

O circuito de saída para vídeo, mostrado na figura 67, gera o sinal de vídeo, e é constituído por um conversor D/A para vídeo (BT106BC) de 8 bits, e dois multiplexers digitais (74LS157). Os dois multiplexers determinam a ordem em que os "pixels" são enviados para o conversor D/A.

No duto serial de dados das VRAMs, são gerados dois "pixels" de 8 bits, em tempos diferentes, estabelecidos pelos sinais de "clock" complementares SCLKL e SCLKH. Primeiramente é gerado o "pixel" menos significativo, habilitado por SCLKL, e a seguir é gerado o "pixel" mais significativo habilitado por SCLKH. 


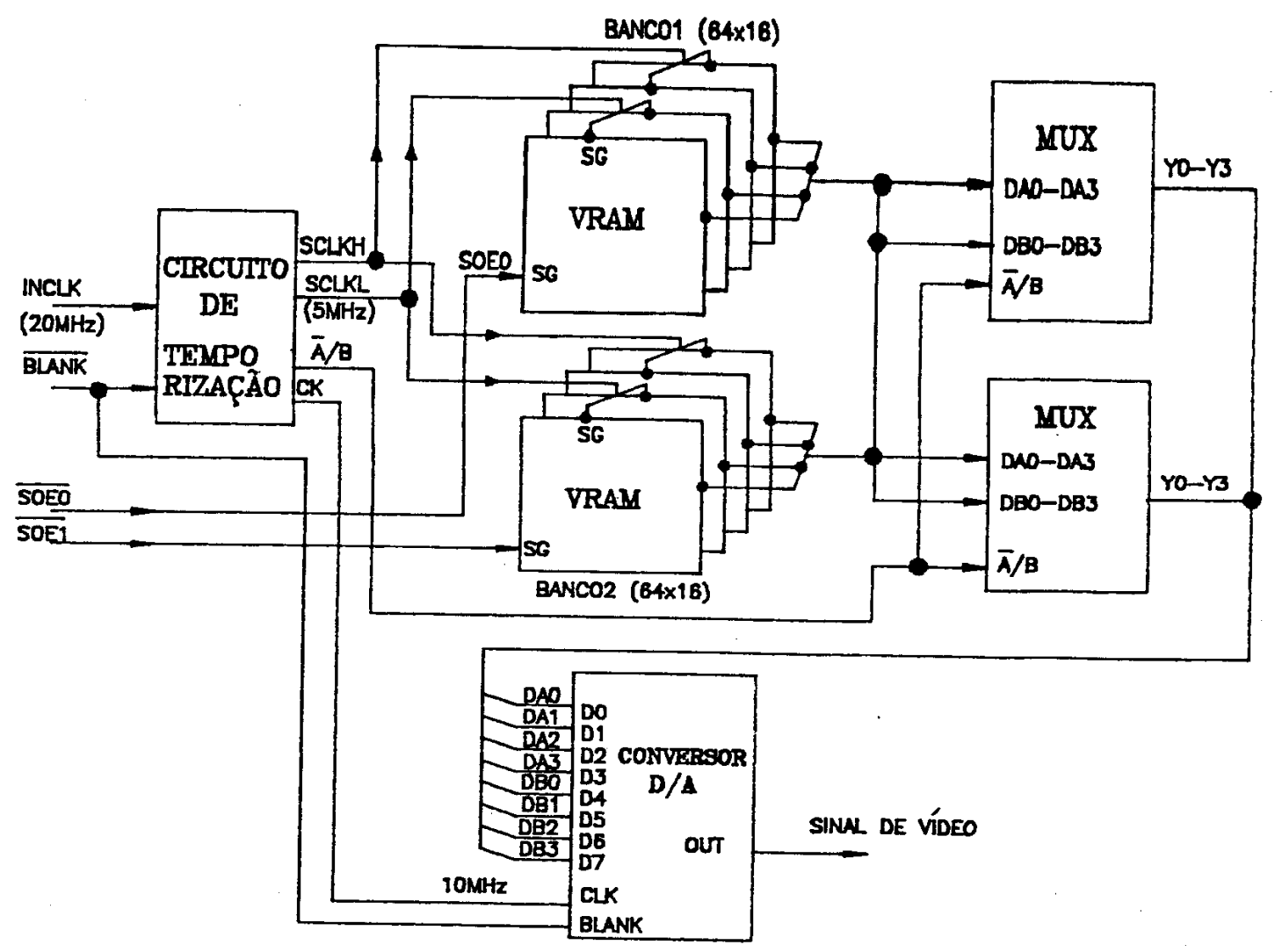

Figura 67 - Circuito de Saída para Video.

O BT106BC contem internamente um conversor D/A de 8 bits, um registrador e um amplificador de referência, e permite uma taxa de "pixel" máxima de $50 \mathrm{MHz}$ (figura 68). Todas as entradas deste conversor são compatíveis com TTL. Na transição positiva de cada ciclo de "clock", como mostrado na figura 69, os 8 bits de dados são armazenados internamente no conversor D/A de 8 bits.

A entrada REFWT é armazenada na transição positiva do sinal de "clock", e quando em " 1 " força as entradas do conversor D/A para FFH. No projeto esta entrada foi colocada em " 0 ". 


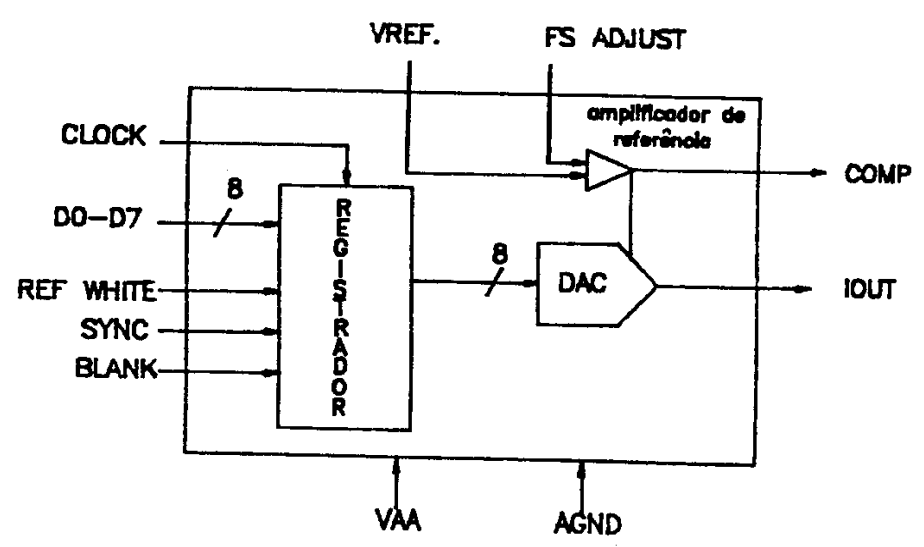

Figura 68 - Diagrama em Blocos Interno do Conversor D/A BT106

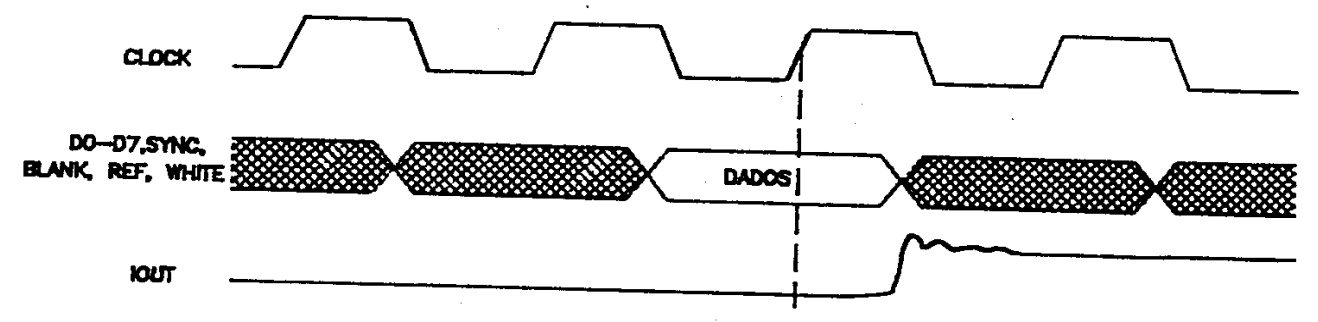

Figura 69 - Diagrama de Tempo de E/S para o Conversor D/A BT106

A corrente de saída de fundo de escala é determinada pelo resistor externo (RSET) de 549 ohms ligado entre o pino FS e o GND analógico. Este valor de RSET é típico para a geração do padrão de vídeo RS-343A para uma carga de 37,5 ohms.

A entrada VREF requer uma referência externa de $1,2 \mathrm{~V}$.

Na entrada CLK é aplicado o "clock" de "pixel" do sistema de vídeo, que para o sistema implementado vale $10 \mathrm{MHz}$.

A entrada COMP gera uma compensação para o amplificador de referência. Um capacitor de cerâmica de $0,01 \mathrm{uF}$ em série com um resistor deve ser conectado entre este pino e o pino VAA, que é a alimentação analógica (5 V), a fim de 
possibilitar a máxima rejeição de ruído da fonte de alimentação.

A entrada SYNC é a entrada para vídeo composto, e foi colocada em nível "0".

A entrada BLANK é a utilizada para "blank" composto, e foi conectada à saída de "blank" composto, /BLANK, do TMS34010.

\subsubsection{Circuito de Temporização do Vídeo}

A função do circuito de temporização de vídeo é idêntica à do circuito de temporização do sistema anterior, isto é, gerar os sinais de sincronismo para o conversor D/A, para os multiplexers e para as saídas seriais das memórias VRAMs. Estes sinais são obtidos a partir do sinal INCLK de $20 \mathrm{MHz}$, do TMS34010.

O circuito é mostrado na figura 70, e é constituído por "flip-flops" tipo D (74LS74), utilizados como divisores por 2.

A frequência de "pixel" de $10 \mathrm{MHz}$, aplicada ao conversor D/A (BT106), define a frequência aplicada aos multiplexers e a frequência dos "clocks" seriais das memórias VRAMs. Como o conversor D/A consegue armazenar um "pixel" de 8 bits a cada período de "clock" de $10 \mathrm{MHz}$, e as memórias geram 2 "pixels" de 8 bits a cada período de "clock" serial, a frequência do "clock" serial deve ser a metade da frequência de "pixel" do conversor, isto é, $5 \mathrm{MHz}$.

Na verdade são gerados dois sinais de "clock" para as VRAMs, SCLKL e SCLKK, que são complementares. SCLKL é conectado às memórias que geram o "pixel" menos significativo, enquanto que SCLKH é conectado às memórias que geram - "pixel" mais significativo. Os sinais SCLKL e SCLKH devem ser inibidos durante o retraço horizontal e vertical, intervalo de tempo em que ocorrerá um ciclo de transferência de memória para registrador de deslocamento.

Os "pixels" provenientes das memórias são transmitidos aos multiplexers. A frequência do sinal aplicado às entradas $A / B$ dos multiplexers também deve ser de 5 $\mathrm{MHz}$, pois a cada meio período do sinal destas entradas, é liberado um "pixel" para o conversor D/A. O diagrama de tempo da figura 71 ilustra a temporização de vídeo. 


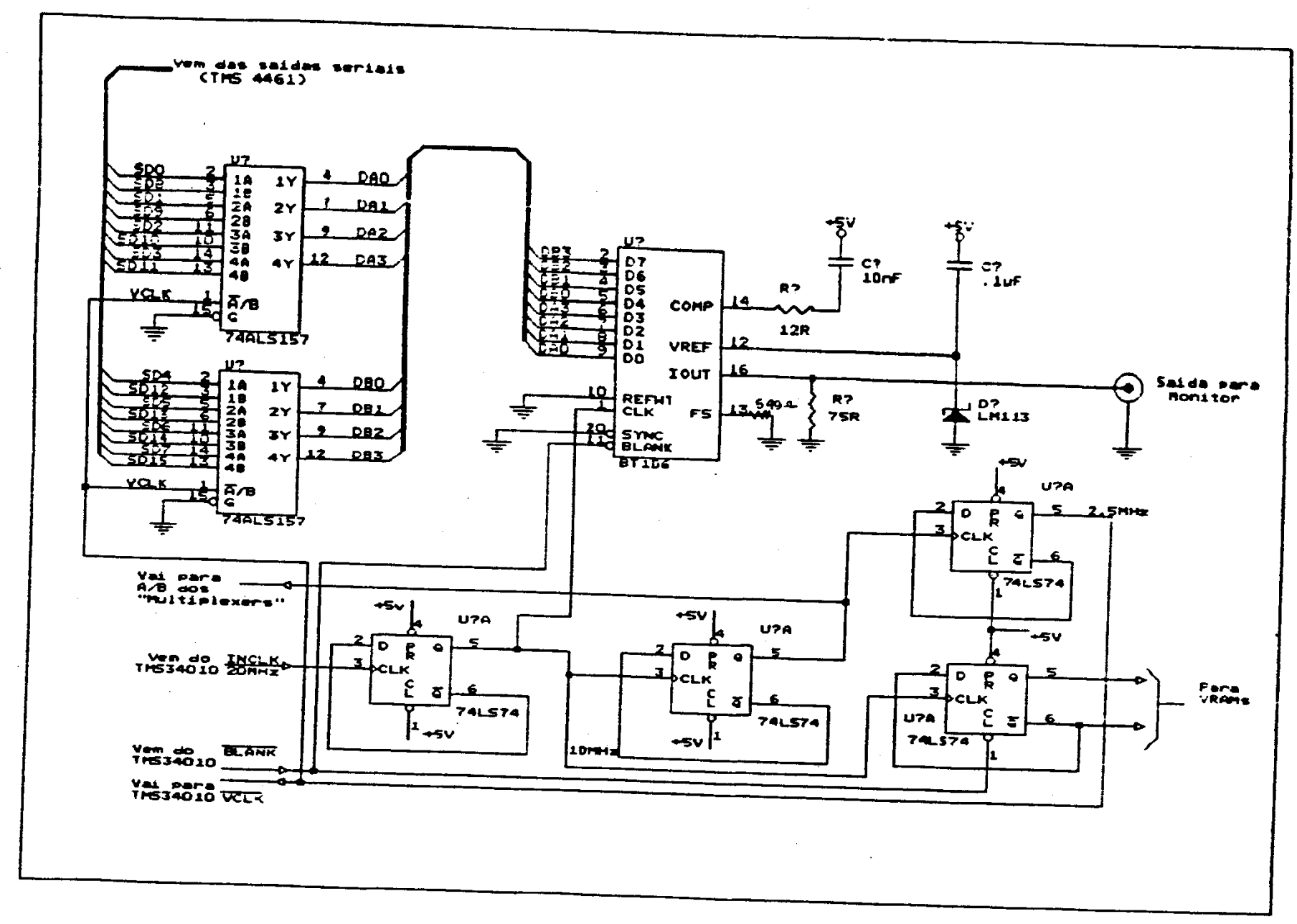

Figura 70 - Circuito de Temporização do Vídeo. 


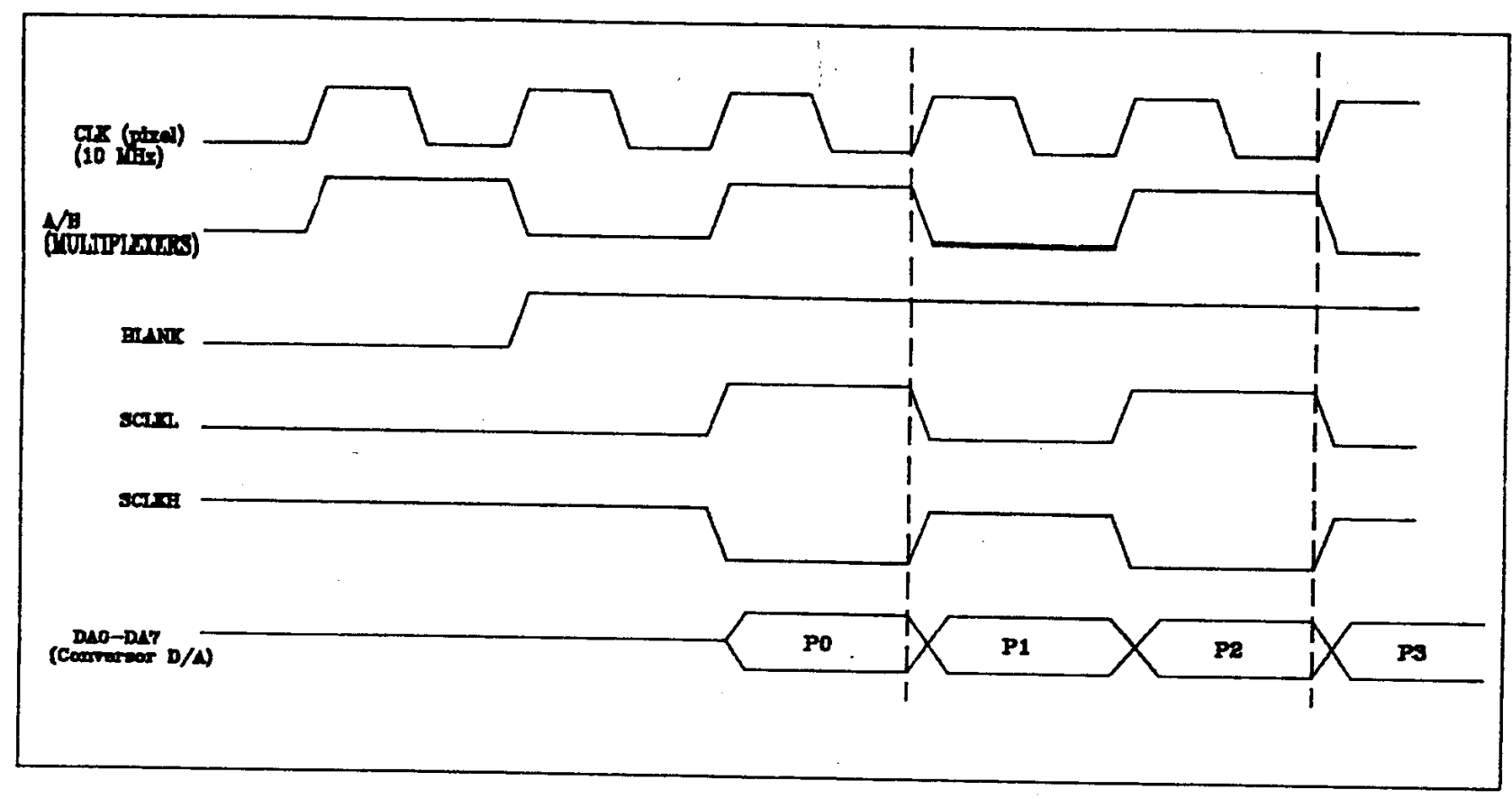

Figura 71 - Diagrama de Tempo para o Circuito de Saída para Vídeo

É interessante observar que neste sistema, a resolução da tela em relação ao sistema anterior, foi modificada somente no número de bits do "pixel". Este aumento refletiu em frequências mais rápidas para SCLKL, SCLKH e para a entrada A/B do multiplexer.

Assim, utilizando-se um circuito de temporização semelhante, para um sistema onde o "pixel" seja de 16 bits, as frequências para SCLKL (ou SCLKH) terão o dobro do valor que tinham para o sistema com "pixels" de 8 bits, isto é $10 \mathrm{MHz}$. Além disso, neste caso não haverá necessidade de dois "clocks" diferentes para as VRAMs, já que o "pixel" é de 16 bits. Desta forma, aumentando-se o número de "pixels" por linha, ou - tamanho do "pixel", pode-se atingir rapidamente o limite em frequência dos registradores de deslocamento das VRAMs (25 MHz). Neste caso seria necessário ou a adição de registradores de deslocamento externos ou a a alteração da organização do "frame buffer", conforme sugerido no capítulo 11.5.4 da referência [12]. A sugestão feita nesta referência é que as palavras da imagem com endereços pares e as com 
endereço ímpares, sejam armazenadas em dois bancos separados de VRAMs. Na lógica de seleção, o bit de endereço A4 selecionaria uma das palavras. $O$ endereço da linha seria o mesmo para os dois bancos, o que aumentaria a dissipação de potência em relação ao sistema com banco único. Mas por outro lado, esta organização teria a vantagem de reduzir a taxa na qual os dados seriam gerados para o refrescamento da tela. Além disso, com os dois bancos de VRAMs ter-se-ia dois conjuntos de registradores de deslocamento, aumentando o número de linhas desenhadas entre ciclos de refrescamento da tela.

0 aumento do tamanho do "pixel" leva também à necessidade de mais memória, de maneira que dobrando-se o tamanho do pixel dobra-se a quantidade de memória necessária para armazenar a imagem.

\subsubsection{Interface Serial}

O circuito da interface serial (figura 72) é semelhante àquele desenvolvido no sistema anterior, item 4.1.1.5. A diferença é que a lógica para seleção do 8251, e para a geração dos demais sinais de controle, foi implementada com duas PALs 16L8. Além disso o mapeamento foi modificado.

A tabela IX mostra os endereços atribuídos a cada operação realizada no 8251A.

Tabela IX - Mapa de Endereços para a Interface Serial-

Sistema com 256 Níveis de Cinza

\begin{tabular}{|ll|}
\hline endereço & \multicolumn{1}{c|}{ operação } \\
\hline 0210 000OH & lê dado da 8251A \\
$02101000 \mathrm{H}$ & lê status da 8251A \\
0200 000OH & grava dado na 8251A \\
$02001000 \mathrm{H}$ & grava controle na 8251A \\
0220 0000H & ativa "reset" \\
0230 0000H & desabilita "reset" \\
\hline
\end{tabular}




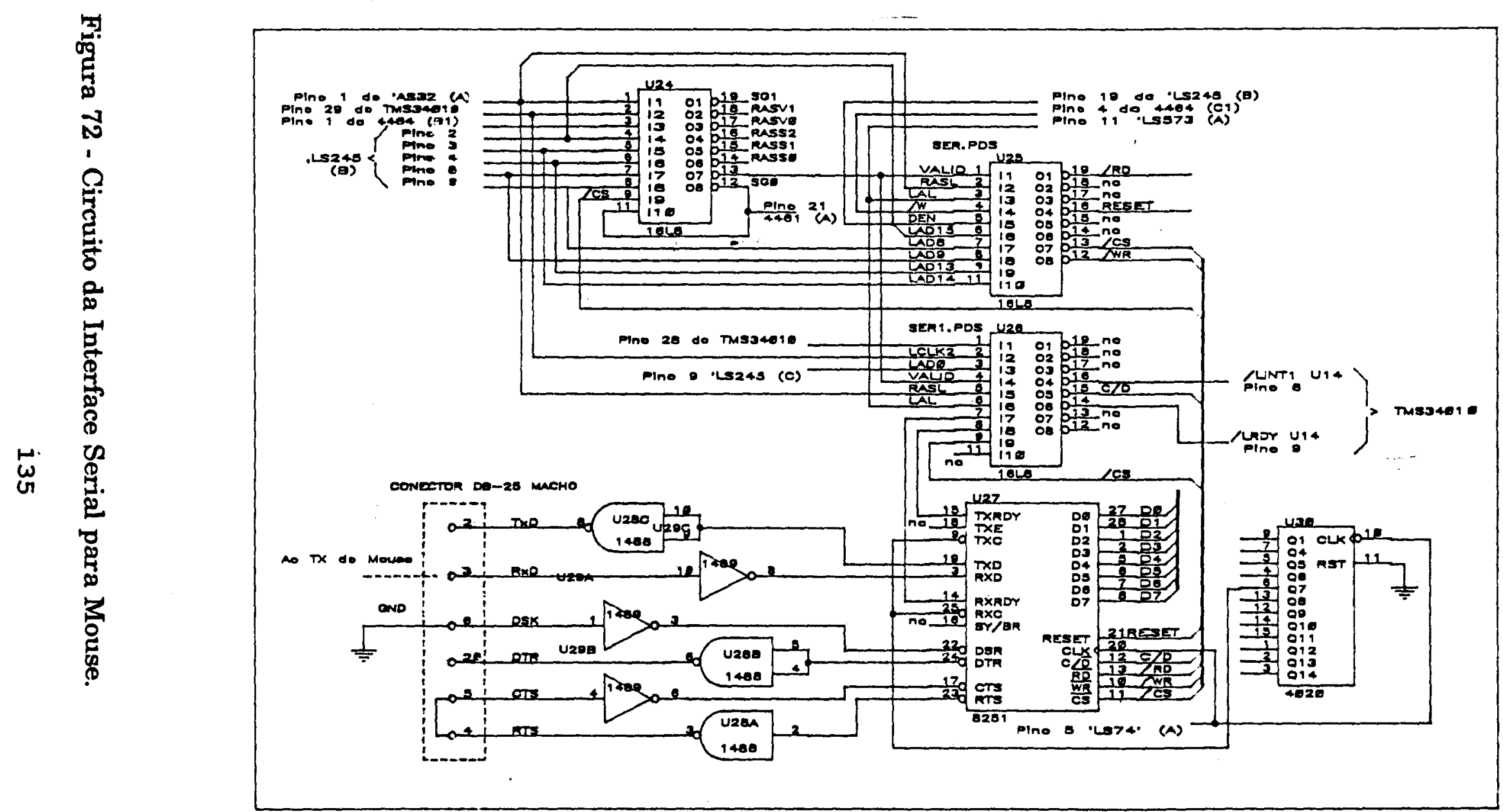


As equações das PALs são mostradas nas figuras $73 \mathrm{e} 74$. Estas equações foram realizadas de forma a ser reproduzido nas PALs, exatamente o circuito lógico de controle da interface serial, do sistema implementado anteriormente (item 4.1.5), mas com o mapeamento dado pela tabela IX.

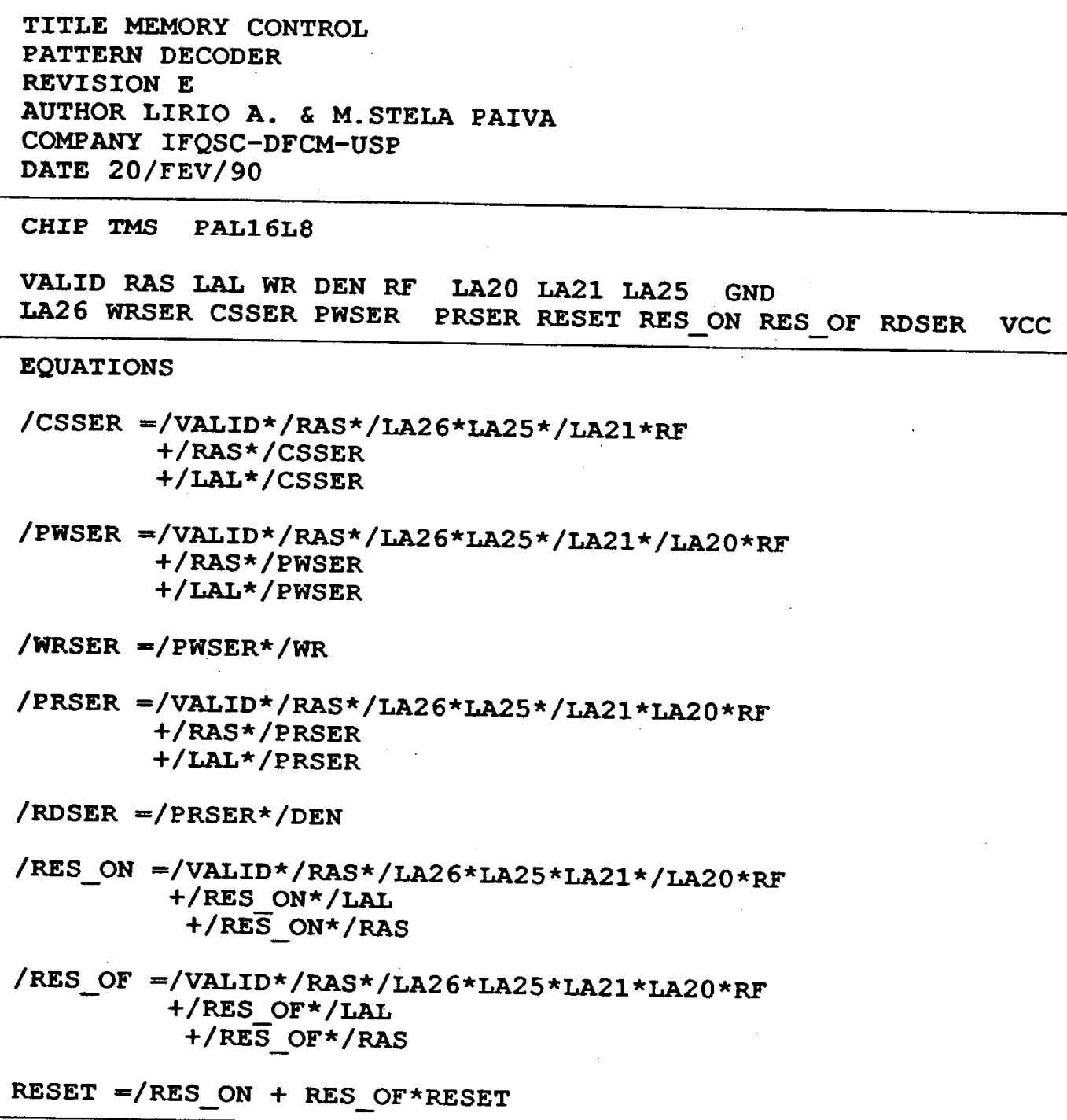

Figura 73: Equações da PAL para a Interface Serial, parte A - Sistema com 256 Níveis de Cinza 
TITLE MEMORY CONTROI

PATTERN DECODER

REVISION E

AUTHOR IIRIO A. \& M.STELA PAIVA

COMPANY IFQSC-DFCM-USP

DATE 20/fev/90

CHIP TMS PAL16L8

CLK1 CLK2 LA12 VALID RAS LAL RXRDY TXRDY CSSER GND NC NC PLRDY LRDY CD LINTI NC NC NC VCC

EQUATIONS

/PLRDY $=/$ PLRDY $* / C S S E R$

$+($ CLK $1 *$ CLK $2 * / C S S E R)$

$/ C D=/$ VALID $* /$ RAS $* / L A 12$

$+/ C D * / R A S$

$+/ C D * / L A I$

/LINT1 =RXRDY +TXRDY

/LRDY $=$ PLRDY*/CSSER

SIMULATION

TRACE_ON

TRACE_OFF

Figura 74: Equações da PAL para a Interface Serial, parte B Sistema com 256 Níveis de Cinza 


\subsubsection{Registradores de E/S do GSP}

\subsubsection{Registradores Alterados pelo Tamanho do "Pixel"}

Os registradores dedicados à geração dos sinais de sincronismo para vídeo, /HSYNC, /VSYNC e /BLANK mantem-se idênticos ao do primeiro sistema, já que o número de linhas e "pixels" da tela mantem-se os mesmos.

Em relação ao sistema anterior foram modificados apenas aqueles registradores que dependem do tamanho do "pixel". Estes registradores são os seguintes:

a.) DPYSTRT : o campo LCSTRT deste registrador é programado com 00 , indicando que uma linha de varredura é mostrada entre ciclos de refrescamento. Cada linha contem agora 4096 bits (512 "pixels" de 8 bits), que é o valor máximo que os registradores de deslocamento das VRAMs conseguem armazenar.

b.) CONVDP : este registrador foi programado com $0013 \mathrm{H}$, o que corresponde a um "pitch" da tela de $1000 \mathrm{H}$.

c.) PSIZE : este registrador foi programado com 8 , valor correspondente ao número de bits do "pixel".

\subsubsection{Resumo dos Valores Utilizados}

A tabela $X$ resume o conjunto de valôres programados nos registradores de E/S, para este sistema. 
Tabela X - Registradores de E/S para o Sistema com 256 Níveis de Cinza

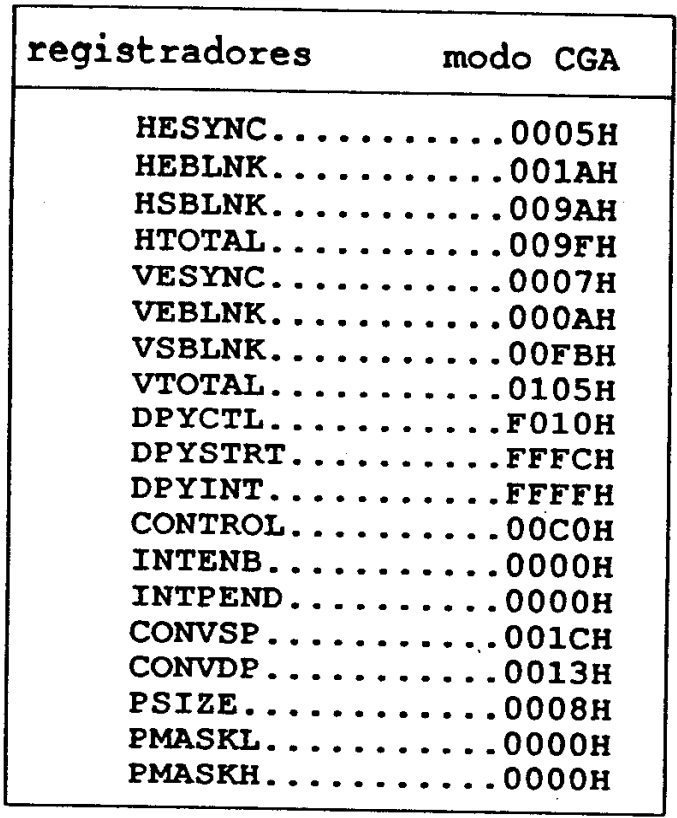




\section{Capítulo V}

\section{"Software"}

O "software" que é apresentado neste capítulo, foi desenvolvido para avaliar o funcionamento e desempenho do "hardware", e fornecer os subsídios substanciais para o desenvolvimento do "software" básico aplicativo.

Os programas que serão descritos a seguir, foram desenvolvidas na forma de subrotinas, e fazem parte de um programa principal que determina a ordem de execução das mesmas. Cada subrotina que utiliza funções gráficas, contem a definição dos parâmetros gráficos requeridos pelas respectivas funçóes. Isto dá flexibilidade à subrotina no que se refere à alteração dos parâmetros gráficos, que é realizada somente para a subrotina em questão.

Nos ítens seguintes são apresentadas as seguintes subrotinas e programas que foram desenvolvidos:

a.) subrotina para inicialização dos registradores

b.) subrotina para inicialização da "Color Palette"

c.) subrotina para apagar a tela

d.) subrotina para mostrar o padrão de cores da "Color Palette"

e.) subrotina para trocar o banco de memória de imagem

f.) subrotina para desenhar caracteres ASCII

g.) subrotina para controle do "mouse"

h.) programa para configurar o vídeo para o modo entrelaçado

i.) programa para trocar alternadamente os bancos de memória

j.) programa para divisão da tela em duas partes 


\section{k.) programa para realizar o "pan" horizontal \\ 1.) programa para realizar o "pan" vertical}

Além destes programas, é explicado no item 5.2.13 o cabeçalho ("header"), de um arquivo objeto executável do. GSP. Este cabeçalho é incluído no arquivo fonte da imagem, através de um programa desenvolvido em linguagem $C^{1}$, que após compilado e executado gera o arquivo objeto da imagem no formato requerido pelo GSP.

\subsection{Programa Principal}

Como já mencionado anteriormente, a função do programa principal é a de estabelecer a ordem de execução das subrotinas. Esta sequência é definida na subrotina DSPFIL, a qual atribui a cada subrotina a ser executada um número definido através de um diretivo "set". Esta informação é usada pelo programa principal, que busca na lista definida na subrotina DSPFLL, o número da subrotina a ser executada. Este valor é multiplicado por 2 e é somado ao endereço inicial de uma tabela de saltos (JMPTBL). Na multiplicação é utilizada a instrução de rotação à esquerda, com o valor 5. Este valor é usado porque o endereçamento é a nível de bit.

Na tabela de saltos estão definidos os endereços iniciais, a partir dos quais se encontram as instruções para a chamada da subrotina correspondente.

O anexo 1.1 contem a listagem do programa principal e da subrotina DSPFIL.

\subsection{Subrotinas e Programas}

1 por Agma J. M. Traina 


\subsubsection{Subrotinas para.Inicialização dos Registradores}

O programa de inicialização consiste na programação dos registradores de $\mathrm{E} / \mathrm{S}$, e dos registradores do arquivo B que armazenarão os parâmetros definidos para as funções gráficas.

O exemplo de cálculo dos valores destes registradores é mostrado no capítulo 5.

No anexo 1.2 são mostrados quatro exemplos de programas de inicialização, cada um para um sistema com diferente configuração de tela. Nestes programas é incluído o arquivo "gspregs.hdr", que contem a definição dos nomes dos registradores. As caracteríticas do sistema gráfico para cada exemplo são as seguintes:

a.) exemplo 1

. monitor no modo CGA

- frequência horizontal: $15750 \mathrm{~Hz}$

. frequência de "pixel" : $10 \mathrm{MHz}$

- configuração da tela: 256 linhas

512 "pixels"/linha

4 bits por "pixel"

b.) exemplo 2

- monitor no modo CGA

- frequência horizontal: $15750 \mathrm{~Hz}$

. frequência de "pixel" : $10 \mathrm{MHz}$

. configuração da tela: 256 linhas

512 "pixels"/linha

8 bits por "pixel" 
c.) exemplo 3

- monitor no modo EGA

. frequência horizontal: $21850 \mathrm{~Hz}$

. frequência de "pixel" : $15 \mathrm{MHz}$

. configuração da tela: 340 linhas

512 "pixels"/linha

4 bits por "pixel"

d.) exemplo 4

No programa do exemplo 4 pode-se selecionar um entre dois sistemas, com configurações diferentes, dependendo se a variavel sdb340 do programa for 0 ou 1.

A tabela XI ilustra a configuração do sistema para cada valor de sdb340.

Tabela XI - Configuração do sistema para o exemplo 4, anexo 1.2

\begin{tabular}{|c|c|c|c|}
\hline sdb340 & freq. horiz. & freq. de "pixel" & config. da tel \\
\hline 1 & $15750 \mathrm{~Hz}$ & $25 \mathrm{MHz}$ & $\begin{array}{l}256 \text { linhas } \\
1024 \text { "pixels"/linha } \\
4 \text { bits/"pixel" }\end{array}$ \\
\hline 0 & $15750 \mathrm{~Hz}$ & $10 \mathrm{MHz}$ & $\begin{array}{l}256 \text { linhas } \\
512 \text { "pixels"/linha } \\
8 \text { bits/"pixel" }\end{array}$ \\
\hline
\end{tabular}

\subsubsection{Subrotina para Inicializar a "Color Palette"}

Esta subrotina é dependente do "hardware", já que a tabela de cores da "Color Palette" deve ser carregada nas primeiras posiçóes da memória de vídeo, correspondentes à primeira linha que será desenhada na tela.

No anexo 1.3 são apresentados dois exemplos. Nestes exemplos, o registrador 
A2 contém a posição inicial da memória de vídeo, a partir da qual a tabela de cores será carregada, e o registrador Al contém o endereço inicial da tabela de cores na memória de programa.

No primeiro exemplo é definida uma única tabela de cores.

No segundo exemplo são definidas três tabelas de cores. 0 endereço inicial da tabela que será carregada é definido no "label" PONTX. Cada vez que uma das tabelas é carregada na memória de vídeo, é armazenado em PONTX o endereço da tabela seguinte.

\subsubsection{Subrotina para Apagar a Tela}

Esta subrotina estabelece uma cor de fundo para a tela.

No anexo 1.4 são apresentados três exemplos de programas para apagar a tela:

a.) exemplo 1 - destina-se ao primeiro sistema já descrito no item 4.1, com 256 linhas horizontais, 512 "pixels" e 4 bits por "pixel". É estabelecida uma cor de fundo para a memória de vídeo, onde esta cor é definida previamente no programa principal. A função gráfica FILL XY foi selecionada para estabelecer a cor de fundo.

Nesta subrotina, inicialmente são carregados os parâmetros gráficos para a função FILL XY. Em seguida esta função é executada, preenchendo 511 linhas da memória de vídeo com a cor selecionada. O motivo de se usar o valor 511 é que o banco de memória pode conter até duas imagens, pela configuração da tela utilizada neste sistema.

b.) exemplo 2 - destina-se ao segundo sistema descrito no item 4.2, com 256 linhas horizontais, 512 "pixels" e 8 bits por "pixel". A cada linha do fundo é atribuído um tom de cinza, obtendo-se como efeito final um fundo em degradée. A função gráfica FILL XY é usada para executar a atribuição do tom de cinza a cada linha.

c.) exemplo 3 - permite selecionar o sistema gráfico com 256 linhas/1024 
"pixels"/4 bits por "pixel", com sdb340 igual a 1, ou o sistema gráfico com 256 linhas/512 "pixels"/ 8 bits por "pixel", com sdb340 igual a 0 . É estabelecida uma cor única para o fundo usando-se a função gráfica FILL XY.

\subsubsection{Subrotina para Desenhar o Padrão de Cores da "Color Palette"}

Esta subrotina desenha na tela um retângulo, o qual é dividido em 16 áreas, cada uma das quais é preenchida com uma das cores da "Color Palette". Para isso utiliza a função gráfica FILL XY.

$O$ "offset" da função FILL XY usa endereçamento linear o que a torna dependente do "hardware". Como esta figura deveria ser utilizada em sistemas com outras configurações, foram desenvolvidos dois macros, o SOMALIN e o SOMAPIX, tornando-a assim independente do "hardware". Desta forma para utilizar este programa em um sistema com outra configuração, é necessário apenas modificar os parâmetros gráficos, não havendo necessidade de alterar endereço físico de memória.

O macro SOMALIN determina o valor do endereço que dista um número "nl" de linhas especificadas, de um endereço inicial dado. Como este cálculo é feito em termos do "pitch" do sistema, isto o torna independente da configuração utilizada.

O macro SOMAPIX determina o valor do endereço que dista um número "np" de "pixels" de um determinado "pixel", cujo endereço é conhecido.

A listagem desta subrotina encontra-se no anexo 1.5.

5.2.5 Subrotina para Trocar o Banco de Memória de Imagem

Esta subrotina permite trocar o banco de memória de imagem, através da modificação do endereço inicial da memória de vídeo, no registrador DPYSTRT.

Dois exemplos são apresentados no anexo 1.6. 0 exemplo 1 foi desenvolvido para o primeiro sistema, descrito no item 4.1, enquanto que o exemplo 2 foi 
desenvolvido para o segundo sistema (item 4.2).

Para o exemplo 1 a diferença entre os endereços iniciais das duas imagens ocorre no bit 11 do registrador DPYSTRT, e o "field" 1 é estabelecido como sendo de 1 bit, de forma a modificar somente 0 bit 11.

Para o exemplo 2, a diferença entre os endereços iniciais das duas imagens ocorre no bit 12 do registrador DPYSTRT.

0 registrador $\mathrm{A} 9$, em ambos programas, contem o endereço inicial da primeira ou da segunda memória de imagem, e é usado pelos outros programas para desenhar figuras em cada uma das memórias de imagem.

\subsubsection{Programa Para Desenhar Caracteres ASCII}

Este programa permite sobrepor um texto sobre uma imagem, utilizando o recurso de transparência.

A linha constituída por uma sequência de caracteres ASCII, deve ser terminada por um caracter nulo. Cada caracter tem 8 "pixels" de largura e 16 "pixels" de altura. Os caracteres são definidos no arquivo "CHARSET.ASM", que foi fornecido pelo fabricante.

As coordenadas $\mathrm{X}$ e $\mathrm{Y}$ da posição inicial da sequência de caracteres na tela são definidas no programa principal, assim como o endereço inicial da sequência de caracteres no programa.

A listagem do programa encontra-se no anexo 1.7 .

\subsubsection{Programa Para Controle do Mouse}

Este programa consistiu no desenvolvimento de um cursor que se movimenta sob o controle do "mouse".

A figura escolhida para representar este cursor foi a cruz.

Para permitir a visualização do cursor em imagens com qualquer tom de cinza, 
foram utilizadas duas cruzes, uma mais interna com o tom de cinza mais intenso (branca), e a outra externa com o tom de cinza mais escuro (preto).

0 programa é dividido em três partes.

A primeira parte consiste na definição dos parâmetros que serão utilizados nas rotinas de interrupção, e na programação da interrupção, como é mostrado no diagrama em blocos das figuras 75 e 76. Todos os valores dos registradores dos arquivos A e B, a serem utilizados posteriormente nas rotinas de interrupção, são armazenados numa pilha, endereçada por um registrador A ou B. Este recurso foi usado para evitar que estes valores fossem destruídos na pilha endereçada pelo ponteiro da pilha (SP), pelos dados das subrotinas que são executadas após esta, já que a maioria destas subrotinas utiliza a pilha endereçada pelo SP.

A segunda parte consiste na rotina de interrupção INTERR, que lê um dado, verificando se o mesmo é um dado de controle. Em caso positivo, o controle do programa é passado para a rotina correspondente a este dado de controle, a qual armazena um código numa posição de memória. Este código será usado posteriormente pelo "software" que será implantado no sistema.

Após o dado de controle, o mouse envia 4 "bytes" correspondentes à sua movimentação nas direções X e Y. A cada "byte" enviado é solicitado um pedido de interrupção. $O$ valor 4 é carregado no registrador $A 3$, e é usado pela rotina de interrupção seguinte, a rotina $\mathrm{XY}$, indicando que a mesma será executada nas próximas 4 solicitações da interrupção LINT1. O endereço inicial desta rotina é carr gado no vetor de interrupção.

Ainda neste programa é criada uma área de 512 "bytes", para armazenamento dus uados provenientes do "mouse", utilizada para a comparação dos mesmos com aqueles armazenados num analisador lógico, para análise e depuração do sistema.

A terceira parte do programa consiste na rotina de interrupção $X Y$, que lê um dado do "mouse", verifica se o mesmo é positivo, e passa o controle do programa para uma das rotinas para a movimentação do cursor. 
SUEROTZNA PARA A INTERPACE SIIRIAL.

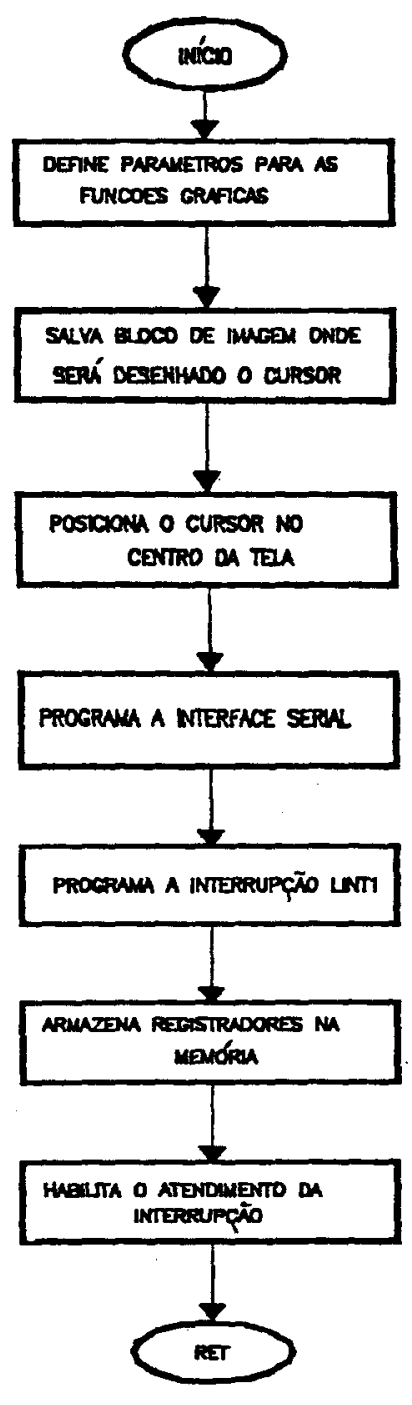

ROTWM DE DTTERRUPCAO "NNTERT"

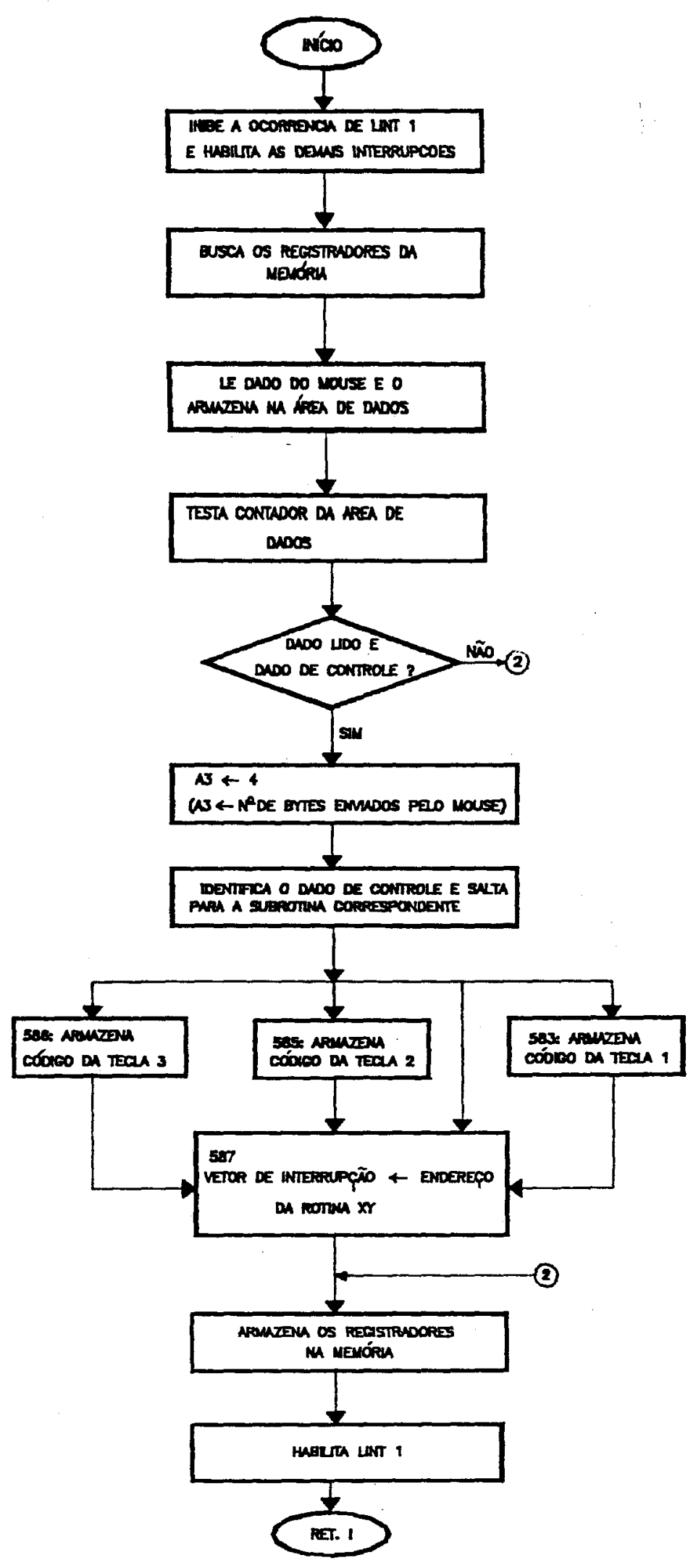

Figura 75 - Diagrama em Blocos para o Programa "Mouse" - Parte 1. 
ROTDNA DE INTERRUPÇÃO XY

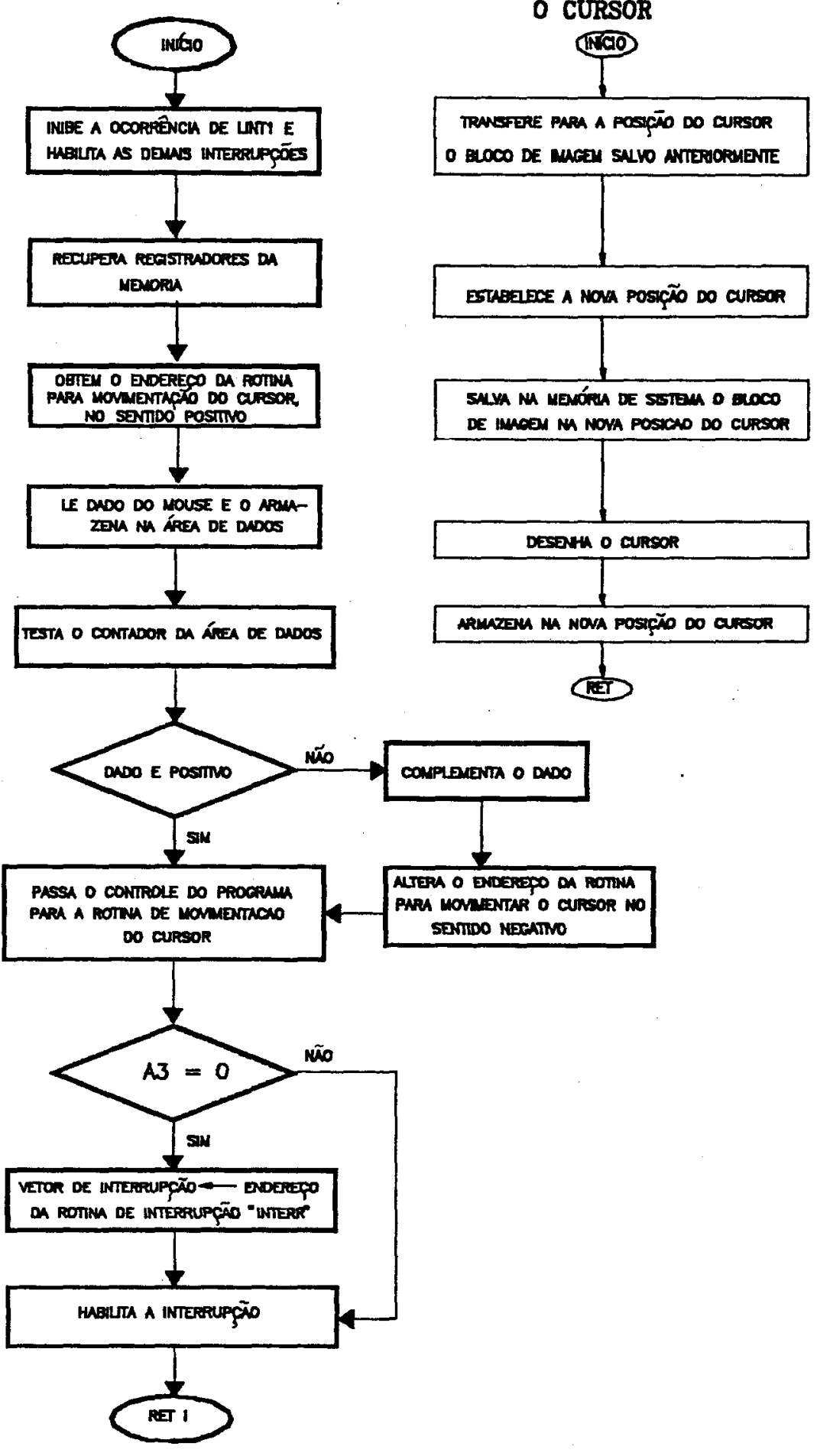

Figura 76 - Diagrama em Blocos para o Programa "Mouse" - Parte 2. 
Existem 4 rotinas para movimentação do cursor:

XDIR: movimenta o cursor para a direita;

XESQ: movimenta o cursor para a esquerda;

YCIMA: movimenta o cursor para cima;

YBAIXO: movimenta o cursor para baixo.

Cada uma destas rotinas inicialmente transfere o bloco de imagem salvo anteriormente, para a posição de memória de imagem na qual se encontra o cursor, recuperando a imagem naquela posição. Em seguida estabelece a nova posição do cursor de acordo com o dado recebido do "mouse", salva o bloco de imagem desta nova posição, e finalmente desenha o cursor a partir desta posição.

As subrotinas para salvar e recuperar blocos de memória, e para desenhar o cursor utilizam além do recurso de transparência, as seguintes funções gráficas para a transferência de blocos de "pixel": PIXBLT B,XY/ PIXBLT XY,L/ PIXBLT L,XY.

A listagem deste programa encontra-se no anexo 1.8 .

\subsubsection{Programa para Configurar o Vídeo para o Modo Entrelaçado}

Este programa possibilita a visualização de imagens com maior resolução no eixo $Y$, resultando numa matriz de $512 \times 512 \times 8$, para o padrão CGA.

Como já mencionado anteriormente, no modo entrelaçado cada "frame" é constituído por dois campos de linhas de varredura horizontal. Na tela são mostradas linhas alternadas dos dois campos. São executadas duas varreduras verticais separadas para cada "frame", uma para as linhas pares e outra para as linhas ímpares.

No TMS34010, o modo de varredura entrelaçado é selecionado quando o bit NLL do registrador DPYCTL for programado para "0". Além disso o valor do campo DUDATE do registrador DPYCTL deve ter o dobro do valor usado no modo não 
entrelaçado. Isto faz com que durante o refrescamento da tela, sejam saltadas linhas alternadas, nos campos pares e ímpares.

No programa desenvolvido para o sistema do item 4.2, programando-se o registrador DPYCTL para vídeo entrelaçado, aumenta-se o número de linhas de 256 para 512. Como consequência o dobro de memória de vídeo é requerido, já que se tem o dobro de linhas em relação ao modo não entrelaçado.

No programa foi utilizada a figura LIE, com o fundo em degradée de cinza. A subrotina que apaga a tela, teve de ser modificada para desenhar cada duas linhas com o mesmo tom de cinza, já que a tela passou a ser constituída por 512 linhas.

A listagem do programa encontra-se no anexo 1.9.

\subsubsection{Programa Para Trocar Alternadamente os Bancos de Memória}

Este programa foi desenvolvido para o sistema do item 4.2 (256 níveis de cinza), e mostra alternadamente as imagens de dois bancos de memória de vídeo. Um tempo de atraso é inserido entre a troca de bancos, a fim de permitir a visualização da imagem por um tempo adequado.

Para a troca dos bancos foi utilizado o registrador DPYSTRT, que contem o endereçamento inicial de refrescamento da tela.

0 primeiro banco de memória de vídeo inicia no endereço $00000000 \mathrm{H}$, enquanto o segundo banco inicia no endereço 0010 0000H. Portanto a passagem de um banco para outro consiste apenas na troca do bit de endereço A20. Este bit corresponde ao bit A12 do registrador DPYSTRT. Assim, complementando-se este bit, troca-se o banco de memória que esta sendo mostrado.

A listagem do programa encontra-se no anexo 1.10. A subrotina DSPFIL contem a sequência de subrotinas que serão executadas. Após o programa de inicialização, é apagada a primeira tela, é desenhada a primeira sequência de caracteres (string1), e é executada a subrotina FIL4, que desenha as letras LIE com a função gráfica FILL L, em degradée de cinza, dentro de uma moldura retangular. No final deste programa 
é modificado o endereço de memória para o segundo banco. Este segundo banco é apagado e é desenhado o texto "LABORATÓRIO DE INSTRUMENTAÇÃO ELETRÔNICA - 1990", a partir da subrotina que desenha caracteres, e com o fundo em degradée de cinza. Para isso foram utilizados os recursos de transparência, e a função lógica "and" da fonte com o complemento do destino (CONTROL $=0800 \mathrm{H}$ ).

Após serem desenhadas as duas imagens, é executado um loop de atraso, e é feita a reprogramação do registrador DPYSTRT, para mostrar o segundo banco. A partir daí o programa é mantido em "loop" entre a subrotina que gera o tempo de atraso e a subrotina que altera o registrador DPYSTRT, de forma a mostrar alternadamente as duas imagens.

\subsubsection{Programa Para Dividir a Tela em Duas Partes}

Este programa foi desenvolvido para o sistema gráfico do item 4.2, e simula uma imagem cujo "pitch" seja maior que o da tela, ou seja, a imagem não pode ser vista completamente na tela. A tela é então dividida em duas partes, e em cada parte é programado o trecho da imagem que se deseja visualizar.

Para simular uma imagem maior do que a tela, foram utilizadas duas figuras, desenhadas uma ao lado da outra, como é mostrado na figura 77. As figuras utilizadas são as mesmas descritas no item 5.2.9.

0 "pitch" da imagem constituída pelas duas figuras, tem o dobro do valor do "pitch" da tela. Isto levou a alterar, no programa de inicialização, os registradores que dependem do "pitch": o registrador CONVDP, e o campo DUDATE do registrador DPYCTL, que teve o seu valor duplicado.

A visualização de uma ou outra figura é possível com a alteração do "offset" (B4) para um valor conveniente. Para a primeira figura o "offset" é $>0000$, enquanto que para a segunda figura o "offset" é de $>\mathbf{1 0 0 0}$. 


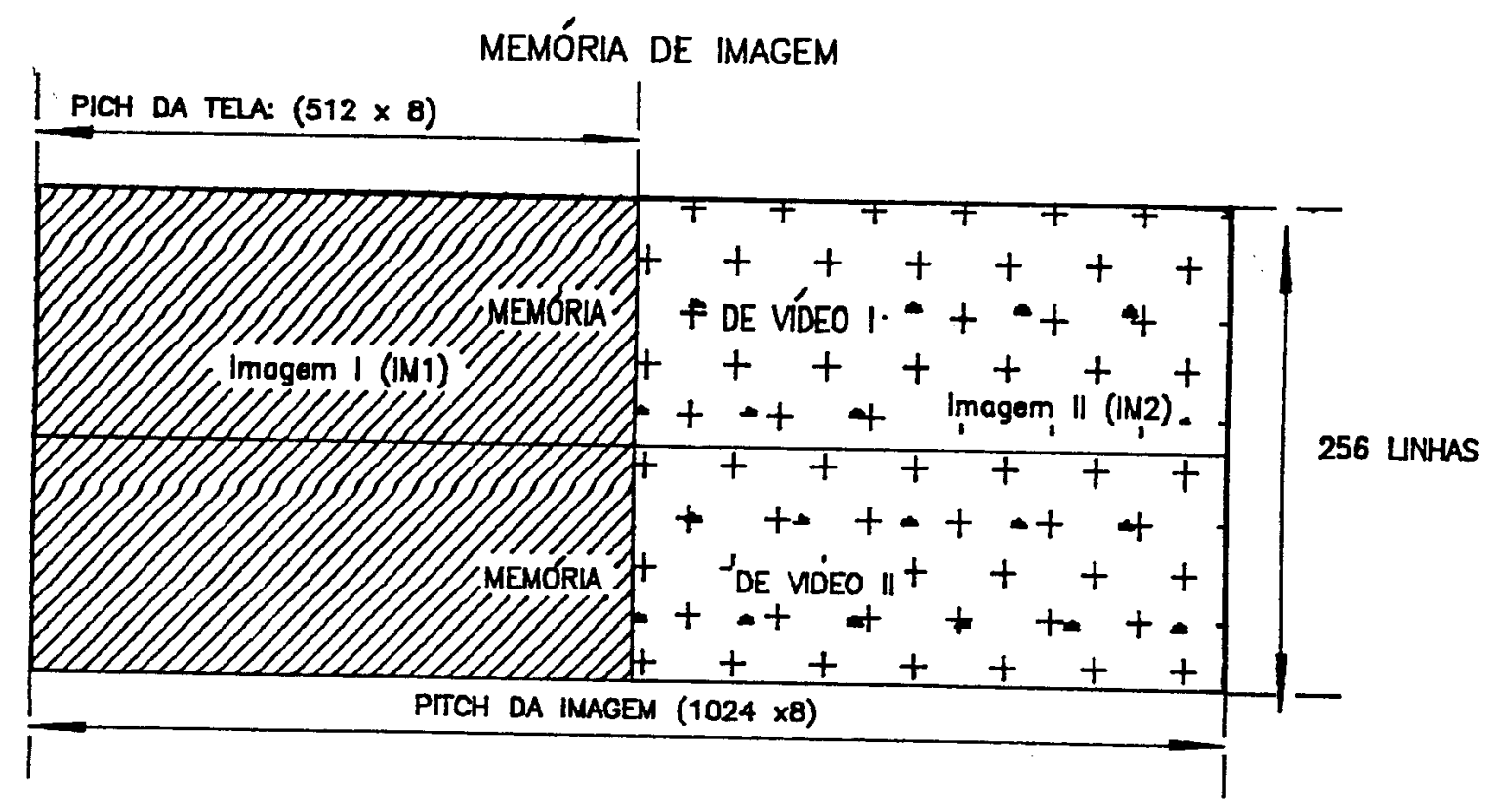

Figura 77 - "Frame Buffer" com "Pitch" Maior que o da Tela.

Um dos recursos fornecidos pelo GSP para mostrar uma imagem como esta é o de interrupção do vídeo ("display interrupt), o qual consiste em programar o GSP para ativar a interrup̧̧ão DI, quando uma linha especificada está sendo mostrada na tela. A partir desta linha uma outra imagem passa a ser mostrada, como é pode ser visto na figura 78.

Para a interrupção do vídeo(DI) ser ativada, o bit DIE do registrador INTENB deve ser programado com 1 , e o registrador DPYINT deve ser programado com o número da linha de varredura horizontal desejada. O conteúdo de DPYINT é comparado com o do registrador VCOUNT. Quando VCOUNT=DPYINT, a interrupção do vídeo é solicitada e o bit DIP no registrador INTPEND é estabelecida para 1. Isto coincide com o início do retraço horizontal que marca o fim da linha designada pelo valor contido em DPYINT.

Para aplicações de divisão da tela, um novo valor deve ser carregado no registrador DPYADR, imediatamente após a transição 0 para 1 do bit DIP. Este novo valor de DPYADR não afetará a linha que segue imediatamente ao fim do intervalo do retraço horizontal corrente, mas afetará a próxima linha. 
TELA

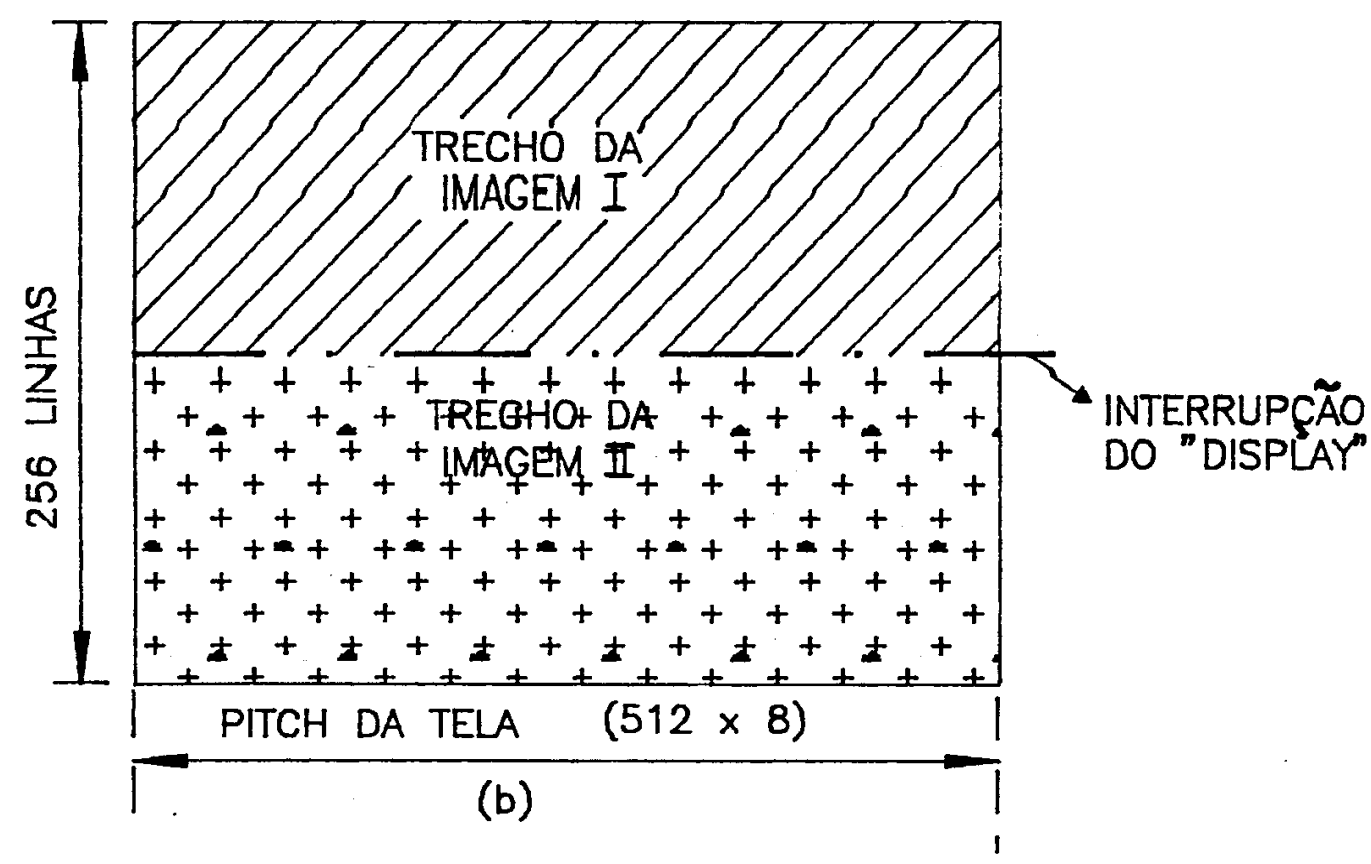

Figura 78 - Tela do Monitor de Vídeo Contendo Duas Vistas Diferentes da Memória de Imagem.

Na listagem, que se encontra no anexo 1.11, o programa DSPFIL mostra a sequência das subrotinas que são executadas. Inicialmente é executado o programa de inicialização dos registradores, no qual foram modificados os registradores B3(DPTCH), DPYCTL e CONVDP. Em seguida é estabelecido o fundo para a primeira imagem, com o programa APAGA, e é desenhada a figura LIE.

O próximo programa a ser executado é o PADRÃO, que modifica o "offset" para $1000 \mathrm{H}$, endereço inicial da figura 2. É desenhado o fundo para a segunda figura. $O$ programa PADRÃO é executado novamente para realizar a função lógica $E$, da fonte ace complemento do destino, que foi anteriormente alterada pelo programa APAGA. Uma vez desenhada a segunda figura, é executado o programa HPAN para a in $\rightarrow$ rupção do vídeo.

A primeira figura pode ser mostrada a partir de qualquer linha, sendo 
necessário para isso apenas programar o registrador DPYSTRT com o valor adequado.

A segunda figura também pode ser iniciada a partir de qualquer linha, desde que o registrador DPYADR seja programado adequadamente, após a interrup̧̧ão do vídeo.

A grande desvantagem deste método reside na necessidade de monitorar a ocorrência da interrupção do vídeo através do programa. Isto ocorre porque o intervalo do retraço horizontal é insuficiente para o atendimento da interrup̧̧ão do "display". A duração do retraço horizontal é de aproximadamente 12,3 us. Somente a latência da interrupção utiliza 16 estados de máquina, o que para o sistema em questão corresponde a 12,8 us. A latência da interrupção consiste nas operaçōes de salvar o contador de programas e o "status" na pilha, e carregar o contador de programa com o endereço da rotina a ser executada.

\subsubsection{Programa para Realizar "Pan" na Horizontal}

O GSP contém recursos que facilitam a implementação de "pan" na horizontal. Um dos registradores de E/S, DPYTAP, é dedicado a esta finalidade. Durante um ciclo de refrescamento da tela, os 16 bits deste registrador são combinados através de um "ou" lógico, com o valor gerado nos pinos LAD0-LAD15 durante o tempo do endereço da coluna, da seguinte forma: o bit 0 de DPYTAP é combinado com o LAD0, o bit 1 de DPYTAP é combinado com LAD1, e assim por diante. Isto significa que o endereço da coluna gerado durante o ciclo de refrescamento da tela é um "ou" lógico dos bits 2 a 7 de DPYADR, e dos bits 0 a 15 de DPYTAP.

Em aplicações de "pan", o valor 0 em DPYTAP posiciona a tela na posição mais à esquerda do "frame buffer". Incrementando DPYTAP, a tela desloca-se para posições mais à direita através do "frame buffer".

Dois programas foram desenvolvidos para realizar o "pan" na horizontal, um para o sistema de 4 bits (item 4.1) e outro para o sistema de 8 bits (item 4.2). Estes programas serão descritos a seguir. 


\subsubsection{Sistema com "Pixel" de 8 Bits}

Foi desenvolvido para este sistema um programa idêntico àquele descrito no item 5.2.10, onde o "frame buffer" tem o "pitch" maior do que o da tela. As figuras utilizadas para a simulação da imagem foram as mesmas daquele item.

Incrementando o registrador DPYTAP para se fazer o "pan" na horizontal, verificou-se que a primeira imagem iniciou no ponto correto conforme estabelecido pelo registrador DPYTAP, mas o trecho esperado da segunda imagem não foi mostrado, e em seu lugar foi mostrado o restante da primeira imagem.

Verificou-se que a causa deste efeito devia-se à lógica interna das VRAMs. As memórias VRAMs utilizadas são de 64Kx4, e organizadas numa matriz de 256 linhas por 256 colunas. Durante um ciclo de tranferência de memória para registrador de deslocamento, os dados referentes a uma linha da memória são transferidos para os registradores de deslocamento internos à VRAM. Se o conteúdo dos registradores de deslocamento for suficiente para desenhar apenas uma linha da tela, não será possível a realização do "pan" na horizontal, pois a lógica interna da memória não permite que os registradores sejam carregados com dados de duas linhas diferentes. Este é exatamente o problema verificado no sistema gráfico em questão.

Desta forma este tipo de VRAM restringe o "pan" na horizontal, a sistemas cujas resoluções de tela sejam tais que os registradores de deslocamento das VRAMs tenham capacidade para armazenar os dados de mais de uma linha da tela.

Para o sistema de 8 bits o problema ficaria resolvido trocando-se as VRAMs por outras cujos registradores de deslocamento tivessem maior capacidade, ou então utilizando a organização de memórias mencionada no item 4.2.3, onde as palavras com endereços pares e ímpares são armazenadas em bancos de VRAMs separados. 


\subsubsection{Sistema com "Pixel" de 4 Bits}

Para o sistema de 4 bits o "pan" na horizontal é possível, pois os registradores de deslocamento das VRAMs tem capacidade para armazenar os dados de duas linhas horizontais. Além disso este sistema pode também armazenar duas telas diferentes.

Nesta programa, como no anterior, foram desenhadas duas figuras de maneira tal que simulassem uma imagem com "pitch" maior que o da tela do monitor de vídeo, como é mostrado na figura 79.

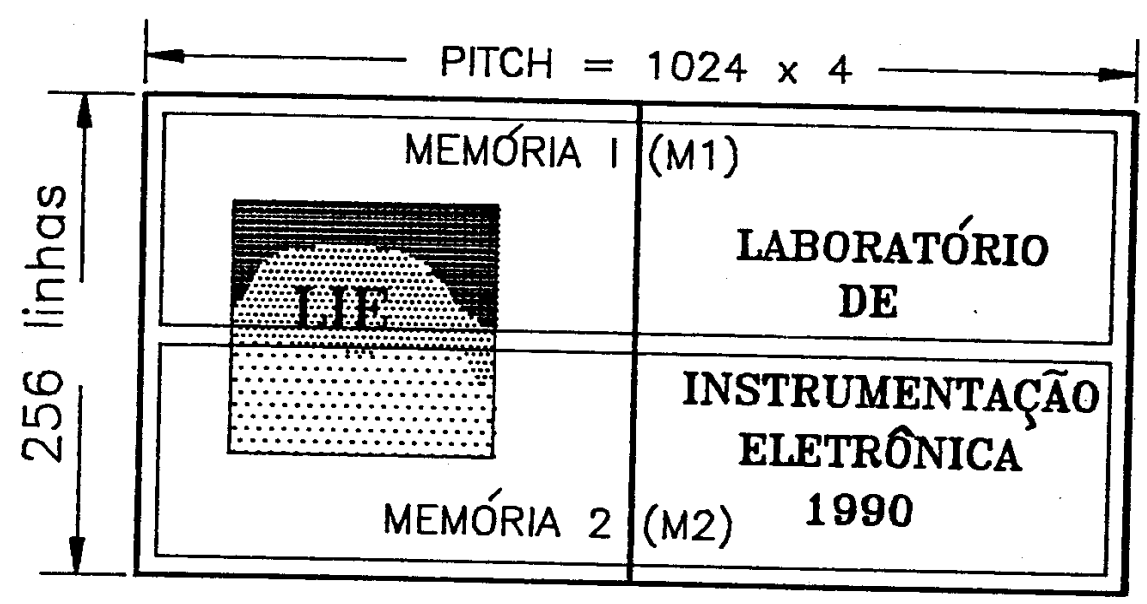

Figura 79 - Memória de Imagem para "Pan" na Horizontal.

Nesta figura, em M1 e M2 foram desenhadas respectivamente as letras LIE, e a sequência de caracteres " LABORATÓRIO DE INSTRUMENTAÇÃO ELETRÔNICA - 1990 ".

Na rotina para "pan" considerou-se um "frame buffer" que tivesse o comprimento de 3 "pitches" de tela, da forma como é mostrada na figura 80. Isto foi necessário para manter a continuidade da imagem durante o "pan", ou seja, para não ocorrer um salto para IM1 ao se deslocar de IM2 para IM1. Desta forma o cursor pode se movimentar indefinidamente para a direita, sem a ocorrência de descontinuidade. 


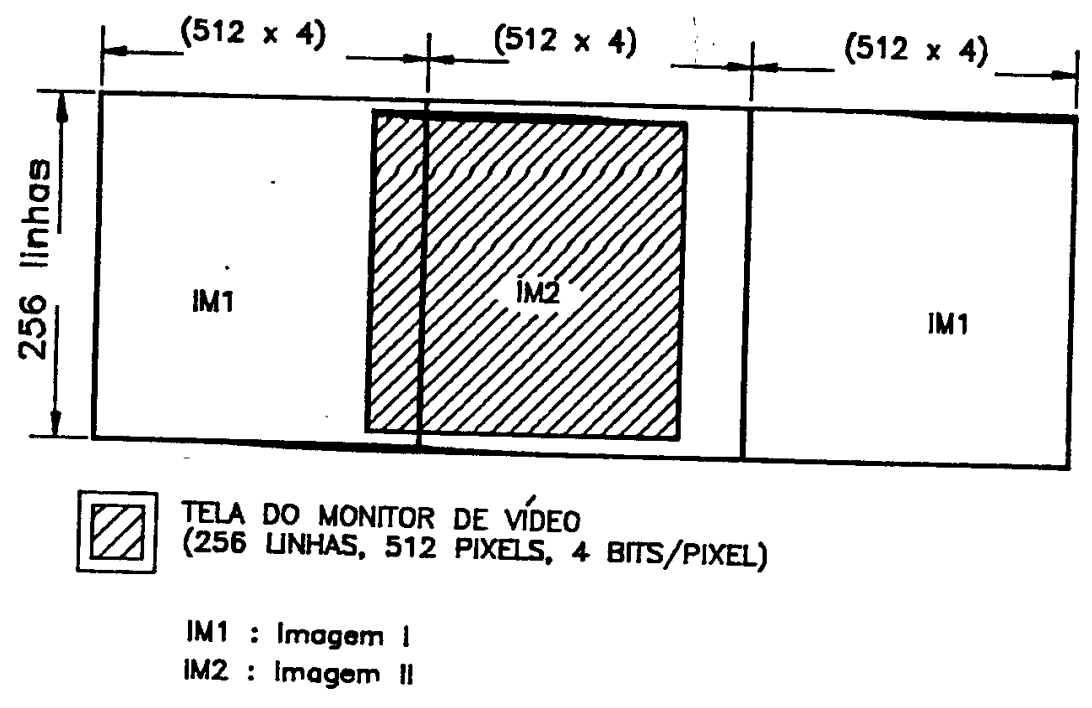

Figura 80 - "Pan" Horizontal - Deslocamento da Tela sobre a Imagem Original.

A tela é deslocada sobre o "frame buffer" quando o cursor alcança o fim da tela.

Como não foi utilizado número com sinal, estabeleceu-se a origem da tela na posição mais à esquerda da imagem IM1. Desta forma quando o cursor atinge esta posição, o movimento do mesmo (e consequentemente da tela) para a esquerda é inibido. Esta restrição do programa não traz quaisquer prejuízos, já que se pode visualizar quaisquer partes das imagens IM1 e IM2.

O programa desenvolvido para este sistema, apresentado no anexo 1.12, primeiramente inicializa os registradores, a seguir carrega a tabela de cores da "Color Palette", e desenha as figuras nas memórias M1 e M2. Finalmente é executado o programa para movimentação do cursor através do "mouse", no qual foi incluída a rotina para "pan" na horizontal.

Duas observações importantes devem ser feitas neste programa:

- a primeira é que o registrador para "pan", DPYTAP, é incrementado por palavra, enquanto que o cursor é incrementado por "pixel". Assim uma correção deve ser feita no valor de DPYTAP, de forma a sincronizar o movimento do cursor com o deslocamento da tela. 
- a segunda observação refere-se à "Color Palette". A maneira como foi implementada em "hardware", requer que a tabela de cores seja carregada a cada retraço vertical. $\mathrm{Na}$ rotina para "pan" isto implica na necessidade de recarregar os dados da "Color Palette" na memória de vídeo a cada deslocamento da tela. Para evitar isto o "hardware" teria de ser modificado de forma que a tabela de cores da "Color Palette " fosse carregada através do modo "command load", e não a cada retraço vertical.

\subsubsection{Programa para Realizar "Pan" na Vertical}

Este programa foi desenvolvido para o sistema com "pixel" de 4 bits, e foi simulada uma imagem com dimensão na vertical maior do que a da tela. Para a simulação foram utilizadas as mesmas imagens já descritas no item 5.2.11. A figura 81 ilustra a forma como as imagens foram desenhadas no "frame buffer".

$\mathrm{Na}$ rotina de "pan" na vertical foi considerado como se o "frame buffer" fosse constituído por 3 telas (figura 82), de maneira semelhante ao "pan" na horizontal, e pelas mesmas razões já descritas no item 5.2.11.

A origem da tela foi estabelecida na posição superior da imagem IM1. Desta forma quando o cursor atinge esta posição, o movimento do mesmo (e consequentemente da tela) para cima é inibido.

O registrador do GSP para fazer o "pan" na vertical é o DPYSTRT, que define o endereço inicial de refrescamento da tela. $O$ conteúdo deste registrador é alterado para atualizar a posição da tela, somente quando o cursor atinge a parte inferior da tela. $O$ valor a ser carregado neste registrador tem de ser corrigido, pois o cursor é incrementado por linha, enquanto este registrador é incrementado a cada duas linhas. Isto ocorre porque o conteúdo dos registradores de deslocamento das VRAMs, contem dados para preencher duas linhas da tela, e assim este registrador foi programado para que duas linhas fossem desenhadas entre ciclos de refrescamento da tela. 


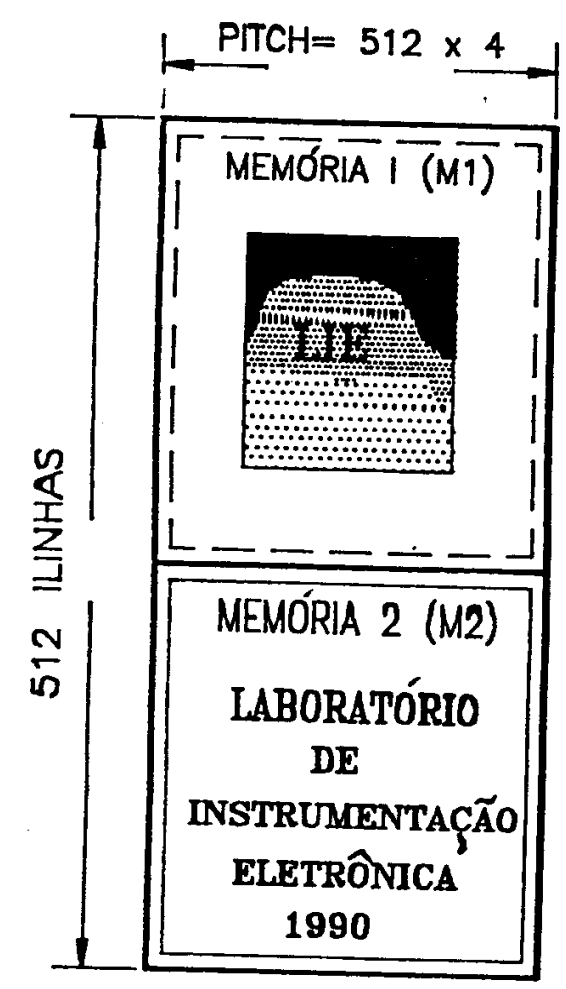

Figura 81 - Memória de Imagem para "Pan" na Vertical.

Outra observaçào importante diz respeito à "Color Palette". A tabela de cores deve ser carregada na primeira linha, que inicia no endereço especificado no registrador DPYSTRT. Assim, cada alteração deste registrador requer o carregamento da tabela de cores para a nova posição. Mas isto implica na destruição da parte da linha da imagem onde será carregada esta tabela. Para evitar isto, o programa salva os dados desta linha na memória de sistema, antes de carregar a tabela de cores numa determinada linha. Estes dados serão devolvidos para a linha em questão quando a tabela de cores for desenhada em outra posição, mantendo a imagem inalterada.

A alternativa a isto seria a modificação do "hardware" para carregar a tabela de cores através do modo "command load".

A listagem desta programa encontra-se no anexo 1.13. 


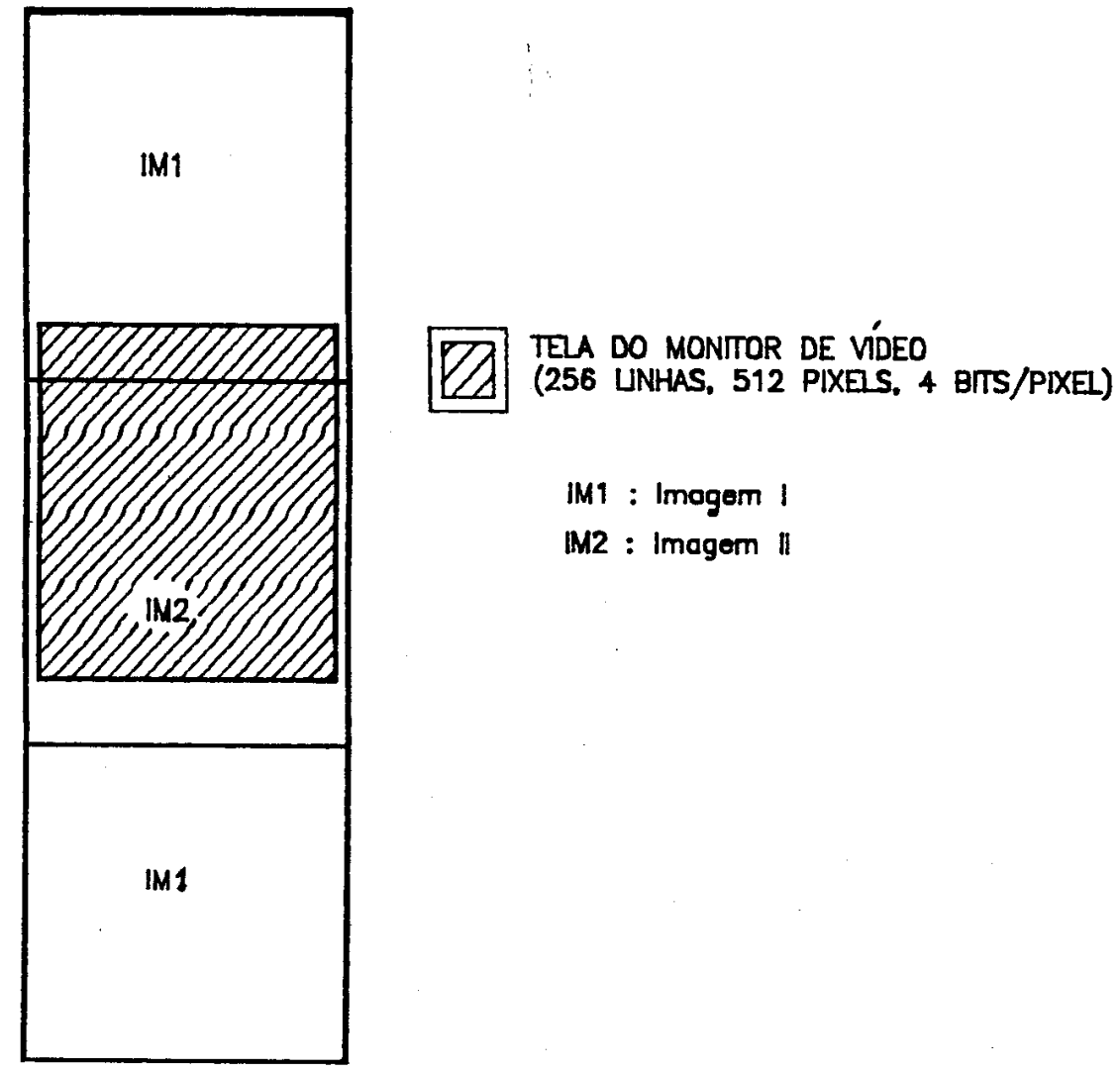

Figura 82 - "Pan" Vertical - Deslocamento da Tela sobre a Imagem.

\subsubsection{Formato de Arquivos de Imagens}

Para carregar as imagens obtidas por RM na memória de vídeo através do programa SDBL, foi incluído no arquivo fonte da imagem, o "cabeçalho" presente em um programa objeto executável do GSP.

Como já mencionado anteriormente, o assembler e o linker do TMS34010 criam arquivos objetos que estão no formato de arquivo objeto geral (COFF: common object file format), que gera métodos mais flexíveis e potentes para gerenciar os segmentos de código e a memória de sistema.

A estrutura do arquivo objeto é constituída pelos seguintes elementos: 
. um arquivo "header";

. informação opcional sobre o "header";

. uma tabela de "headers" das seções;

. dados para cada seção (exceto .bss);

. informação de relocação para cada seção (exceto .bss);

. registro (entries) do número da linha para cada seção (exceto .bss);

- uma tabela de símbolos;

. uma tabela de caracteres.

O assembler e o linker produzem arquivos objeto com a mesma estrutura COFF, exceto que o programa objeto executável não contem registros de relocação. A figura 83 mostra a estrutura global do arquivo objeto.

No cabeçalho anexado a cada imagem foram incluídos somente o arquivo "header", a informação opcional sobre o "header" e a seção de dados, já que o arquivo da imagem é apenas um arquivo de dados.

Os valores atribuídos aos elementos do cabeçalho para o arquivo desta imagem, são mostrados nos itens seguintes. Estes valores foram obtidos das tabelas XIV e XV, do item 5.2.13.4, que mostram parte do conteúdo do arquivo objeto.

\subsubsection{Arquivo "Header"}

Este arquivo contem 20 "bytes" de informação, que descrevem o formato geral de um arquivo objeto. A descrição deste arquivo é mostrada na tabela XII. Os valôres atribuídos aos "bytes" foram obtidos da tabela XV.

\subsubsection{2 "Header" Opcional}

O "header" opcional é usado para executar a relocação durante o "download". A tabela XIII mostra os "bytes" que constituem este arquivo. 


\subsubsection{3 "Header" da Seção de Dados}

Este "header" especifica a posição inicial da seção de dados no arquivo objeto. A tabela XIV descreve os "bytes" que constituem esta seção.

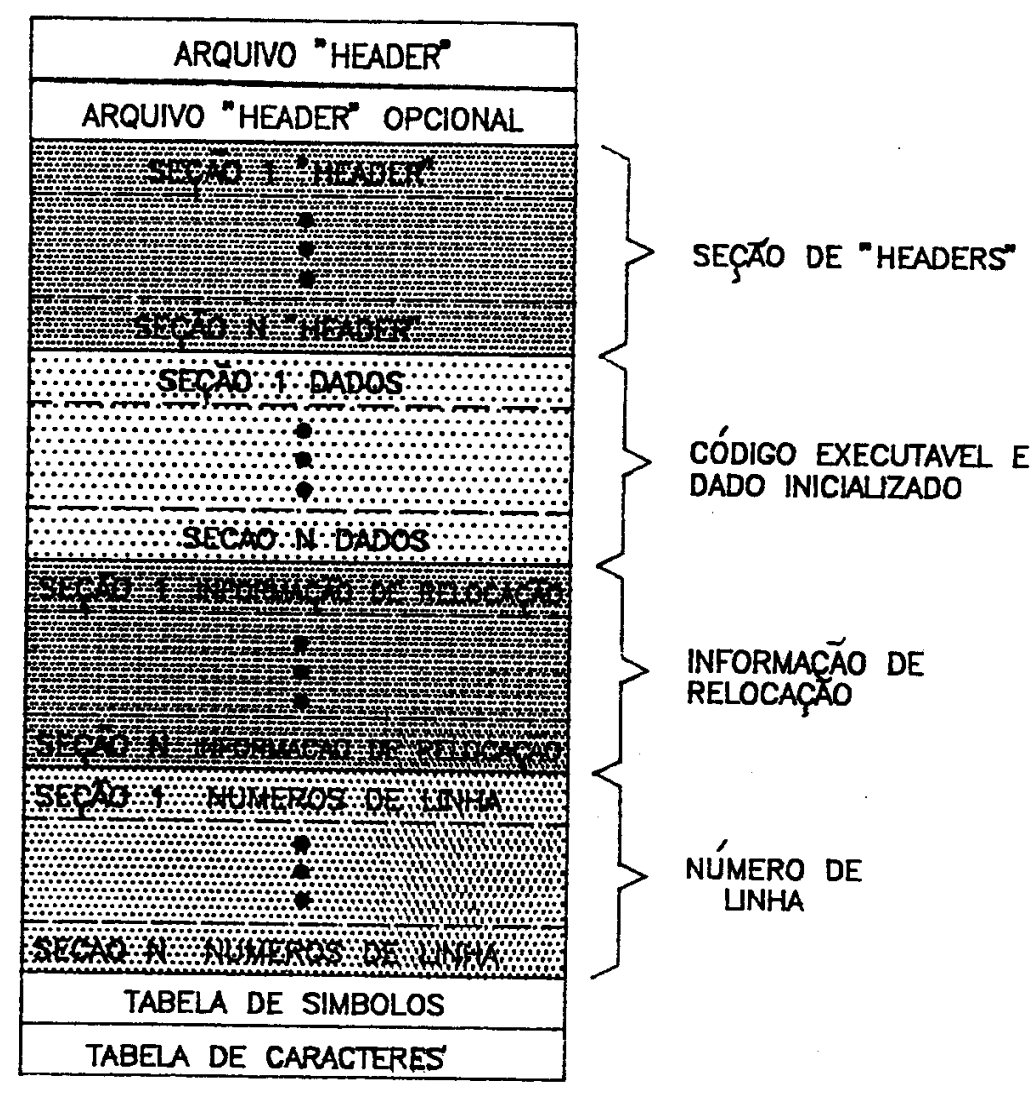

Figura 83 - Estrutura Global para o Arquivo Objeto do TMS34010 
Tabela XII - Conteúdo do Arquivo "Header"

\begin{tabular}{|c|c|c|}
\hline n.o "byte" & valor & descriçao \\
\hline 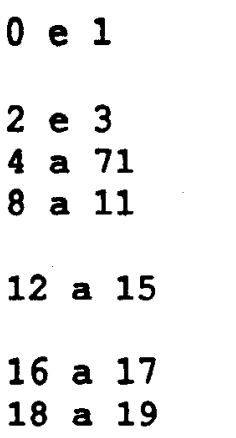 & $\begin{array}{l}090 \\
0001 \\
\text { CEBCDE } \\
00000 \mathrm{C} 58 \\
00000073 \\
001 C \\
0103\end{array}$ & $\begin{array}{l}\text { n.o mágico. Indica que o arquivo pode } \\
\text { ser executado no TMS } 3401 \text {. } \\
\text { número de seçōes do "header". } \\
\text { indica quando o arquivo foi criado. } \\
\text { contem o endereço inicial da tabela de } \\
\text { símbolos. } \\
\text { número de entradas na tabela de } \\
\text { símbolos. } \\
\text { número de "bytes" do "header" opcional. } \\
\text { flags. }\end{array}$ \\
\hline
\end{tabular}

Tabela XIII - Conteúdo do Arquivo "Header" Opcional

\begin{tabular}{|c|c|c|}
\hline n.o "byte" & valo & descriçao \\
\hline $\begin{array}{lll}0 & \text { e } & 1 \\
2 & \text { e } & 3 \\
4 & \text { a } & 7 \\
8 & \text { a } & 11 \\
12 & \text { a } & 15 \\
16 & \text { a } & 19 \\
20 & \text { a } & 23 \\
24 & \text { a } & 27\end{array}$ & 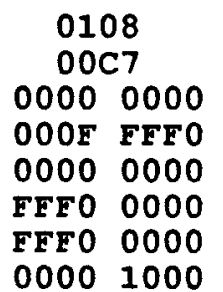 & $\begin{array}{l}\text { n.o mágico. Para o TMS34010 é } 0108 \\
\text { "version stamp" } \\
\text { tamanho do código executável. } \\
\text { tamanho dos bits inicializados. } \\
\text { tamanho dos dados não inicializados. } \\
\text { início do codigo executável. } \\
\text { início do dado inicializado. }\end{array}$ \\
\hline
\end{tabular}

Tabela XIV - Conteúdo da seção de dados

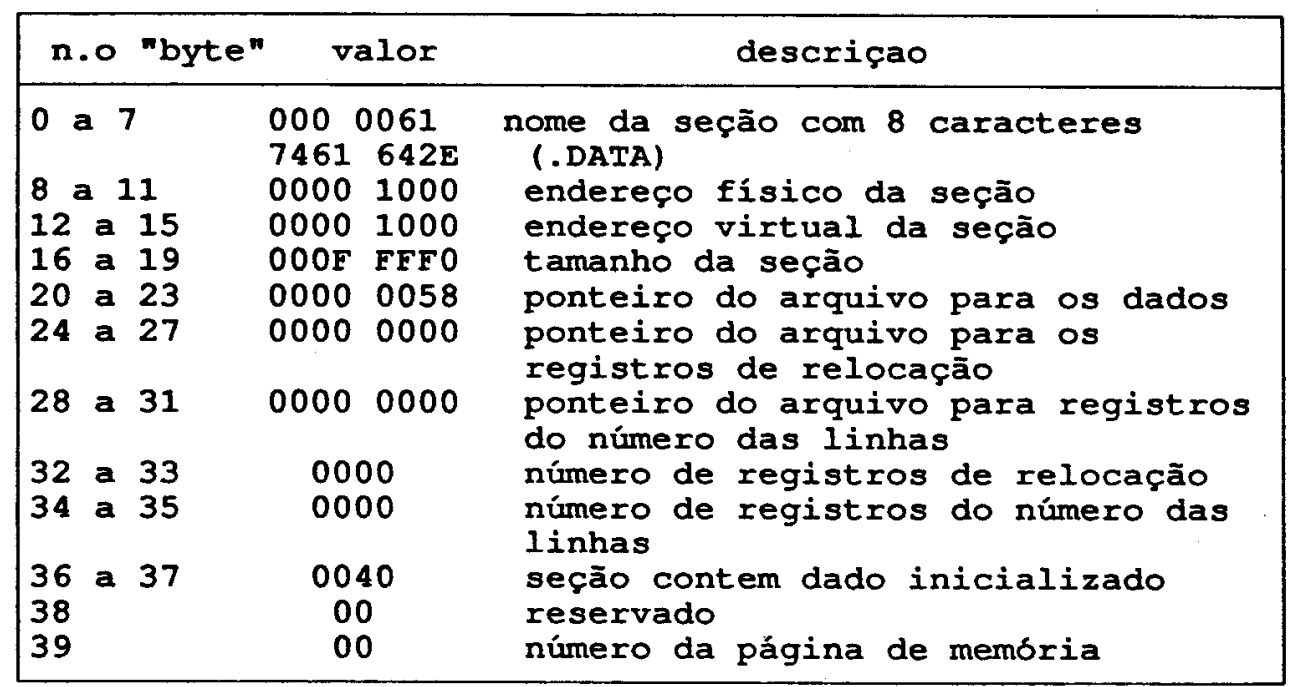




\subsubsection{Exemplo de um Arquivo Objeto de uma Imagem}

As tabelas XV e XVI mostram o conteúdo do início e fim do arquivo objeto de uma imagem tomográfica, a ser visualizada no sistema do item 4.2. Na tabela XV, os dados da imagem iniciam no endereço $58 \mathrm{H}$, e os dados anteriores a este endereço constituem as informações do arquivo "header", do "header" opcional e da seção de dados. A imagem completa é constituída por $64 \mathrm{~K}$ palavras ou $128 \mathrm{Kbytes,} \mathrm{e} \mathrm{na} \mathrm{tabela}$ XVI, o último dado da imagem ocupa a posição $20058 \mathrm{H}$.

Tabela XV - Início do Arquivo Objeto de uma Imagem

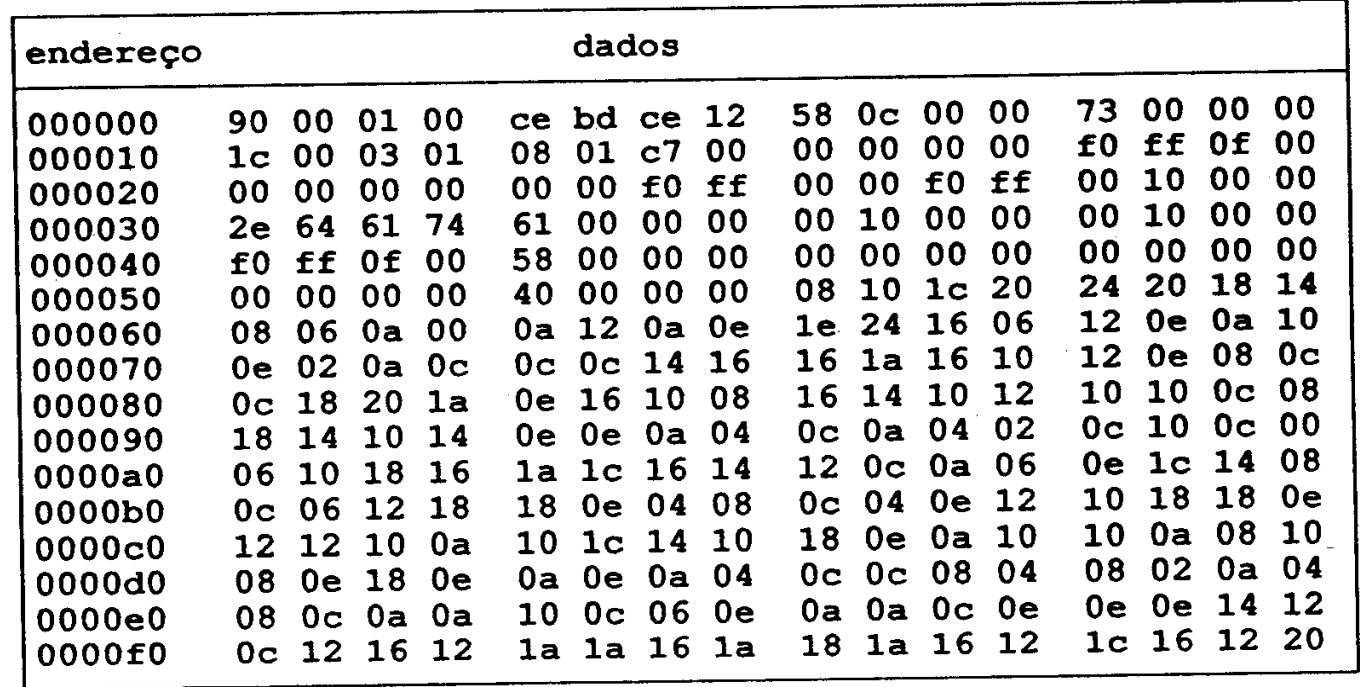


Tabela XVI - Fim do Arquivo Objeto de uma Imagem

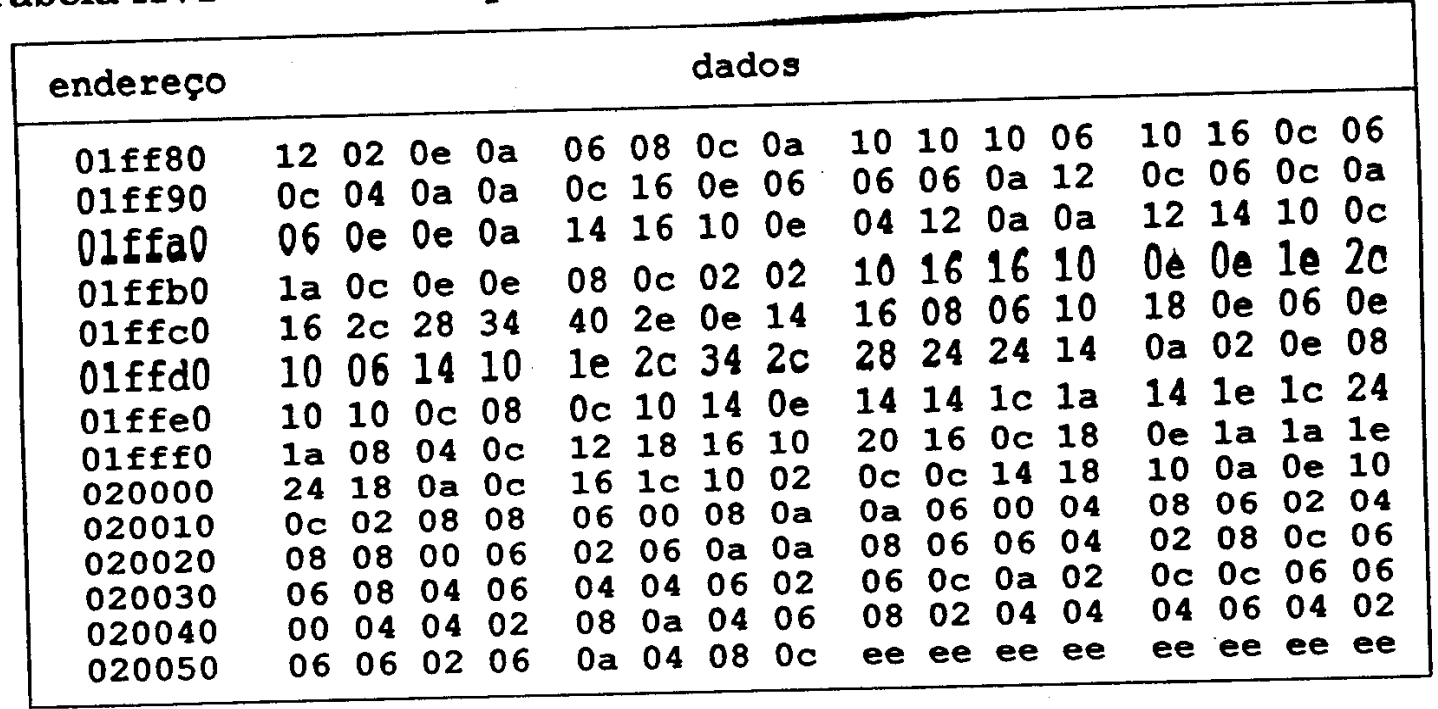




\section{Capítulo VI}

\section{Inclusão de uma Memória EPROM no Sistema Gráfico}

A inclusăo de uma EPROM no sistema gráfico permite que o GSP opere de forma independente, isto é, limitando a necessidade de um processador bospedeiro para a transferência da imagem. Neste caso, ao ser ligado o sistema, ou após "reset", a EPROM é selecionada, e o primeiro programa a ser executado será o programa de inicialização do sistema.

No programa de inicialização, além da programação dos registradores de E/S, pode ser estabelecida a cor de fundo da tela, e desenhada uma figura ou escrita uma mensagem na tela, indicando que o sistema está aguardando comandos.

O projeto que será descrito a seguir foi desenvolvido para o sistema descrito no item 4.2. Neste projeto são previstas duas EPROMs de $8 \mathrm{Kx8}$ (2764), com tempo de acesso de $250 \mathrm{~ns}$, associadas de forma a constituirem um sistema de memória de $8 \mathrm{~K} \times 16$.

A EPROM foi mapeada no mesmo espaço de endereço que a RAM de sistema I, conforme é mostrado na figura 84. A seleção de uma ou outra memória é autorizada por um "flip-flop", implementado internamente numa PAL, que permite a seleção da EPROM após "reset", ou a seleção da RAM quando é gravado um dado no endereço $>04000000$. Uma vez que a RAM é selecionada, a EPROM é simultaneamente desativada, permanecendo assim até a ocorrência de outro "reset".

A figura 85 mostra o circuito para ligação da EPROM ao GSP. Neste circuito são utilizados dois "latchs" de 8 bits, para armazenar os bits de endereço que serão utilizados no endereçamento e na lógica de seleção da EPROM. Os demais circuitos são aqueles do sistema descrito no item 4.2.

Na verdade um único "latch" seria necessário, caso fosse utilizado o mesmo tipo 
de lógica de seleção para o sistema descrito no item 4.2. Mas isso levaria a equações mais complexas, e ao uso de mais PALs. Com a utilizaçào dos dois "latchs", as equações da lógica de seleção tornam-se mais simples, e o número de PALs é mantido, já que os bits de endereço utilizados na lógica de seleção são armazenados através do "latch".

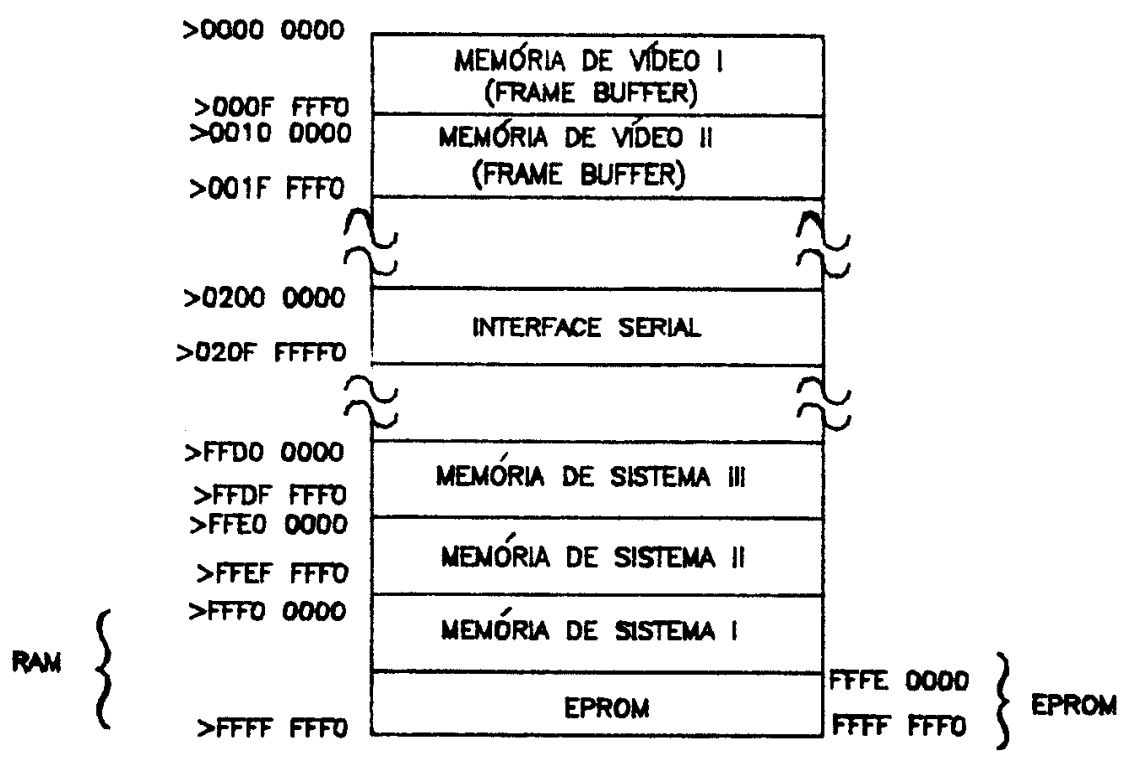

Figura 84: Mapeamento da EPROM no Sistema com 256 Níveis de Cinza

As figuras 86 e 87 mostram o conjunto de equações para o sistema, considerando a EPROM. Nestas equações o sinal MRES é gerado pelo "flip-flop" implementado internamente na PAL, para seleção da EPROM ou da primeira RAM de sistema. $O$ sinal RES_TMS usado na geração de MRES é o sinal RESET do GSP.

Nas equações da interface serial, o sinal RAL é resultante da combinação lógica "E" dos sinais /LAL e /RAS. Este sinal não foi implementado na PAL, por já existir em "hardware" no projeto da EPROM.

A EPROM também necessita de estado de espera, e por isso, na geraçăo do sinal de solicitação de estado de espera (/LRDY), foi incluído o sinal de seleção da EPROM . 


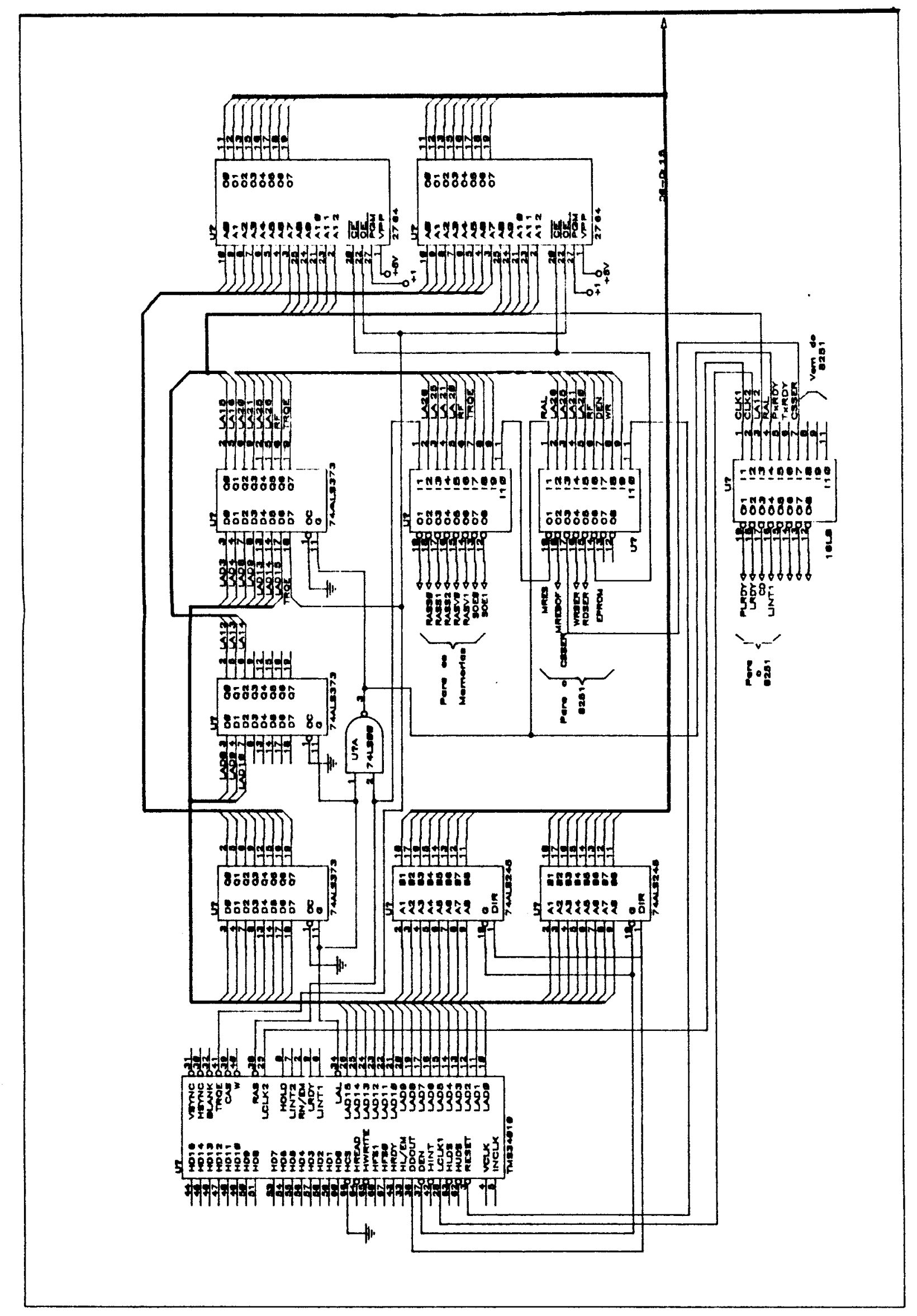

Figura 85: Projeto para Inclusão de uma EPROM - Sistema com 256 Níveis de Cinza 
Uma alteração deve ser feita também na entrada /HCS, do duto do GSP dedicado ao hospedeiro, pois com a EPROM, o GSP deve ser colocado no modo "self Bootstrap" após "reset". Neste modo, a entrada /HCS deve ser mantida em nível lógico baixo no fim do "reset", após o que o GSP executa oito ciclos de refrescamento das memórias dinâmicas, do tipo /RAS-only. Em seguida o GSP busca o vetor de endereço da posição >FFFF FFE0, e inicia a execução do programa que se encontra a partir deste endereço.

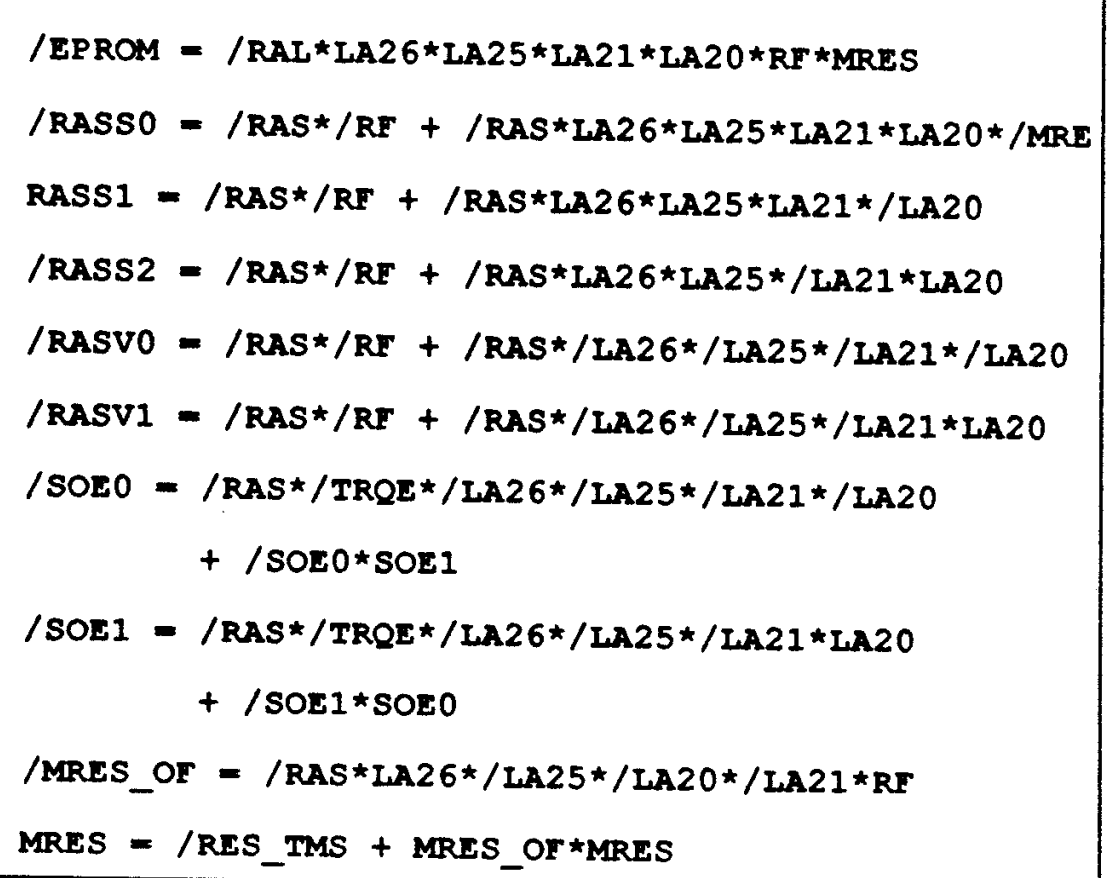

Figura 86: Equações para a Seleção das Memórias Sistema com EPROM 


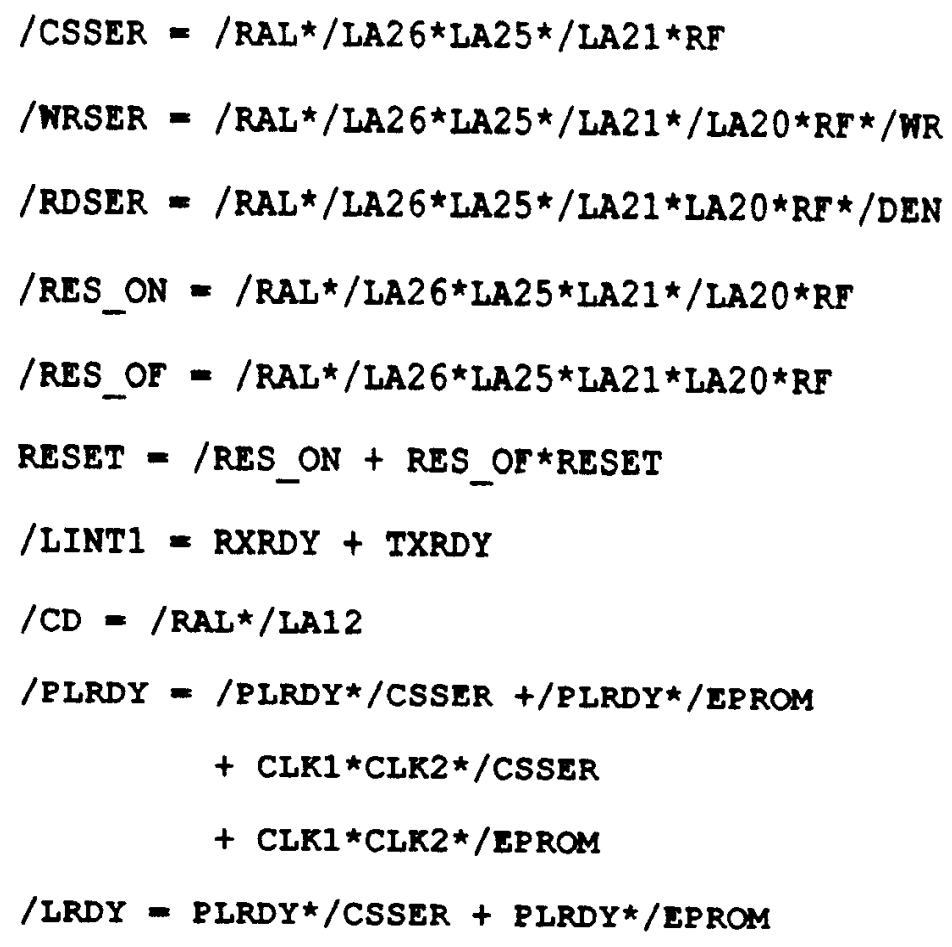

Figura 87: Equações para a Seleção da Interface Serial Sistema com EPROM 


\section{Capítulo VII}

\section{Conclusões}

O projeto desenvolvido mostrou ser bastante flexível e expansível. Além dos padrões CGA e EGA implementados, o sistema pode atingir resoluções de tela tais como 8192 linhas/4096 pixels/16 bits por "pixel".

A interface serial incluida no projeto viabiliza a utilização de um "mouse", tornando-o um sistema interativo.

Embora o objetivo principal do projeto seja visualização de imagens médicas, que na maioria de suas aplicaçóes requer boa resolução na escala de cinza, foi projetado também um sistema capaz de operar a cores utilizando uma "Color Palette".

Os exemplos de "software" realizados para os dois sistemas demonstram o funcionamento das principais características do "hardware", dando amplos subsídios para o desenvolvimento do "software" básico e aplicativo.

O "Boftware", em desenvolvimento, será implantado no sistema com 256 níveis de cinza, e baseia-se na filosofia do padrão X-Window, com o propósito de padronização e portabilidade.

O sistema desenvolvido e descrito no presente trabalho, já se mostrou bastante valioso para a visualização de imagens tomográficas com alta resolução na escala de cinza.

O fato de se tratar de um sistema de visualização com capacidade de processamento local independente, traz grandes vantagens quando comparado com placas VGA, que agem apenas como controladores gráficos. $O$ sistema desenvolvido, 
embora de custo superior ao de uma placa VGA, apresenta capacidade de processamento local para realização de operações tais como "zoom", "pan", tratamento de "mouse", operações lógicas e aritméticas entre imagens, etc.

Estas operações são idênticas às encontradas em Workstations. No entanto, - sistema desenvolvido não apresenta um ambiente multiusuário, com gerenciamento de memória e disco, como numa Workstation, podendo então ser situado entre uma placa VGA e uma Workstation no que se refere a custo e características de "hardware" e "software", consistindo assim num equipamento de grande valor para a visualização e manipulação de imagens. 


\section{BIBLIOGRAFIA}

[1] TEXAS, TMS34010 User's Guide. Texas Instruments Inc., 1986.

[2] TEXAS, TMS34010 Applicatin Guide. Texas Instruments Inc., 1987.

[3] TEXAS,TMS34010 Assembly Language Tools - User's Guide. Texas Instruments Inc., 1987.

[4] TEXAS, TMS34010 512x512 Pixel Minimum Chip Graphics System. Texas Instruments Inc., 1987.

[5] Foley, J. D. \& Van Dam, A. - Fundamentals of Interactive Computer Graphics. Addison Wesley, 1982.

[6] Newman, W. M. \& Srpoul, R. F. - Principles of Interactive Computer Graphics. McGraw Hill, 1979.

[7] Magalhães, L. P. - Computação Gráfica. Editora da UNICAMP, 1986.

[8] Smart, G. \& Baran, N. M. - Face to Face. BYTE, 243-252, setembro 1988.

[9] Whitton, M. C. - Memory Design for Raster Graphics Displays, 48 - 65, março 1984.

[10] Wise, J. L. \& Szejnwald, H. - Display Controller Simplifies Design of Sophisticated Graphics Terminals. Electronics, 153 - 157, abril 1981.

[11] Guttag, K \& Aken, J. V. \& Asal, M. - Requirements for a VLSI Graphics Processor. IEEE Computer Graphics and Application, 32 - 46, janeiro 1986.

[12] Shires, G. - A New VLSI Graphics Coprocessor - The Intel 82786. IEEE Computer Graphics and Application, 49-55, outubro 1986.

[13] Nicholls, Bill - Inside the 82786 Graphics Chip. BYTE, 135-141, agosto 1987.

[14] Killebrew Jr.,C. - The TMS34010 Graphics Systems Processor. BYTE, 193 204, dezembro 1986.

[15] TEXAS, TMS34070 User's Guide. Texas Instruments Inc., 1986.

[16] Kane, G. - CRT Controller Handbook. Osborne/McGraw - Hill, 1978. 
[17] Pinkham, R. \& Novak, M. \& Guttag, K. - Video Ram Excels at Fast Graphics. Electronic Design, 161-184, agosto 1983.

[18] Banon, G. J. F. - Bases da Computação Gráfica. Editora Campus, 1989.

[19] Brigham, J. C. - Round and Round She Goes ... 8514/A or 34010's Wheel of Fortune. IDC Report Summary, dezembro 1989.

[20] Asal, M. \& Short,G. \& Prestom, T. \& Simpson, R. \& Roskell, D. \& Guttag, $\mathrm{K}$. - The Texas Instruments 34010 Graphics Systems Processor. IEEE Computer Graphics and Application, 24-39, outubro 1986.

[21] Solomon, L. - Video Signal and Monitor Design. Computers \& Electronics, 53 - 79, dezembro 1984.

[22] Porter, T. \& Duff, T. - Compositing Digital Images. Computer Graphics, 18(3), 253 - 259, julho 1984.

[23] Baecker, R. - Digital Vídeo Display Systems and Dynamic Graphics. Computer Graphics, 12(3), 48 - 56, 1978.

[24] Nicholls, B. - High Performance Graphics Boards. BYTE, 151 - 155, janeiro 1988.

[25] Ingalls, D. H. H. - The Smalltalk Graphics Kernel. BYTE, 168 - 194, agosto 1984.

[26] Acquah, J. \& Foley, J. \& Sibert, J. \& Wenner, P. - A Conceptual Model of Raster Graphics Systems. Computer Graphics, 16(3), 321 - 328, julho 1982.

[27] Williams, T. - Board-Level Solutions Open New Territory for Image Processing. Computer Design, 53 - 66, maio 1, 1987.

[28] Panepucci, H. \& Donoso, J. P. \& Tannús, A. \& Beckman, N. \& Bonagamba, T. - Novas Imagens do Corpo. Ciência Hoje, 4(20), 46 - 56, setembro/outubro 1985.

[29] Ruggiero, C. A. - Projeto e Construção de um Terminal de vídeo Gráfico, Dissertação de Mestrado. IFQSC, 1983.

[30] Waite, M. - Computer Graphics Primer. Howard W. Sams \& Co., 1980.

[31] Partain, C. L. - Nuclear Magnetic Resonance and Correlative Imaging Modalities. Society of Nuclear Medicine Inc., 1984.

[32] Budinger, T. F. \& Margulis, A. R. - Medical Magnetic Resonance. Society of Magnetic Resonance in Medicine Inc., 1984. 
[33] TEXAS, TMS34010 Software Development Board - User's Guide.Texas Instruments Inc., 1986. 


\section{Anexo 1}

\section{Anexo 1.1 - Programa Principal}

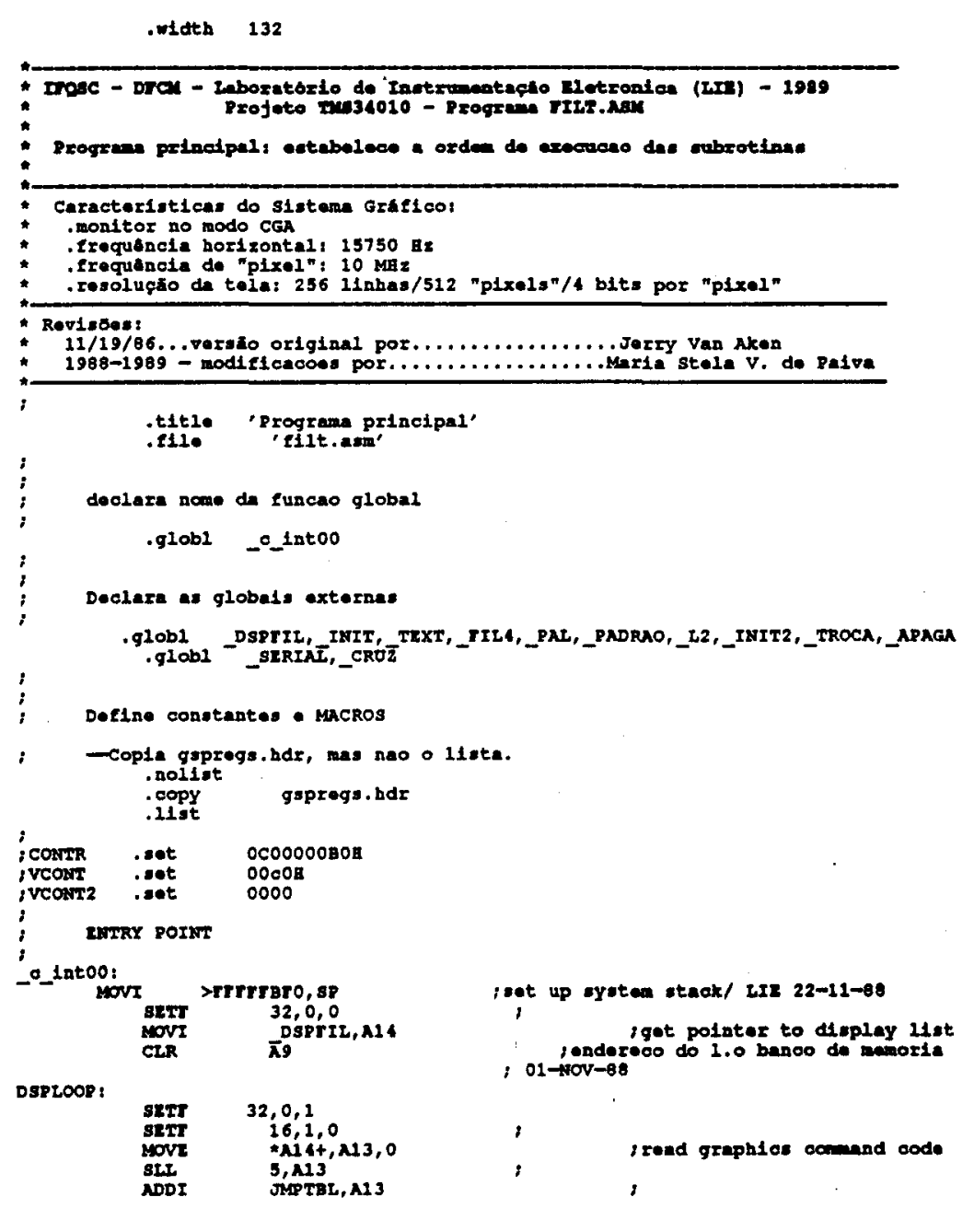

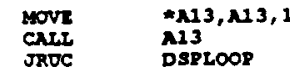

Tap T32
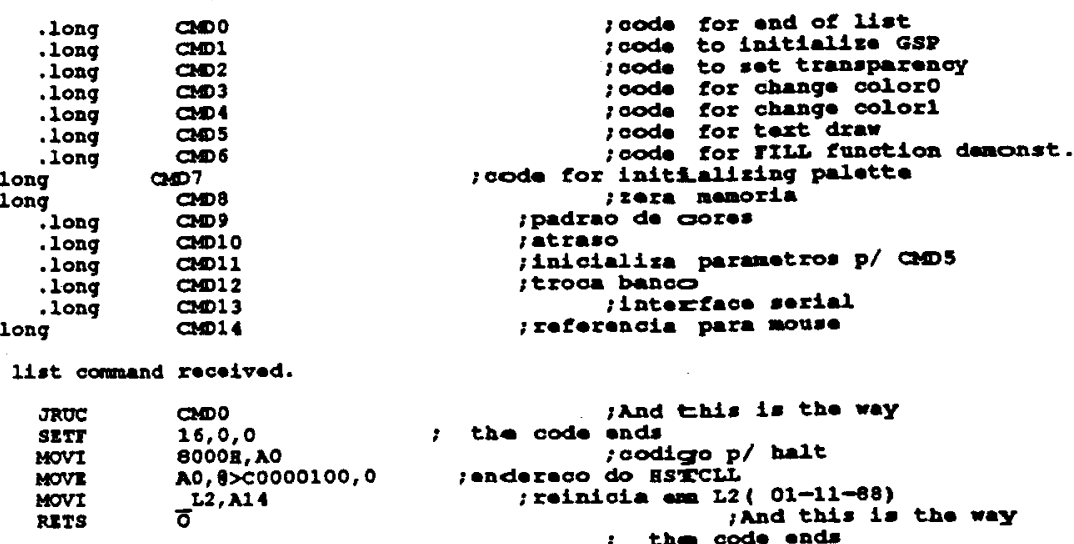

and of

; the code lind this 1. the way

endereco ; codigo pl balt

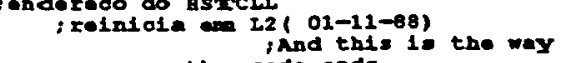

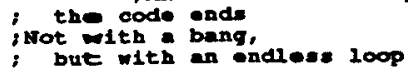

Cam1: Comando para 1nlelallizar o GSP.

MOVI

CMomi: Comand to sot transparonoy bit recelved.

Move 1 M14, 10,0

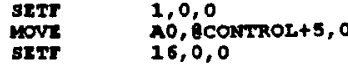

comando para ostabolecos a cor de fundo

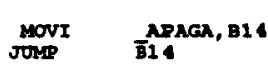

Comband to obange coloro reoelved.

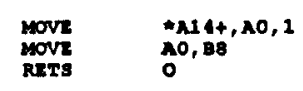

; land colorget zeglete color velue

- Comand to obenge $0010 \mathrm{~s} 1$ racolvad.

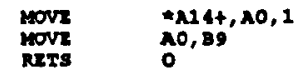

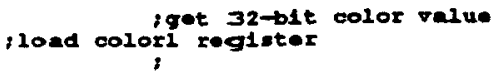

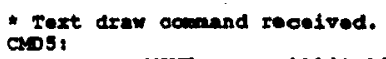

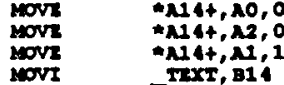

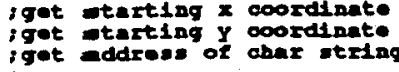

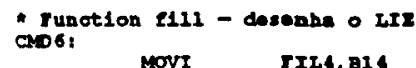



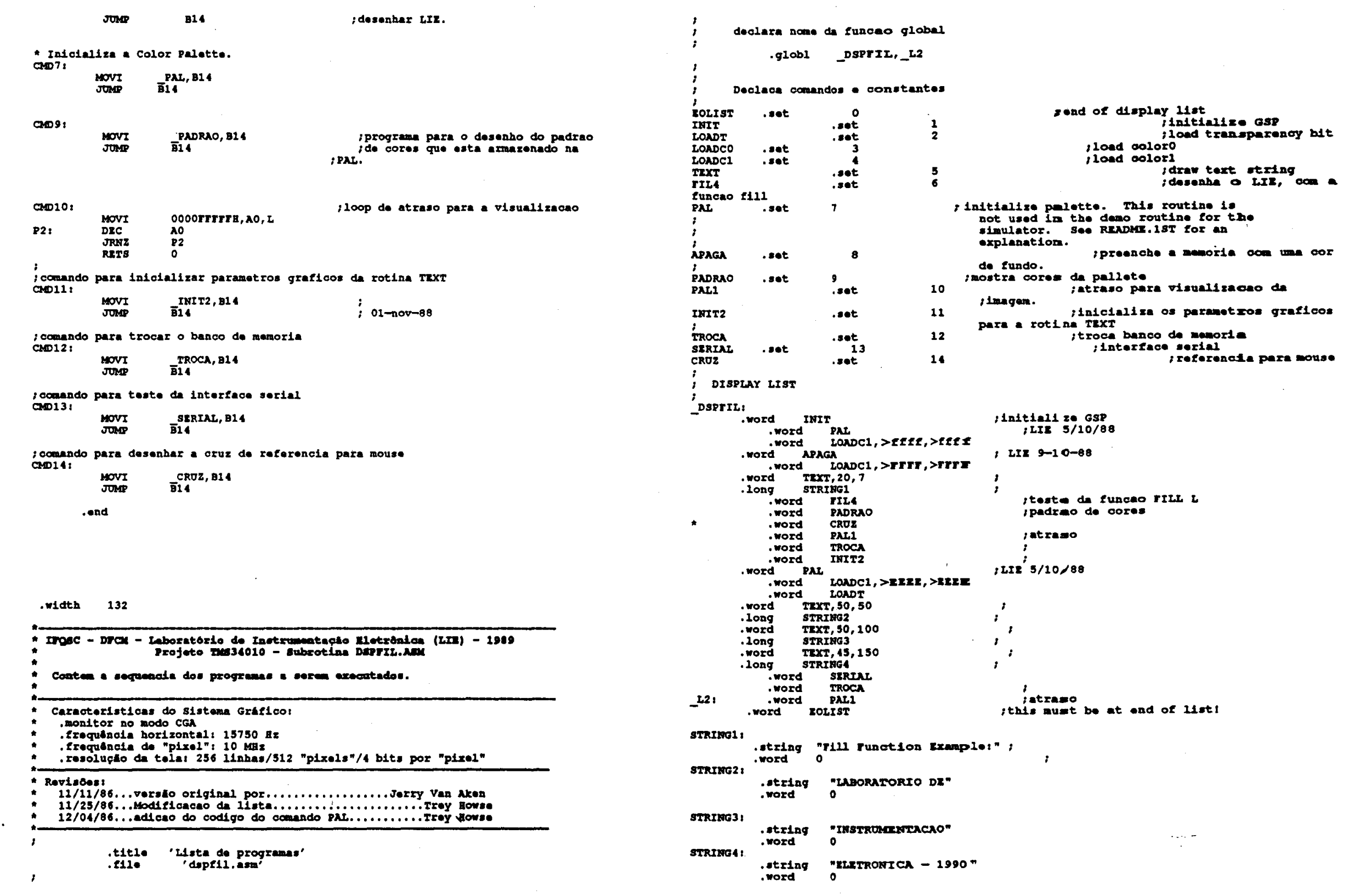
Anexo 1.2 - Subrotinas para Inicialização dos Registradores

\section{Exemplo 1}

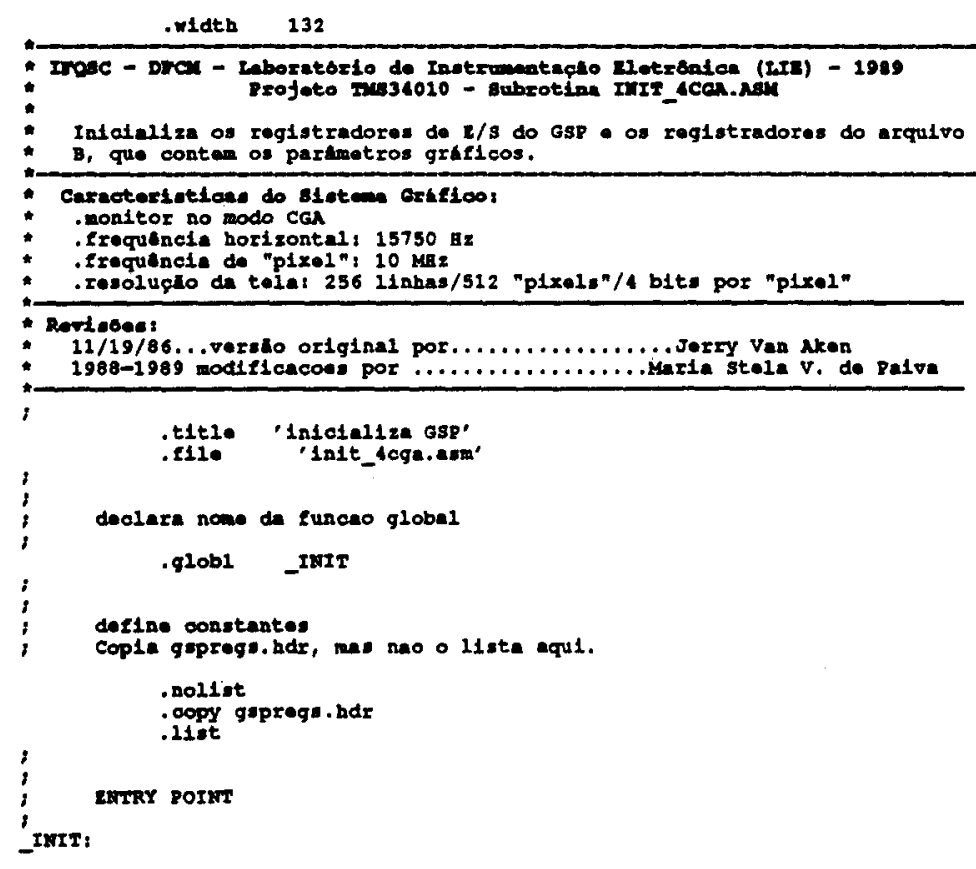

- Iniciallza rogistradores de $z / \mathrm{s}$

\begin{tabular}{|c|c|c|c|c|}
\hline \multirow{2}{*}{ LOOP1: } & 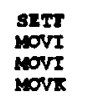 & 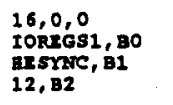 & & 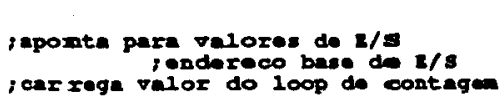 \\
\hline & $\begin{array}{l}\text { Movn } \\
\text { DSJS }\end{array}$ & 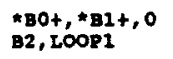 & ; & ; \\
\hline & $\begin{array}{l}\text { Movi } \\
\text { Movis } \\
\text { sovix }\end{array}$ & 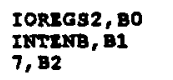 & & 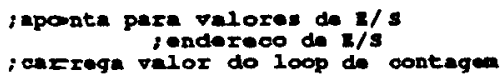 \\
\hline & $\begin{array}{l}\text { Move } \\
\text { DSJS }\end{array}$ & 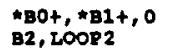 & & \\
\hline
\end{tabular}

- Iniolallza regiatracoroz de

MONT

" rotorna a programa principar

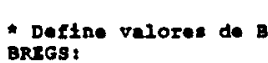

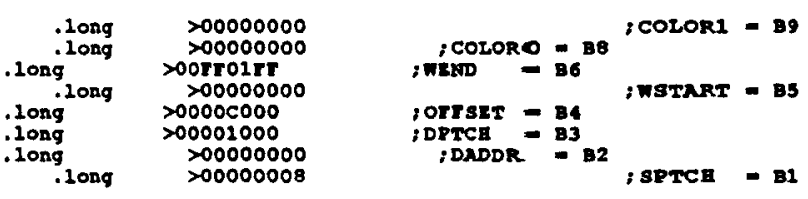

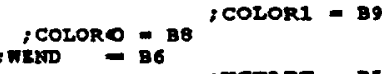
,Orrses $=84$

Dopefine registradores do $\mathrm{E} / \mathrm{s}$.

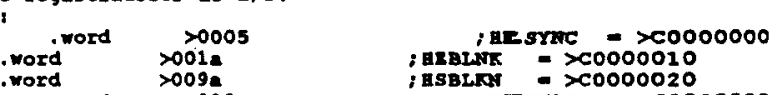

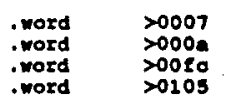

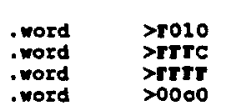

IORIGS2 1

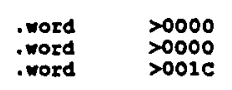

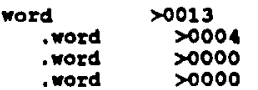




\section{Exemplo 2}

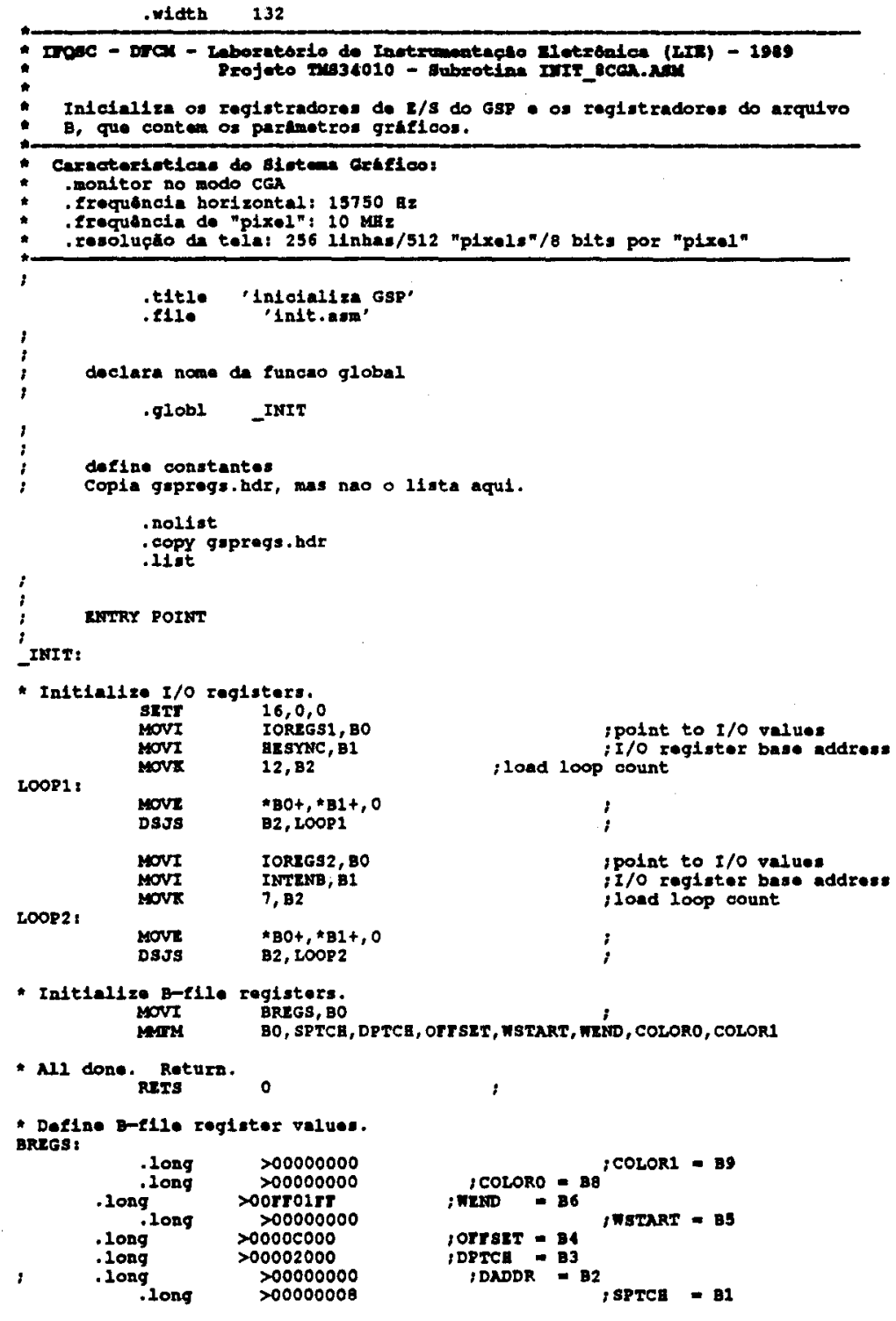

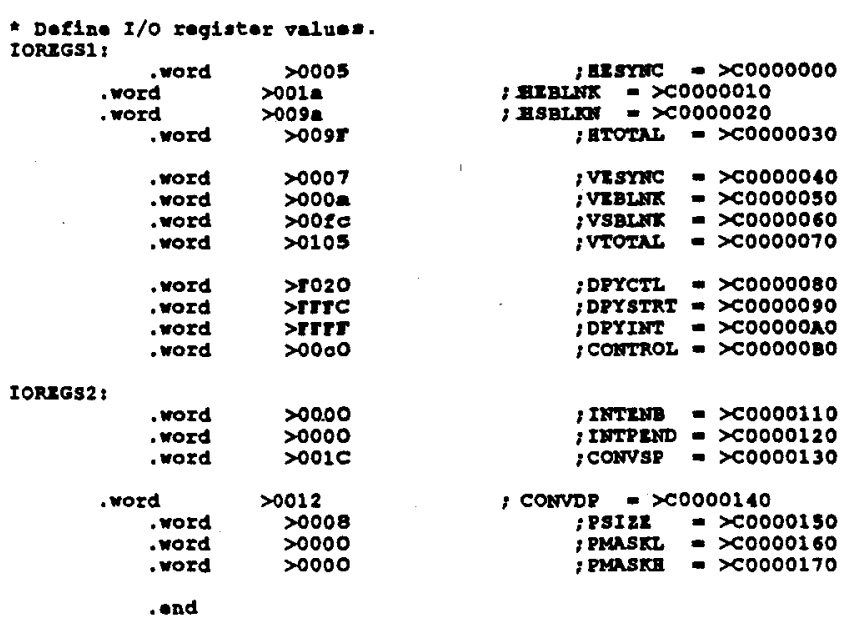

Exemplo 3

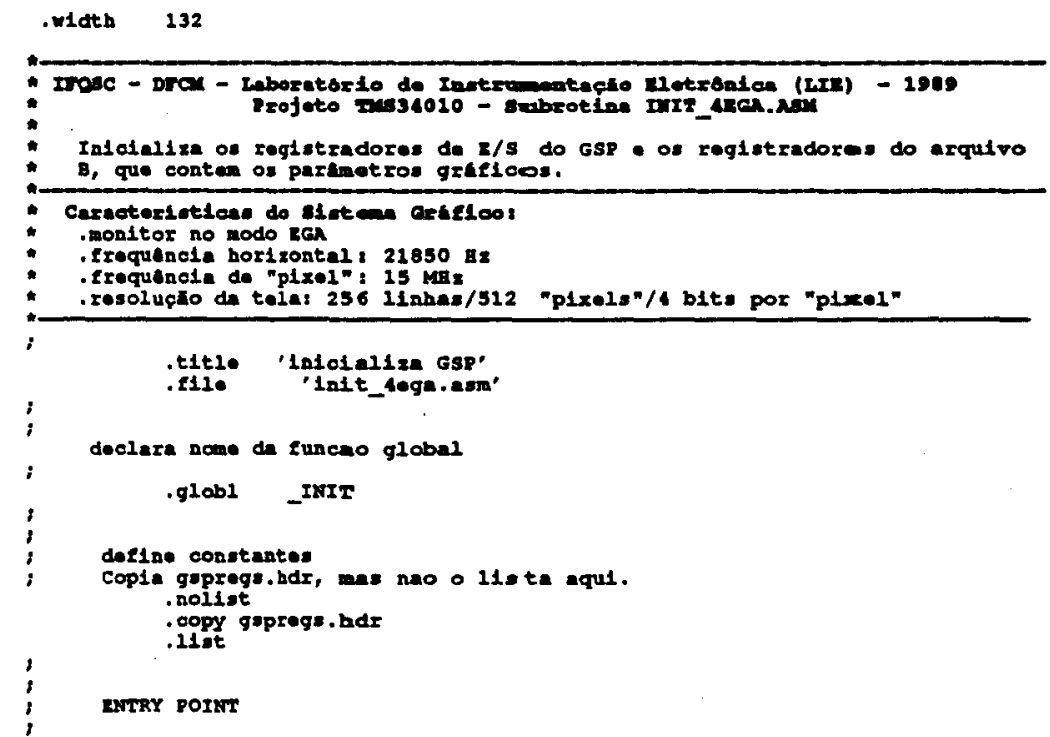


- rmis:

$$
\begin{aligned}
& \text { - Ialtialize I/O rogiatera, }
\end{aligned}
$$

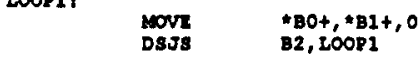

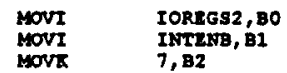

$$
\begin{aligned}
& \text { LoOP2: }
\end{aligned}
$$

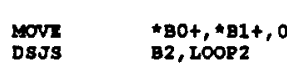

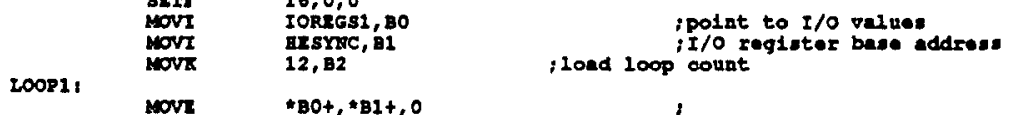

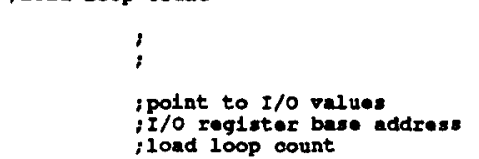

- indtial1ze g-e11e registers.

MOVI

$$
\text { * N11 done. Return. }
$$

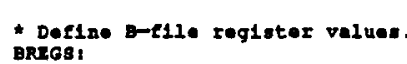

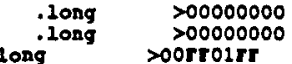

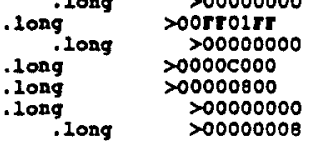

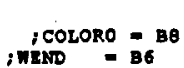

$$
\begin{aligned}
& \text {; MSTART }=\text { BS }
\end{aligned}
$$

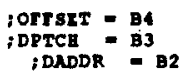

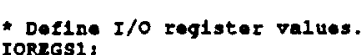

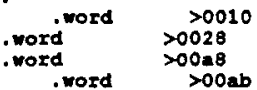

$$
\begin{aligned}
& \begin{array}{ll}
\text {. mord } & >0003 \\
\text { nord } & >0000
\end{array} \\
& \begin{array}{ll}
70260 \\
\text { rord } & >016 \mathrm{c}
\end{array}
\end{aligned}
$$

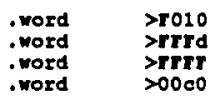

$$
\begin{aligned}
& \begin{array}{ll}
\text {.word } & >0000 \\
\text {.word } & >0000 \\
\text {.mord } & >001 \mathrm{C}
\end{array}
\end{aligned}
$$

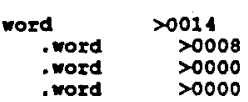

IOREG32:

\section{Exemplo 4}

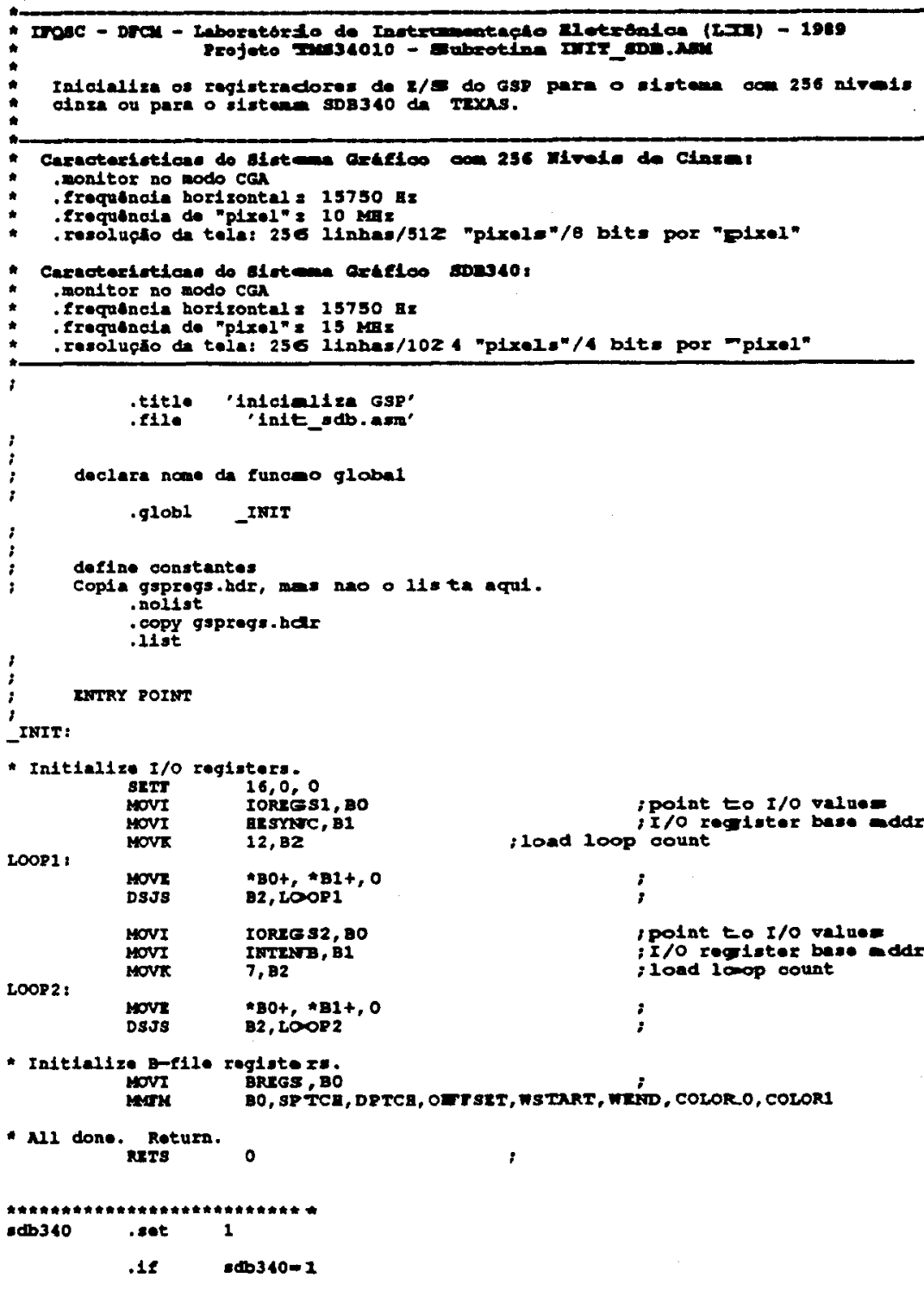

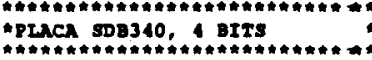




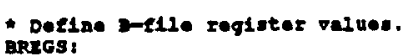

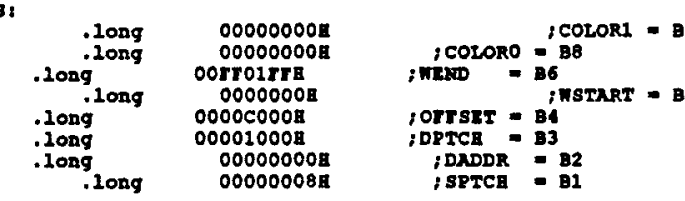

IORegs1

\begin{tabular}{|c|c|c|}
\hline 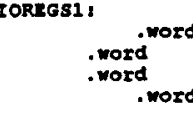 & $\begin{array}{l}000 \mathrm{dR} \\
0079 \mathrm{~A} \\
017 \mathrm{aI} \\
018 \mathrm{CH}\end{array}$ & 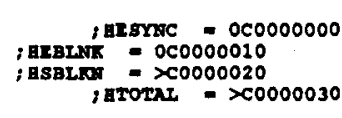 \\
\hline $\begin{array}{l}\text { :mord } \\
\text { : roord } \\
\text { mord } \\
\text { mord }\end{array}$ & 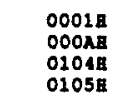 & 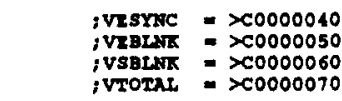 \\
\hline 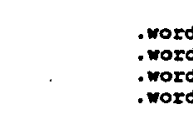 & 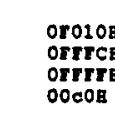 & 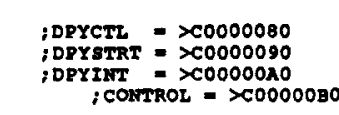 \\
\hline $\begin{array}{l}\text { : } \\
\text { : } \\
\text { mor }\end{array}$ & 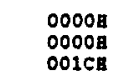 & 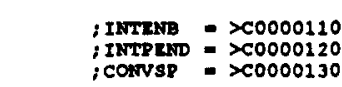 \\
\hline 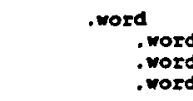 & $\begin{array}{l}0013 \mathrm{R} \\
0000 \mathrm{~A} \\
0000 \mathrm{~B} \\
0000 \mathrm{~B}\end{array}$ & 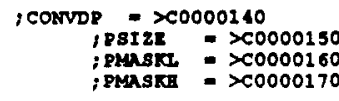 \\
\hline
\end{tabular}

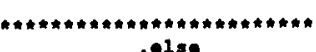

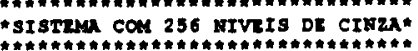

- Define B-f1le reg1ater values.

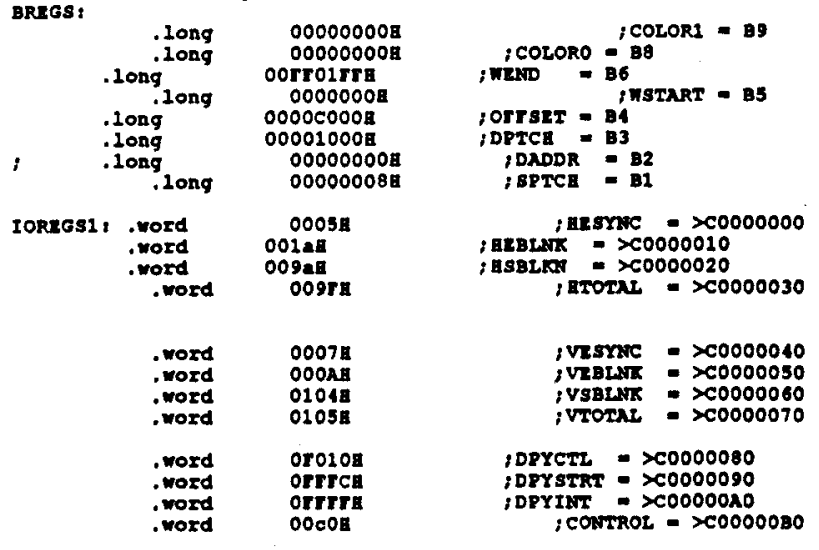

IORras21

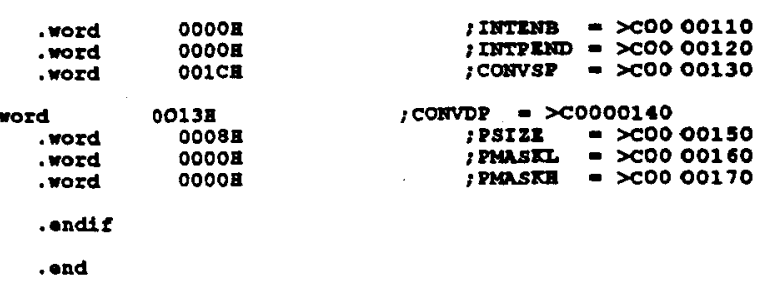

\section{Arquivo GSPREGS.HDR}
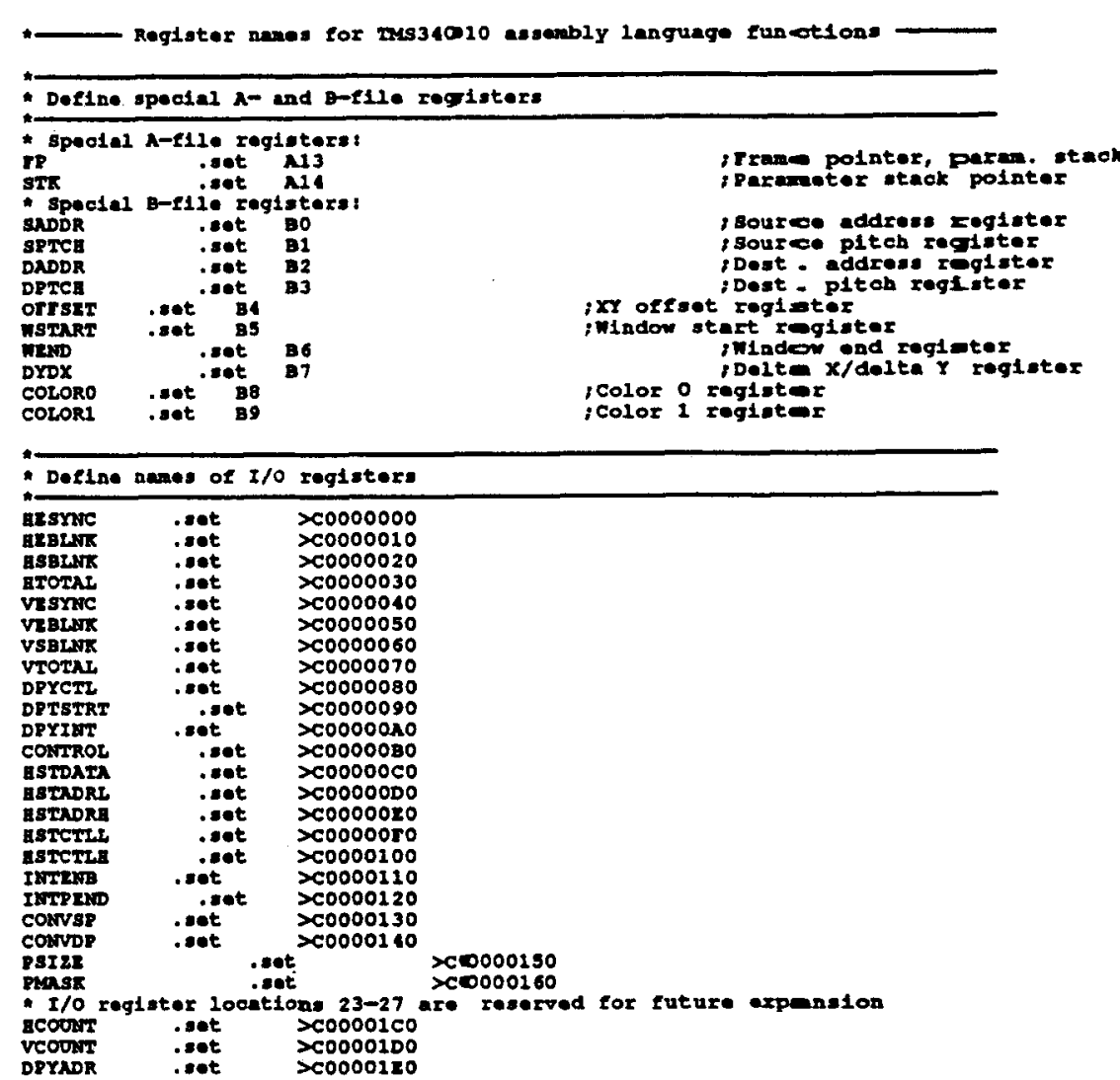


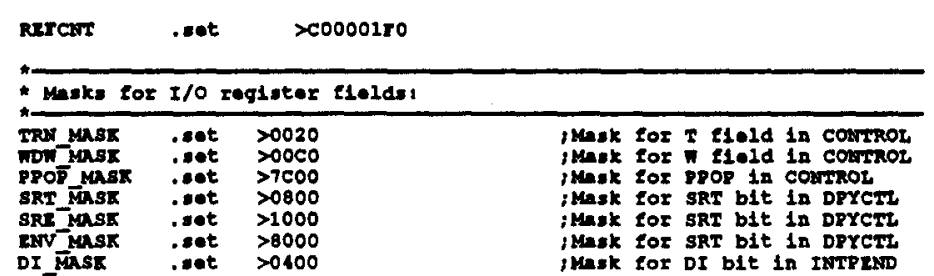

Anexo 1.3 - Subrotina para Inicializar a "Color Palette"

\section{Exemplo 1}

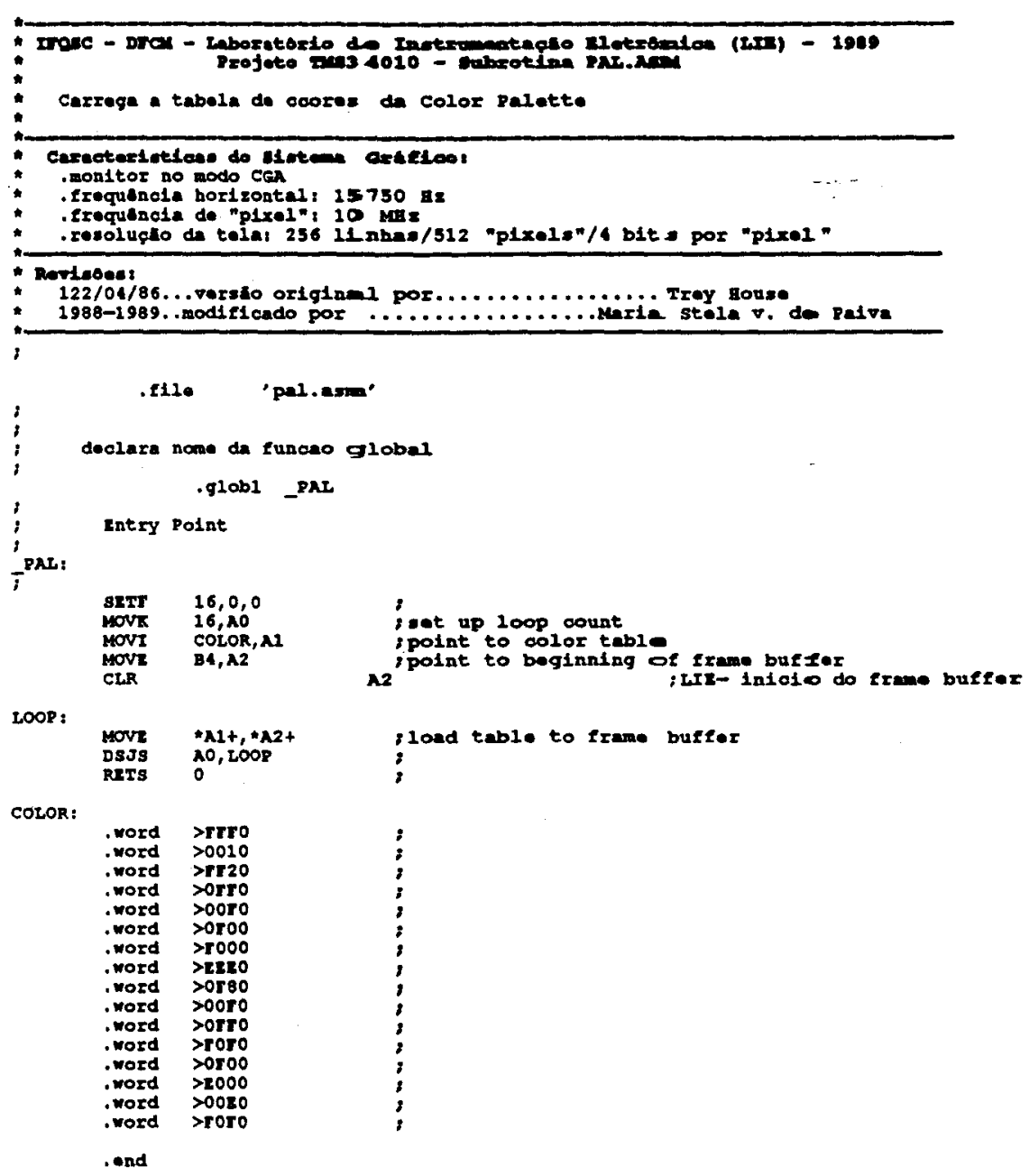

Exemplo 2 

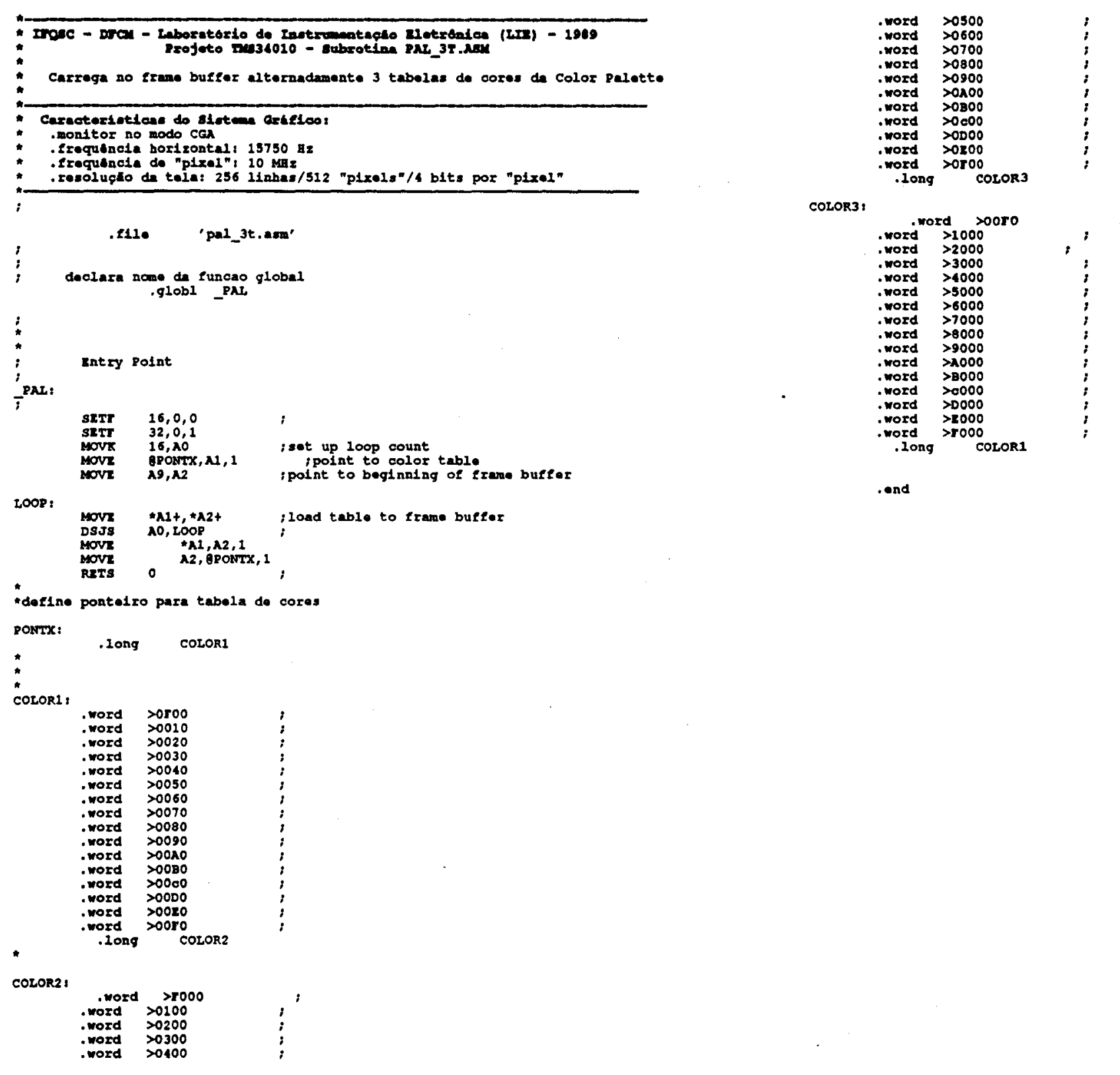

end 
Anexo 1.4 - Subrotina para Apagar a Tela

\section{Exemplo 1}

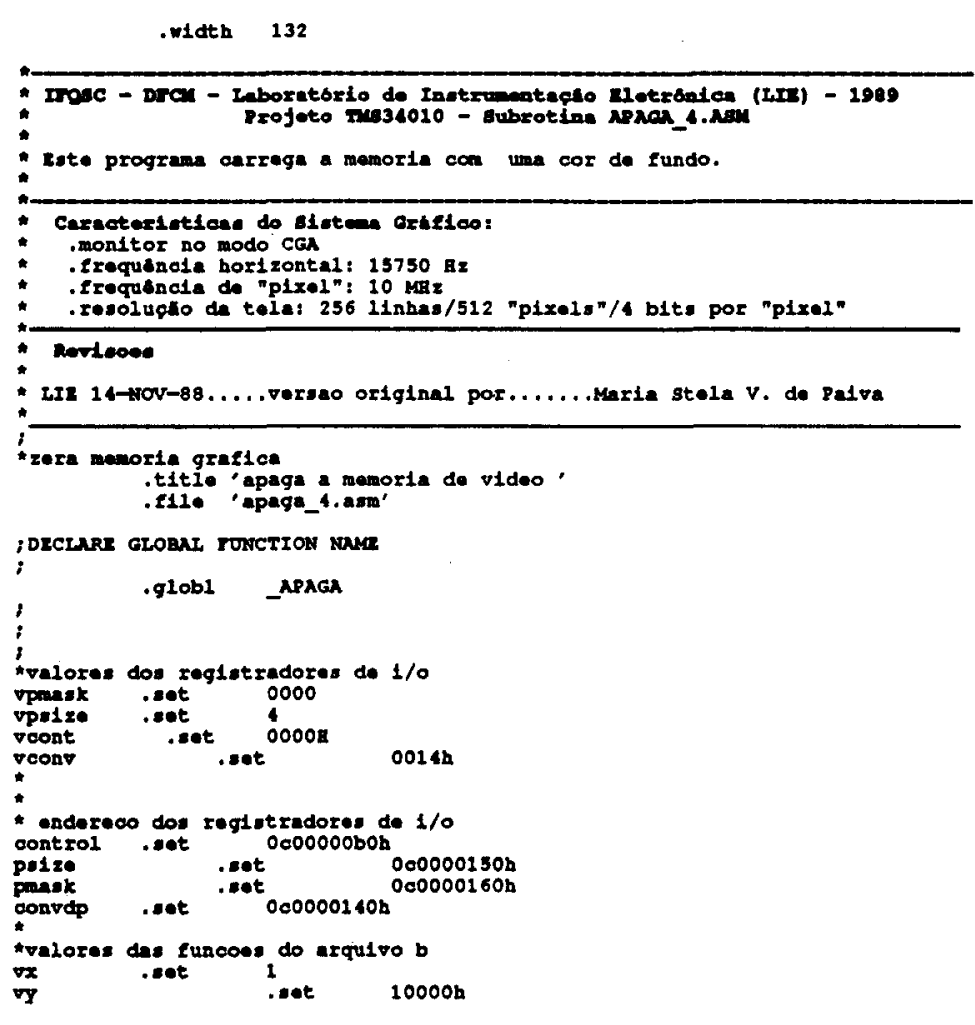

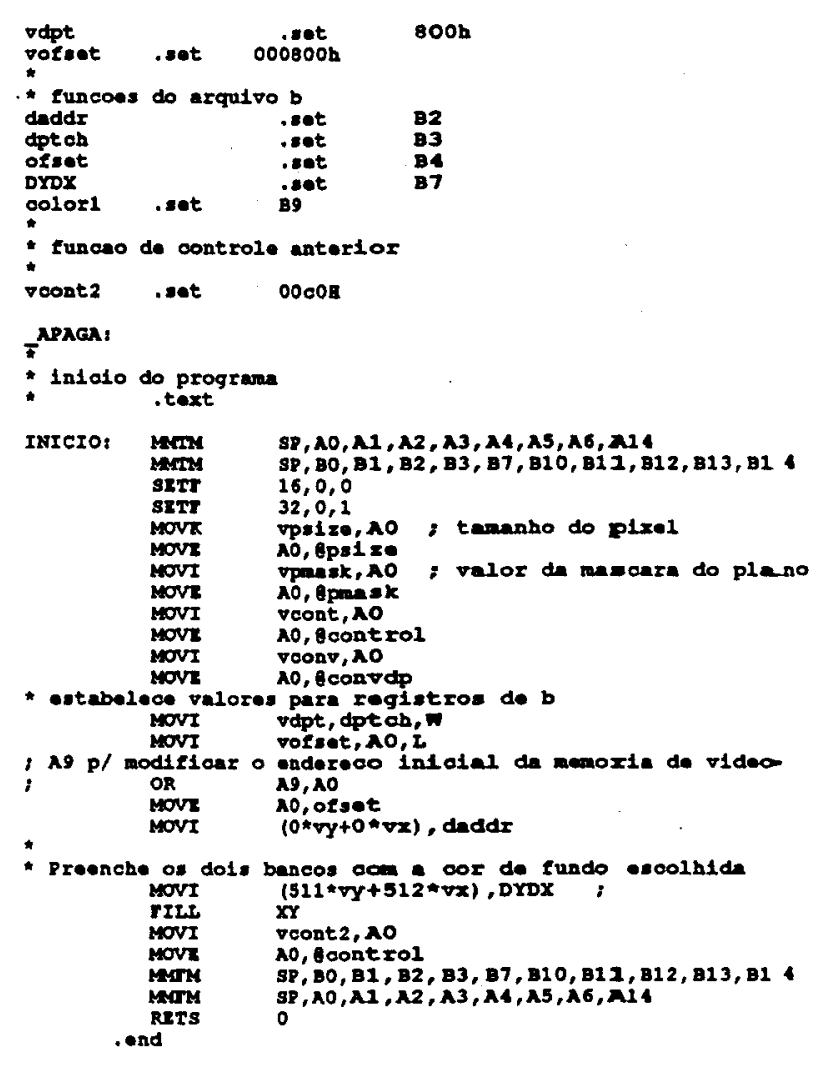

Exemplo 2

w1ath 132

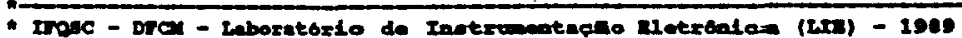



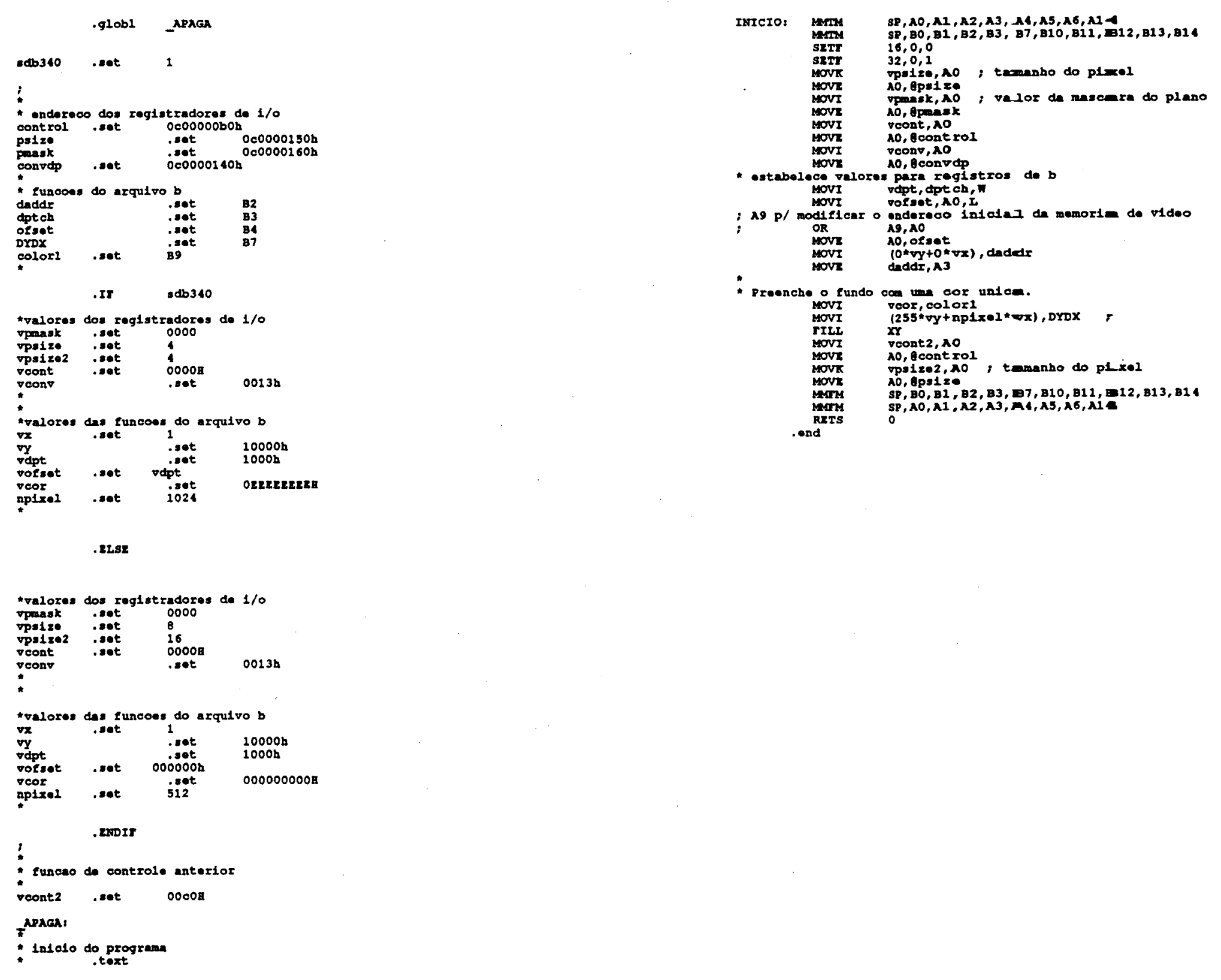
Anexo 1.5 Subrotina para Desenhar o Padrão de Cores da "Color Palette"

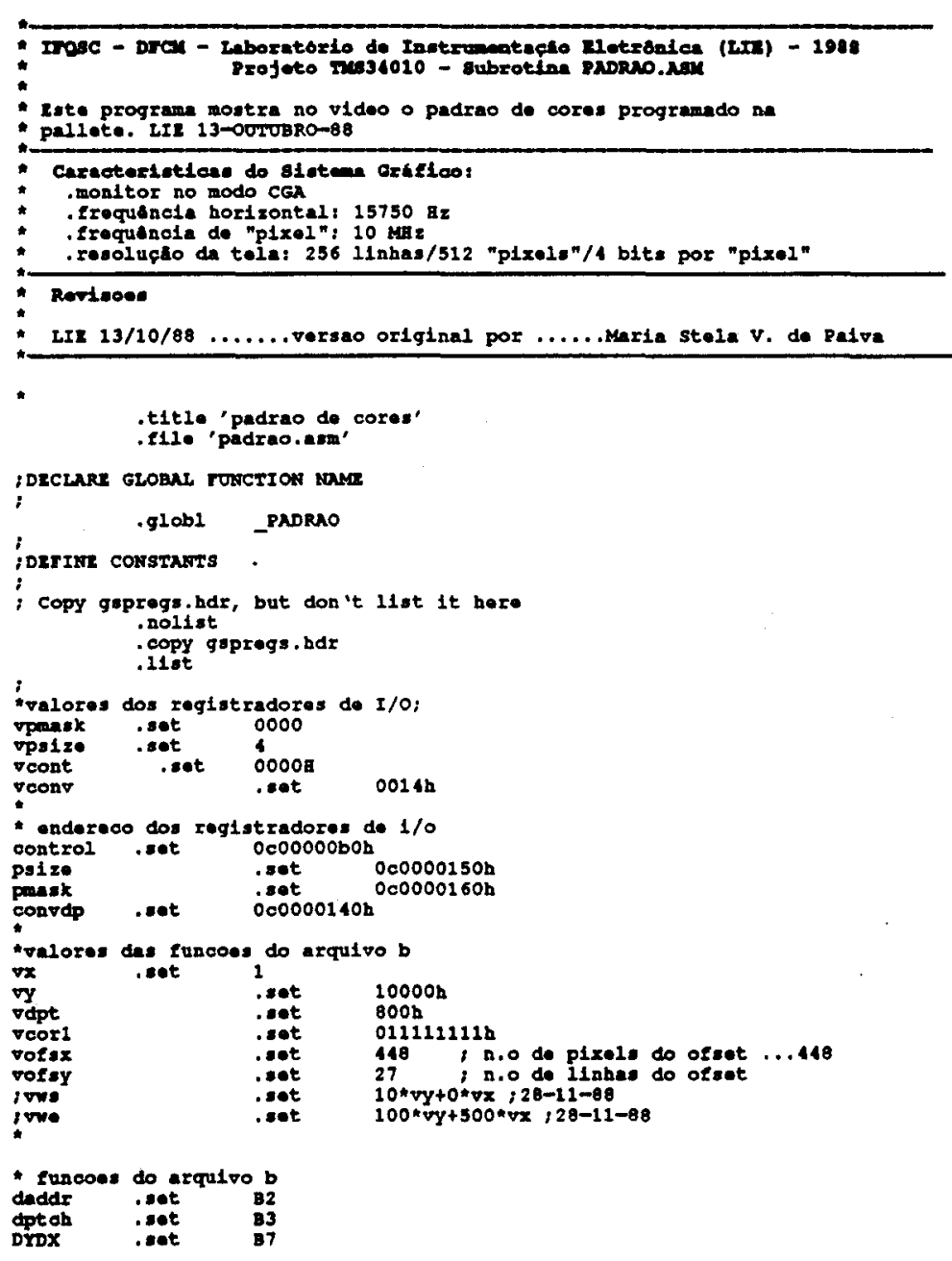

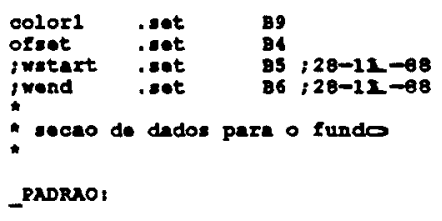
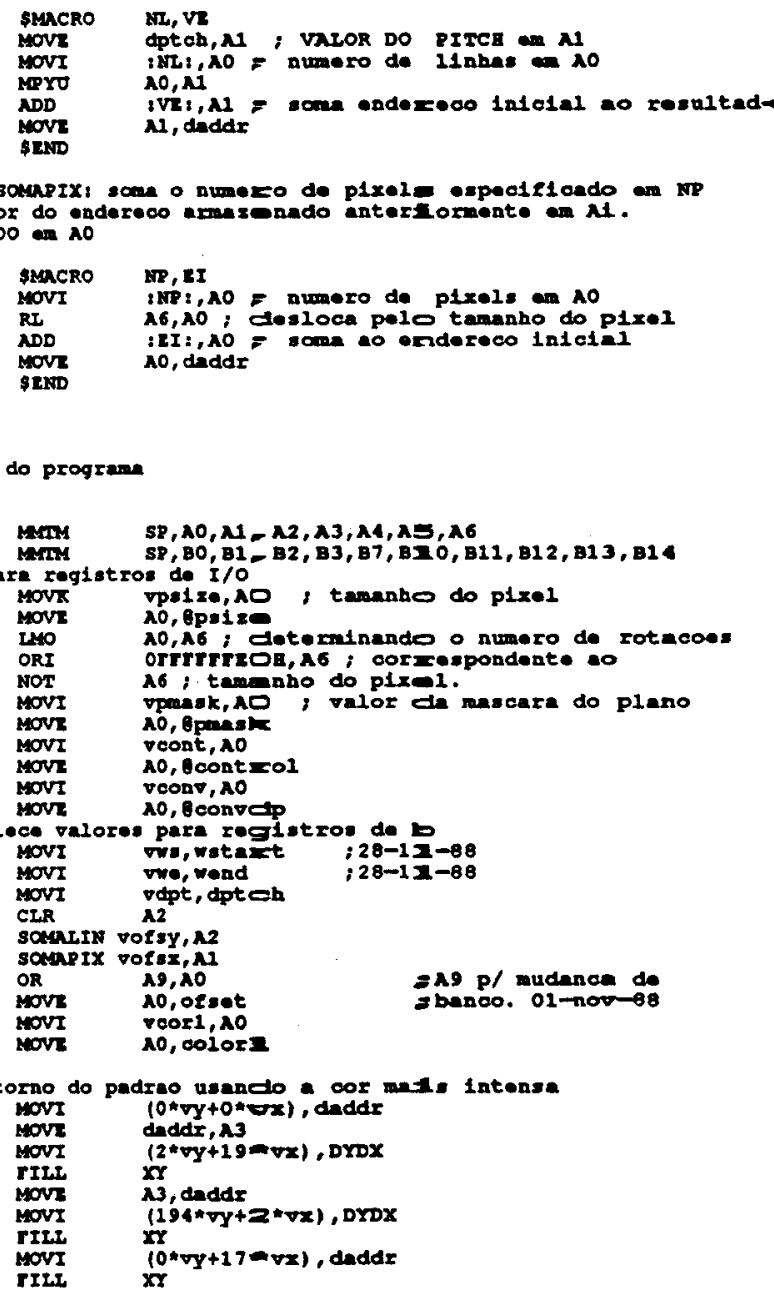


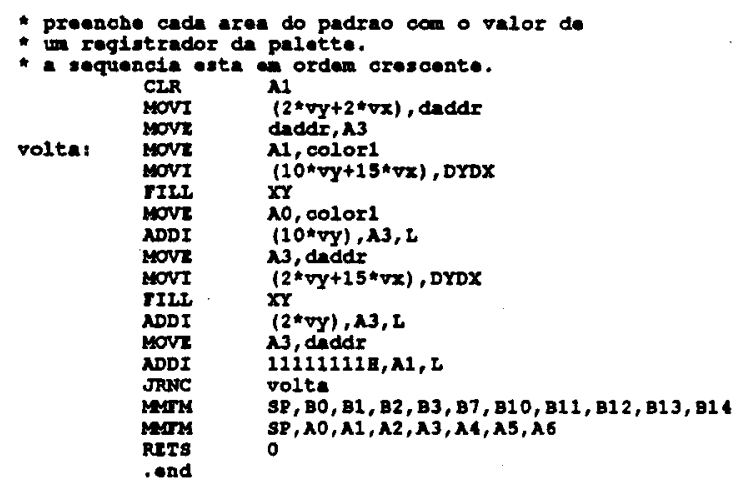

Anexo 1.6 - Subrotina para Trocar o Banco da Memória de Imagem

Exemplo 1

.width $\quad 132$

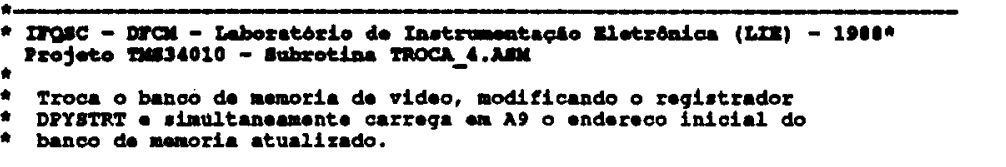

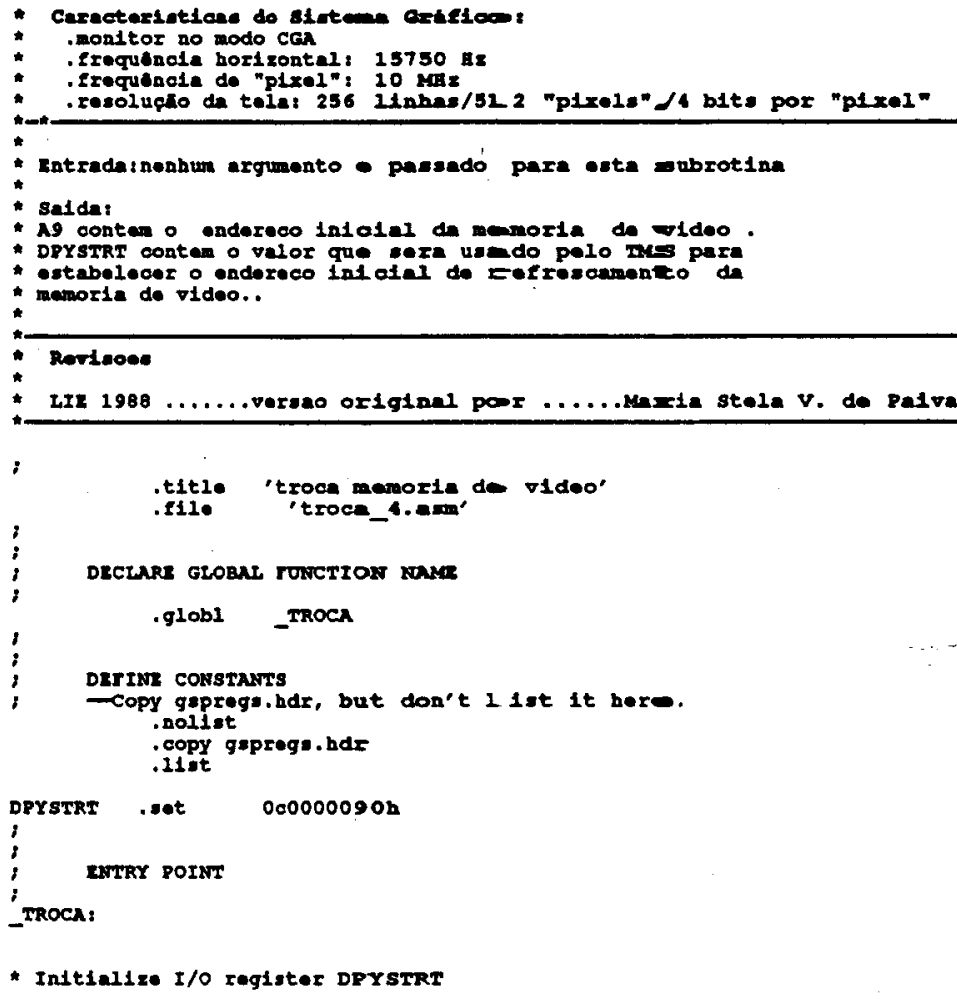

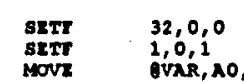

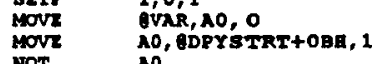

*

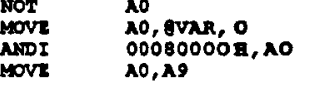

* N11 done. Return.

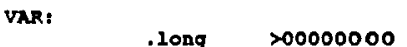

ond 


\section{Exemplo 2}

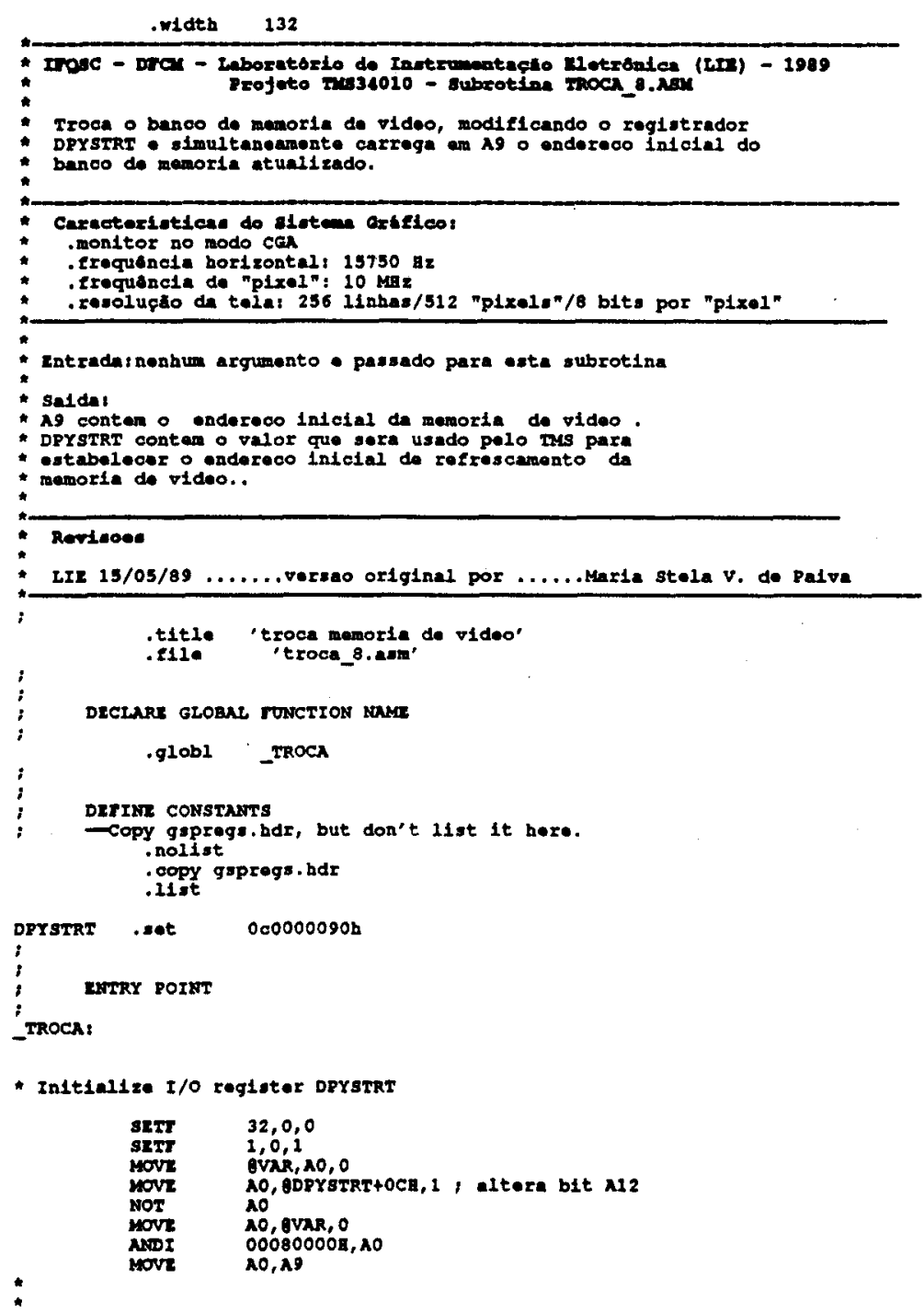

$$
\text { * } 211 \text { done. Retura. }
$$

vaR: $.10 n g \quad>00000000$

.end

\section{Anexo 1.7 - Subrotina para Desenhar Caracteres} ASCII

.w1dth 132

(a) Copyright 1986, Fexas Instrumonte, Incorporated TExT funotion

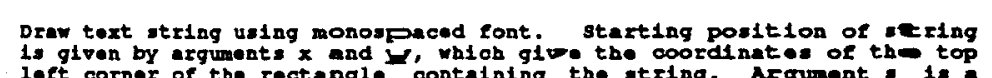

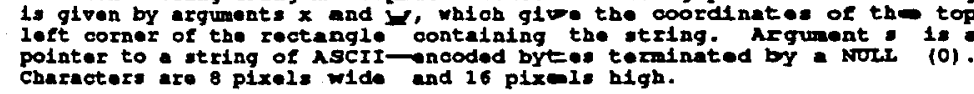

" Thls funetion 12 dosigned to be called Erom a Gsp-c program.

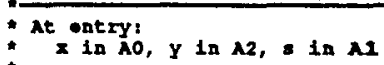

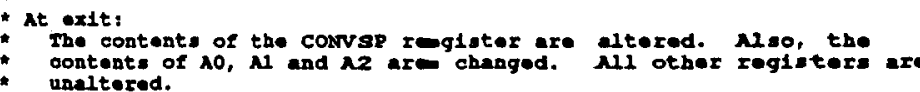

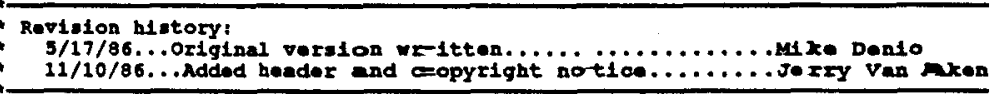

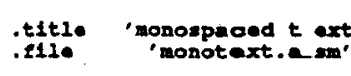

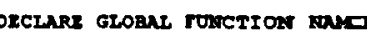

. q10b1 _TExT

DECLARA POIMTRR TO TEXT rON-

.g10b1__obre_xx

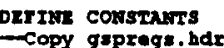

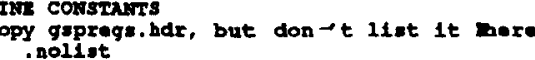

:copy geproga. hdr 


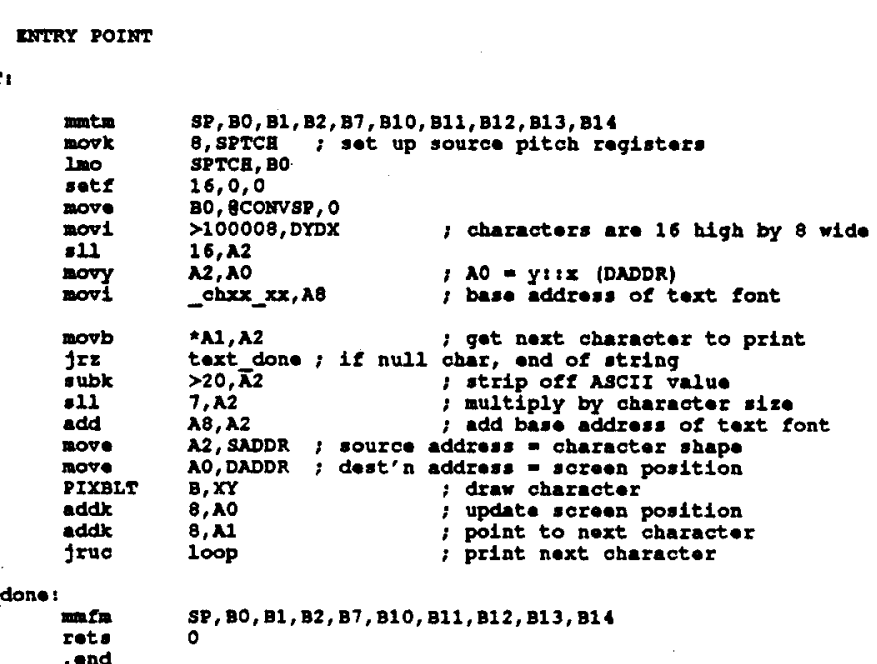

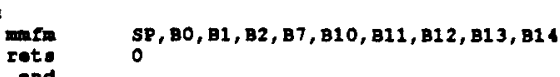

Anexo 1.8 - Programa para Controle do "Mouse"

\section{Exemp lo 1 - Sistema com 16 Côres}

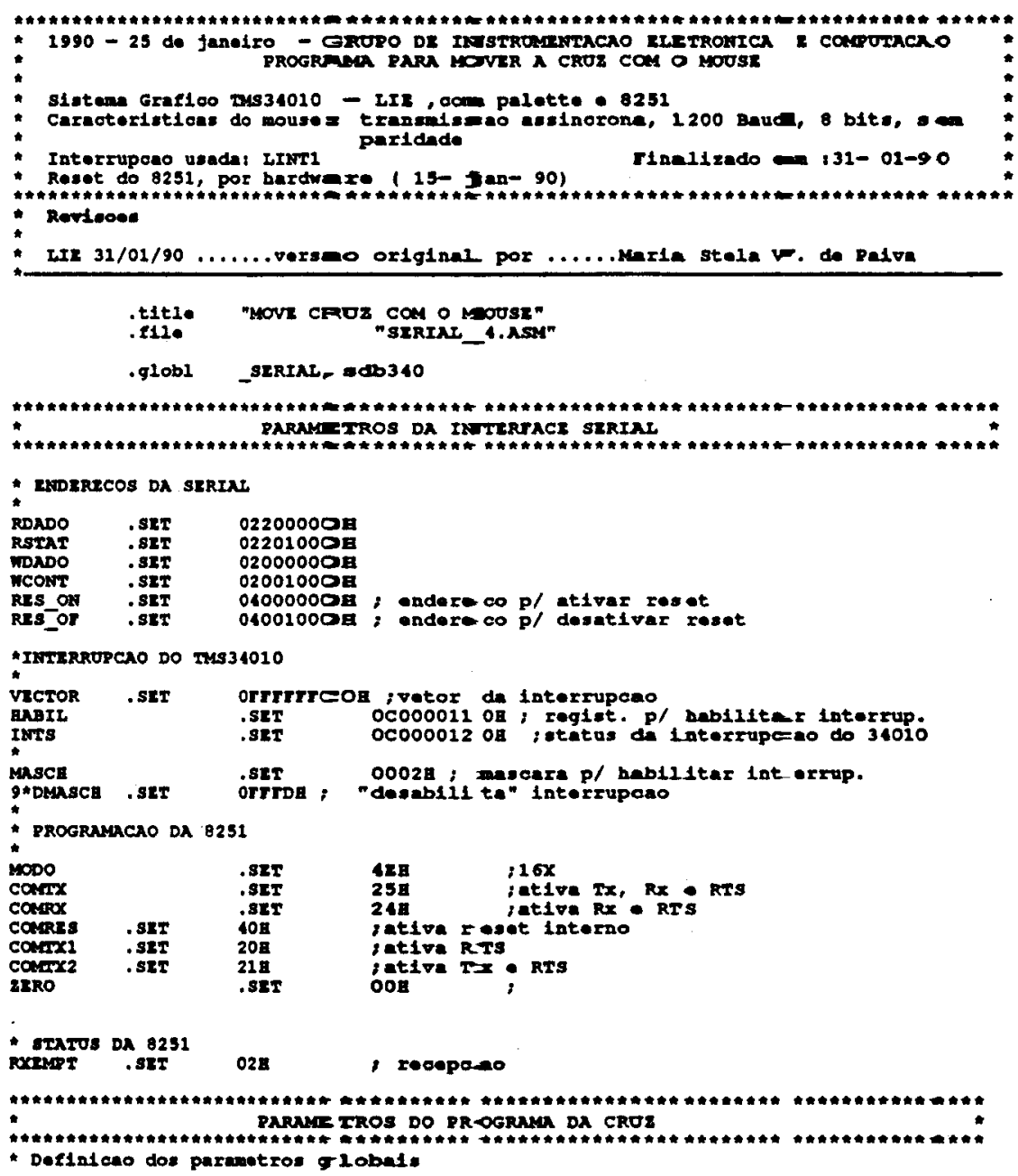


* Roglatradores de $\mathrm{s} / \mathrm{O}$

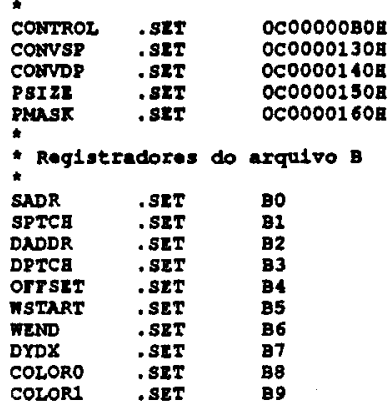

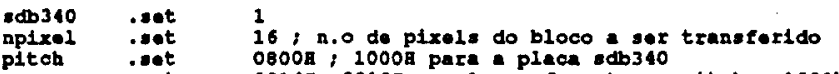

Ir $\quad 5$ sab340

- vasores dos registradorss para o programa grimcipat

* Valores etribuldos aos reglatradores de $1 / 0$

opstzo . szT $4:$ : 8 para a placa sdb340

* valores at ribuicos nos registradores de

votsat .ssr o8008; 1000h para a pleon SDE340

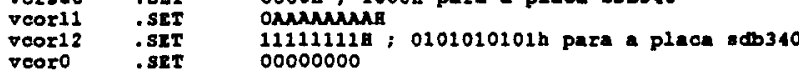

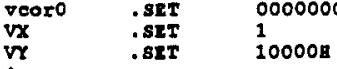

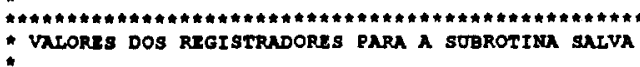

- Velores at zibuidos cos registradores do $I / O$

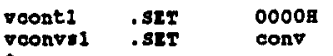

- Valozes etribuidos aos registradores do s

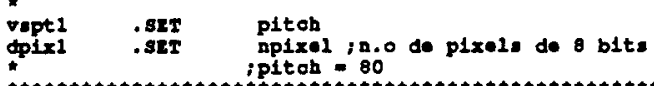

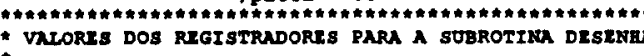

- velores atribuldos aos rogiatradores de $I / O$

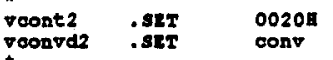

"valores atribuldos aos roglatradores do B

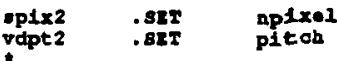

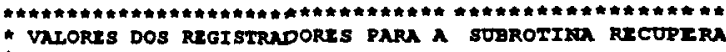

Valores etrtbuldos sos reglatradores de $I / O$

$\begin{array}{lll}\text { voonts } & \text {.SIT } \\ \text { voonvd3 } & \text { SET coopr }\end{array}$

* Velores at ribuldos cos registradores do B

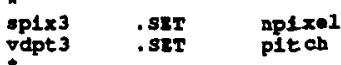

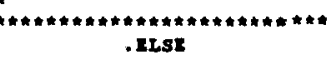

" Valores atribuidos eos registradores de $1 / 0$

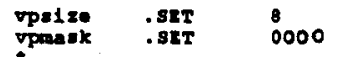

E valoras etribuldos aos registradores de B

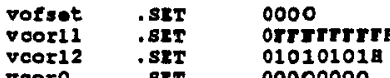

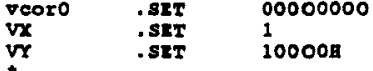

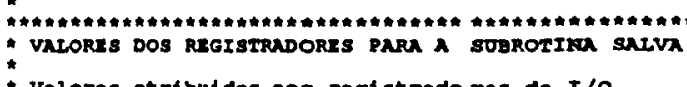

" valores atribuidos coes regiotrado res do $x / 0$

veont1
voonve 1 :SIT

"valores atribuldos con registradoxes de B

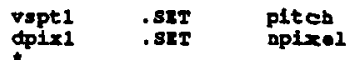

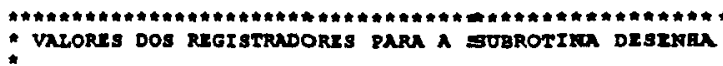

valocos atribuldos cos rogiotradoucos de $x / 0$

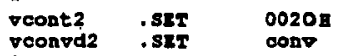

Valozes atribuldos cos rogistradoze: do $B$

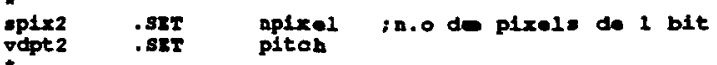

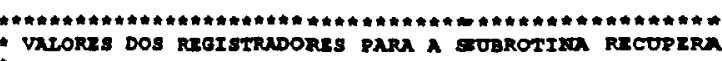

velores atribuldos aos reglatradores de $x / 0$

veont3 .s2T $0000 \mathrm{~B}$ 


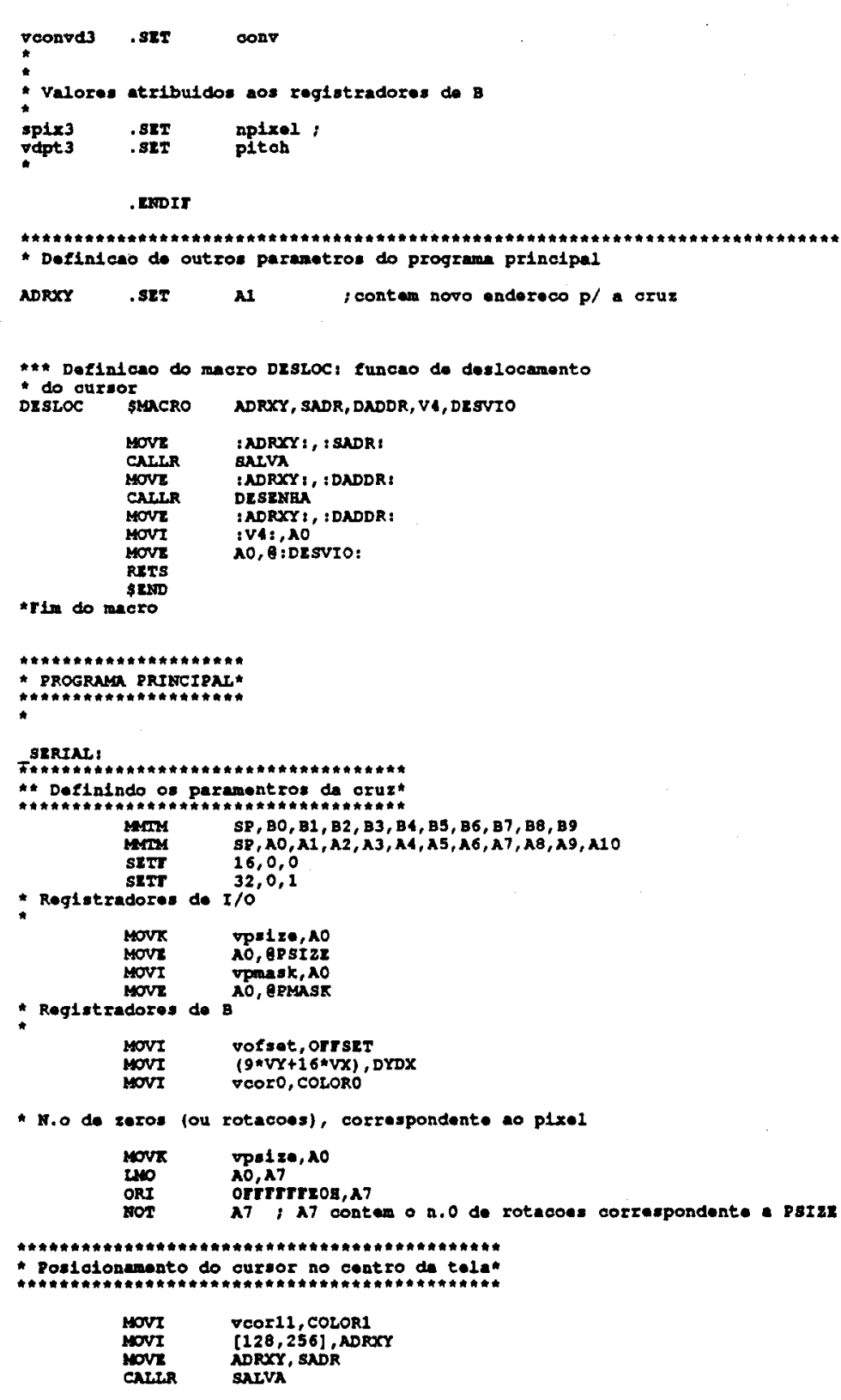




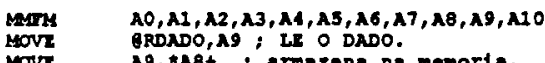

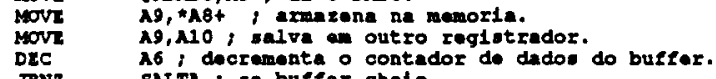

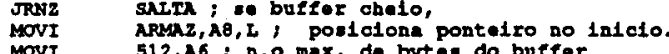

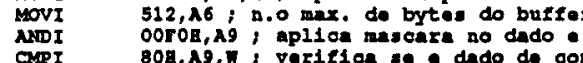

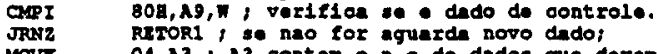

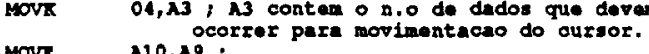

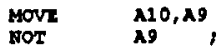

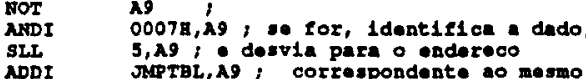

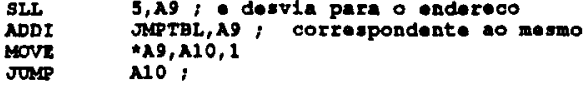

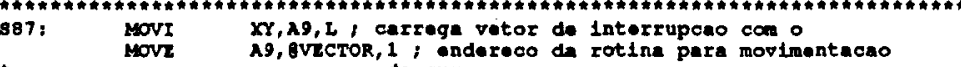
Rritor1:

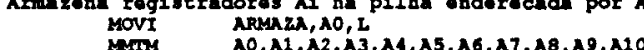

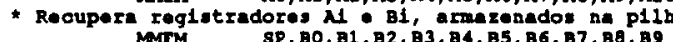

- Babill

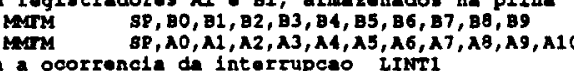

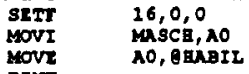

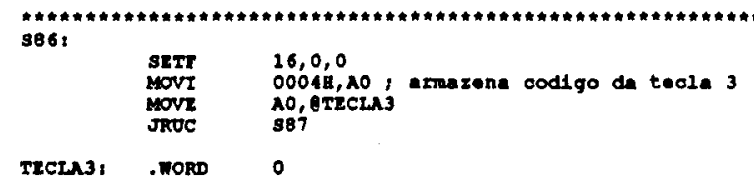

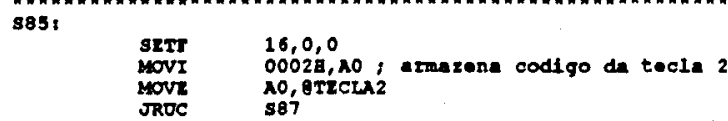

TxCLAz: . MORD

s83!

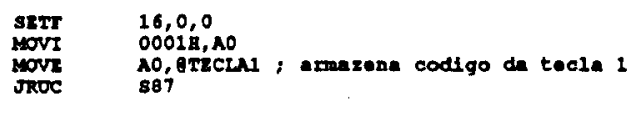

TECLAS: WORD 0

"Znpros:

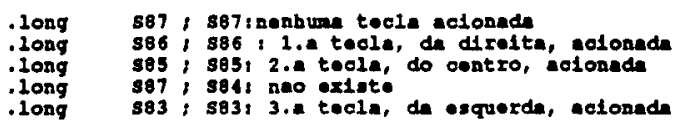

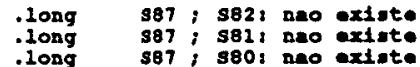

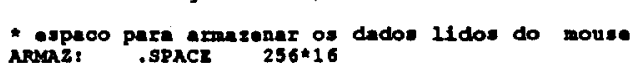

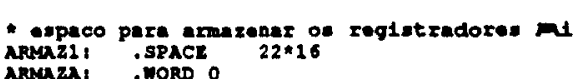

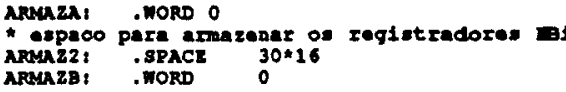

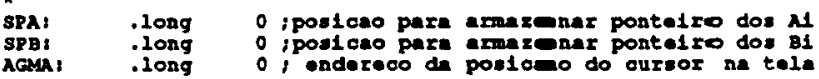

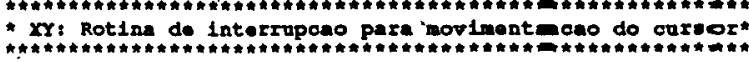

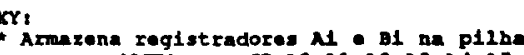

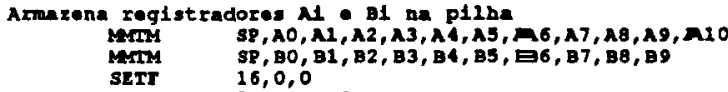

$\vdots$

* A2 aponta

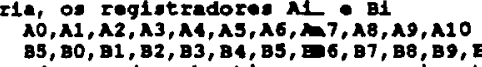

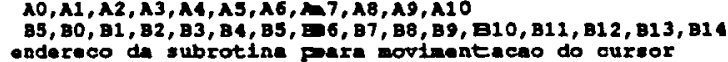

政

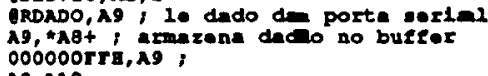

A6: Alo : deromonte $\mathrm{n}$.O de bytos do buetor

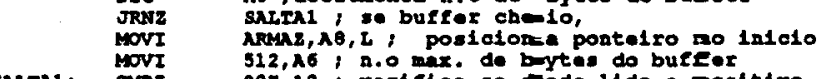

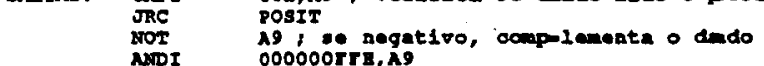

nosis:

Posin. STIF

A2 aponte par-a onderoco de subrotias segulante

0,0

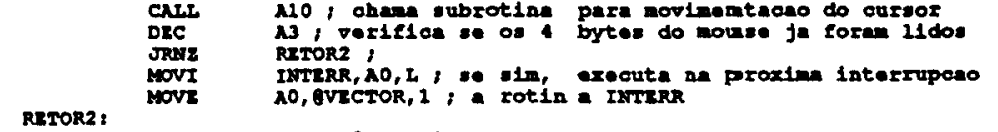

Movr

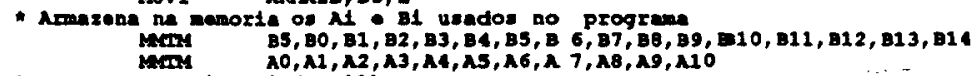

a

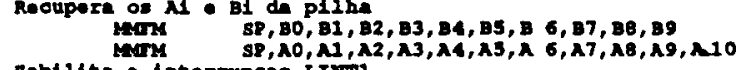

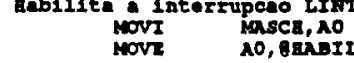


RITI

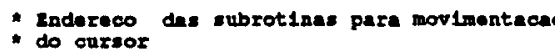

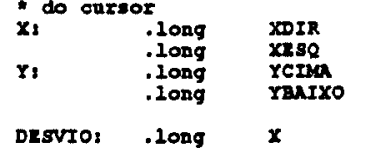

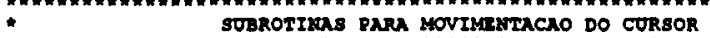

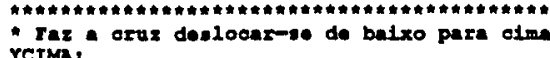

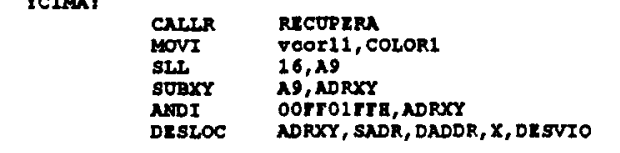

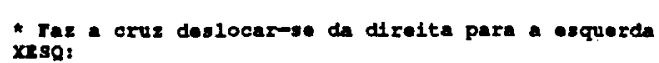

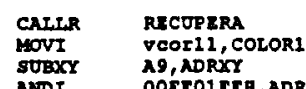

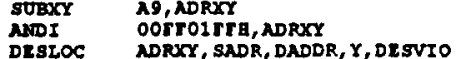

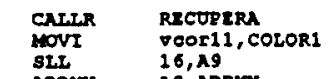

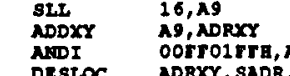

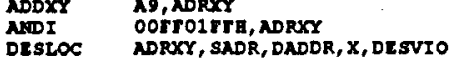

EDIRi

$$
\text { CALIR RTCOPLR }
$$

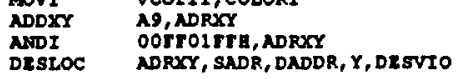

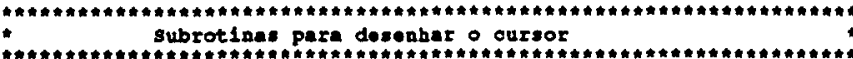

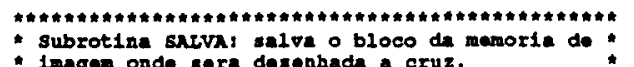

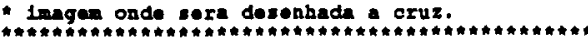

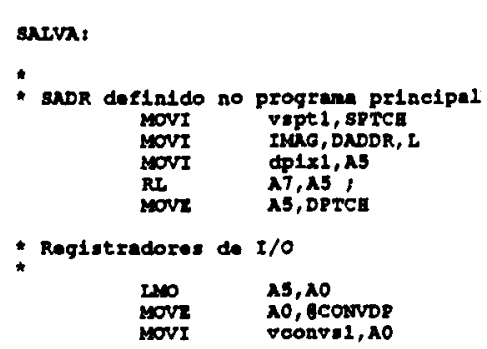

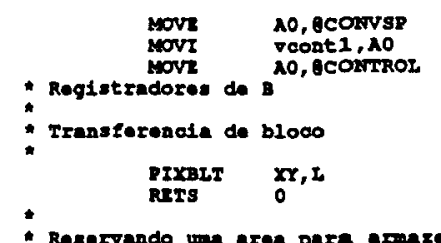

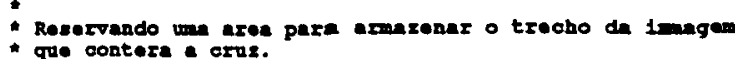

TMag: .SPACR 72m16

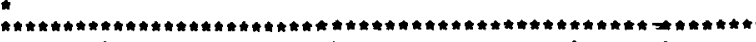

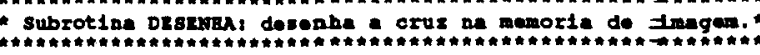

Dxsemua

Registradores de $\mathrm{I} / \mathrm{O}$
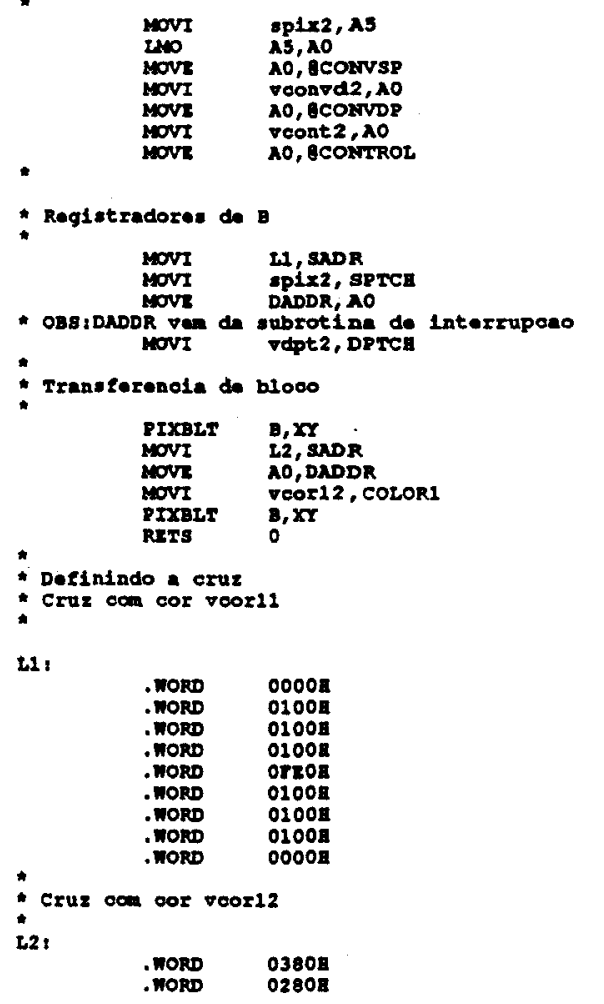


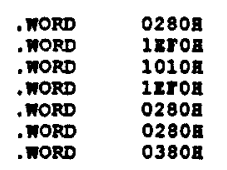

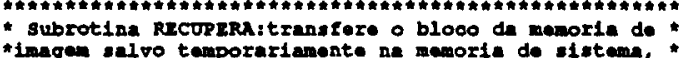

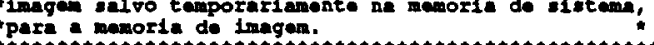

Recopres,

Rogiatradores de

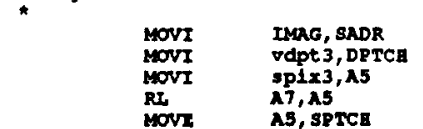

* OBS: DADOR vard do Programe principes

Reglotradores de $I / 0$

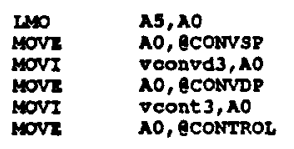

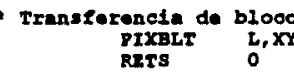

and

\section{Exemplo 2 - Sistema com 256 Níveis de Cinza}

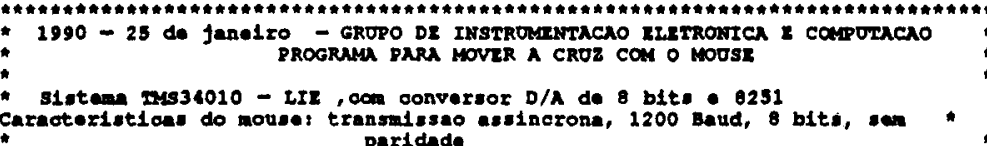

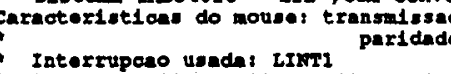

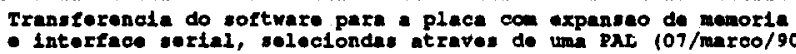

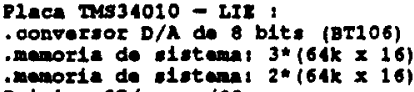

$\operatorname{rim} 107 / \operatorname{mar} 00 / 90$

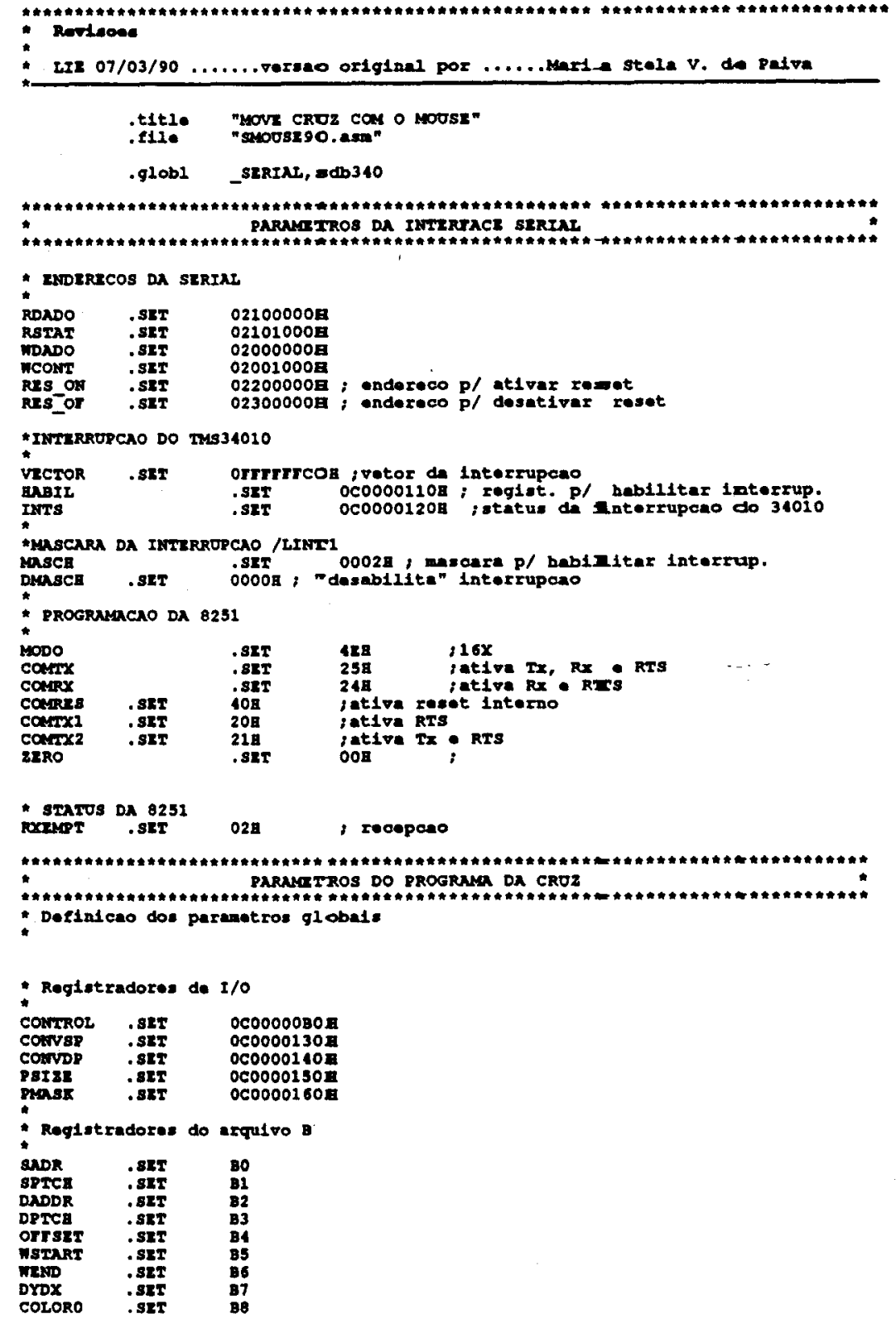

Rovieoce

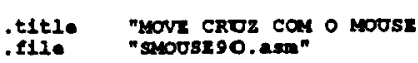

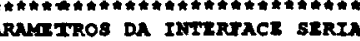

andratcos da serian

$\begin{array}{lll}\text { RDADO } & . S R T & 02200000 \\ \text { RSTAT } & \text {.SET } & 02101000\end{array}$

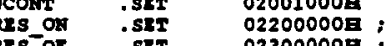

inTERRUPCAO do TMS34010

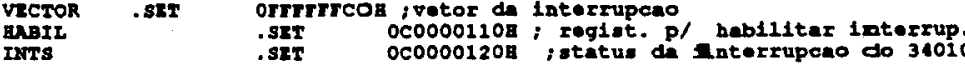

"MASCARA DA INTSRROPCAO /LINT1

PRogramacio da 8231

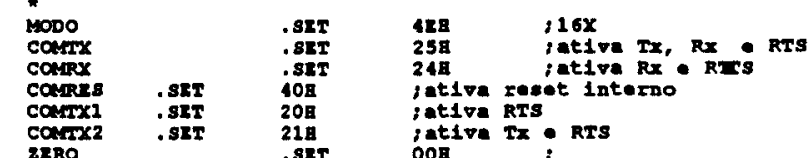

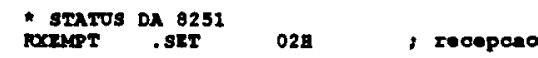

PARNATROS DO PROGRAMA DR CREZ 


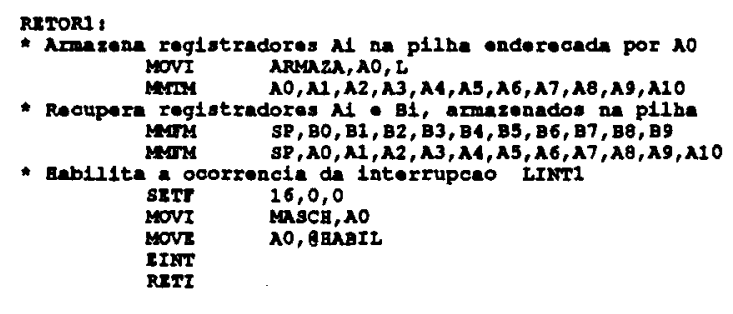

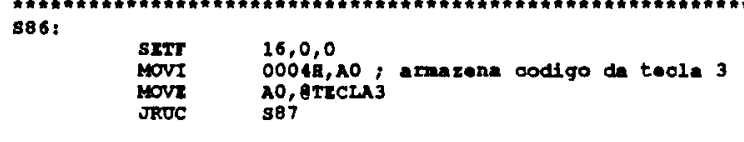

$$
\begin{aligned}
& \text { IRCLA3: . ПORD } 0
\end{aligned}
$$

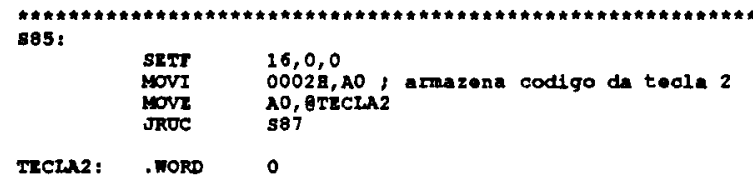$$
\text { s83: }
$$

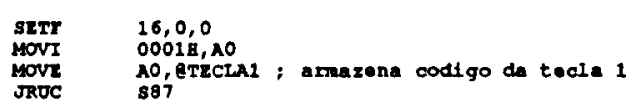

THCLAS: WORD O

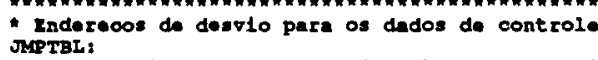

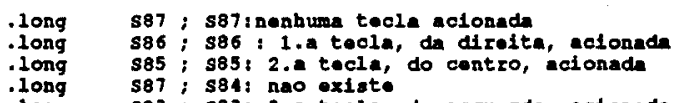

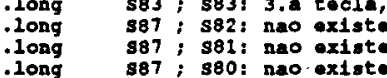

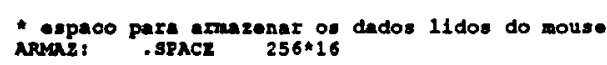

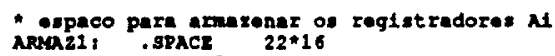

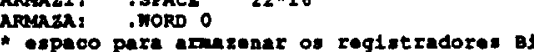

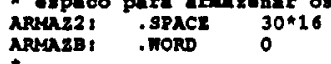

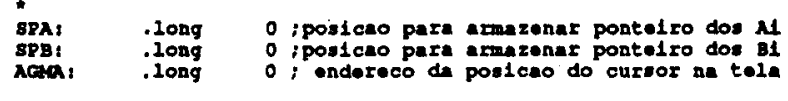

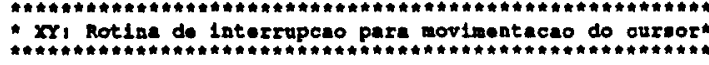

$x$

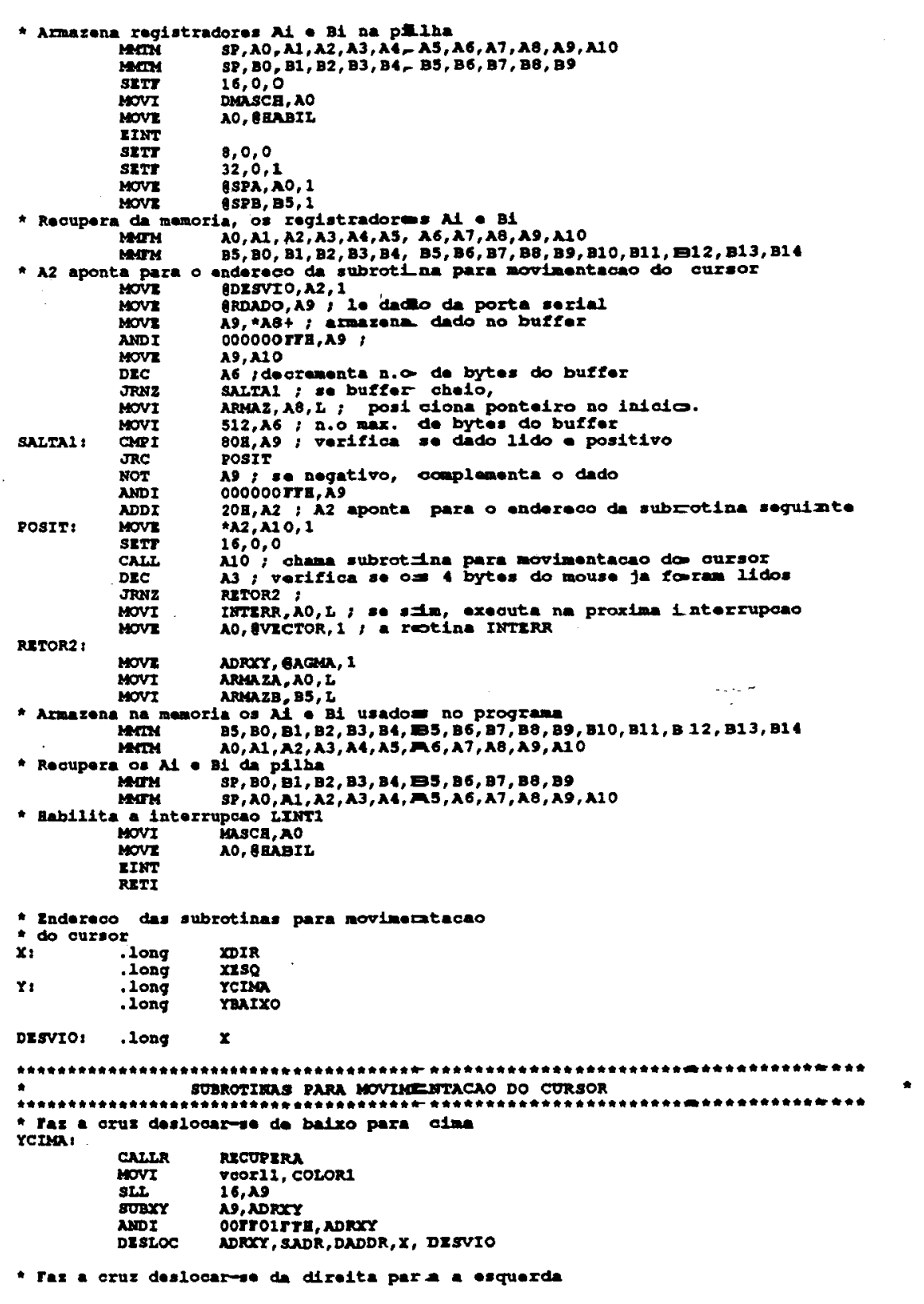

9 
2xso:

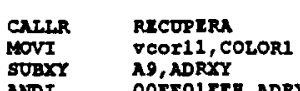

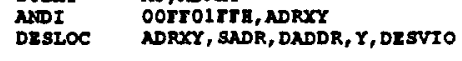

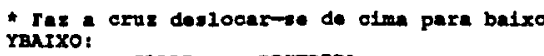

MOVI

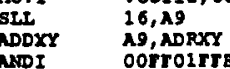

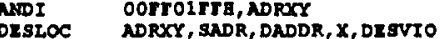

* raz a cruz deslocar-se de osquerda para a ditreita

CRALR
MOVI
NDDXY

ANNI
DESLCC

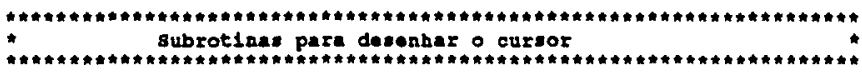

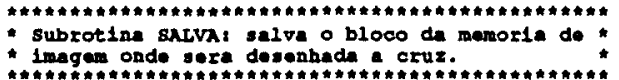

sarve

- sadr dofinido no programa principal

MOVI

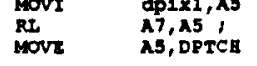

: Ragistradores de $1 / 0$

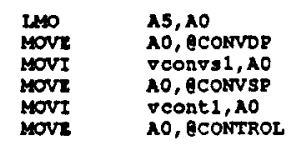

* Registzadores de B

Transtorenaia de blooo

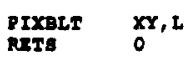

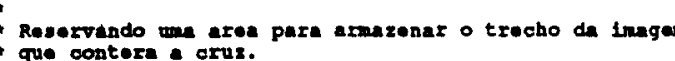

imag, apace 72*16

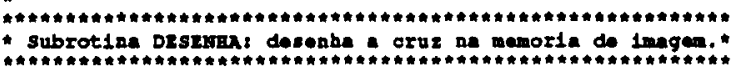

Desersau:

Reglstradoros de $\mathrm{I} / \mathrm{O}$

$$
\begin{aligned}
& \text { movi }
\end{aligned}
$$

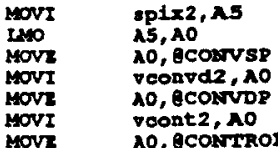

$$
\begin{aligned}
& \text { * Regiotradores de a }
\end{aligned}
$$

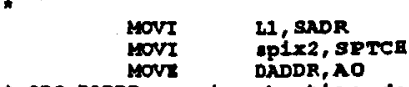

$$
\begin{aligned}
& \text { - OBs:DADDR van da subrotina de interxupcao . } \\
& \text { - Transforenota de blooo }
\end{aligned}
$$

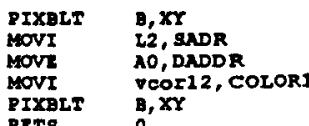

Deflnindo a cruz
Cruz oom dor voor12

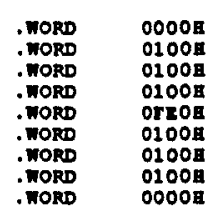
Cruz com cor veor 12
i2:

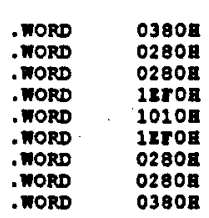

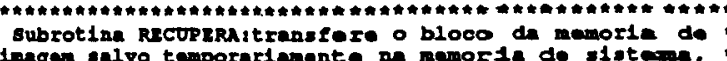

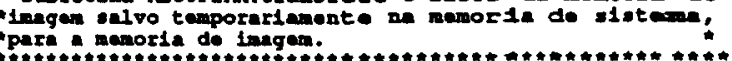

Recorrsa:

Registradores de a

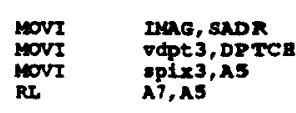




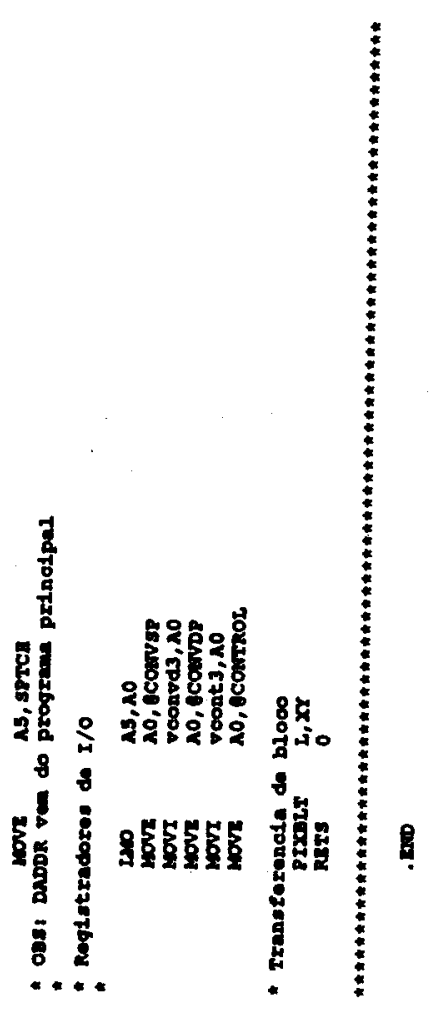


Anexo 1.9 - Programa para Configurar o Vídeo para o Modo Entrelaçado

.width 132

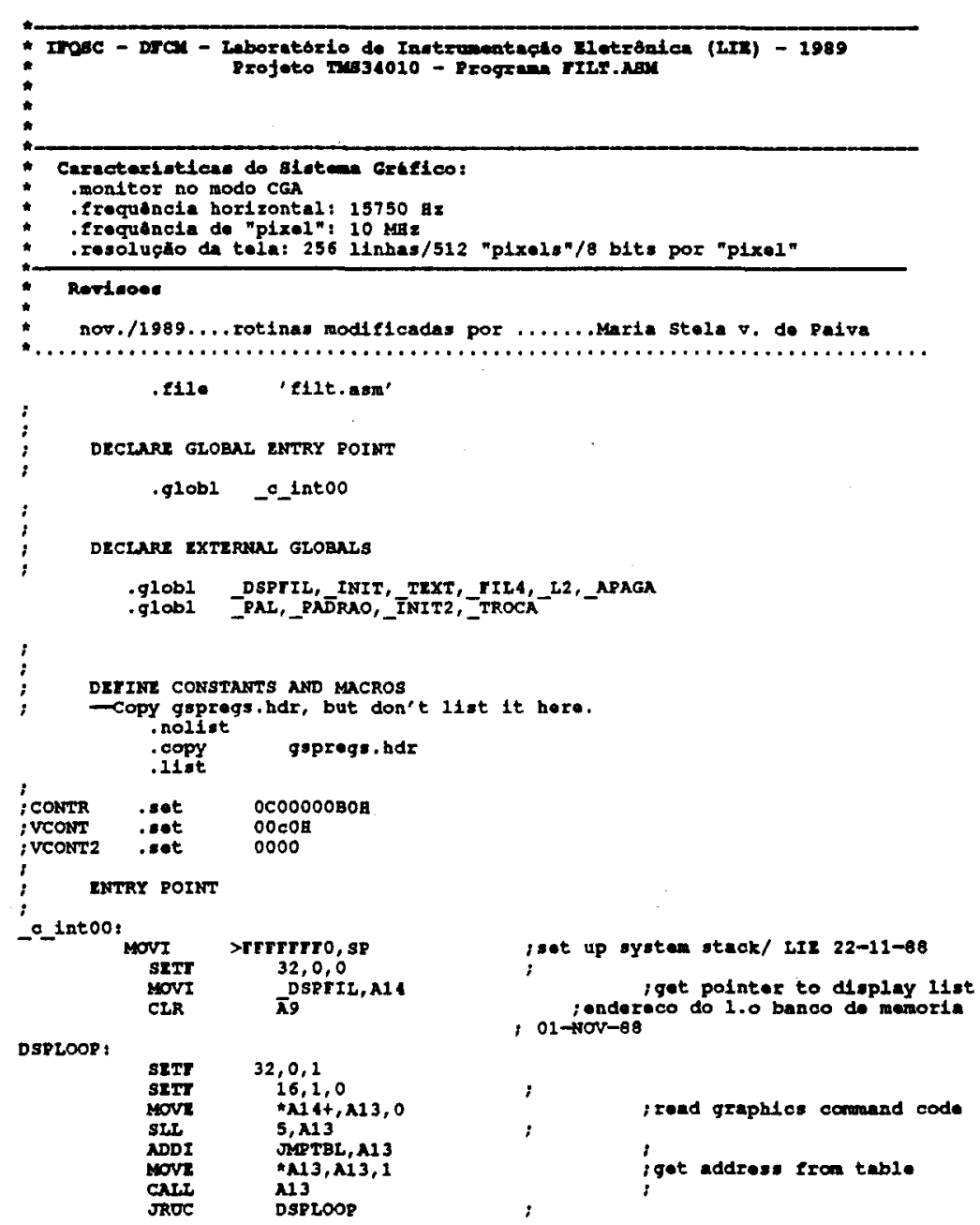

TMPTEL:

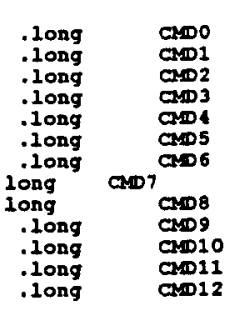

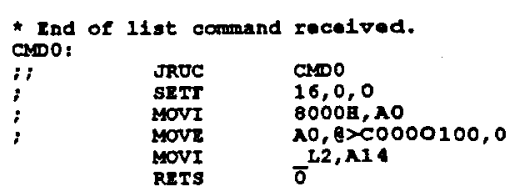

;padrastor

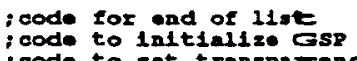

code for change coloro for thext drax

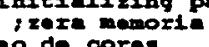

trodien benco

; the cod- ind this 10 the way

, endoraco 'codilgo pl belt

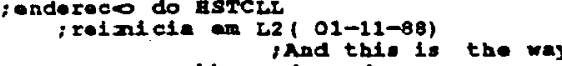
inot the cood onds

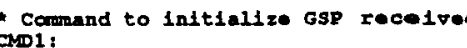

MOVI

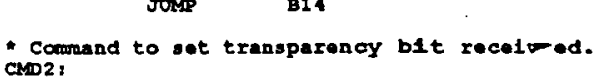

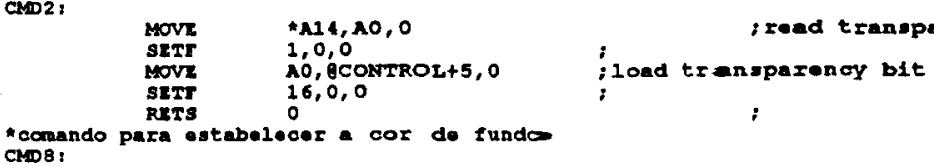

, AO, 0

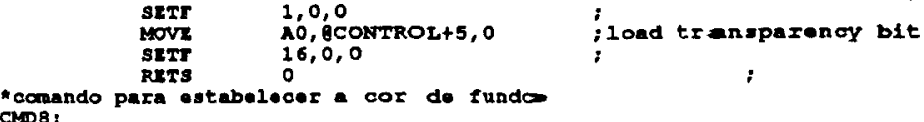

MONI

Command to ohange coloro roceived.
CNOB 3 :

MOVX
MOVI
PITS

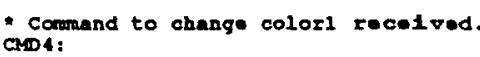

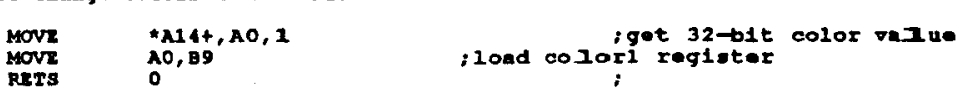

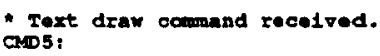

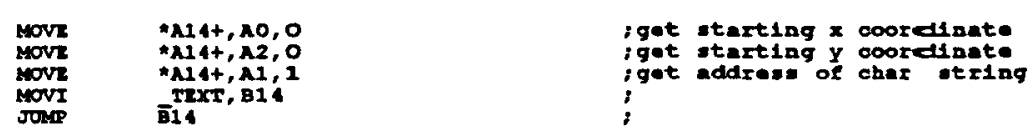

* Function 2111 - dosenha o LIR

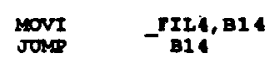

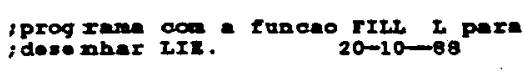

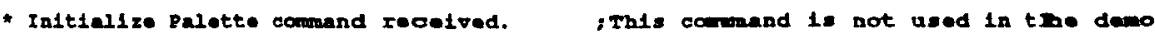



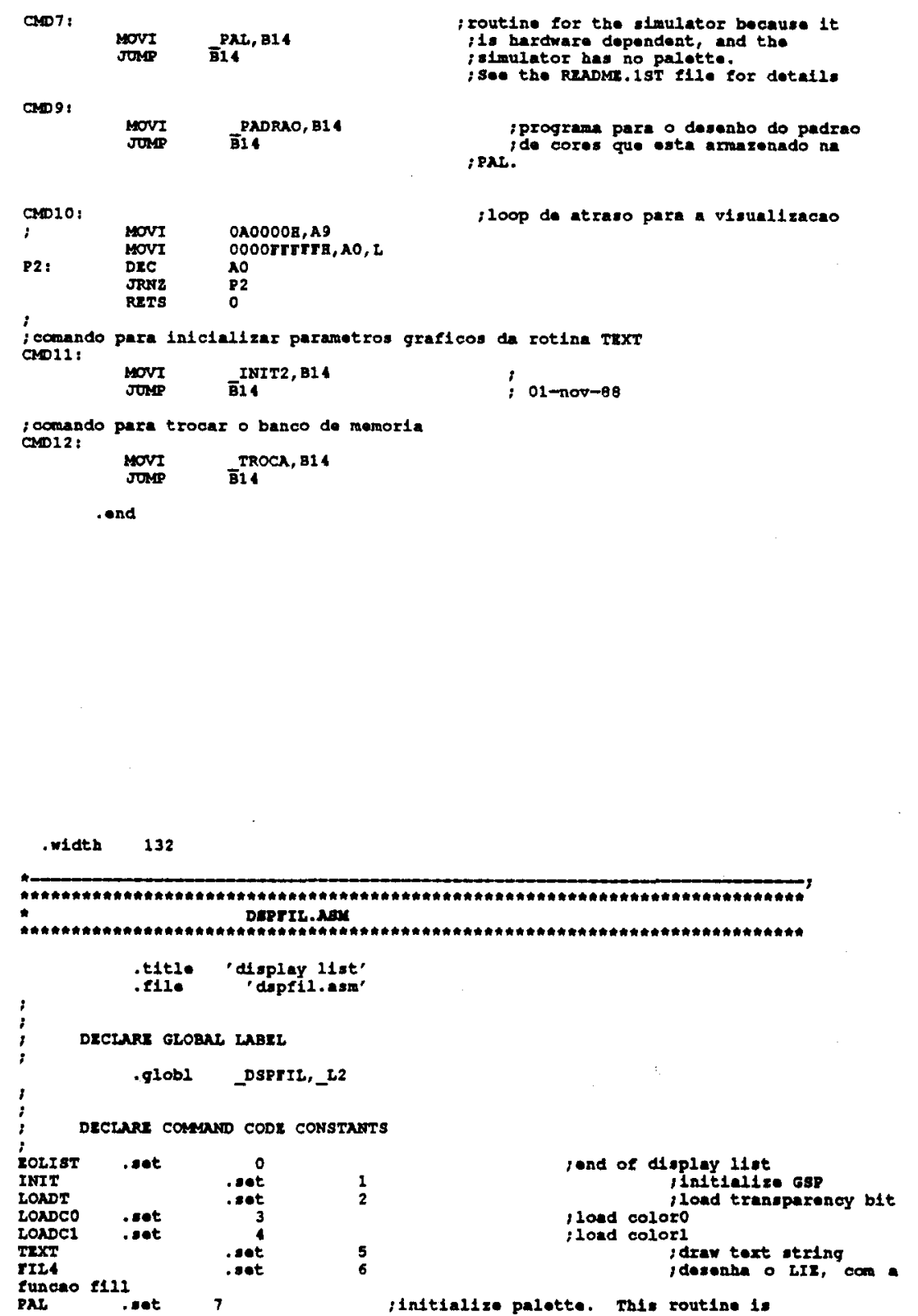

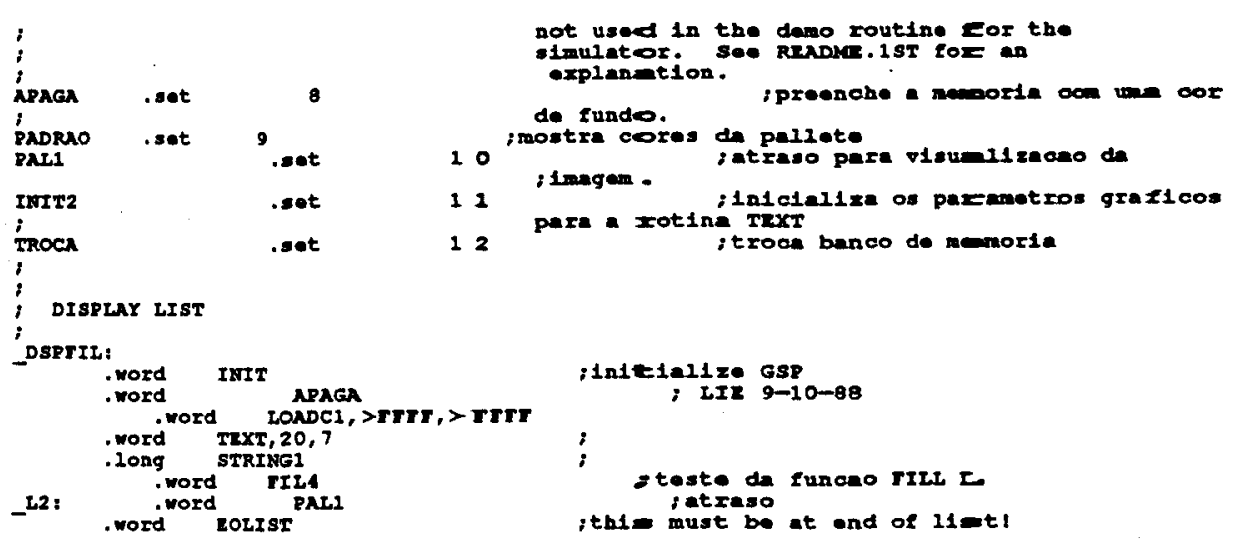

STRING1

.atring
mord
.end

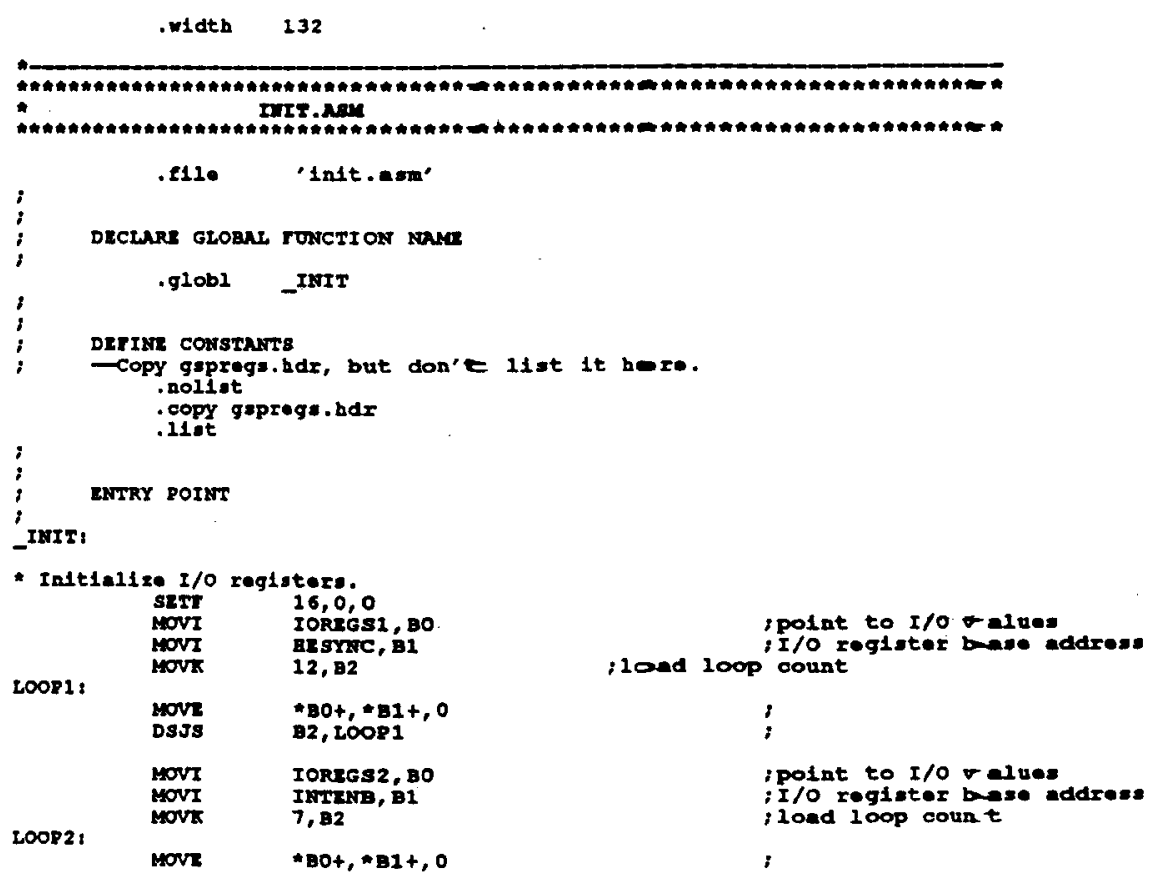



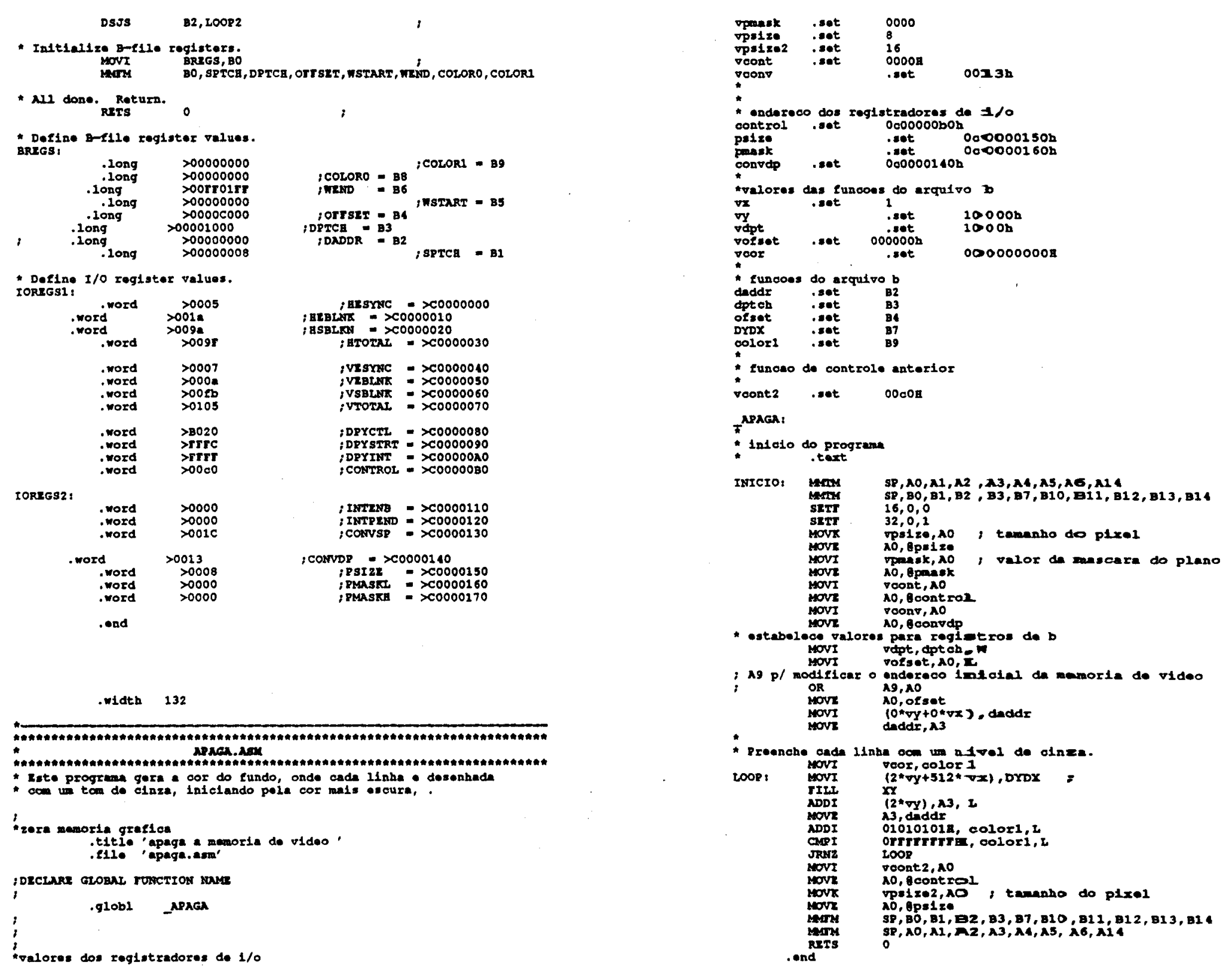

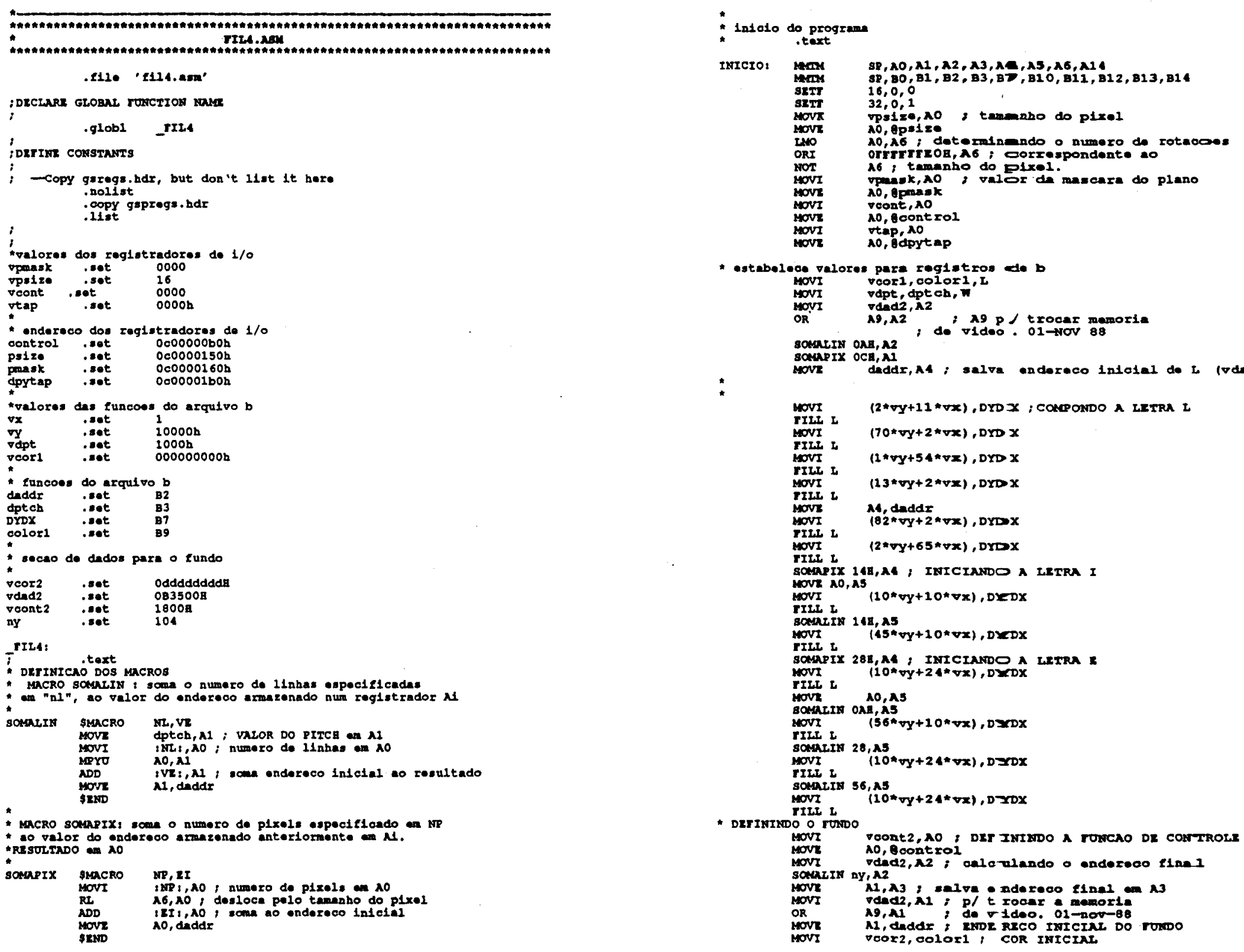


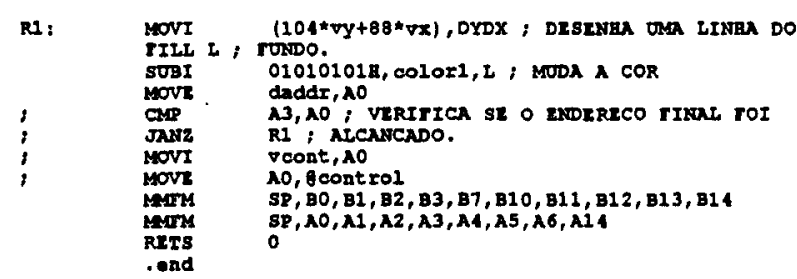

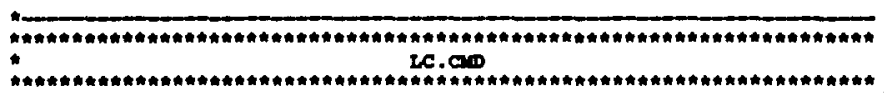

DSPTIL. OBJ
INITS

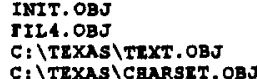

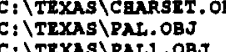

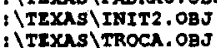

progrant oxigtn $=0 x$ rrroo000 length $=0 \times 00100000$

זc.mer

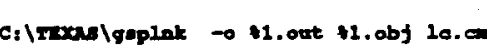

Anexo 1.10 - Programa para Trocar Alternadamente os Bancos de Memória

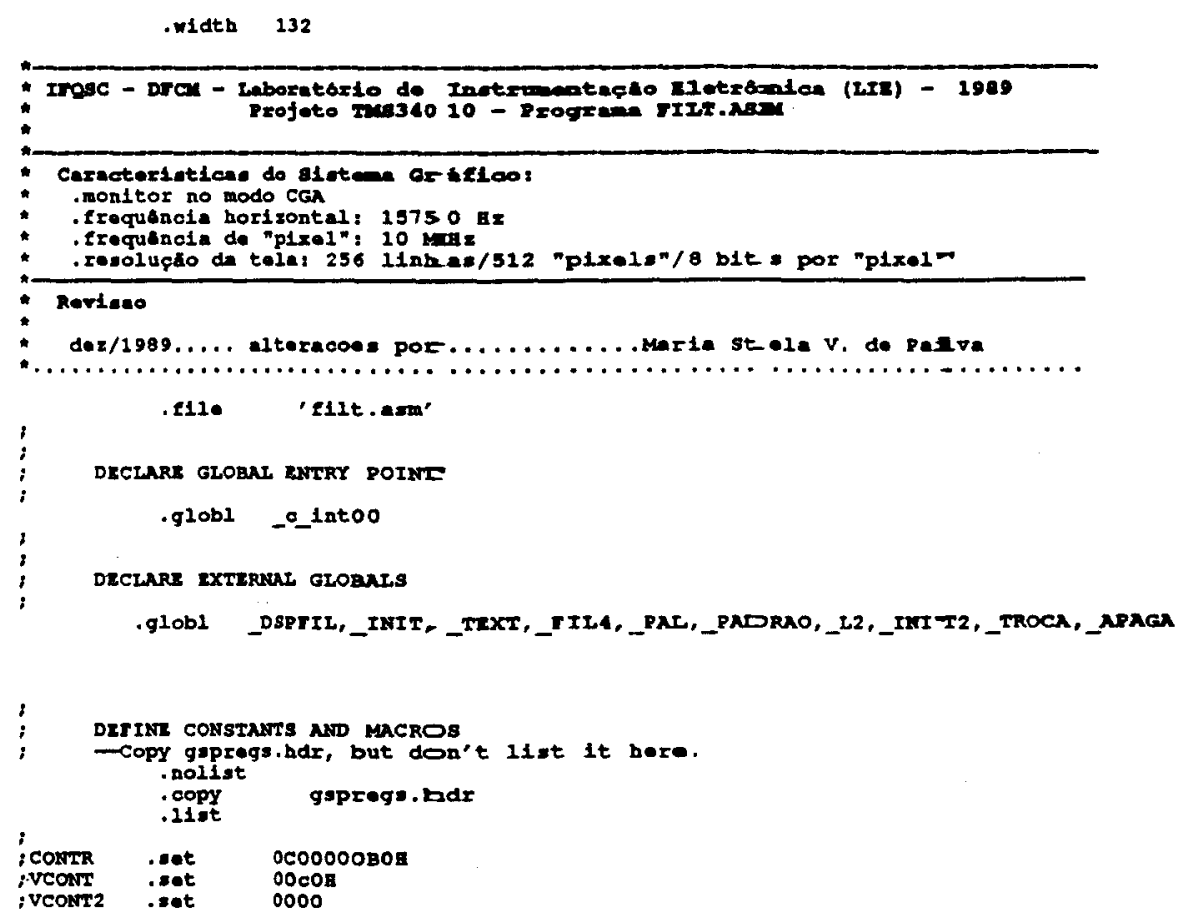



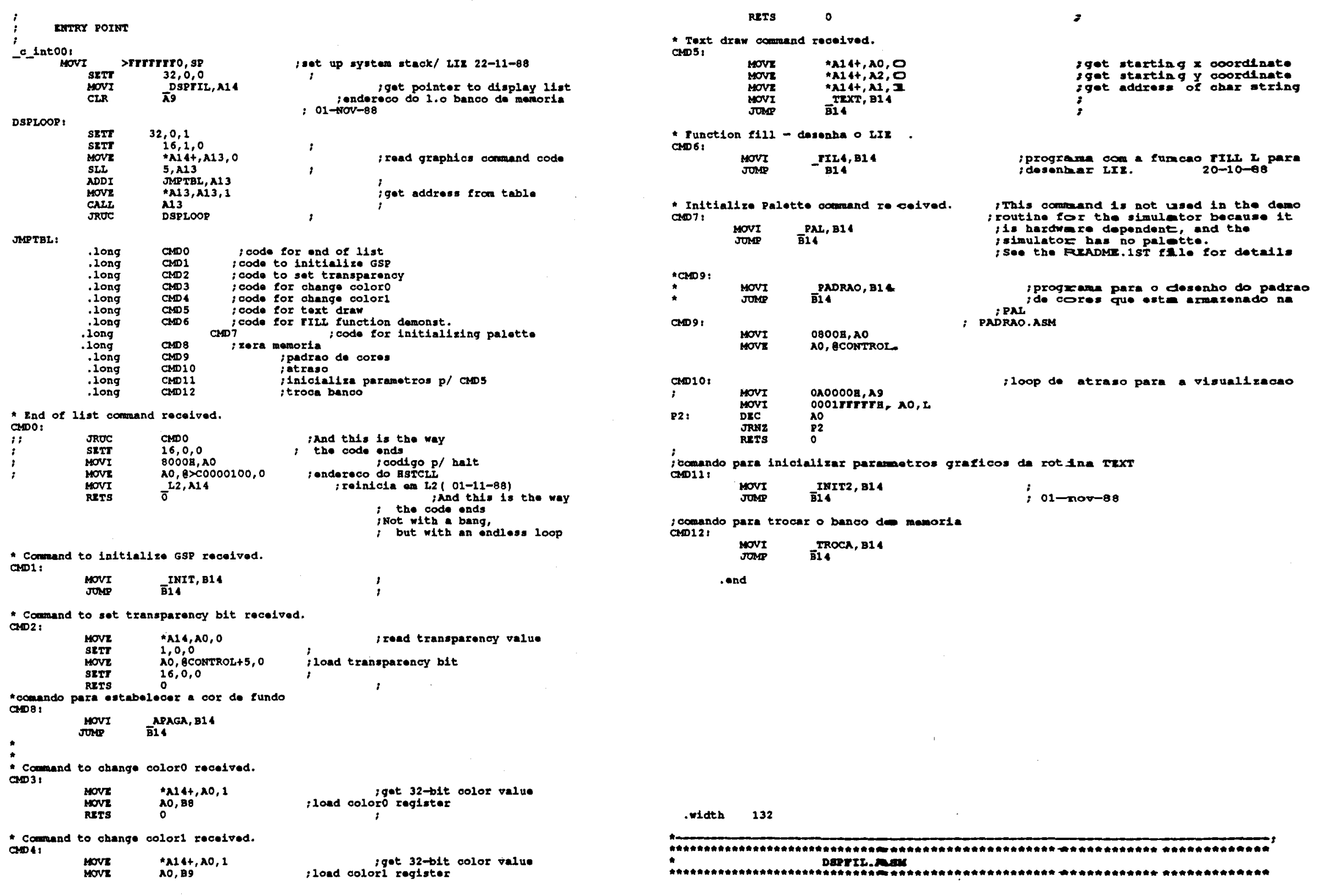

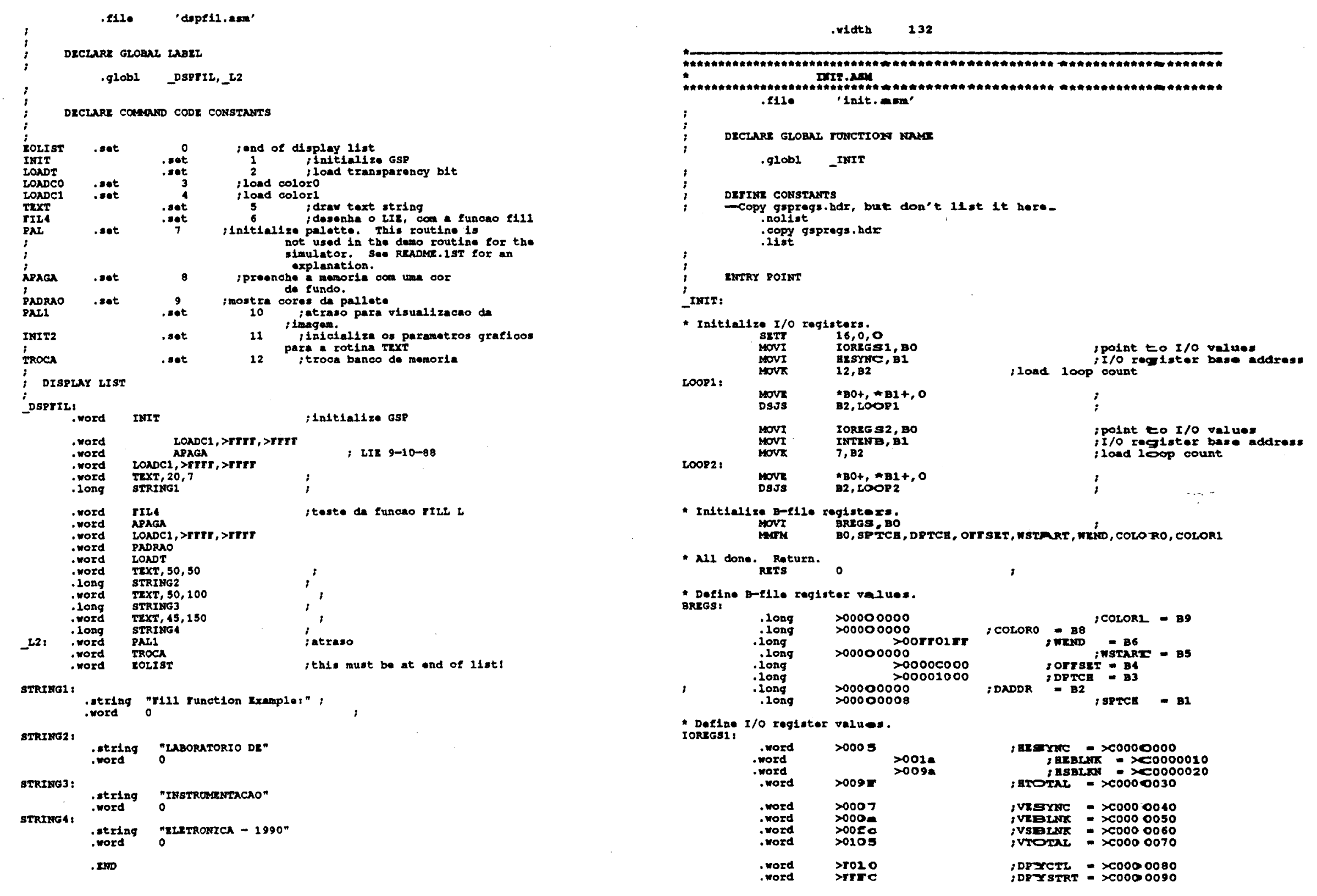

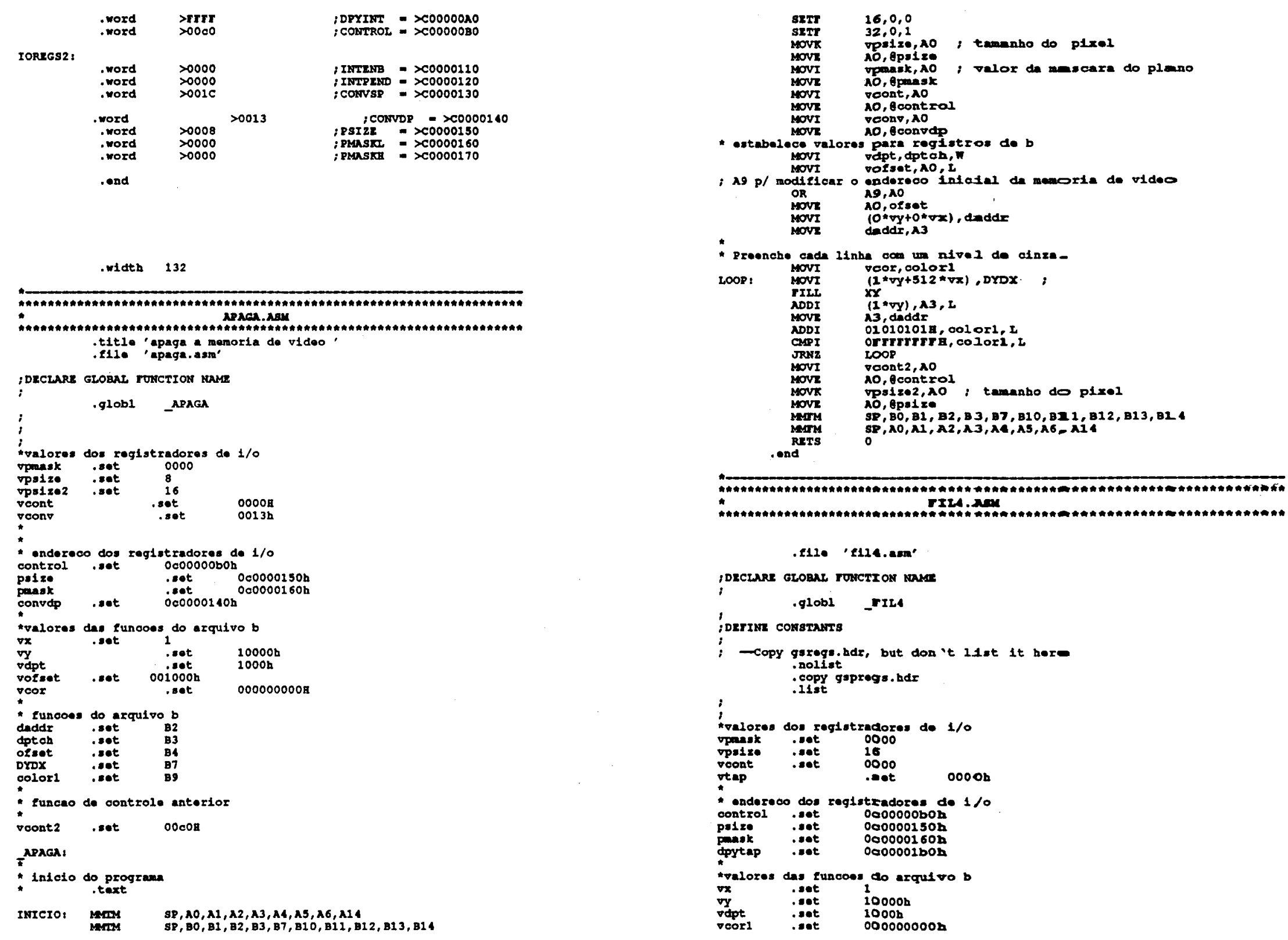

$$
\text { .2110 ' 2114.asm' }
$$

, DECLARE GLOBAR TONCTI ON IRANE

iglobi frle

iderime congtanss

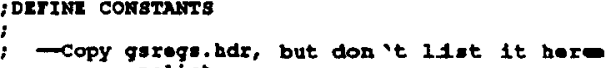

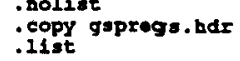

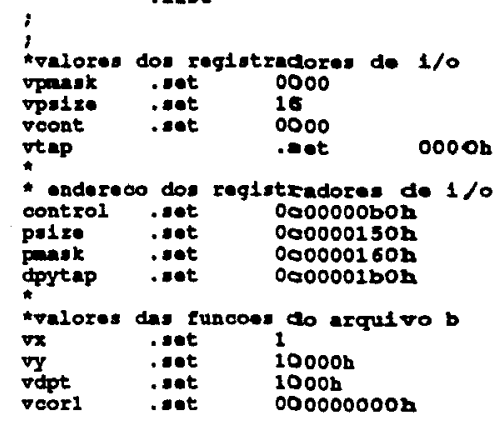



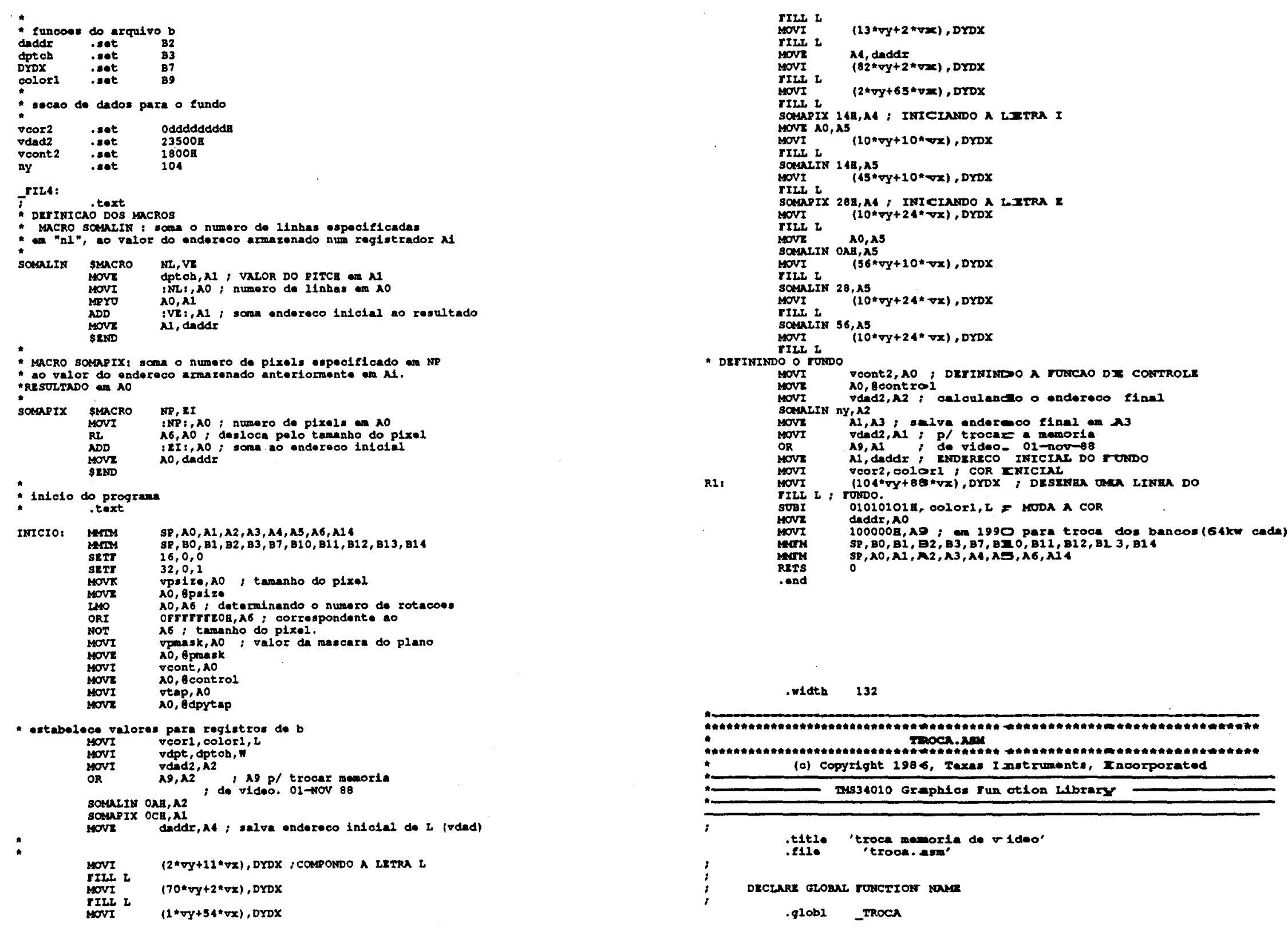


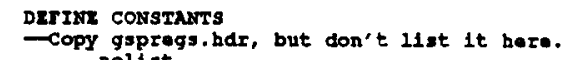

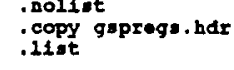

DPYsThx ..et oco0000901

umrRY POINT

* Initiallze I/O regiater DPYstrT

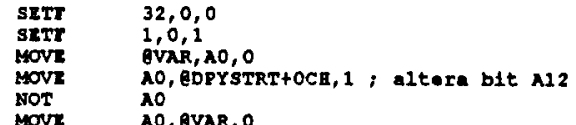

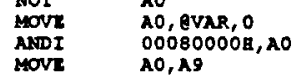

$$
\begin{aligned}
& \text { * All done. Return. } \\
& \text { VAR: .10ng }>00000000
\end{aligned}
$$$$
\text { .ond }
$$

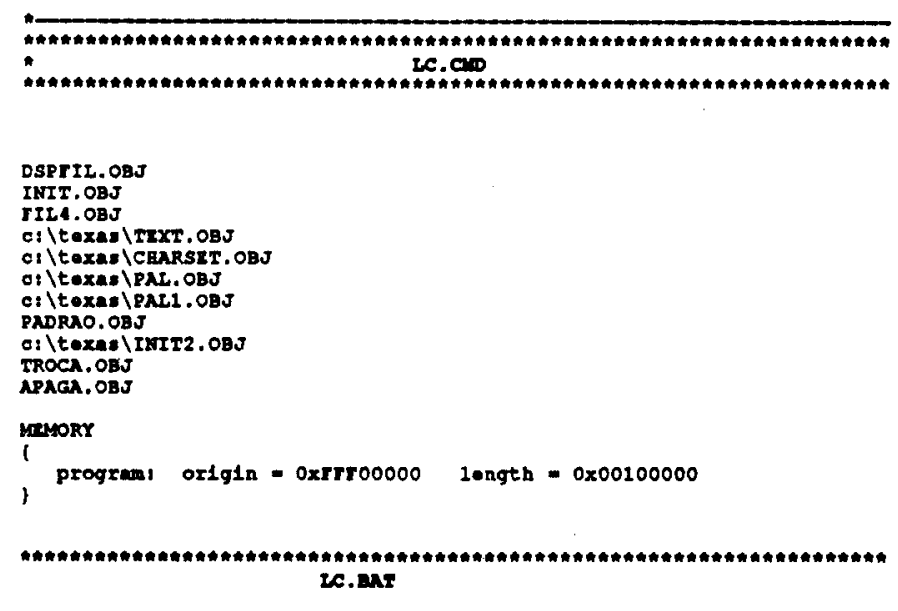

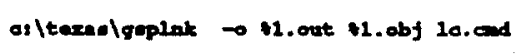

\section{Anexo 1.11 Progranna para Dividir a Tela em D uas} Partes

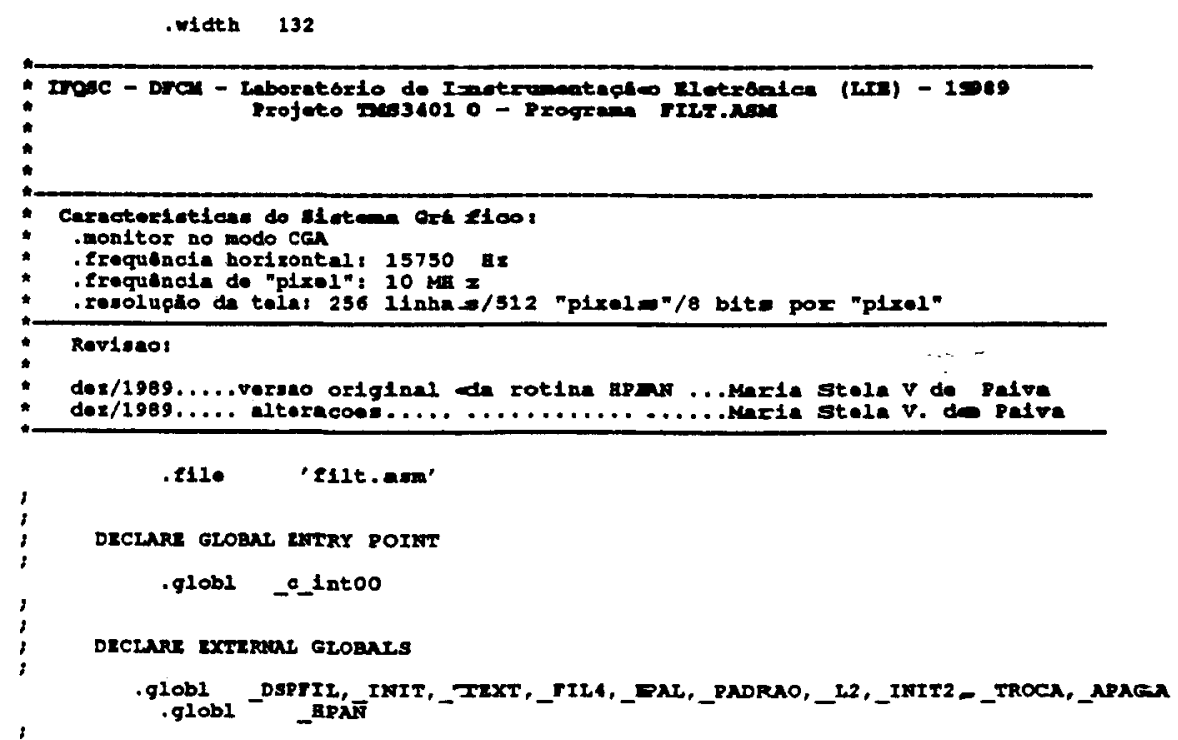




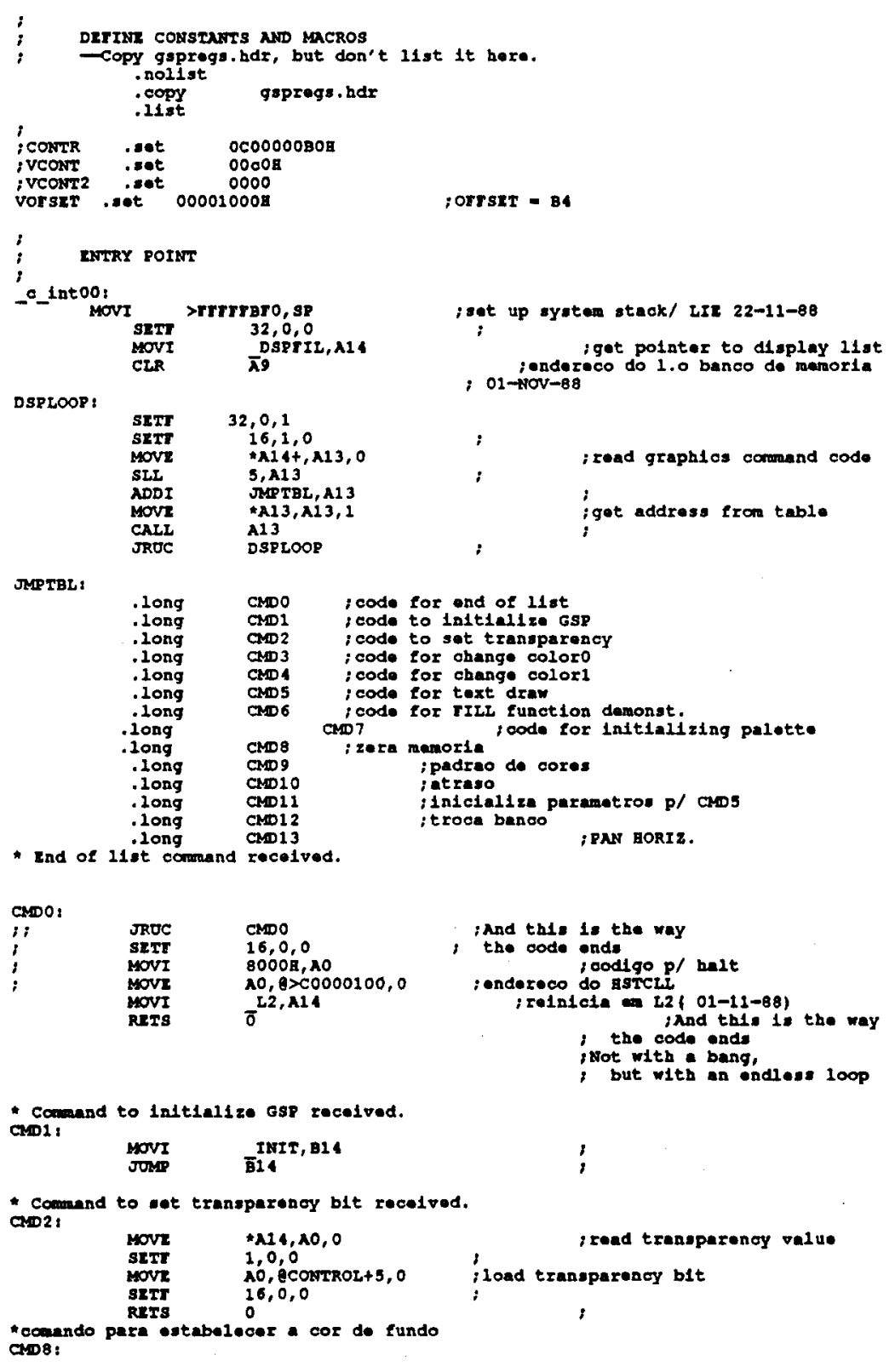




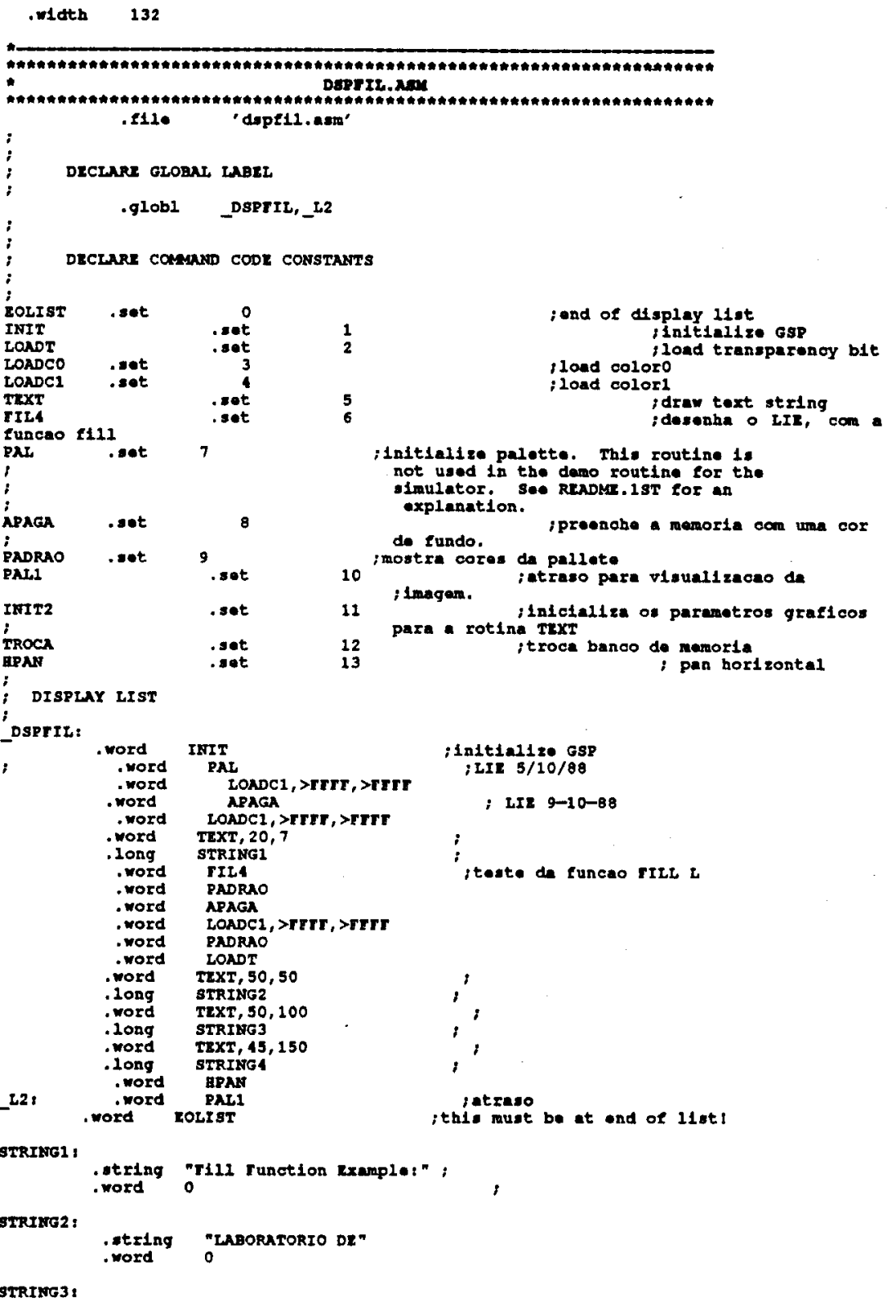

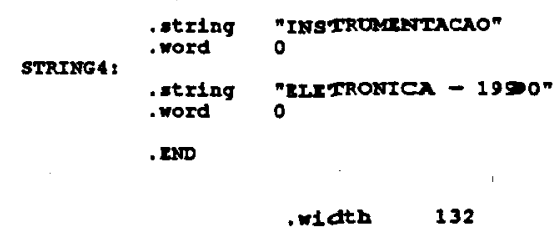

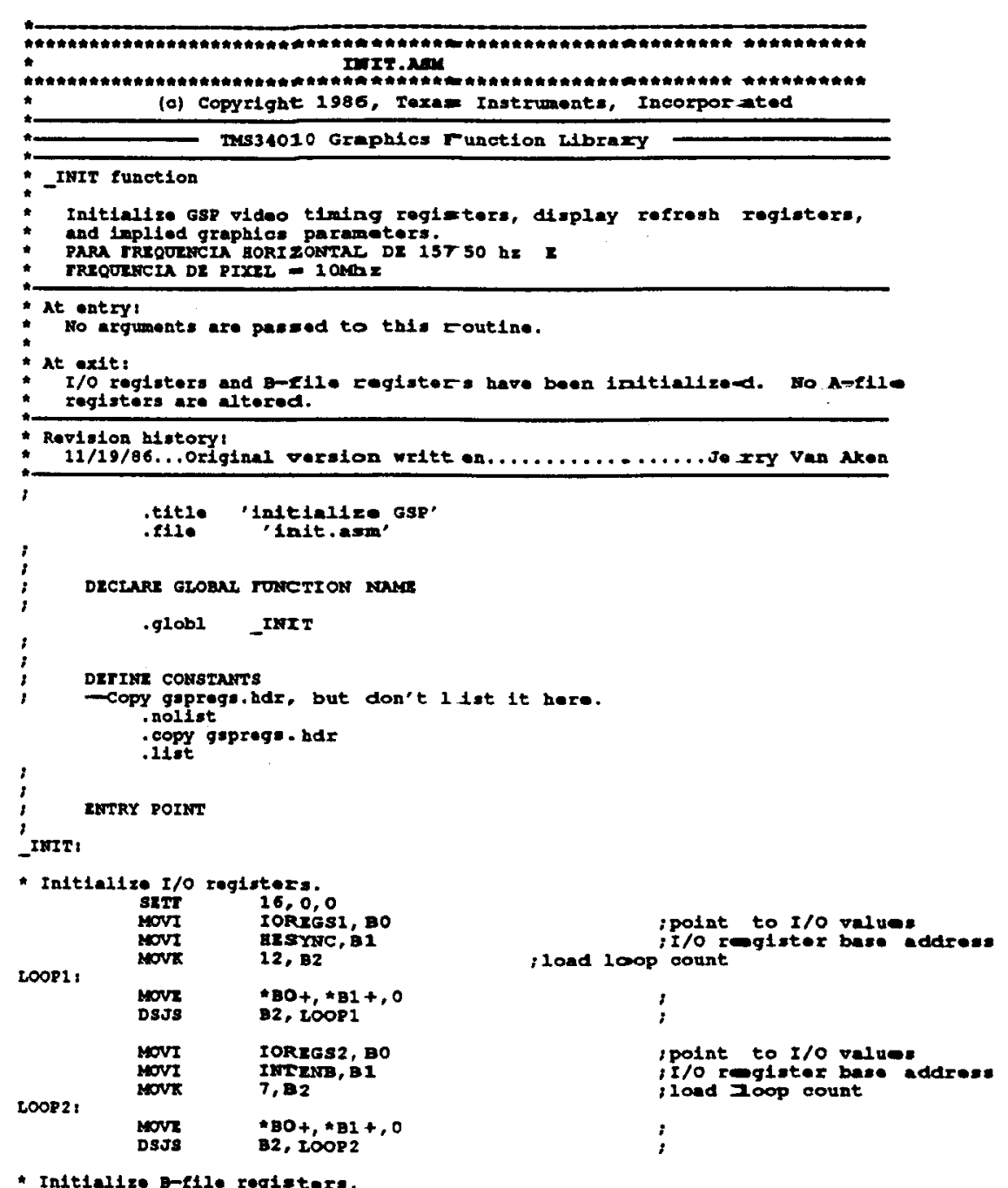

- Initialize B-q11e rogieters. 


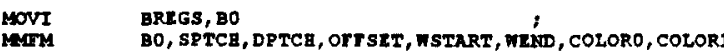
* All done. ${ }_{\text {Rers }}^{\text {Return. }}$ * Define o-rile reglater values.

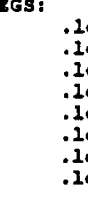

$\begin{aligned} .1 \text { ong } & >000000000 \\ .1 \text { ong } & >00000000\end{aligned}$

$\begin{array}{ll}.1 \text { ong } & >0000000 \\ .10 n g & >0000000\end{array}$

*. Define $1 / 0$ register values.
IORIGS1:

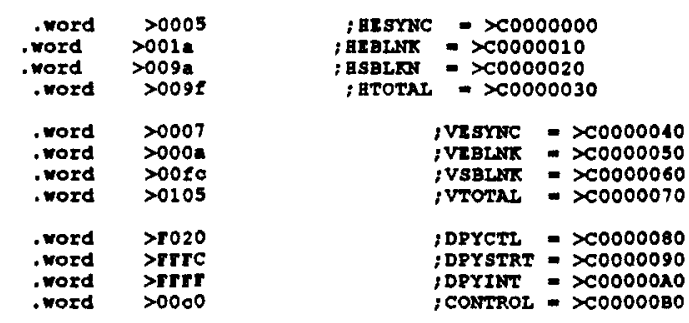

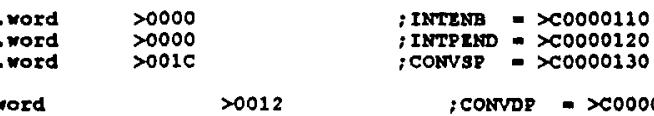

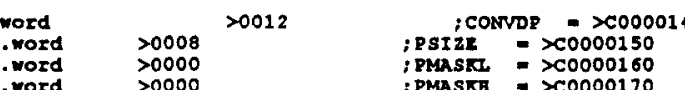$$
\text { end }
$$

.w1ath 132

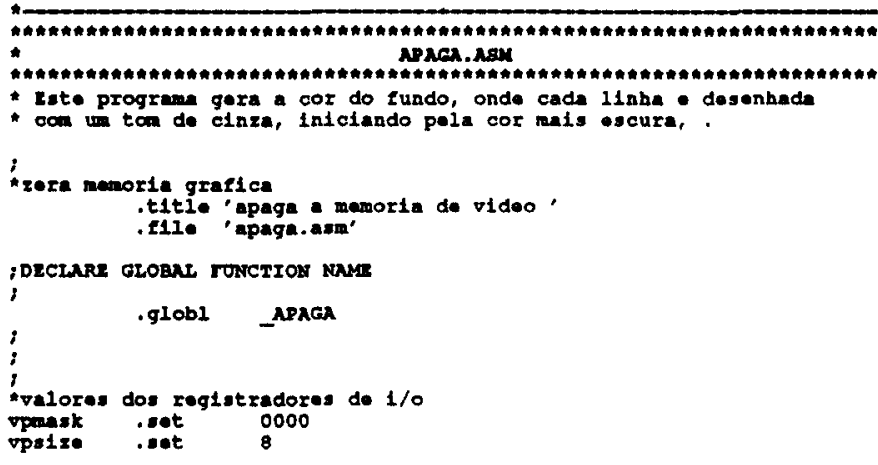

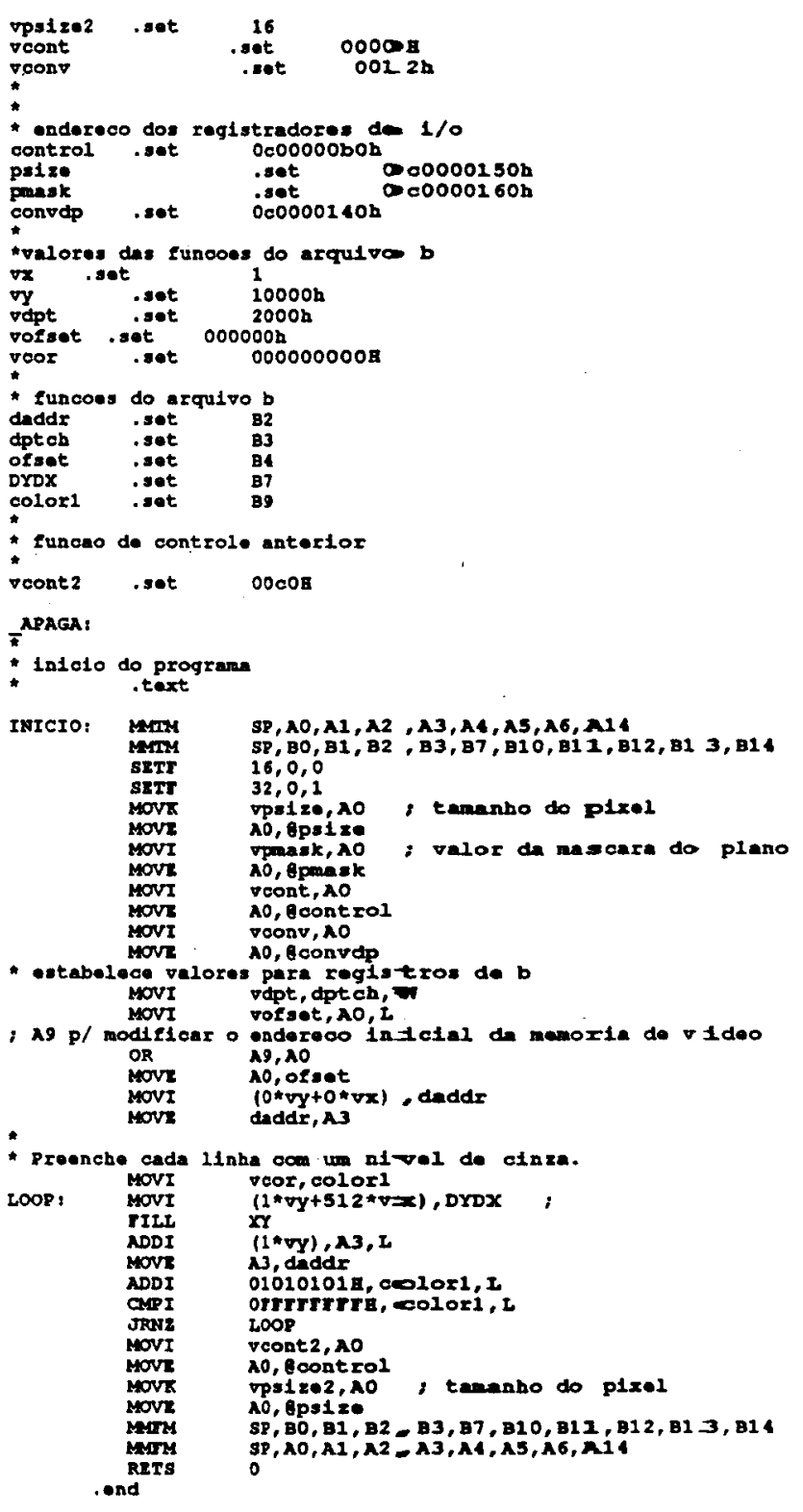




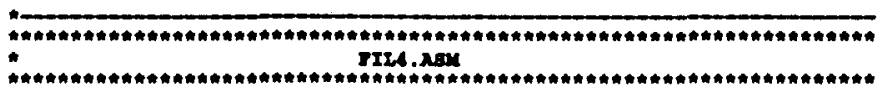

.f11. 'E114.asm'

declapr glodar, ronction mama

glob1 Iris

;orrine constants

-Copy garega.hdr, but don't 11zt 1t hore nollst
. 11 opy gsprogs . hdr

*valores dos reg1stradores de $1 / 0$

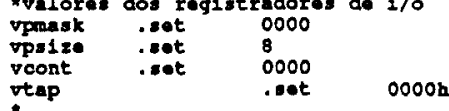

Anderaco doa zegiatradores de $1 / 0$
control . Bot
0e00000boh

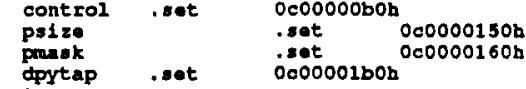

tvelores das funcoos do erquivo b

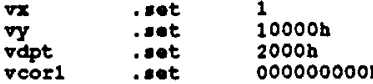

* euncoes do arquilvo b

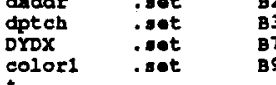

* socao de dados para o eundo

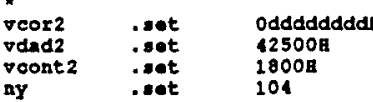

rize:

DRrimrano text Das macros

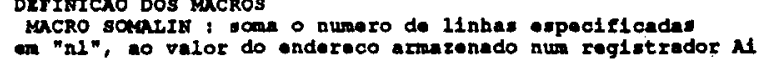

sovaris

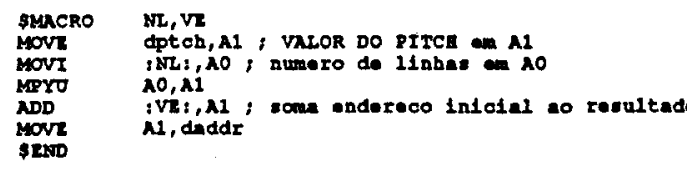

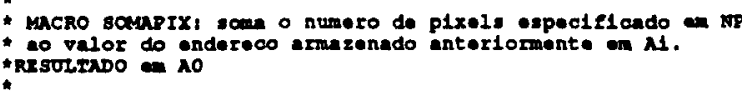

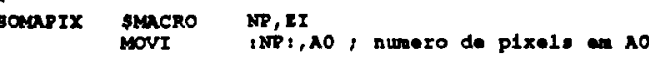

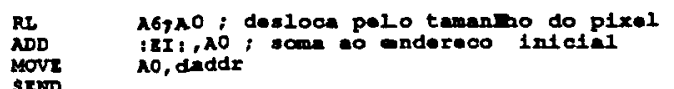

¿1n1010 do prograna

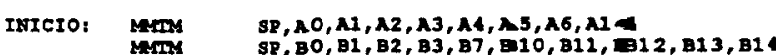

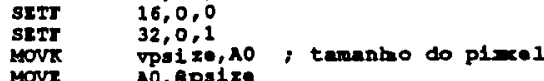

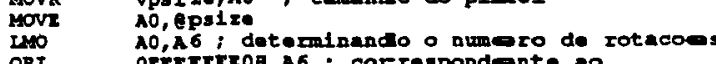

ORI OrrYTrYroa, A6; corrospondonte so

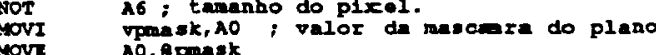

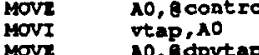

* Astabelece valores para reglatros de
movi
voori, color1,

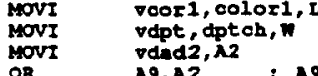

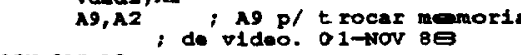

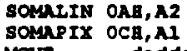

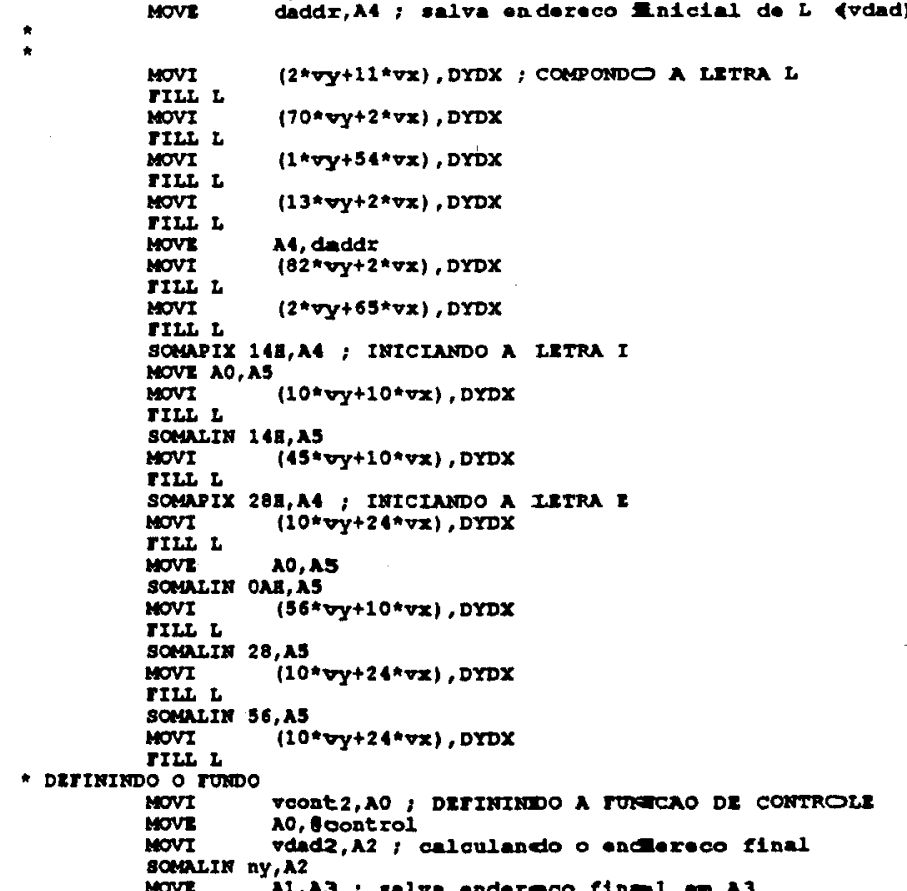


R1:

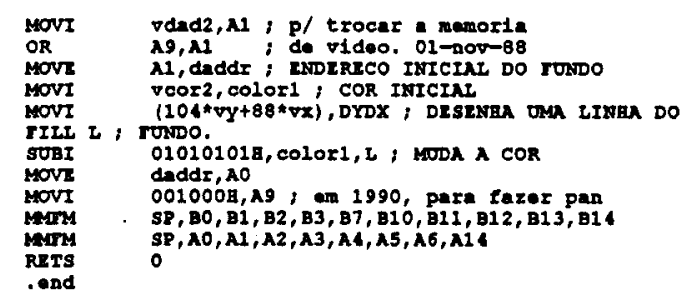

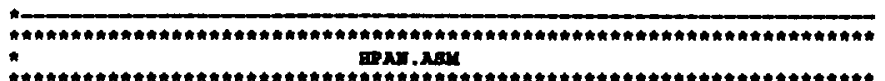

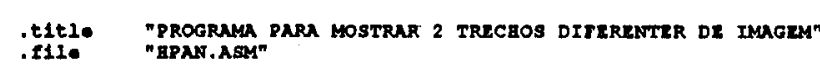
. g10b1__apas

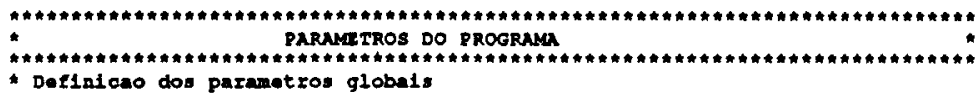

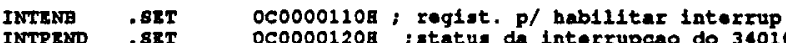

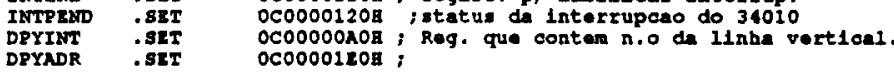

"VDAOR DO RRG DPYADR

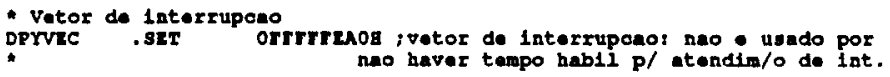

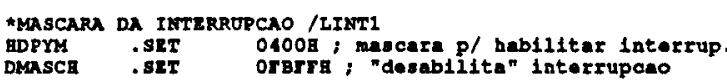

TregtstradoRes de a

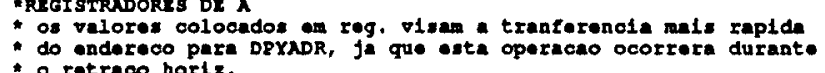

DNDO
VII

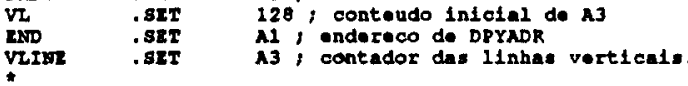

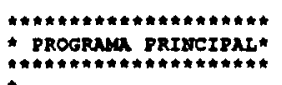

MPAN

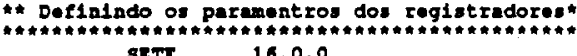

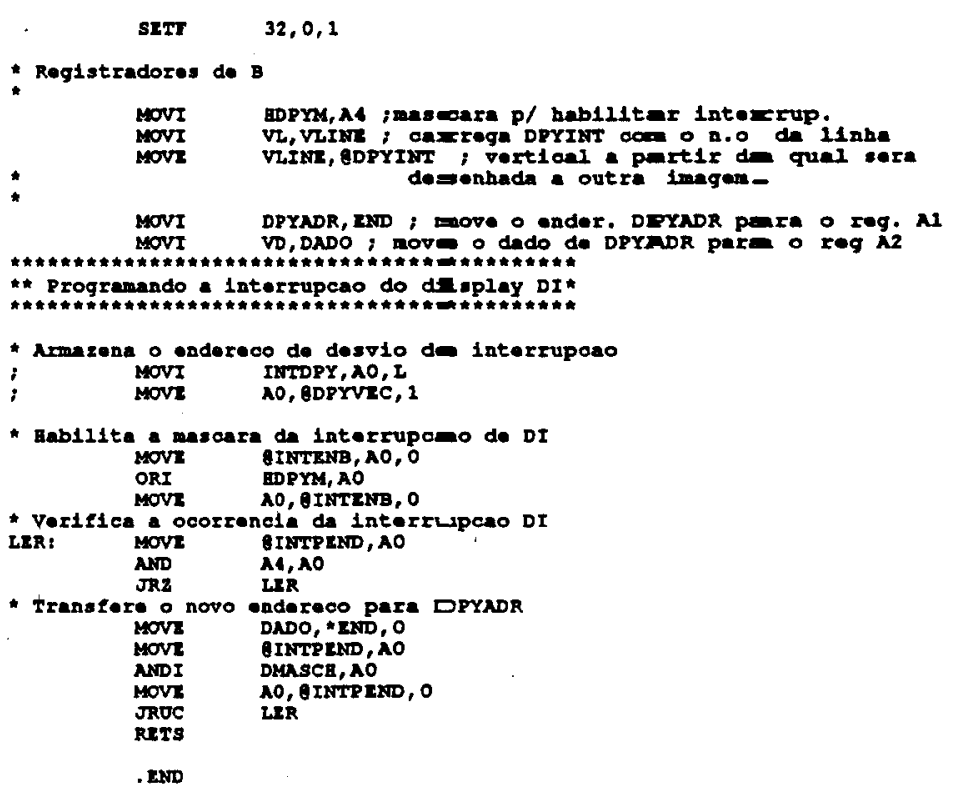

.

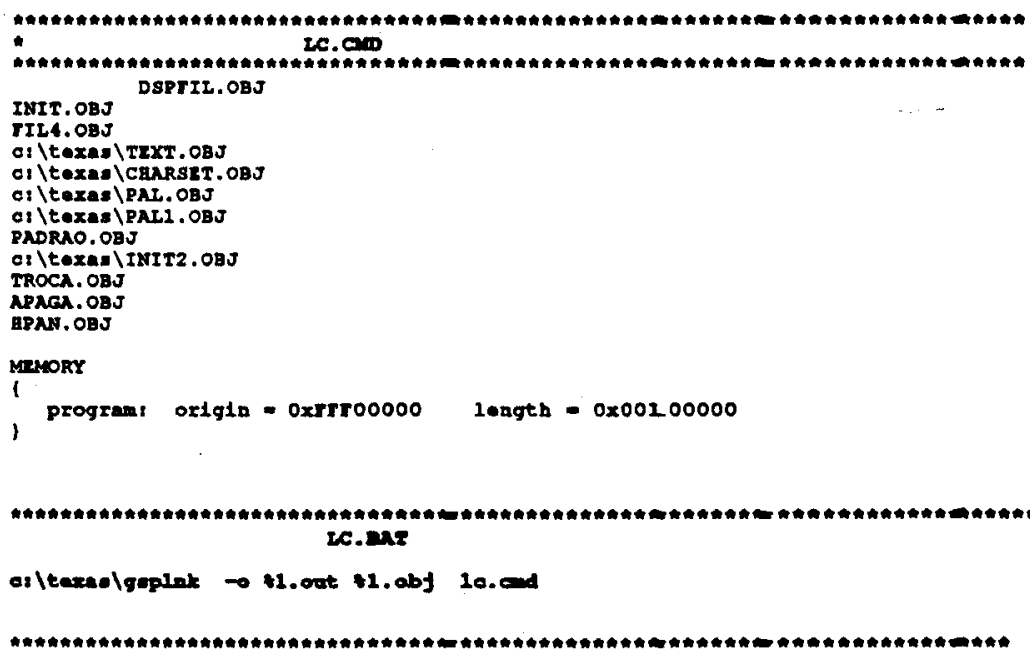


Anexo 1.12 Programa para Realizar "Pan" na Horizontal

.riath 132

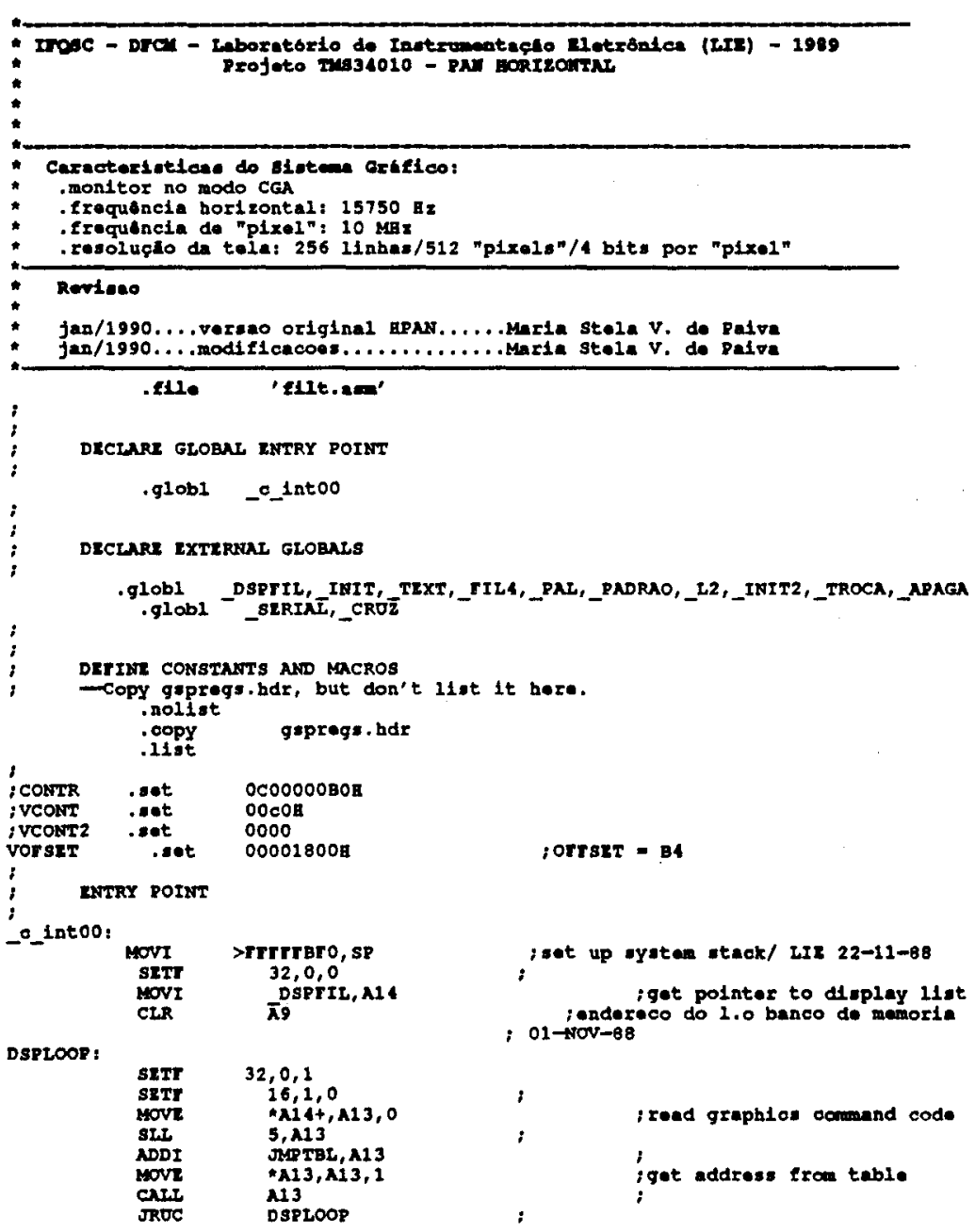

TMPTEL:

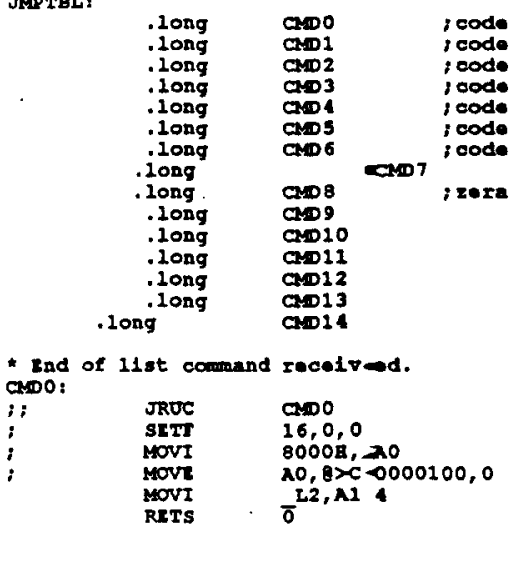

- Comanand to la1tialize GsP roceivod.

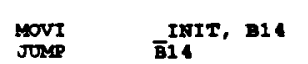

Cand: Comeand to sot transperenoy bit rocoived-

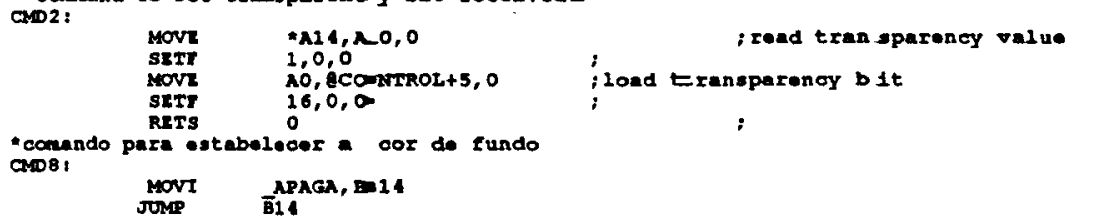

:

"Comenand to obange coloro recolvod.

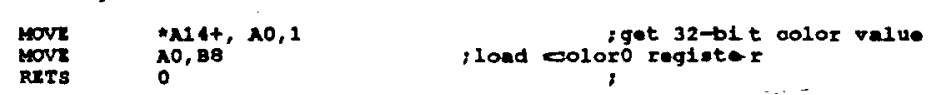

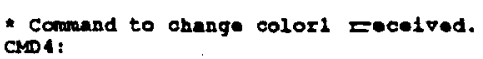

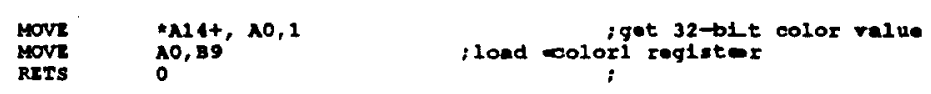

Exost drax ocmenand recolveca.

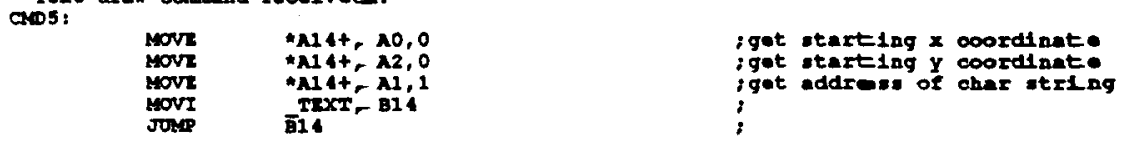

Tunction EI11 - desonbe o LII

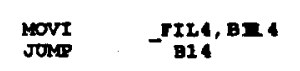

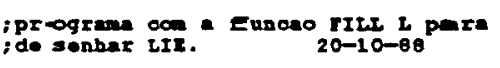

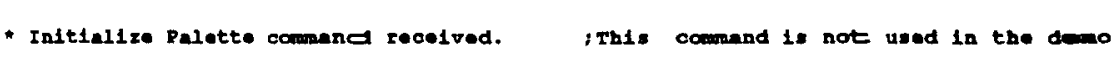




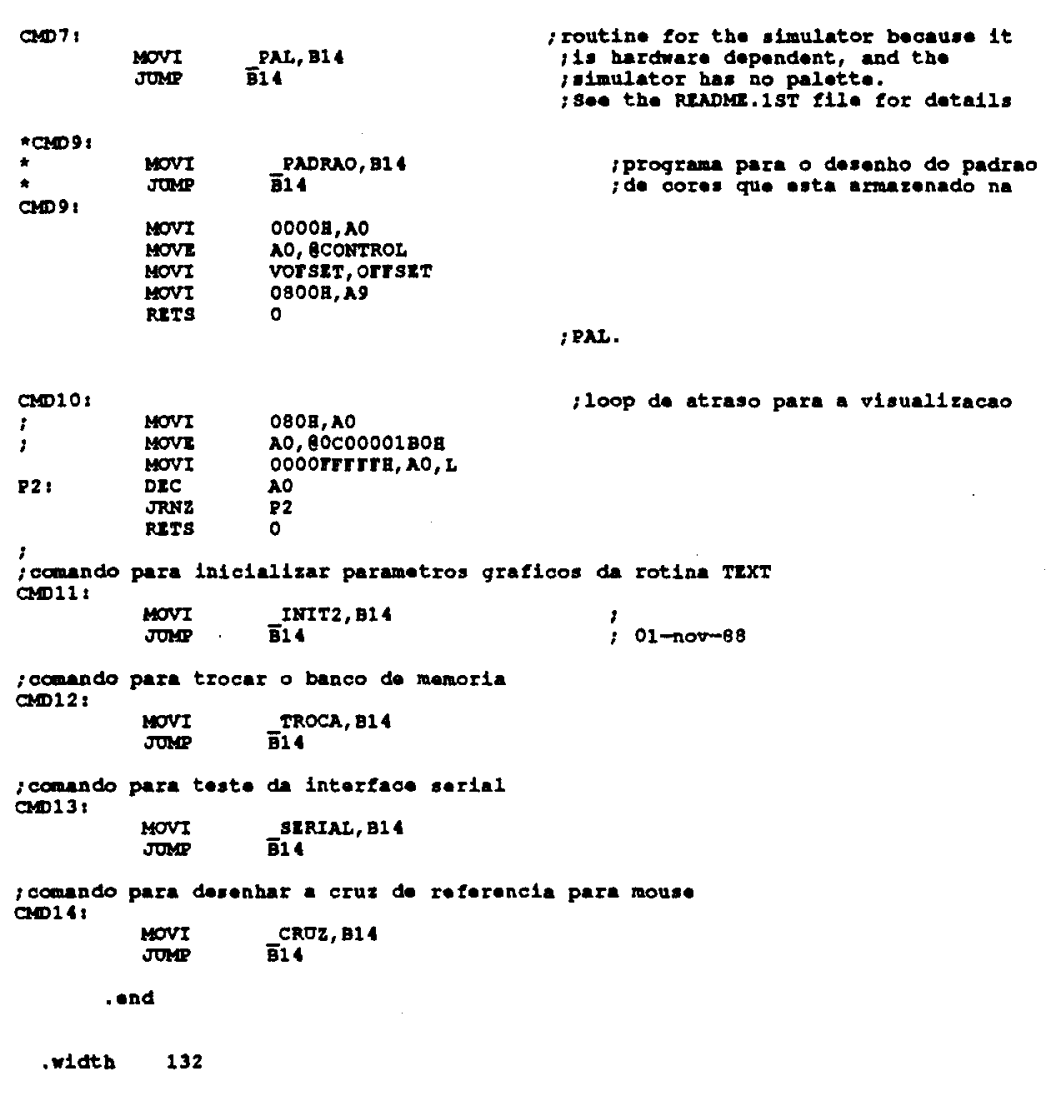

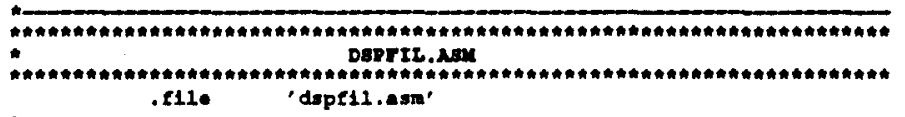

DECLARE GroBar LABRL

$.910 b 1$ _ DsprIL,_L2

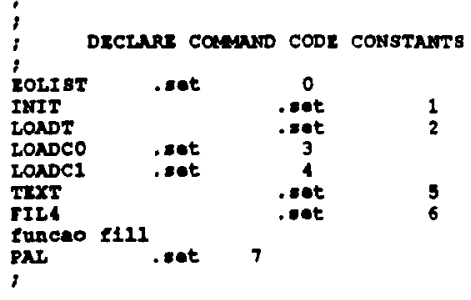

\begin{tabular}{|c|c|c|c|}
\hline APACA & . mot & 8 & \\
\hline $\begin{array}{l}\text { PADRAO } \\
\text { PAI:1 }\end{array}$ &. sot & . sot & 10 \\
\hline $\begin{array}{l}\text { IXrrit2 } \\
\text { graficos }\end{array}$ & & .set & 11 \\
\hline $\begin{array}{l}\text { TROOA } \\
\text { SRRTAR } \\
\text { CROZ }\end{array}$ & . pet & $\begin{array}{l}.80 t \\
.30 t \\
.30 t\end{array}$ & $\begin{array}{l}12 \\
14\end{array}$ \\
\hline
\end{tabular}

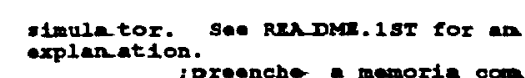

de fundo iprosnche a momorile com wa cor

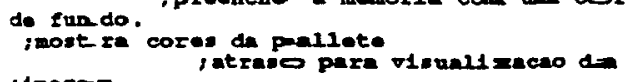
ilmagam. Findolellza on parmotros interfece banco de memorte

'Dspris:

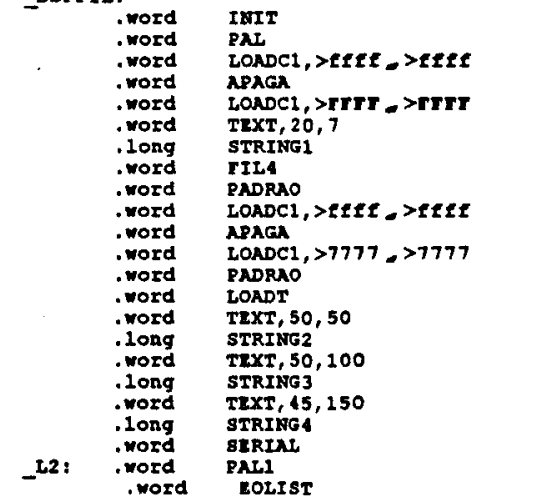

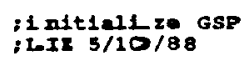

; 2II 9-20-88

': aste de euncao rrue I

;

;

:atraso
; thys mast be at ond of 11yt!

STRING

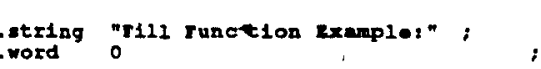

STRIMG 2: .Atring "LMBORATORIO DE"

STRING3: .string "instromantacio"

STRING4: $\begin{aligned} & \text { :tring } \\ & \text { mord }\end{aligned}$

ond

w1ath 132

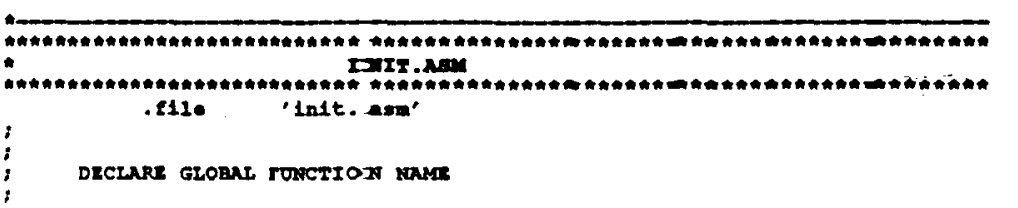

.q1obl_ _ INIT 


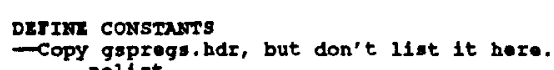

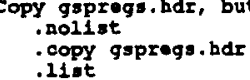

\begin{tabular}{|c|c|c|c|}
\hline \\
\hline \multirow{2}{*}{ Loop1: } & $\begin{array}{l}120 \text { I/O } \\
\text { sury } \\
\text { Movi } \\
\text { Movi } \\
\text { Movix }\end{array}$ & 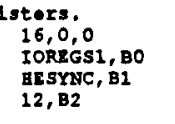 & 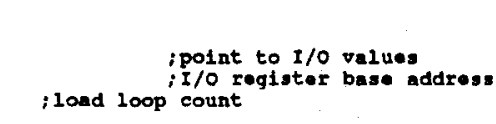 \\
\hline & $\begin{array}{l}\text { Move } \\
\text { DSss }\end{array}$ & $\begin{array}{l}* \mathrm{BO} 0+, \mathrm{BB1+,0} \\
\mathrm{B2}, \mathrm{LOOOP1}\end{array}$ & $;$ \\
\hline \multirow{2}{*}{$.0012:$} & $\begin{array}{c}\text { Movi } \\
\text { Movi } \\
\text { Movk }\end{array}$ & $\begin{array}{l}\text { IOREGS2, BO } \\
\text { INTENB, B1 } \\
7, B 2\end{array}$ & 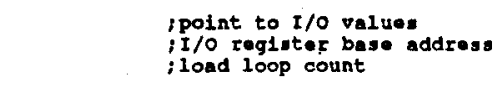 \\
\hline & $\begin{array}{l}\text { Move } \\
\text { Dsus }\end{array}$ & $\begin{array}{l}\approx \mathrm{B} 0+, \ldots \mathrm{B} 1+, \mathrm{O} \\
\mathrm{B2}, \mathrm{LOOOP2}\end{array}$ & $;$ \\
\hline \multicolumn{4}{|c|}{ 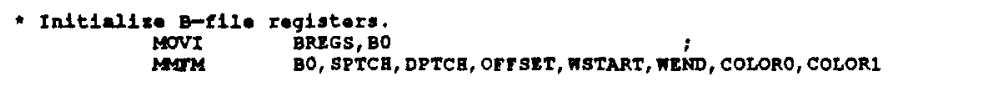 } \\
\hline \multicolumn{4}{|c|}{ * Al1 done. Return. } \\
\hline \multirow{3}{*}{\multicolumn{4}{|c|}{ 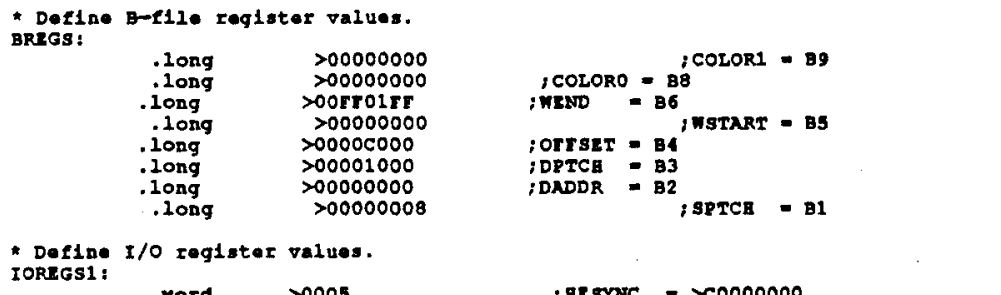 }} \\
\hline & & & \\
\hline & & & \\
\hline & 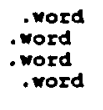 & $\begin{aligned}>0005 & >001 \mathrm{a} \\
& >009 .\end{aligned}$ & 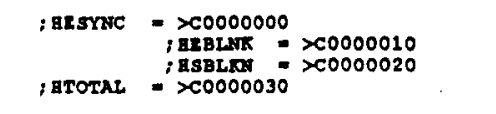 \\
\hline & $\begin{array}{l}\text { : rord } \\
\text { :rord } \\
\text { :mord } \\
\text { mord }\end{array}$ & $\begin{array}{l}>0007 \\
>000 \\
>00 \varepsilon c \\
>0105\end{array}$ & 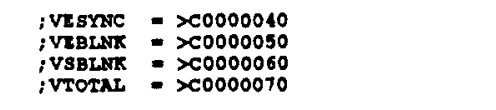 \\
\hline & $\begin{array}{l}\text {.rord } \\
\text { : word } \\
\text { : word } \\
\text { r.ord }\end{array}$ & $\begin{array}{l}>\mathbf{r o 1 0} \\
>>\operatorname{rrrc} \\
>>\operatorname{rrrr} \\
>>000\end{array}$ & 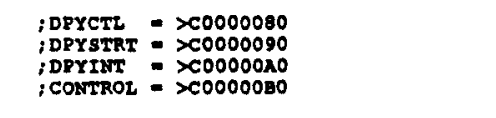 \\
\hline IOREGS2 & $\begin{array}{l}\text { : } \\
\text { : word } \\
\text { :rord }\end{array}$ & $\begin{array}{l}>0000 \\
>0000 \\
>001 \mathrm{C}\end{array}$ & 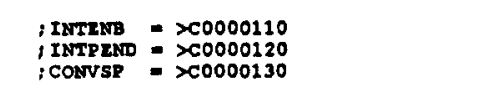 \\
\hline & 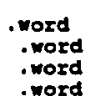 & 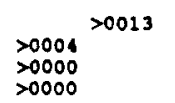 & 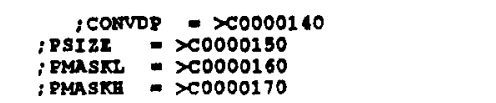 \\
\hline
\end{tabular}

.ridth 132

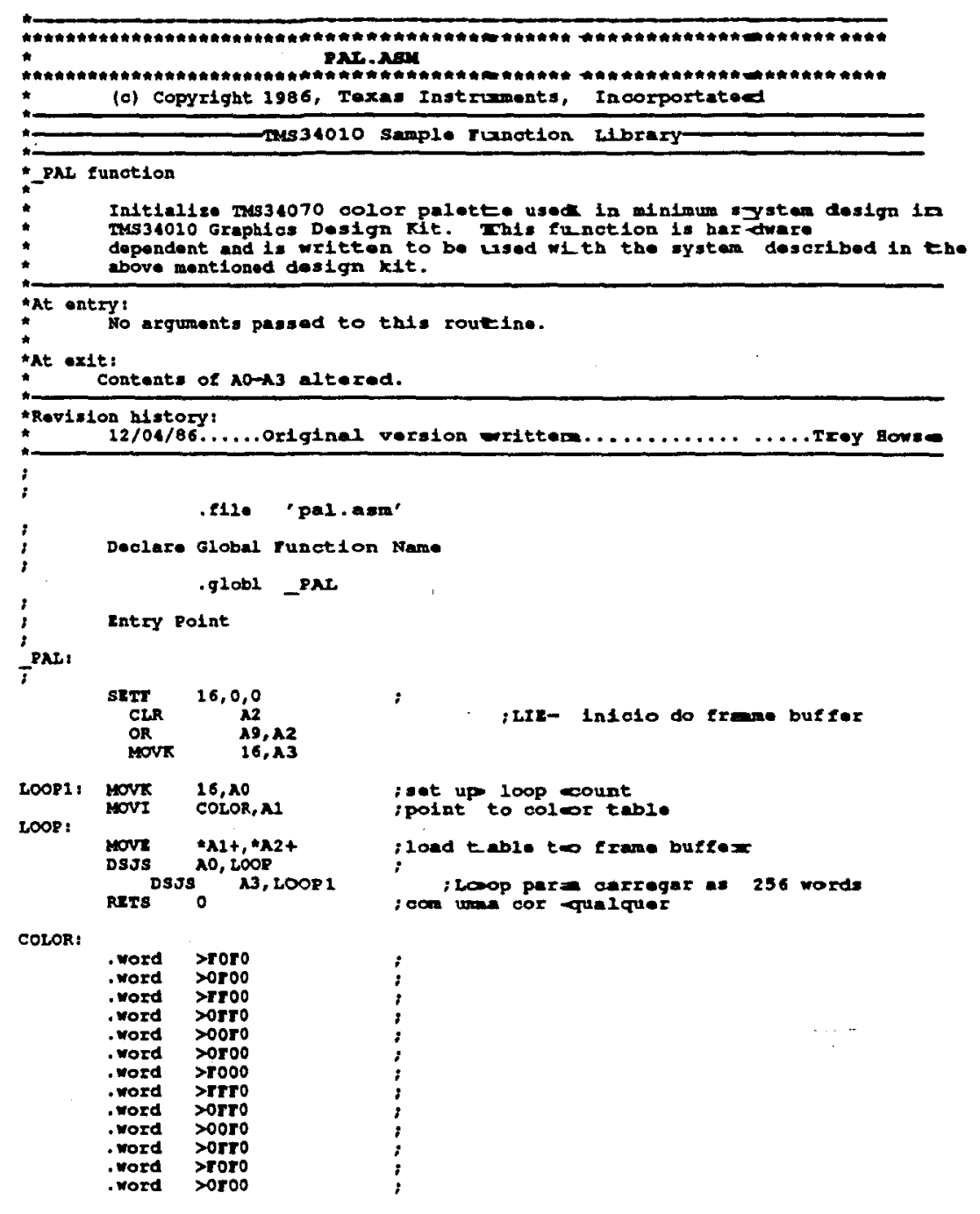




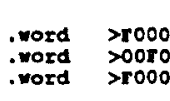

Wlath 132

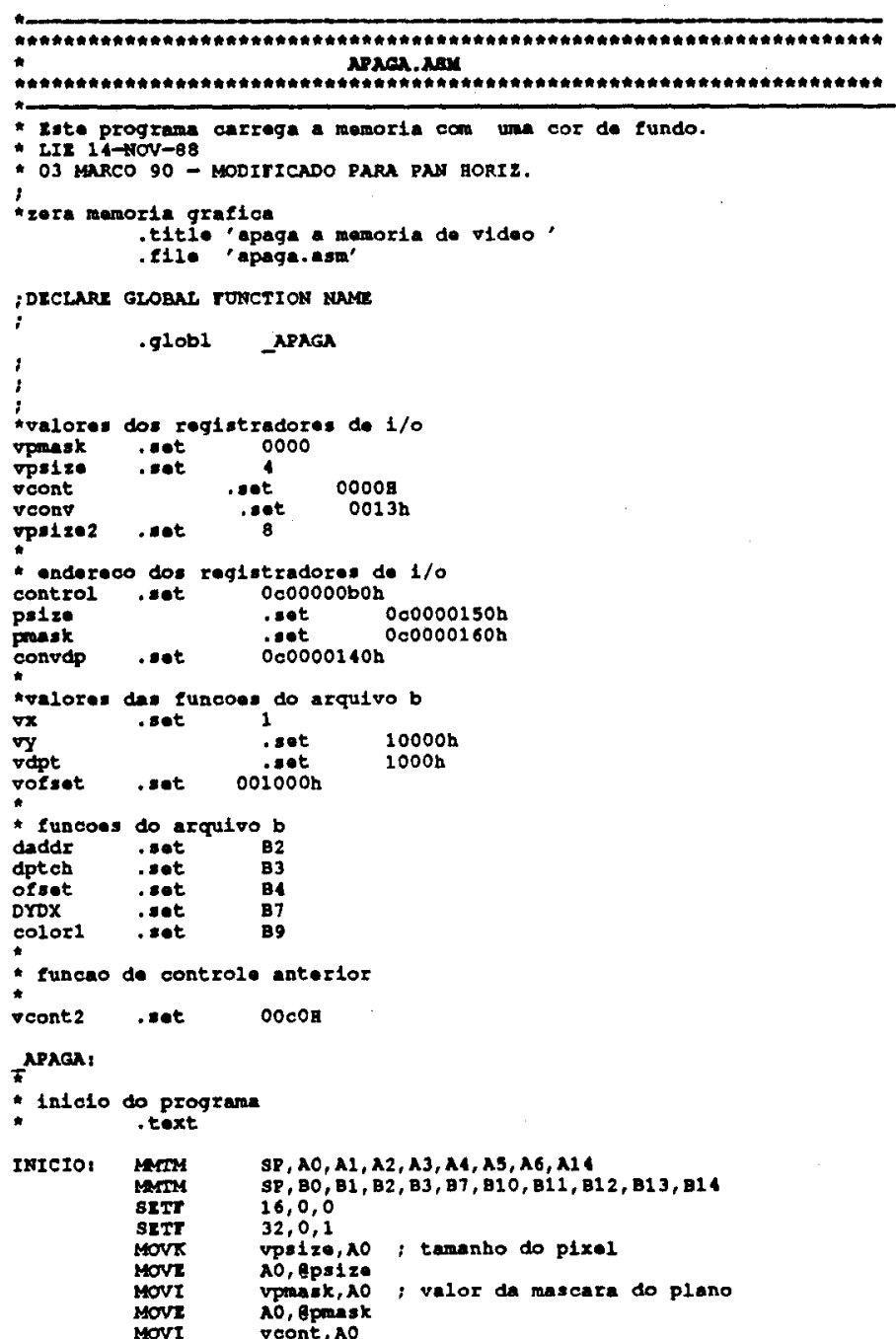

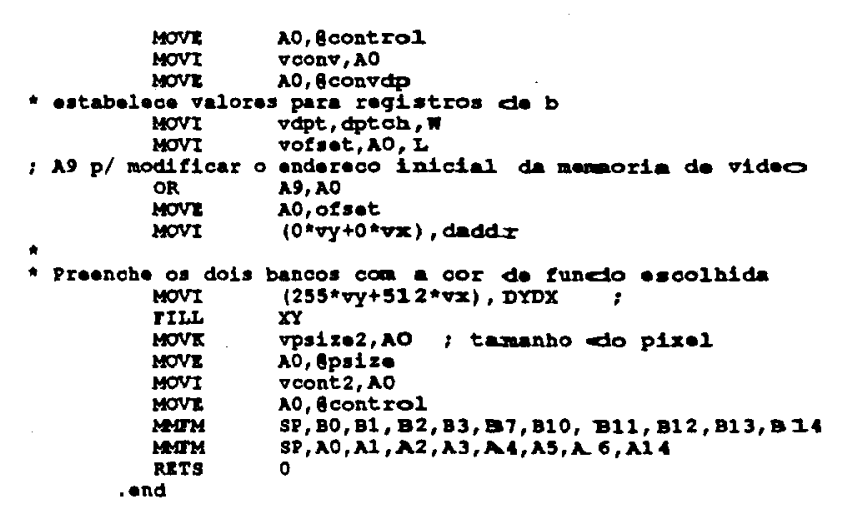

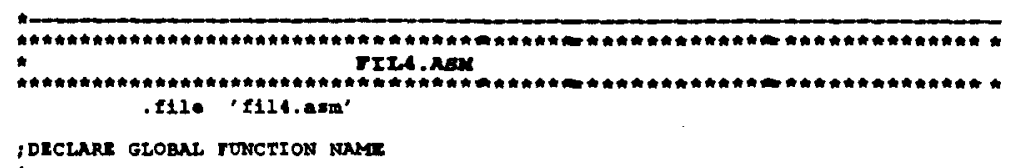

glob1 _ril4

iotrisz constants

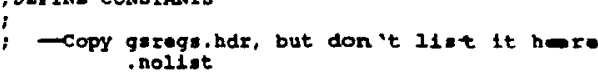
${ }_{11 \nexists t}^{\text {.copy goprogs , hdx }}$

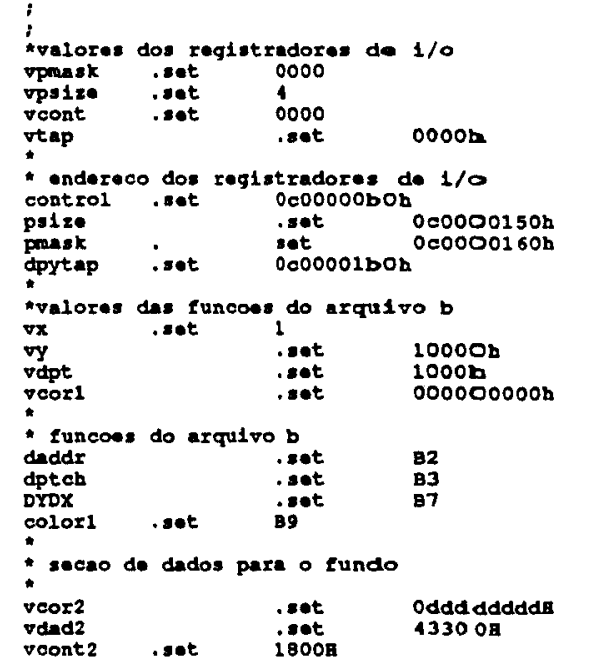

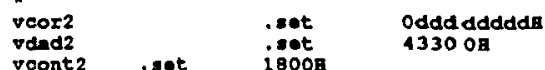



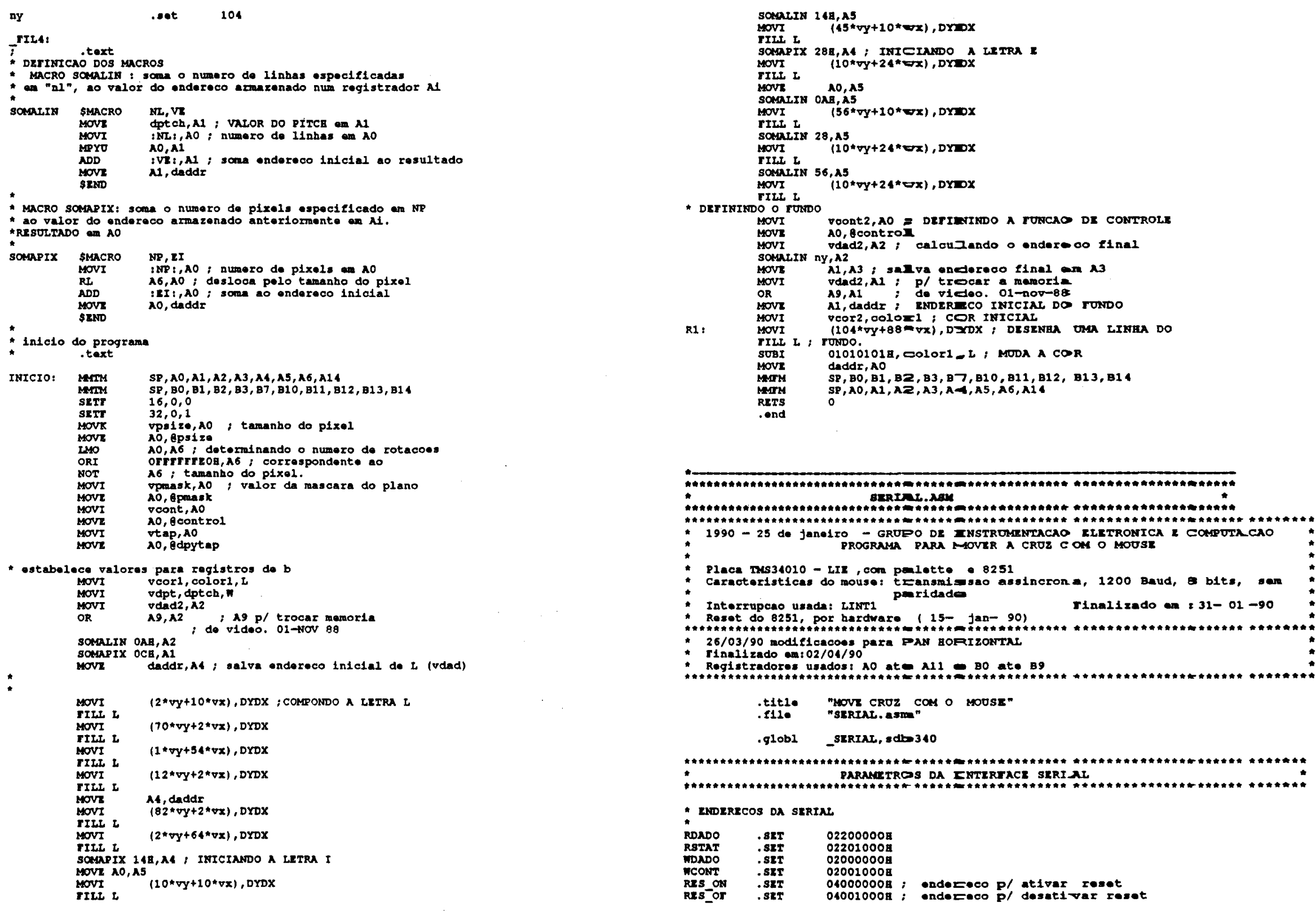


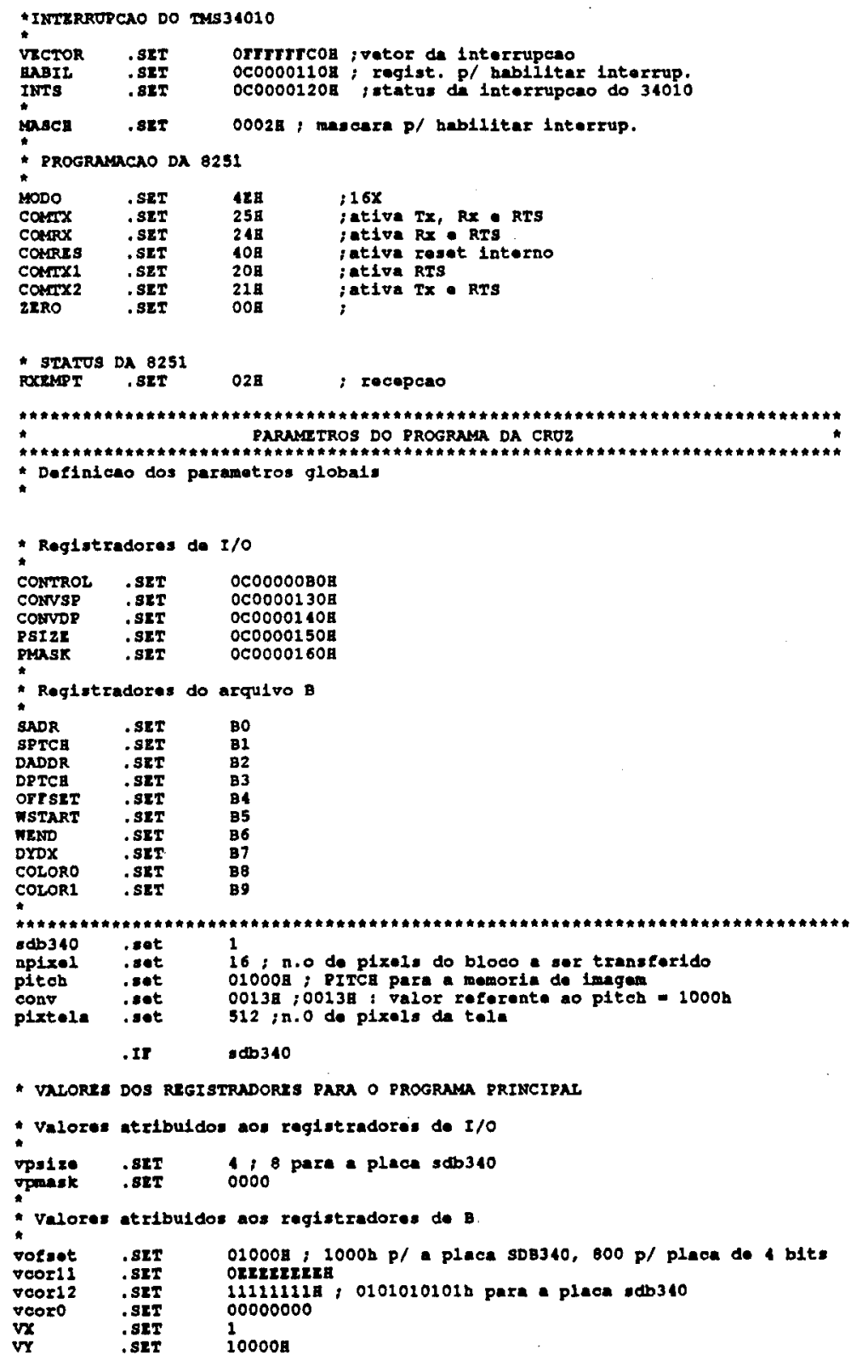




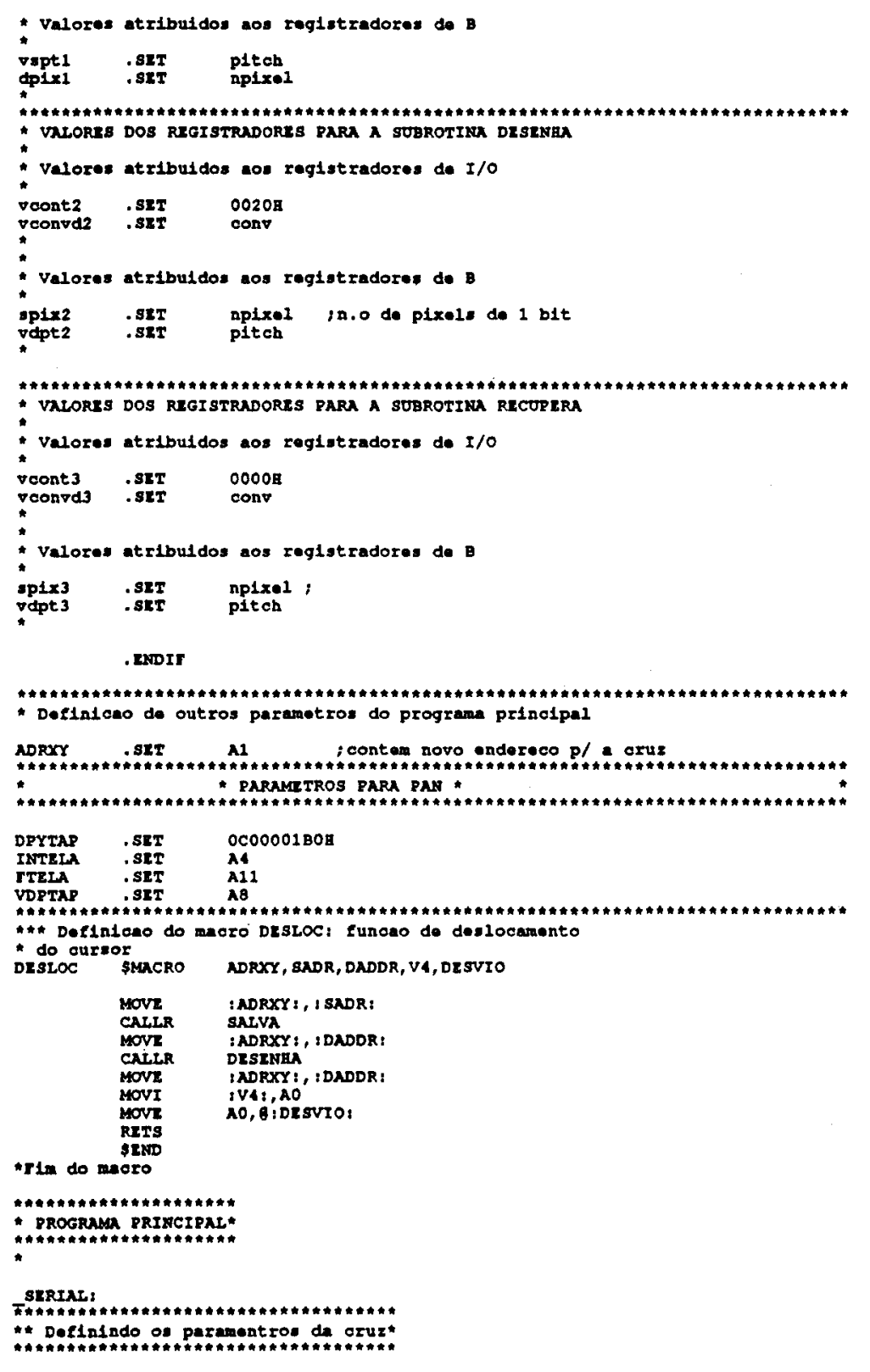

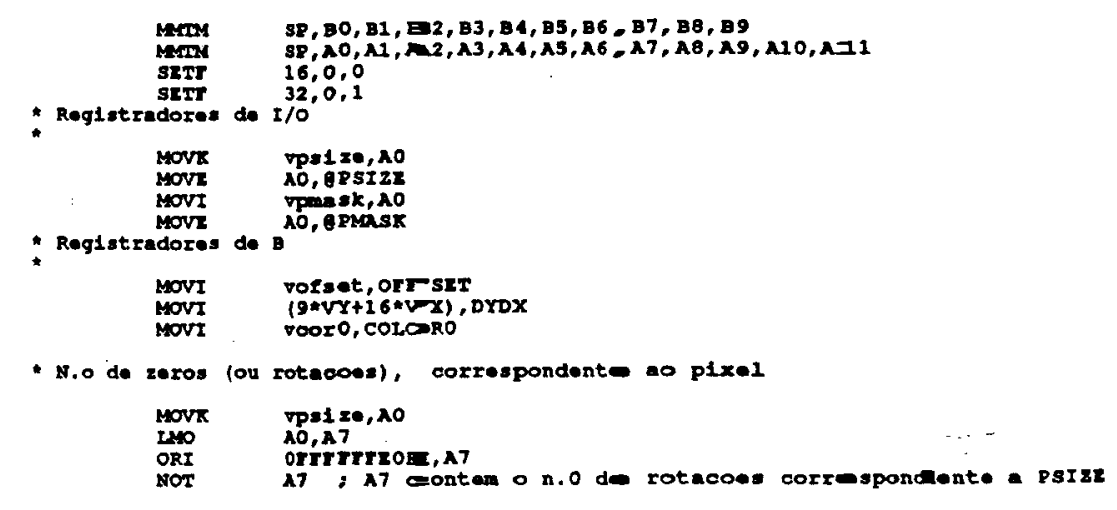

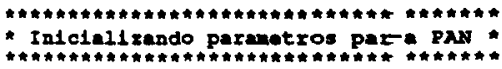

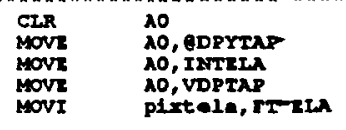

* Posslctonamapto do cursor no contro da ta1s:

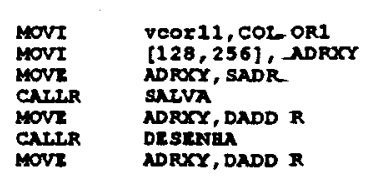

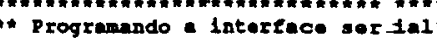

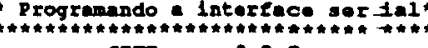

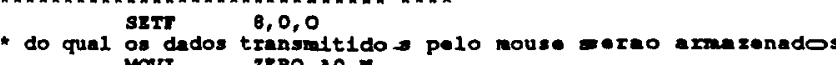

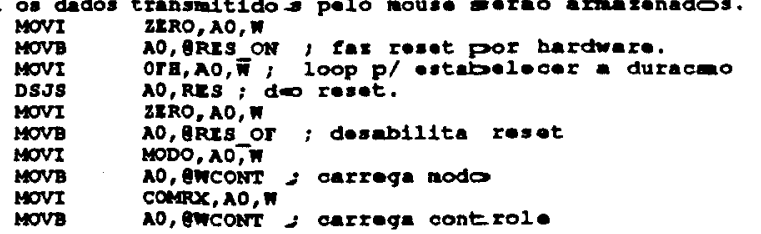

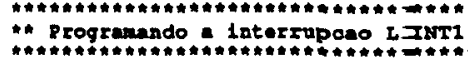

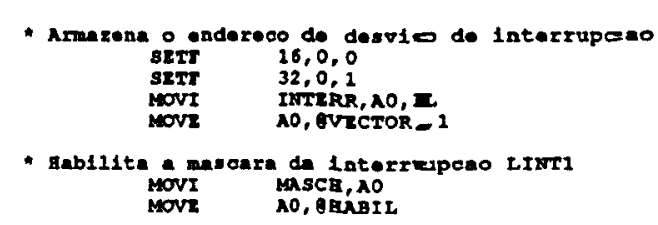




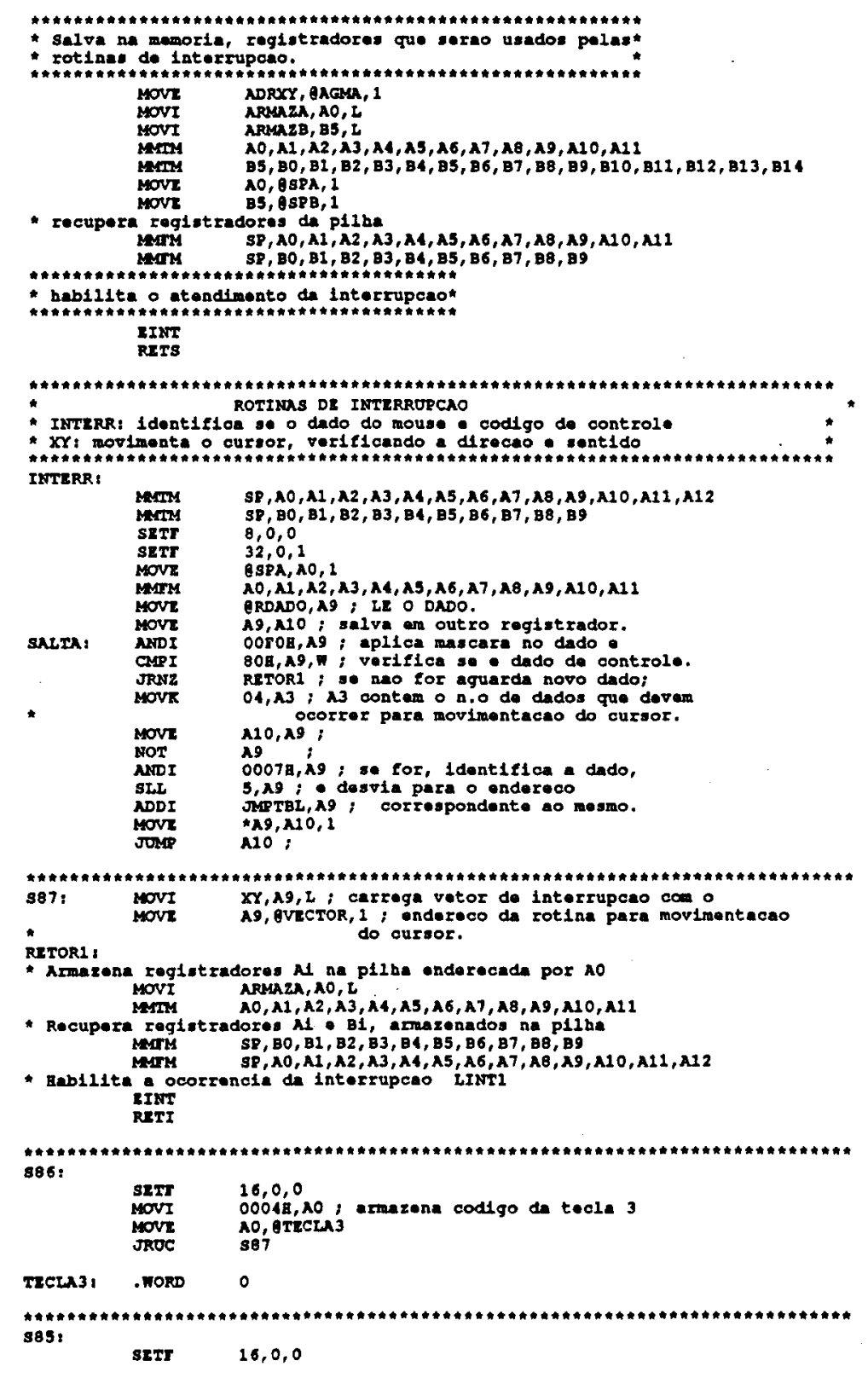

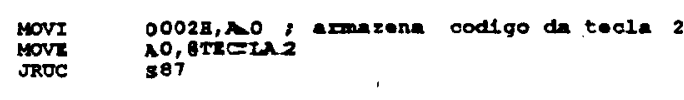

$$
\begin{aligned}
& \text { IrCLA21 - mORD } 0 \\
& \text { s83." }
\end{aligned}
$$

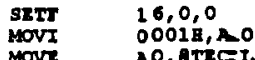

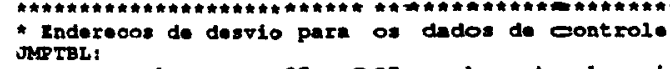

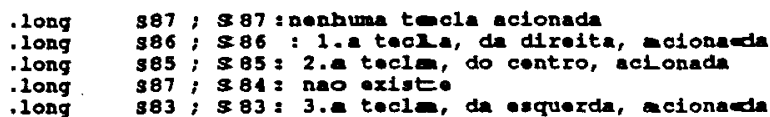

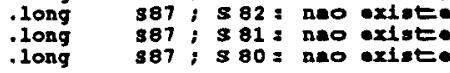

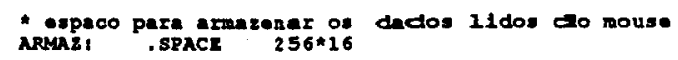

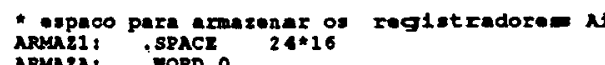

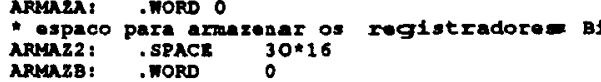

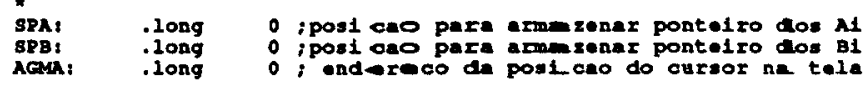

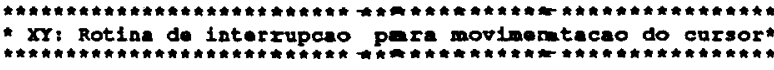

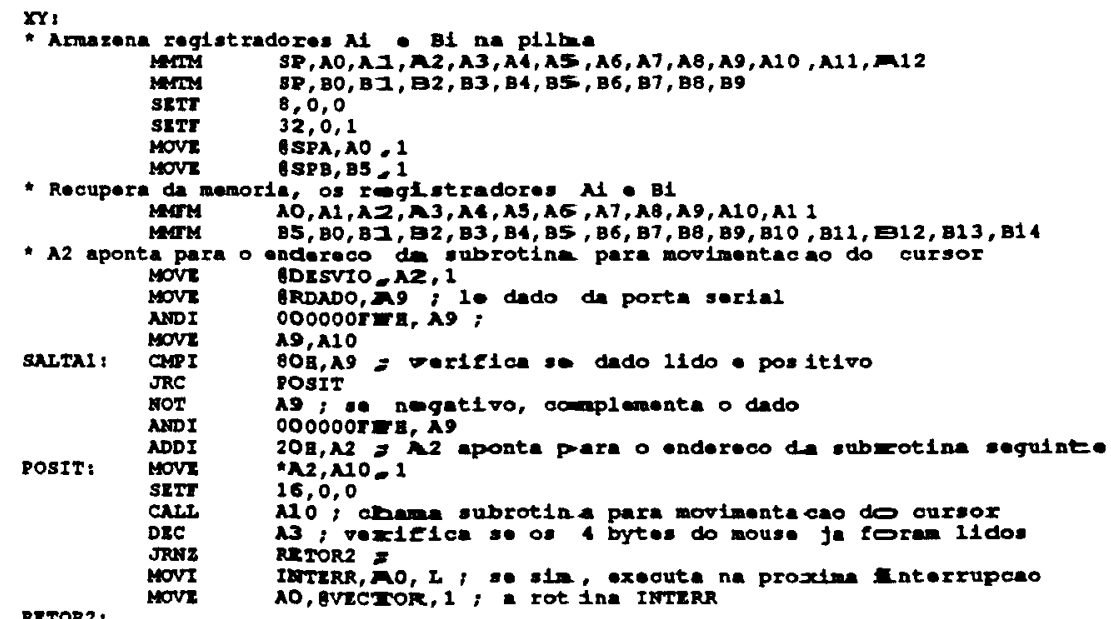

PeTros 


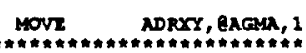

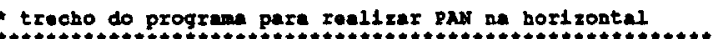

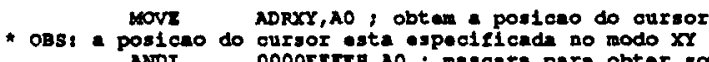

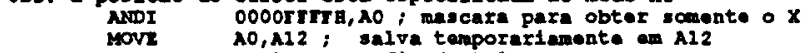

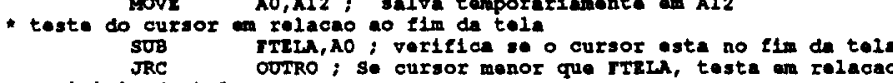

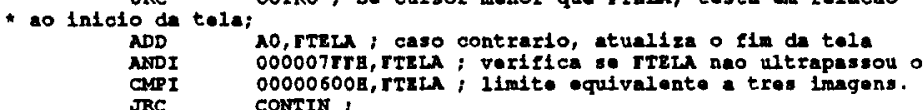

TRC CONTIM

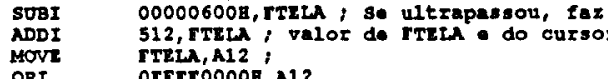

contrs:

ORI

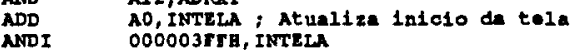

MDPAP, AO Atualiza O Iogistrador quo

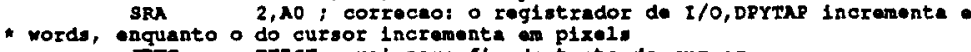

rrest, vai para fin do tosto do curnor

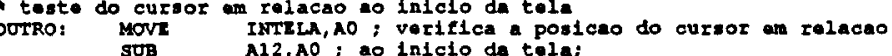

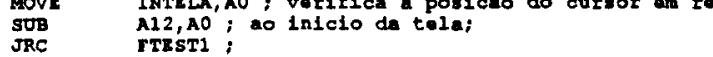

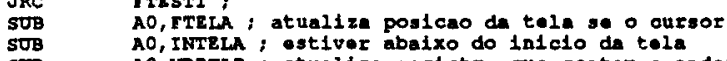

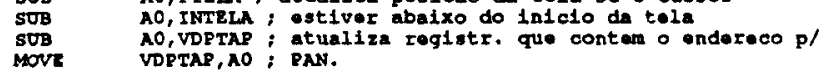

rTrss:

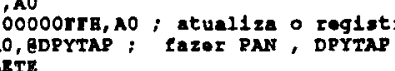
de paxistrz

rTRsT1:

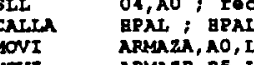

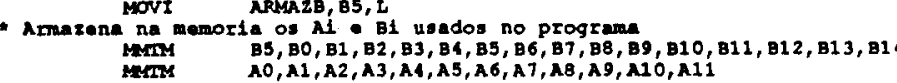

Peoupera

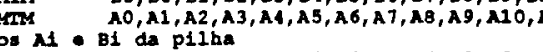

- Babilita int

: Inderaco das subrottnas para movimontacao

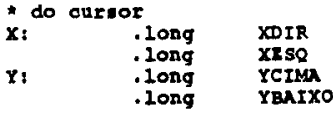

Desvio1 .10ng $x$

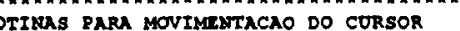

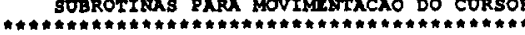
ave do balzo para cima

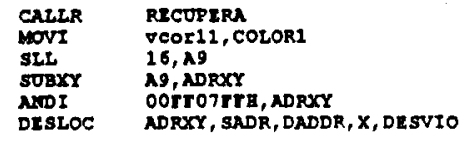

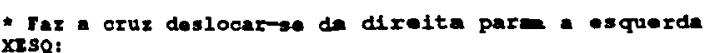

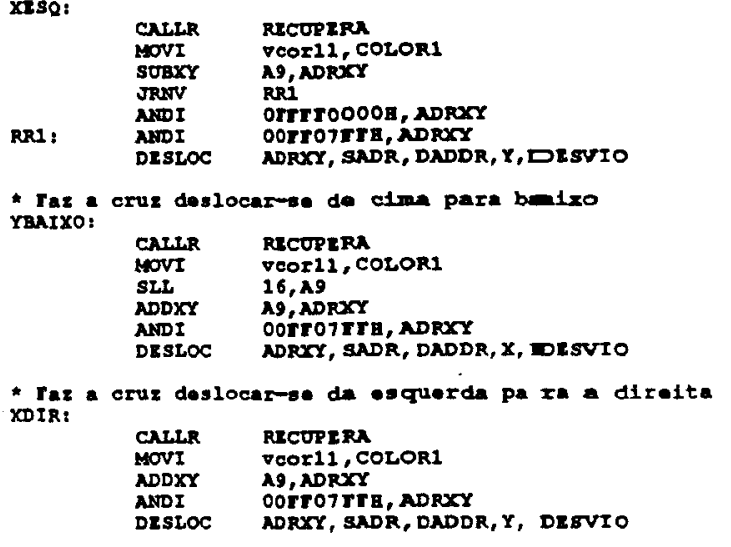

" subrot nase para desenhar o cur sor

"Subrotina sacta: salva o bloco da meracoria de :

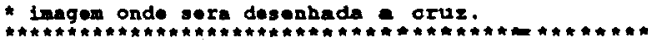

SALVA:

: sadr dofintdo no progrema prinolpal

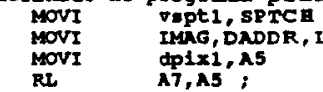

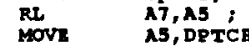

: Reglatradores de $3 / 0$

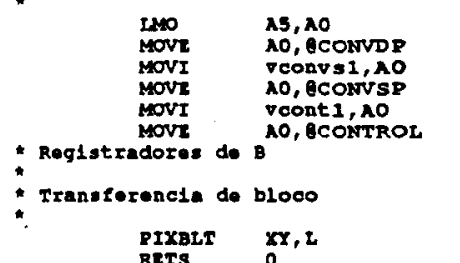

$\underset{\text { Rers }}{\operatorname{PrXBAT}} \int_{0}^{X X, 2}$

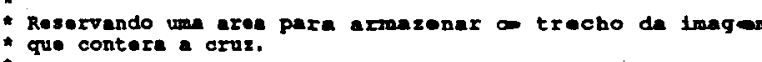

IMAG: SPACR $72 * 16$

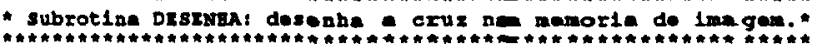


Dxsukga:

Registradores de $1 / 0$

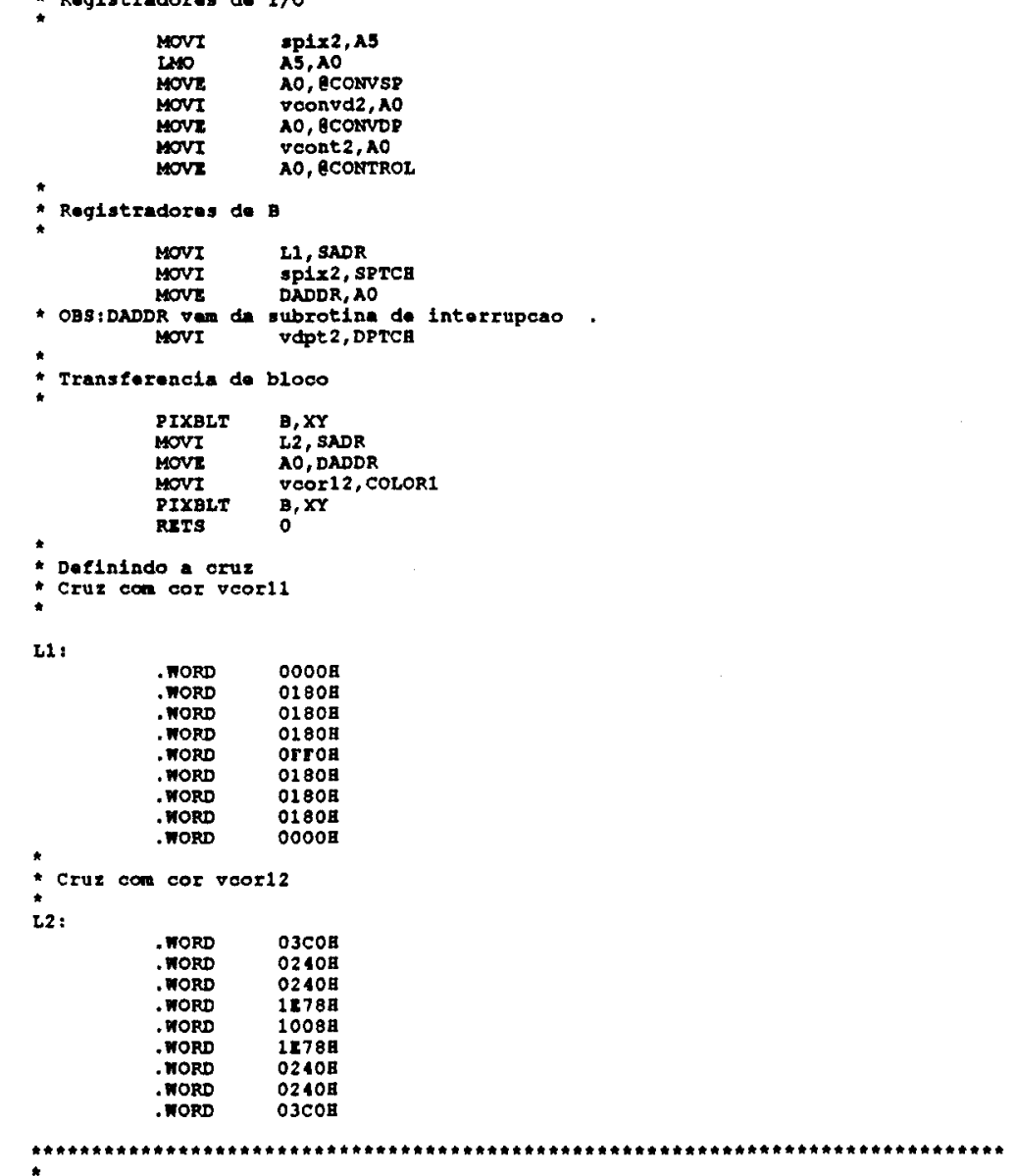

******************************************************

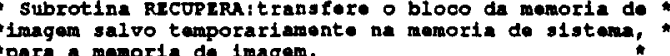

"pare. manorta de Lmagom.

Rxcoprex:

* Rogistradoros de B

MOVI IMAG, SNDR

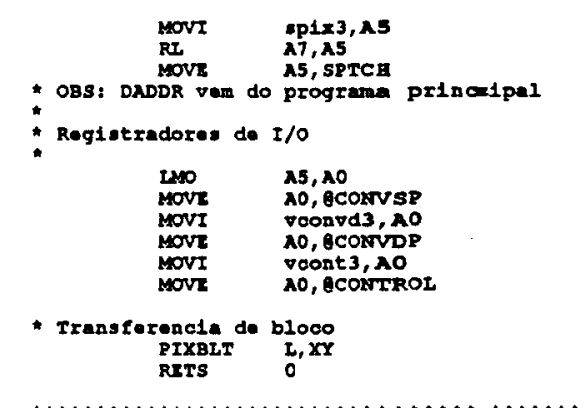

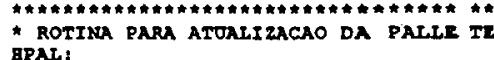$$
\text { ; }
$$

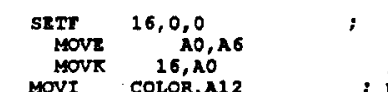

Loop:

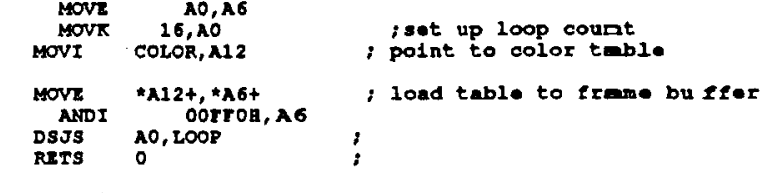

COLOR:

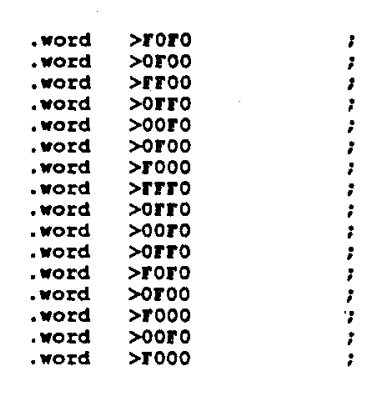

. $2 \mathrm{ND}$ Ic.max

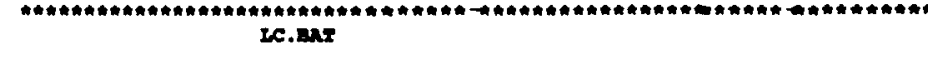

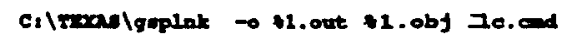

B.

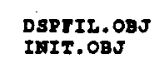

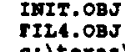

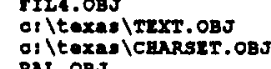

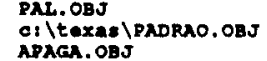




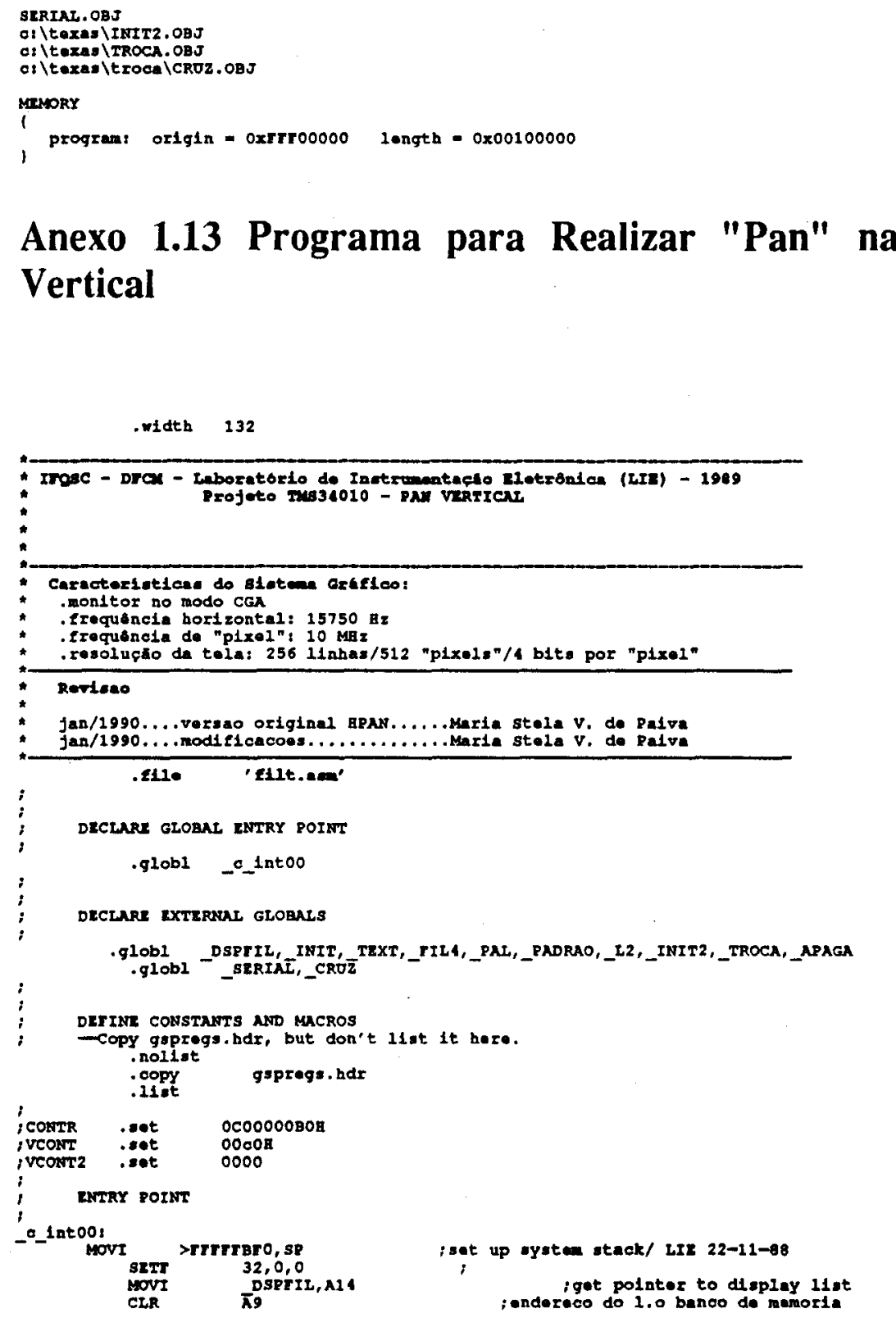

Anexo 1.13 Programa para Realizar "Pan" na Vertical

.width 132

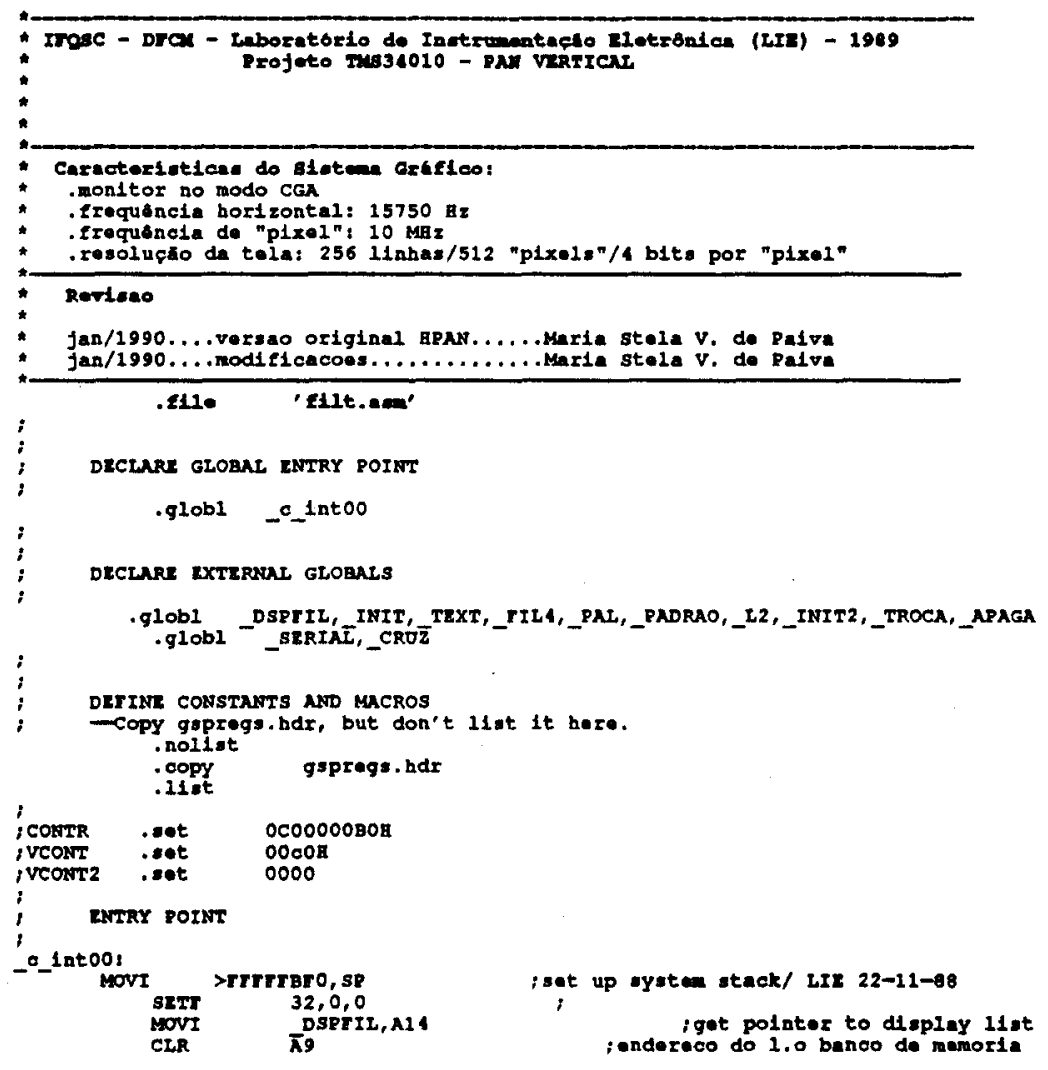

DSPLOOP:

DSPLOOP

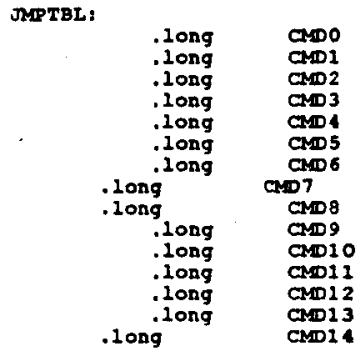

And
canot

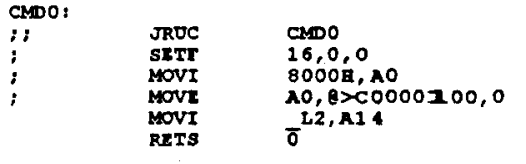

; the code End this 1s the may

tho $=$ codigo $\mathrm{p} /$ belt

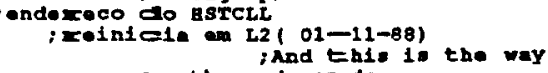
- tse code onds

I roed graphlose comenend oode

żgot address from table

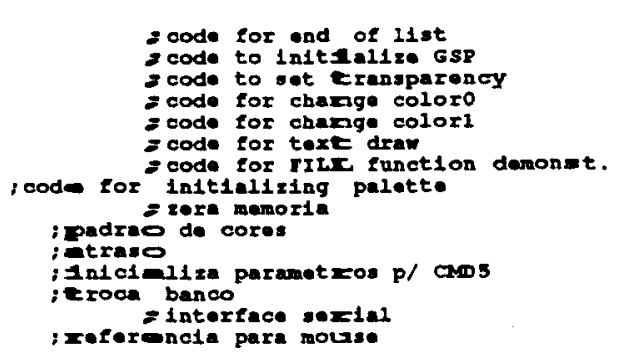

Comand to 1nitialize GSP roceinved.

SOUI

Command to set tranaparency bit rocelved.

Move $\$ 14,10,0$; read transparency value

iload transe parancy blt

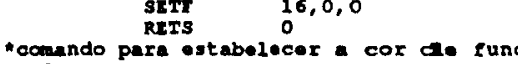

MOVI SPACA, B14

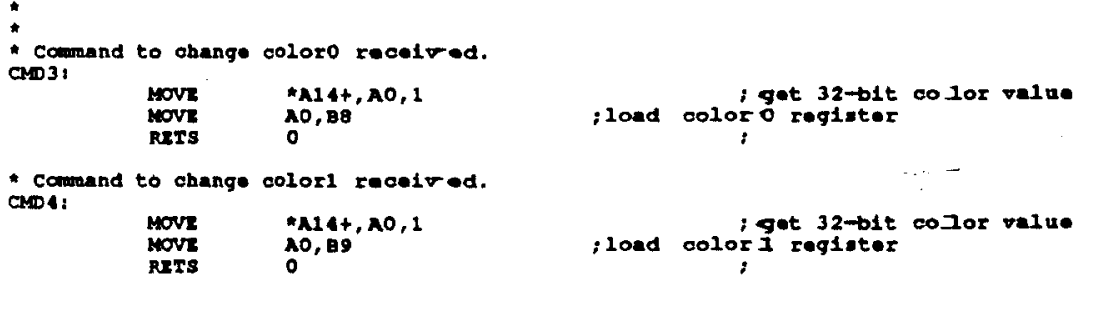

conosit aram commana recolved.

Got atarting $\mathbf{x}$ coordinate 


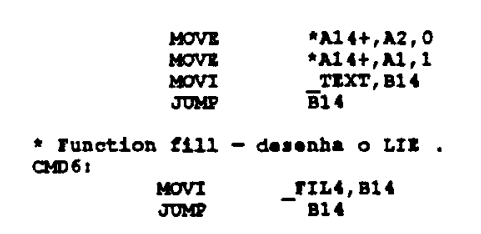

initiallze palette conmand recelved.

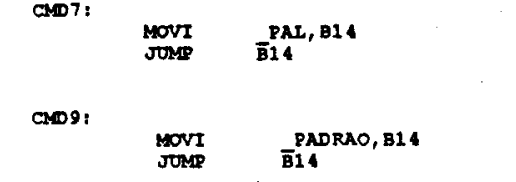

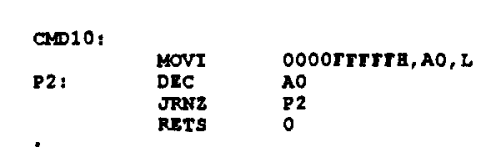

'ceomando para 1niclalizar paramotros graficos de rotina trext

MONI TNI INIT2, B14

comando para trockar o banco de memorla

MOVI $\overline{\text { TROA }}$ TROA, B14

comando para tosto de Interface sorial

MOVI
JOMP
$\mathbf{B} 14$

, comando para desentar a cruz de roferencia para mouse

MOVI $\overline{\text { B14 }}$ CROz, B14

.end

.wiath 132

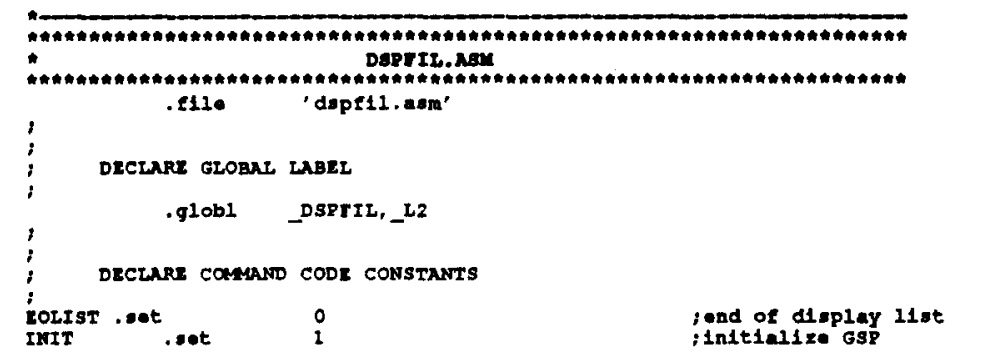

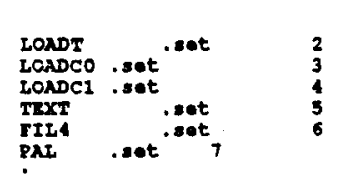

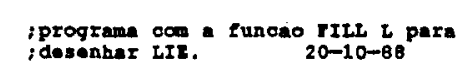

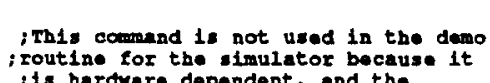

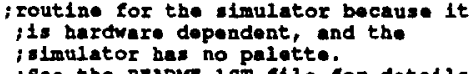

soe the Rexpme. 195 file for dotalls

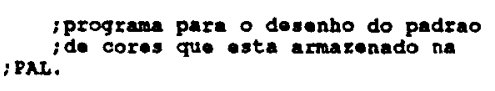

; $100 \mathrm{p}$ de atraso para a visual1 zacao

; 01-nov-88

apdag .set

PADRA .set .sot, 10

INIT2 .set 12

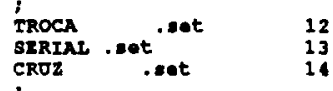

DISPLAY LIsT

Dsprizt.
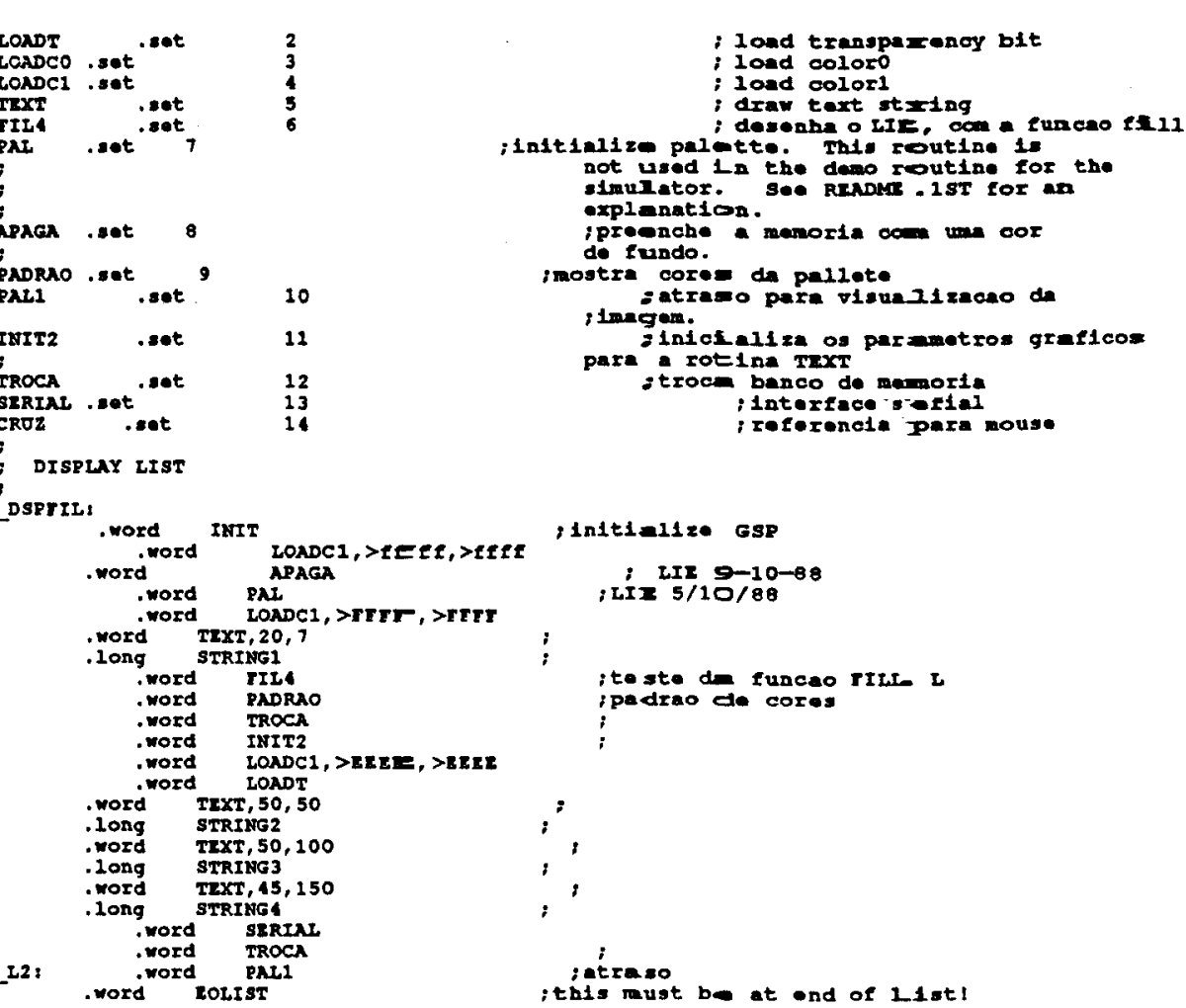

; in1ti=11ze GsP

i if $5 / 10 / 80^{\operatorname{Lix}}$

;te ste du funceo rrts. I
;pedrao de cores

;',

STRIMG1:

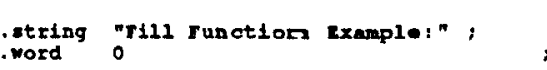

.rtring "rote

STRING3:

intring "Thstromentmacao"

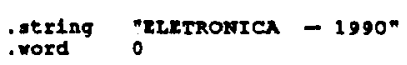

.ond

WIdth 132

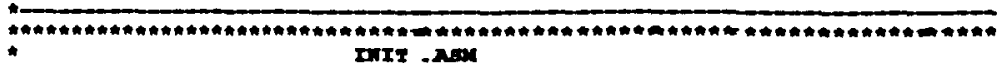




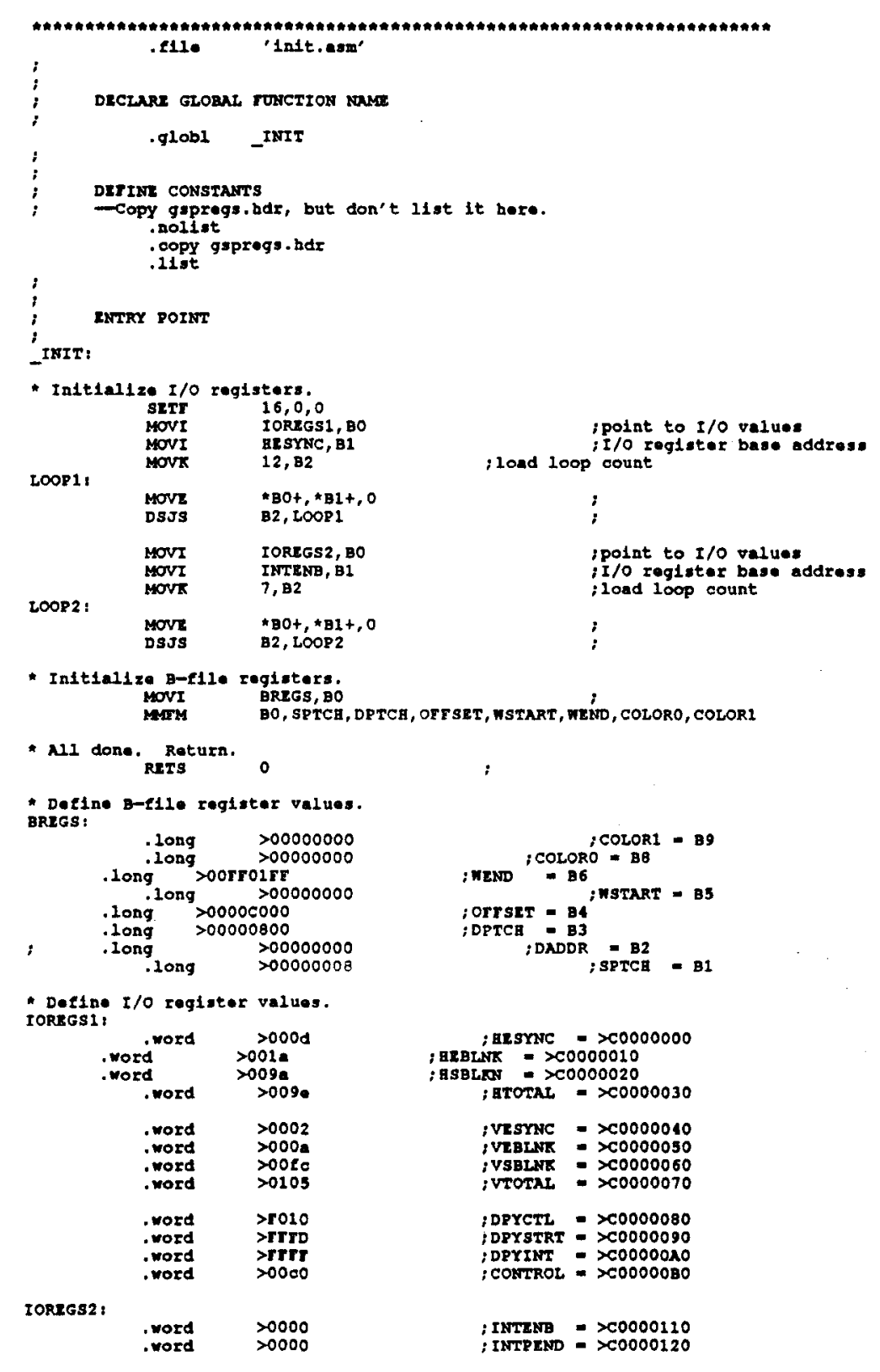




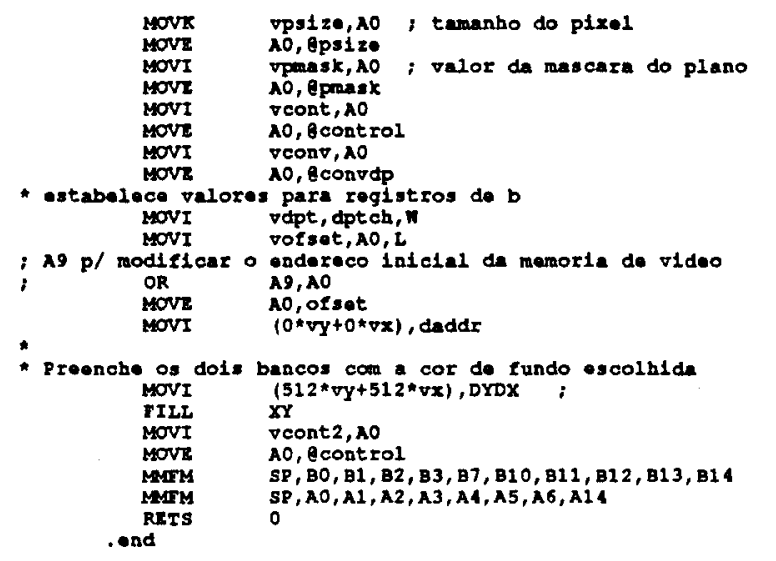

.w1dta 132

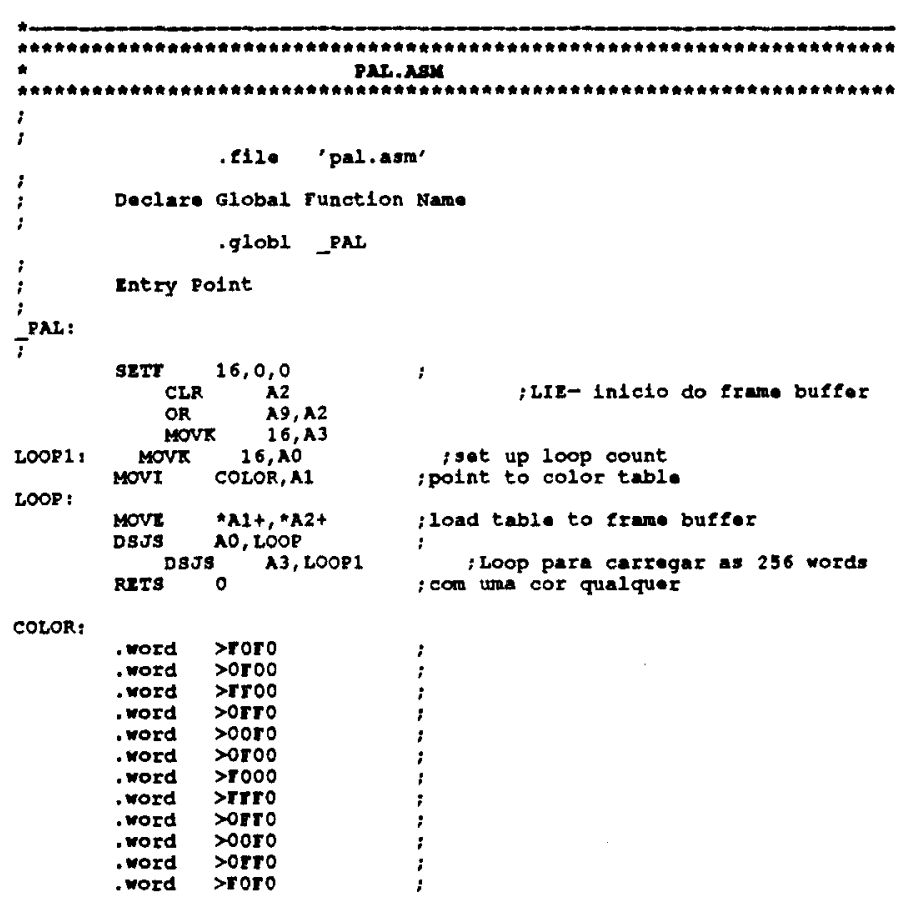

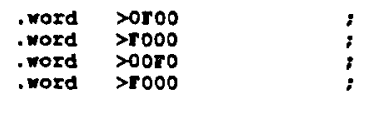

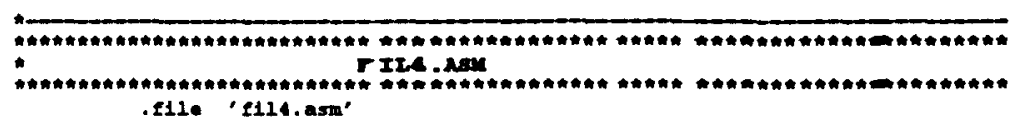

DrCzars Grogar TONCTION RaN

$$
\text { .q10b1_rit4 }
$$

Derime constants

-Copy gsrogs.hdr, but don't 11 st it here

$$
\begin{aligned}
& \text { : nollat } \\
& \text { :oopy gaprogs . bdr } \\
& \text {.119t }
\end{aligned}
$$

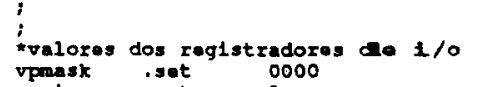

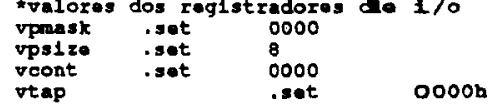

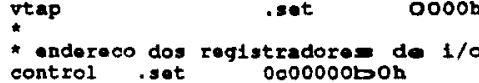

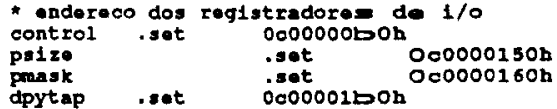

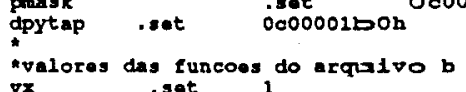

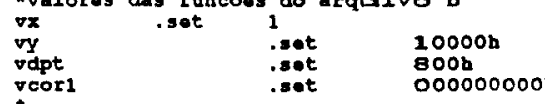

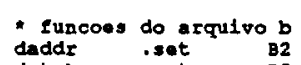

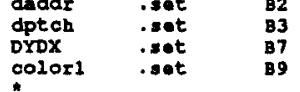

" secao de dados para o funclo

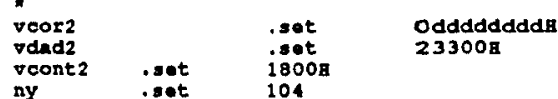

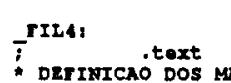

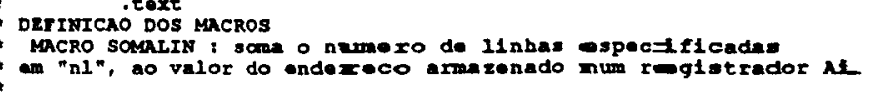

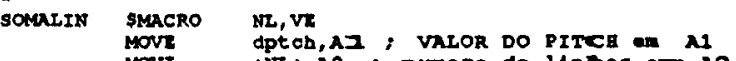

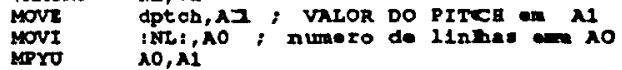

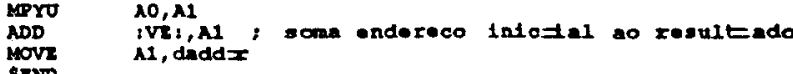

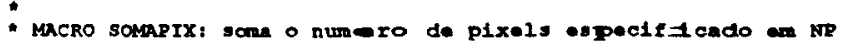




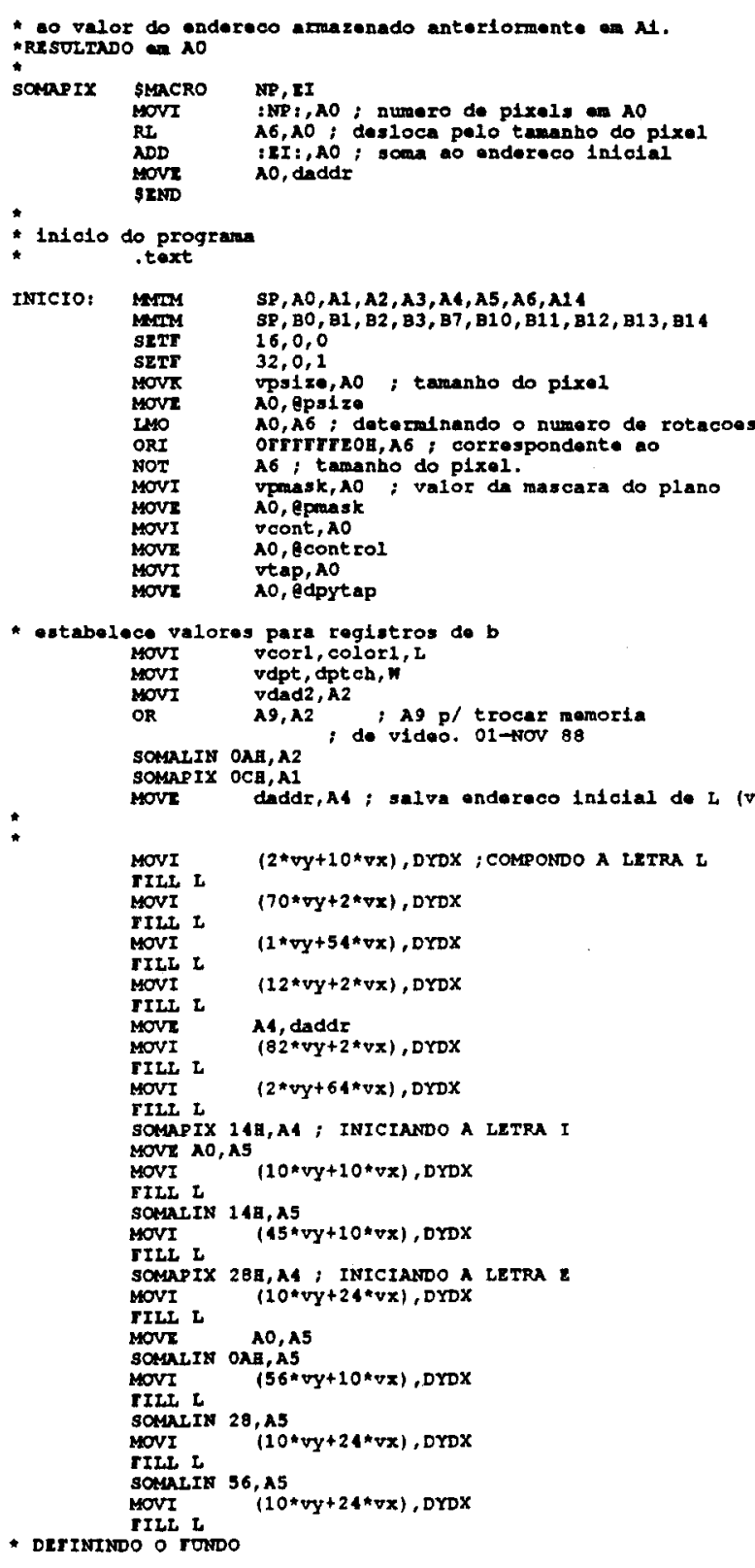

R1:
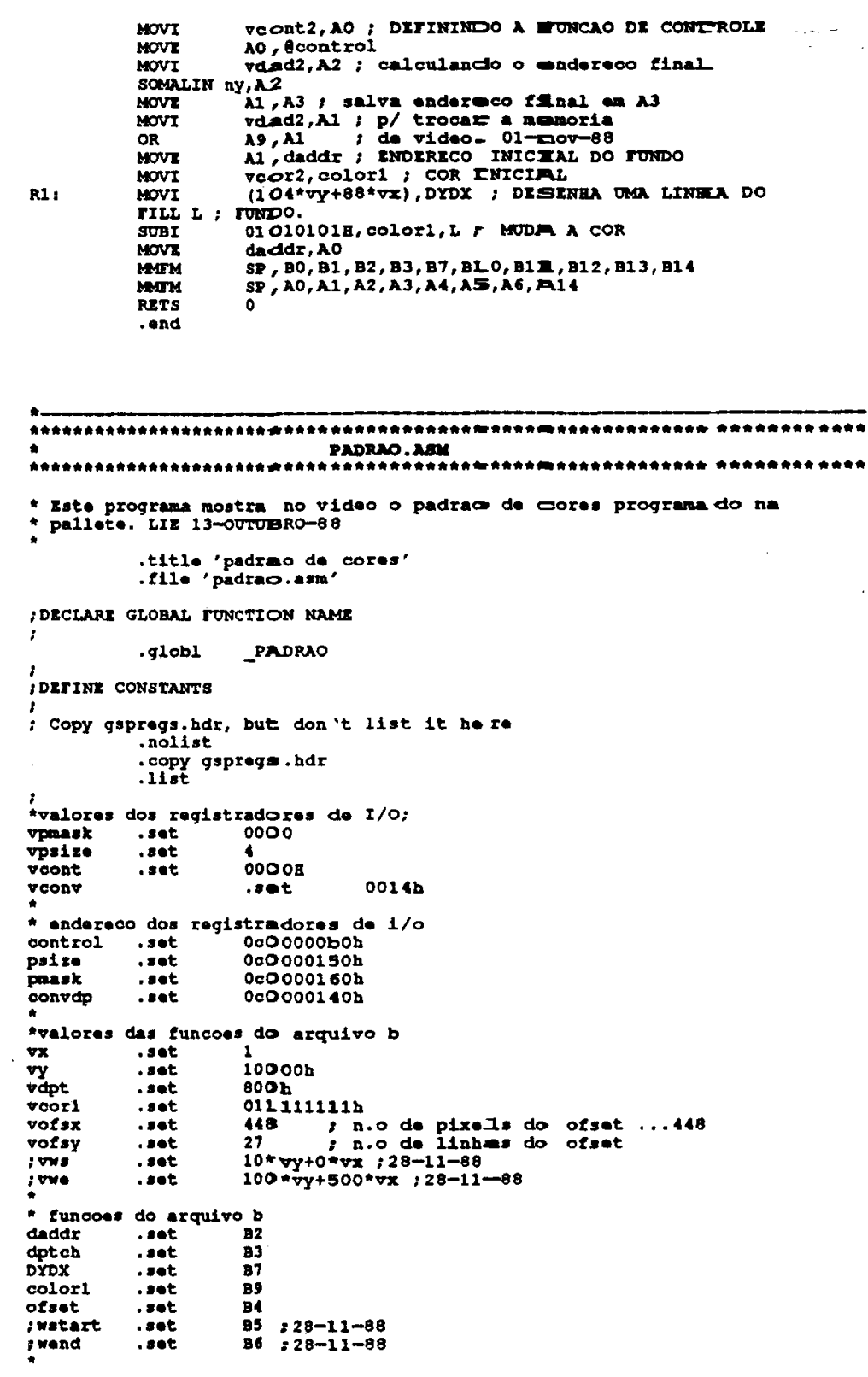
* secao de dados para o fundo

PADRAO:

DOS MACROS

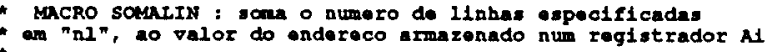

somaris smacro $\mathrm{NL}, \mathrm{Vz}$

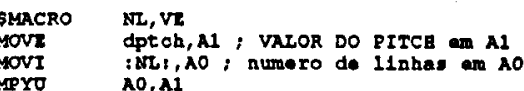

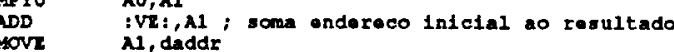

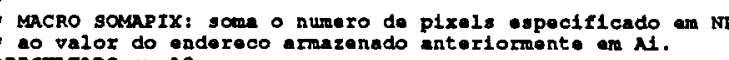
Ristrtado on ao

SOMAPIX SMACRO NP, ET

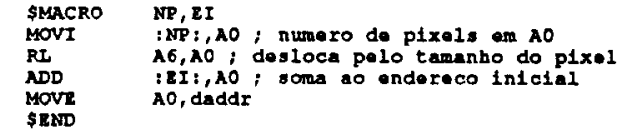

1nicio do programa

INTCIO: MATM SP AO, A1, A2,A3,AA, AS, A6

*Valor para raglatros do $1 / 0$; ; tamanho do p1xo1

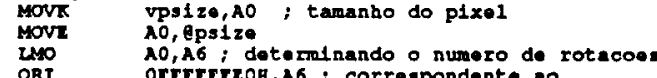

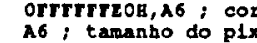

vpmask, A0 ; valor da mascara do plano

move Ao, gcontro

- ostabelo

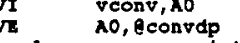

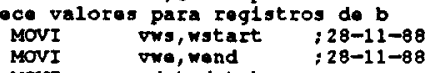

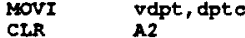

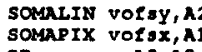

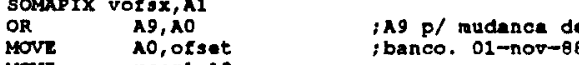

MOVI

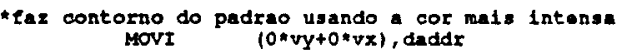

Hovr daddr, A3

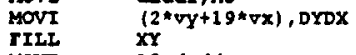

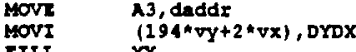

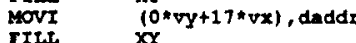

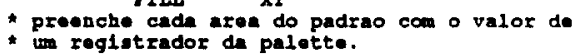

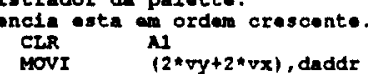

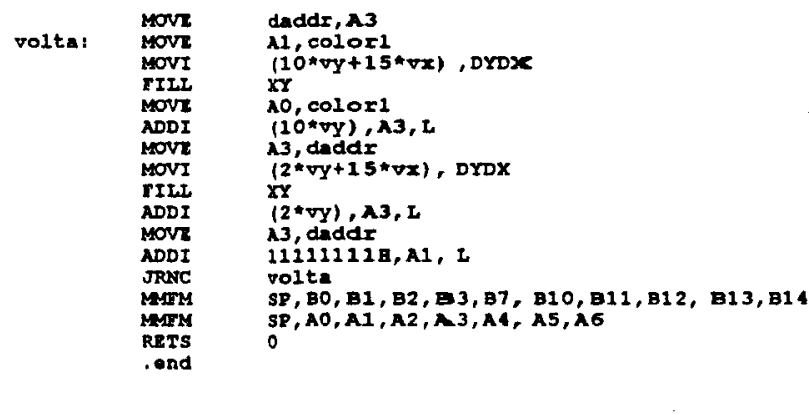

W1dth 132

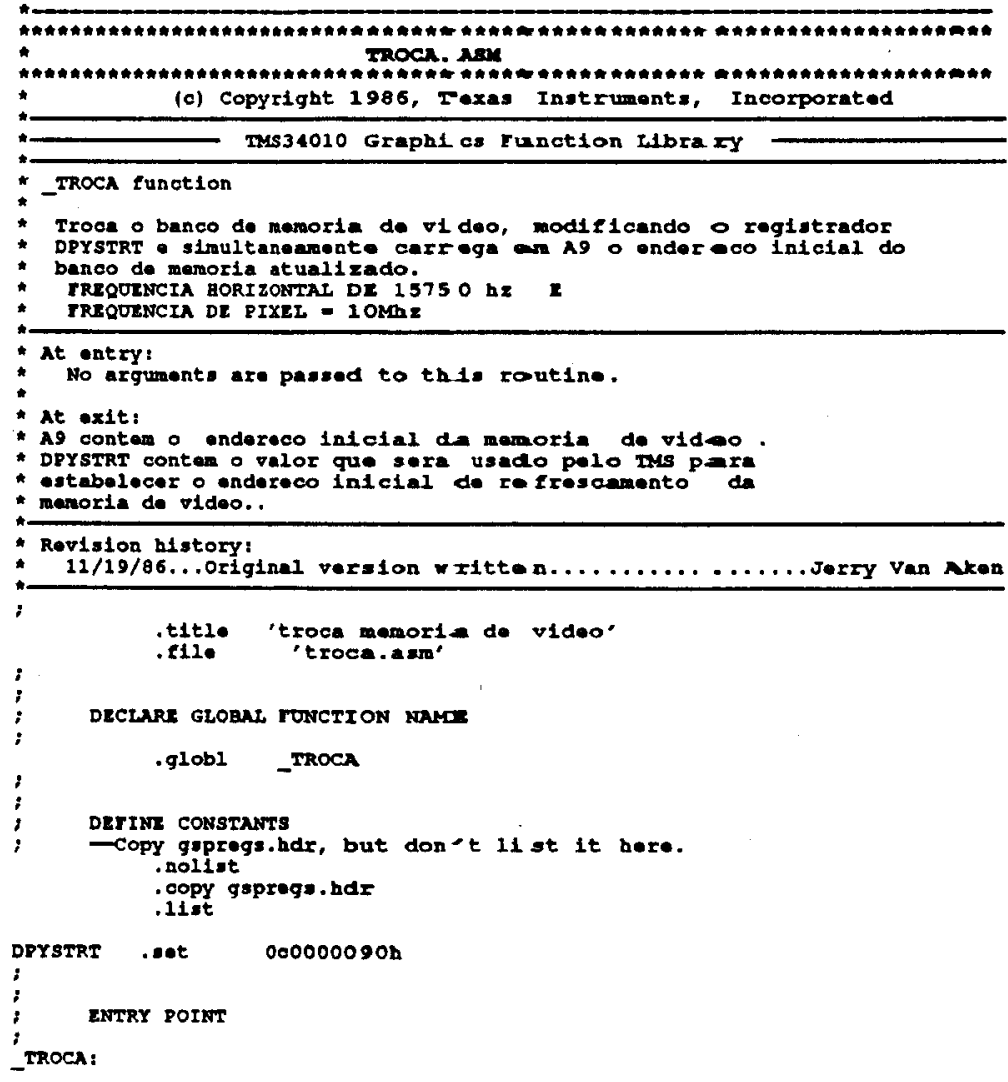


* Init1el1zo $\mathrm{I} / \mathrm{O}$ reglator DPYSTRT

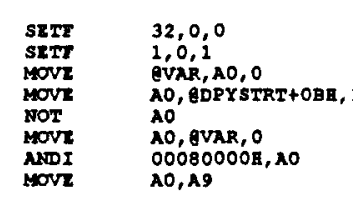

- All done. Return.

VAR: $\quad$. long $>00000000$

ond

width $\quad 132$

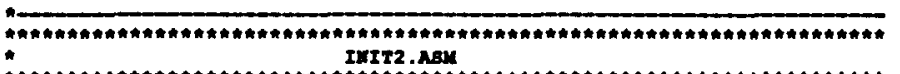
(c) Copyright 1986, Texas Instruments, Incorporated INII2 function

Init1al12: sone GSP display refrosh rogtstors,

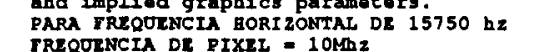

At ogtry:

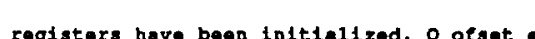

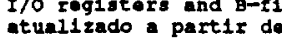

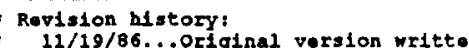

Jarry $\operatorname{Van}$ Aken

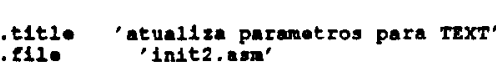

DECLARE GLOBAT RONCTION WANO

. g10b1_LMIT2

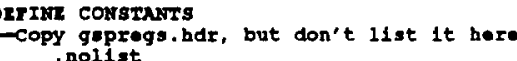

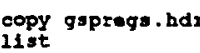

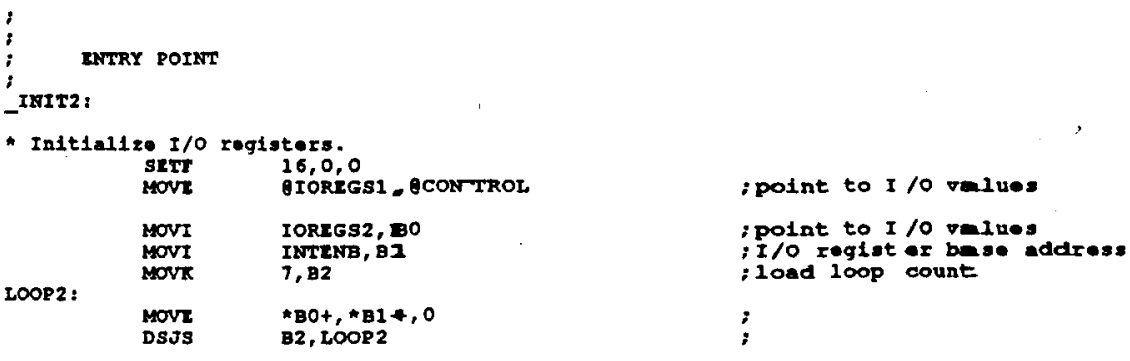

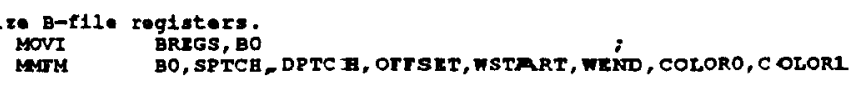

: ondereco taleial da menorte de oideo an as

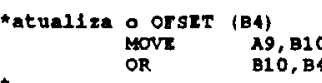

Al1 done. Return.

B. Define B-f110 registar values.

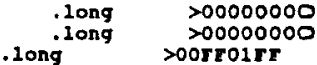

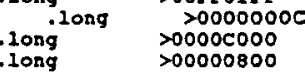

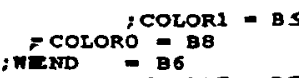

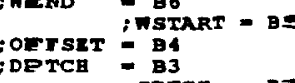

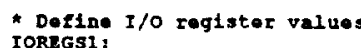

CONEROL - >COOOOOBO

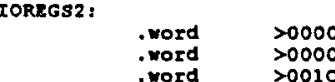

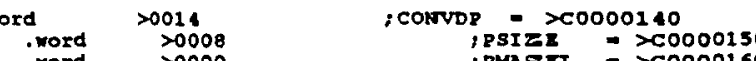

; PmansKR $=>>>00000160$

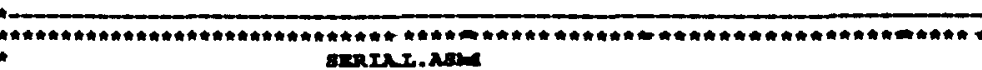

".n.

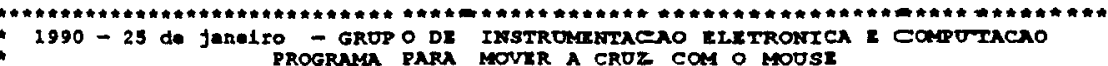

p1aca tus34010 - ine com pe 1ett- 8251 

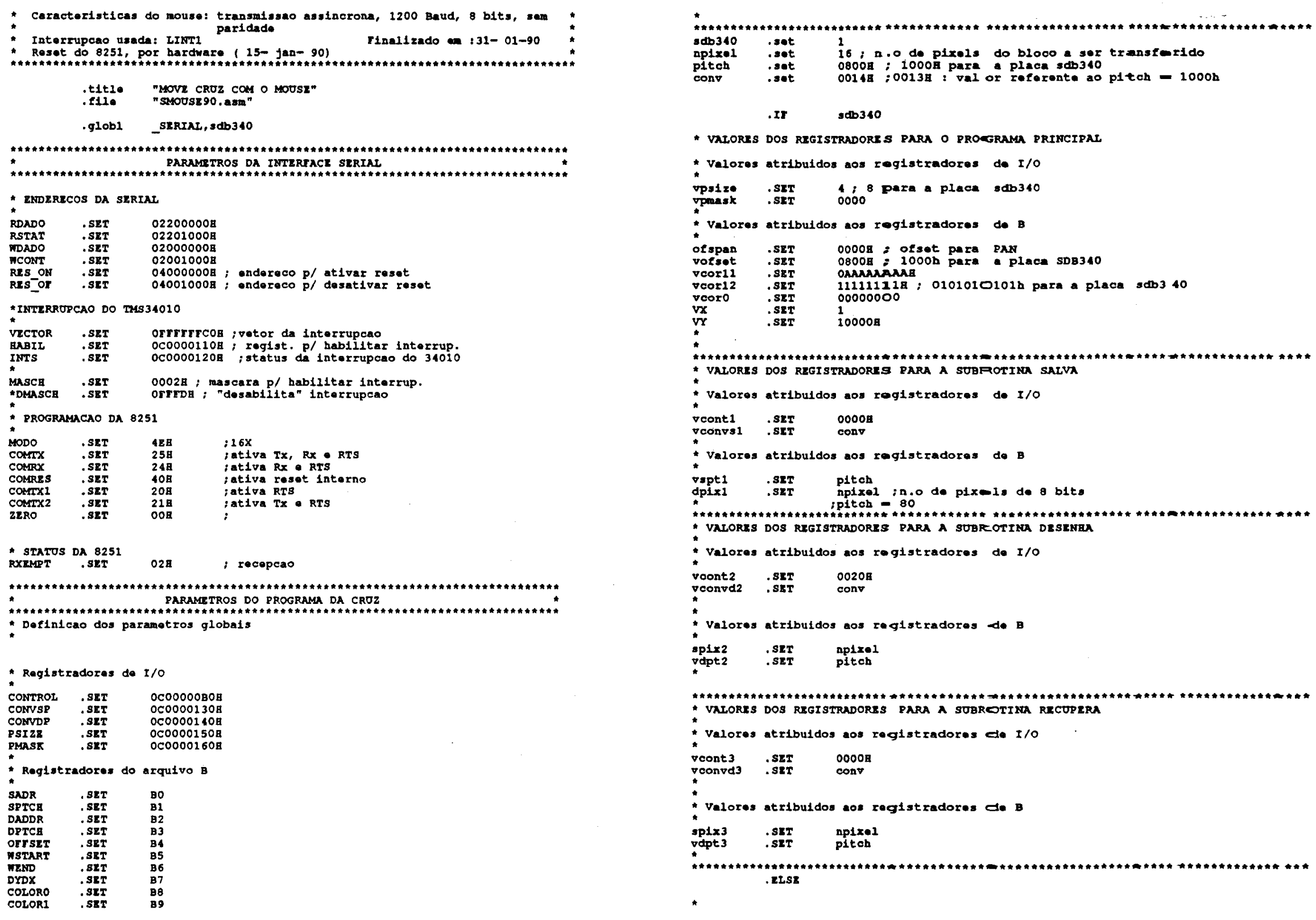

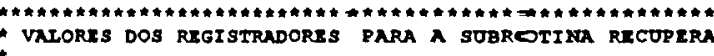

- Valores atribuldos aos registradores de $I / 0$

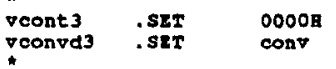

" valores atribuldos aos registradores de

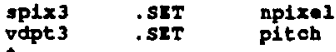

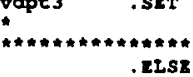




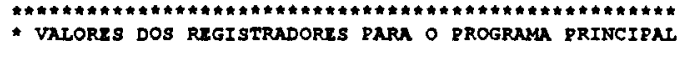

- Valoxes atribuidos aos rogistradores de $I / O$

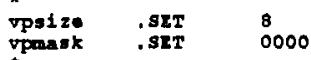

* Velozes atribuidos oos regletradores de $\mathrm{a}$

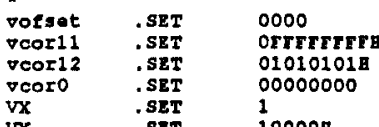

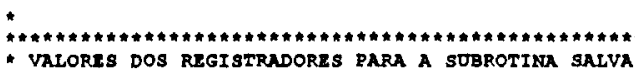

: valores atribuidos aos roglstradores de $x / 0$

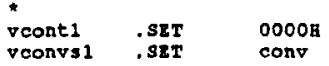

* Valores atribuidos aos rogistradores do

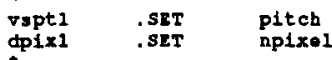

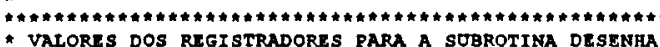

"Valores atribuidos aos rogistradores de I/O

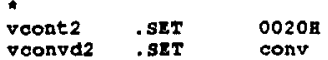

: valores atribuldos aos rogistradores de

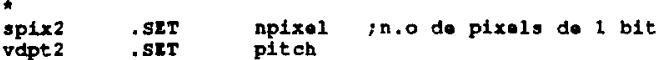

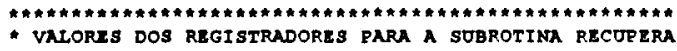

- valores atribuldos aos registradores de I/O

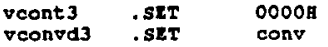

valores atribuldos aos registradores de a

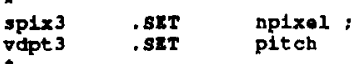

ender

- Defintoao de outros paranatios do programa prinetpal

ADRXY .s2T A1 ; contom novo endoreco p/ a cruz

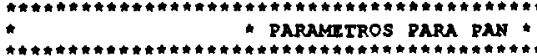

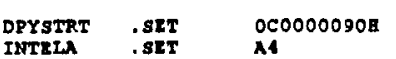

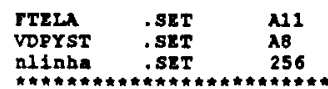

... Definicao do macro DRsLoc: fíncea de deslocamento

DESTOC SMACRO ADRYY, SADR, DADDR, V4, DISUIO

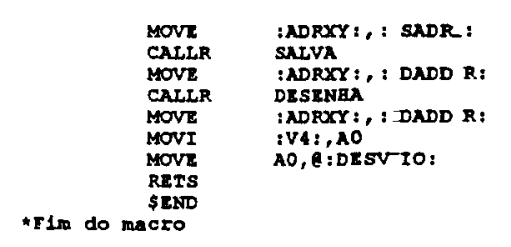

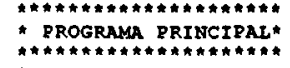

SERIAL:

Dofinindo os paramontros para ermazonar a l lnha da pallote

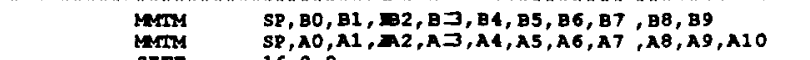

* Rogistradores do $\begin{gathered}\text { SETr } \\ \text { Isto } \\ 32,0,1\end{gathered}$

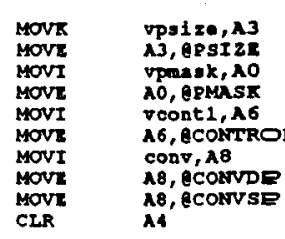

: Registradores de B

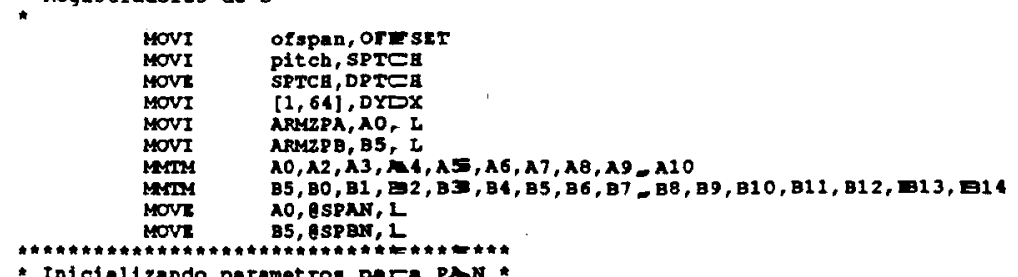

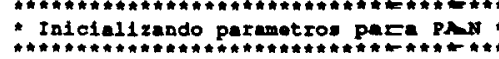

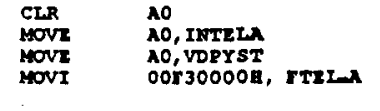

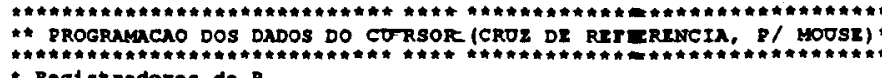

: Rogistradores de B

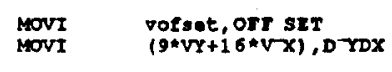




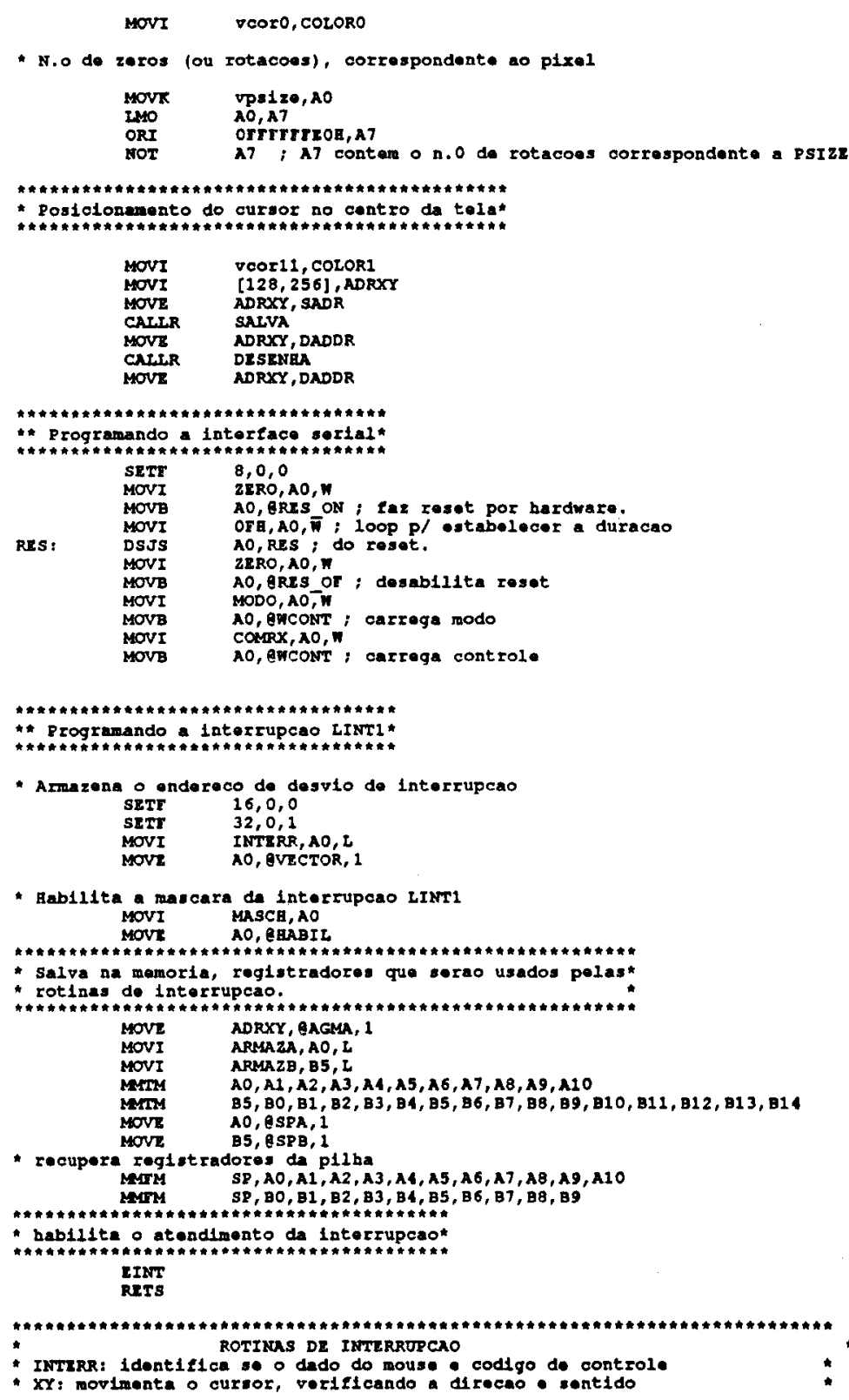



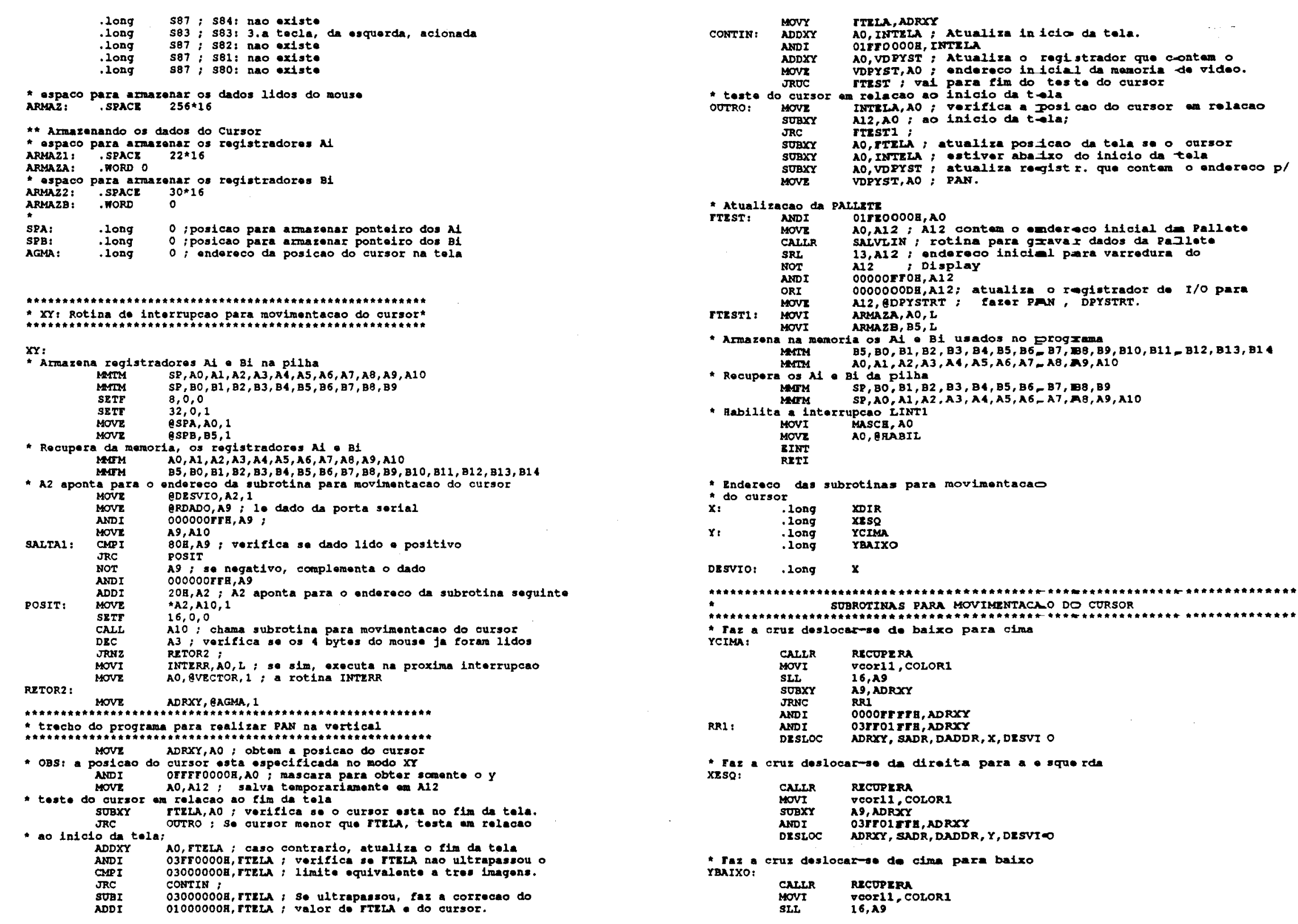

: Endaraco das subrotinas para movimentacao
do oursor

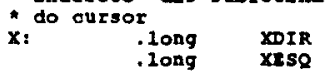

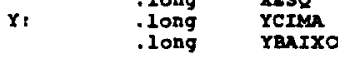
Desvio: .long

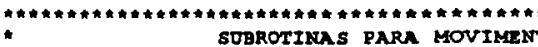

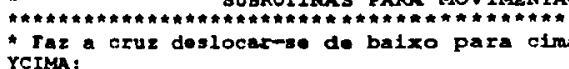
CALLR
MVII
SLTCOPERA
veOr11, COLOR

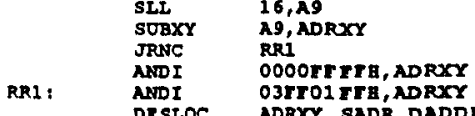

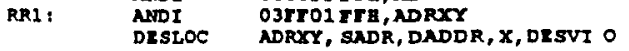

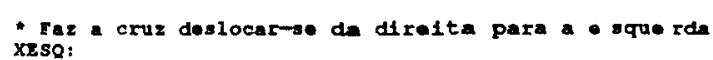

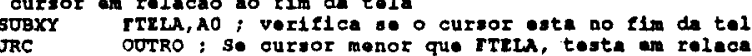

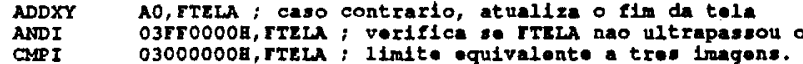
SORI
LDDI
$010000000 \mathrm{O}$, , rTEL ;

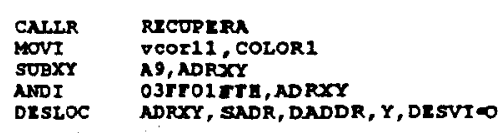

rinuzo: cruz deslocar-se de cima para baixo CALLR
MOVI
SLII 


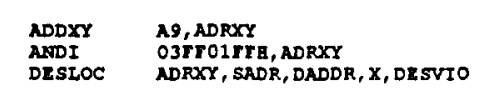

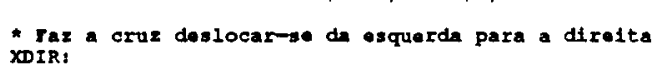

CRILR

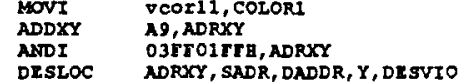

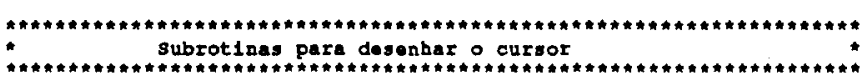

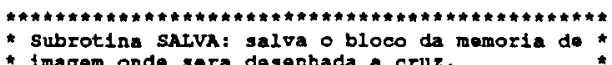

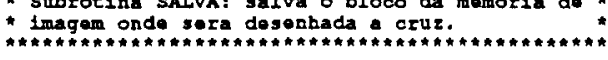

SAlva:

* sadr defindido no programa principal

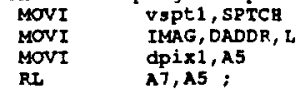

* Registradores de $\mathrm{I} / \mathrm{O}$

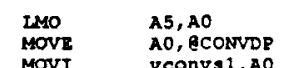

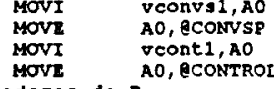

$\underset{\mathrm{RITS}}{\mathrm{PrXs2T}} \int_{0}^{\mathrm{Xr}, \mathrm{L}}$

: Reasorvando una axoa para azmazanar o trocho da lmagom
:ue contora a cruz,

IMAG: .SPACE $72 * 1$

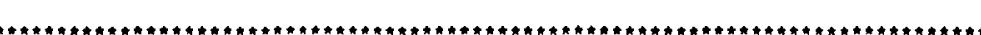

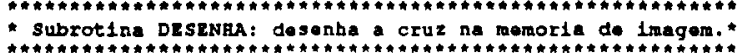

Desenex:

Registradores de $1 / 0$

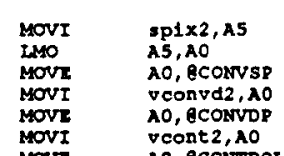

: Rogistradores de B

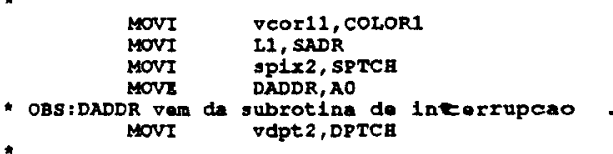

$$
\begin{aligned}
& \text { t Transforenola de bloco }
\end{aligned}
$$

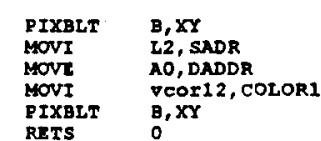

*orinindo cruz
*. Cruz cor cor voor11

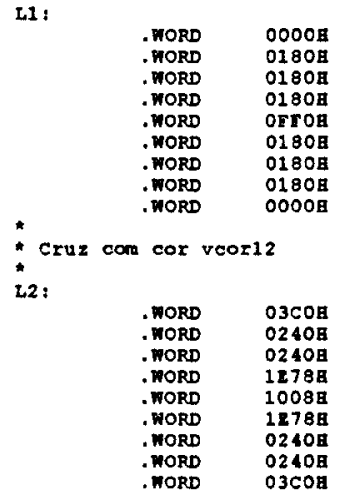

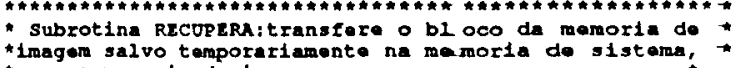

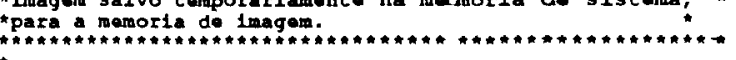
Rxcupra:

: Registradores de a
MOVI
MOVI
MOVI

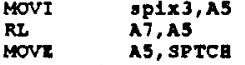
* OBS: DADDR van do prograna princ1 pal
* Registradores de $1 / 0$

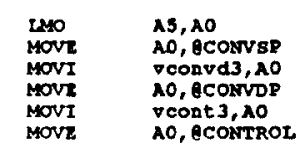




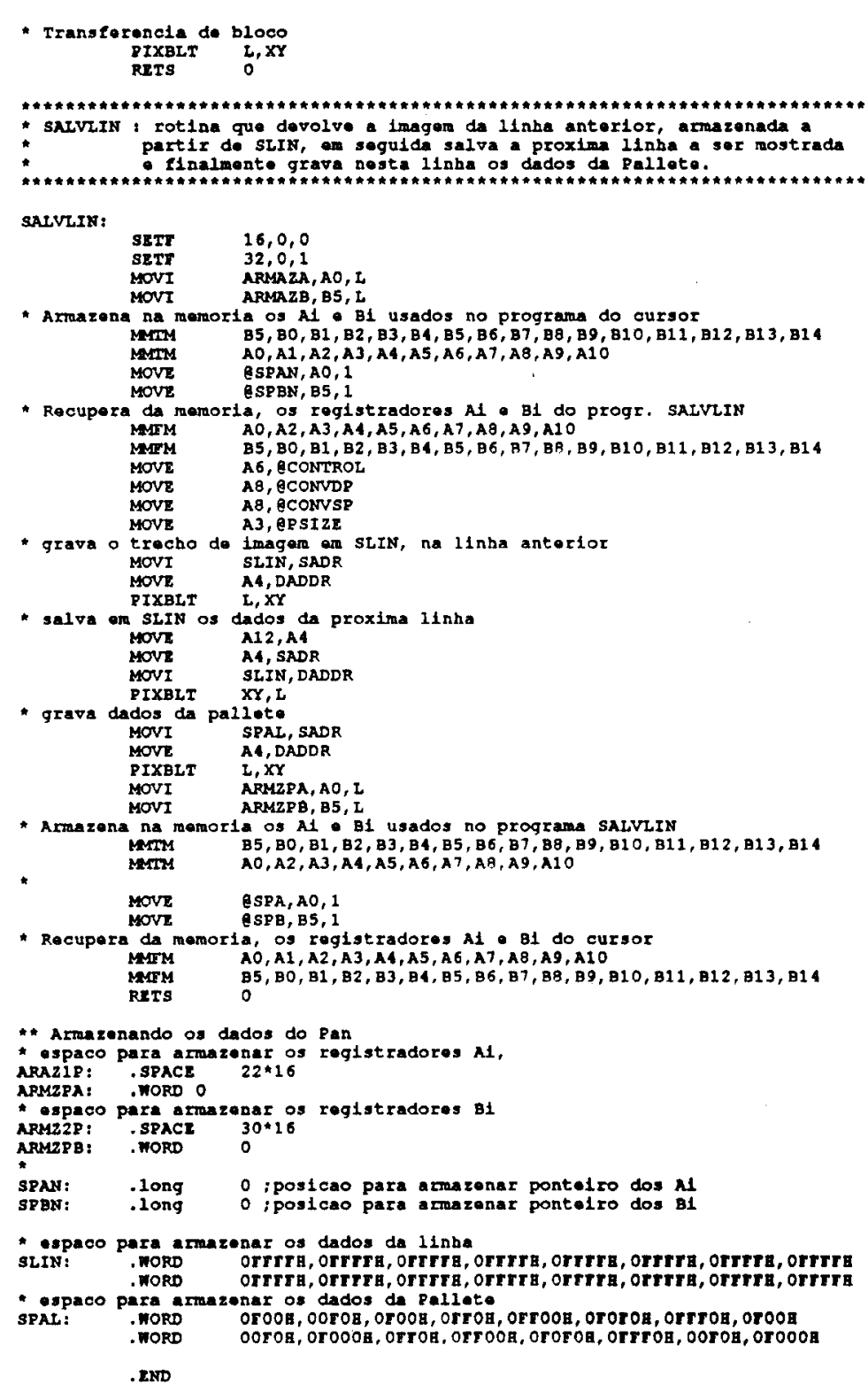

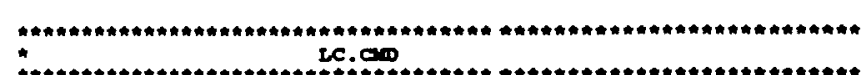

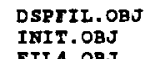

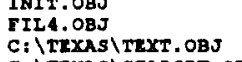

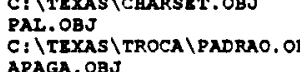

APAGA. OBJ
SRRIAL.

C: TLXSASTROCAIINIT2.08J

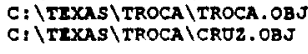

MEMORY

program: or1g1n = 0xrrro0000 length $=0 \times 00100000$

IC.

C: IrExas \goplak -o \$1. out 11 . oby 10.00 